\title{
Contemporary Canadian military/media relations: Embedded reporting during the Afghanistan War
}

\author{
by \\ Sherry Marie Wasilow \\ Submitted to the Faculty of Graduate Studies and Research in \\ partial fulfillment of the requirement for the degree of \\ Doctor of Philosophy \\ in
}

Communication

Carleton, University

Ottawa, ON

2017

(c) 2017 Sherry M. Wasilow 


\begin{abstract}
News reporters have been sporadically attached to military units as far back as the Franco-Prussian War of 1870, but the U.S. implemented the first official and large-scale embedded program in 2003 during the Iraq War. The Canadian Forces Media Embedding Program (CFMEP) was officially implemented in 2006 during the Afghanistan War. While considerable research has been carried out on the U.S. and British embed programs and their impact on media coverage, there has been very little academic study of Canada's CFMEP, or its impact on media coverage of the Afghanistan War. This work seeks to investigate Canadian military/media relations throughout a period of roughly 10 years during Canada's mission in Afghanistan. In doing so, it will examine how official procedures governing media coverage - particularly embedding policy - gave shape to the war reporting received by Canadians.
\end{abstract}

First, within the broader subject area of military/media relations, this study establishes the origins of embedded reporting, and Canada's reasons for becoming involved in the Afghanistan War. Second, it weaves together academic, official (both military and government), and journalist perspectives regarding the practice and effects of embedded reporting on Canadian war reporting during the Afghanistan mission. Third, it analyzes coverage by four major media organizations of Canada's participation in the Afghanistan War during a 10-year period: from its initial military contributions in 2001 through to the end of troop deployment in 2011. It is the latter two components that fill a research void. 
Results indicate first, continued concern with, and debate regarding, the concept of media objectivity; second, very high discontent among government officials with embedded media coverage of diplomatic and humanitarian efforts during the Afghanistan mission; third, largely untapped benefits of dis-embedded reporting, a unique component of the CFMEP in comparison to other countries' embed programs; and fourth, a discernible impact of framing due to the fundamental configuration of a military-hosted and maintained embed program. It is primarily within the last three sets of findings that we can see the structural influence of an embed policy negotiated by two disparate cultures, the military and the media, on media coverage. The major result of an accord between the imperatives and constraints of the news media and those of the military was an overwhelming focus on the military - to the exclusion of diplomatic and humanitarian efforts - and more specifically military excursions, injuries, deaths, and ramp ceremonies. Several future policy considerations are offered later in the study, including a call for media organizations to conduct post-war debriefing sessions for embedded reporters on lessons learned. 


\section{ACKNOWLEDGEMENTS}

I wish to express deep gratitude to: my supervisor, Dr. Christopher Dornan, for guiding me through the doctoral process, with perpetual good cheer, yet not pulling any punches; Dr. André Turcotte, who supported my goals from day one and was always my invaluable go-to person for real-world advice; and Dr. Michèle Martin, who willingly disrupted her retirement to help me make my work stronger - all three individuals are in the Department of Journalism and Communication at Carleton University in Ottawa, Ontario. I further thank Dr. Elinor Sloan of the Department of Political Science for her helpful comments, and must note my appreciation for the support I received from the Faculty of Graduate and Postdoctoral Affairs, Carleton University, Ottawa, Ontario. Finally, I wish to thank Dr. David Taras of the School of Communication Studies at Mount Royal University for his positive and constructive input.

I would like to thank my three sons - Max, Quinn, and Greyson - for their love, patience, and willingness to put up with too many "breakfasts for dinner" and the constant clutter on the dining table, and who are truly my best accomplishments in life.

I greatly appreciate the financial aid provided to me by the Robert McKeown Doctoral Scholarship in Communication, and the Social Sciences and Humanities Research Council Doctoral Fellowship. 
I would especially like to acknowledge two individuals who gave me invaluable support I didn't always know I needed: Sandy Milne, Coordinator of the Woman Abuse Program at Family Services Ottawa, and Barbara Wexler, MSW RSW, both of Ottawa.

Words cannot express my appreciation for the support and love given to me by family and friends, even if they didn't always understand why I had chosen this route. Please know that I always strive to remember the kindnesses shown to me by the many wonderful people I've encountered in my life.

Far too often we take for granted those individuals who reliably make things happen, and have our backs when dealing with byzantine rules and regulations: my thanks to Coleen Kornelsen and Michelle Bateman, currently and formerly with the Department of Journalism and Communication at Carleton University.

Many, many thanks to my interview participants. You greatly impressed me with your observations, insights, humour, and willingness to share your time with me. I am particularly grateful to Lieutenant Colonel Christian Lemay, who supported my research tremendously, helped me to circumvent barriers, and is a true gentleman. I would like to acknowledge the support and enthusiasm of Jeff Sallot, an excellent reporter and - even more importantly - a genuinely kind human being. I must also thank Chief of Defence Staff General Jonathan Vance, who personally helped me overcome bureaucratic hurdles. 
Unexpectedly, I would like to thank that handful of individuals who minimized and obstructed my desire to pursue and complete my Ph.D. Your objections helped to fuel my fire.

Last but certainly not least, I dedicate this work to the memory of Elizabeth (Liz) Metcalfe, a dear friend who was tragically killed in a motorcycle accident during the early part of my Ph.D. program. Always larger than life, Liz believed in reaching for your dreams, no matter the obstacles, and savouring every drop of life along the way. You are, and always will be, deeply missed. 


\section{TABLE OF CONTENTS}

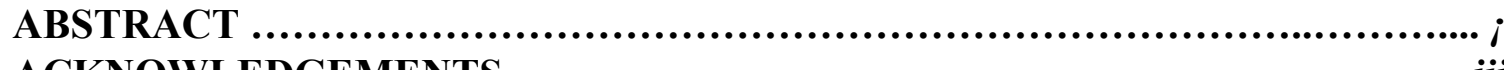

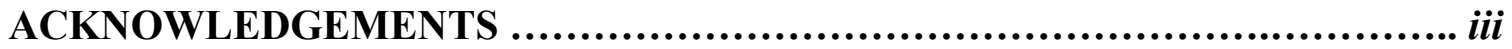

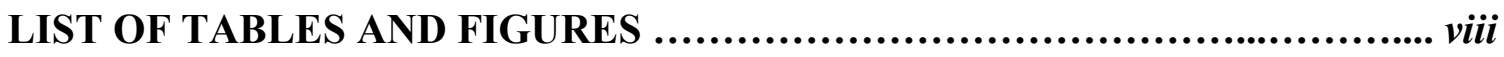

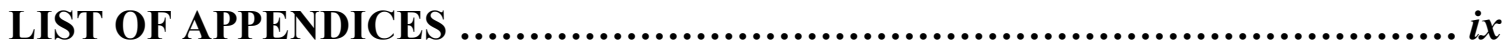

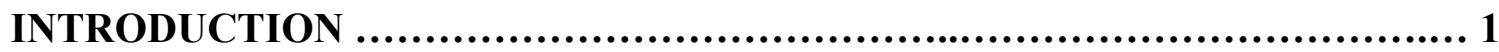

CHAPTER ONE: HISTORY OF MILITARY/MEDIA RELATIONS LEADING

TO EMBEDDED REPORTING ..................................................... 20

1.1 Tracing the roots of embedded reporting ........................................ 21

1.2 Technological advances used to conduct war as well as communicate warfare.. 27

Conclusions ...................................................................... 69

CHAPTER TWO: WHEN WORDS CAN LEAD TO WAR ..................... 76

2.1 Language as a form of power: Critical Discourse Analysis ..................... 77

2.2 Media effects research: refined with time .................................. 89

2.3 Using Discourse to Frame a War ............................................. 97

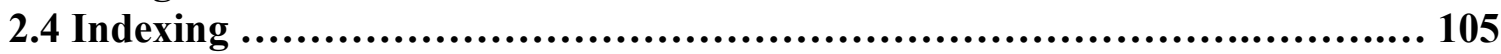

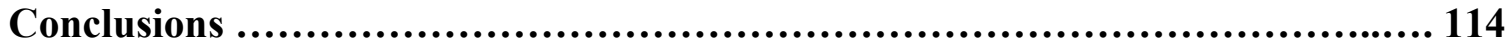

CHAPTER THREE: CANADA'S INVOLVEMENT IN AFGHANISTAN........ 120

3.1 Why Canada became involved ........................................... 122

3.2 The evolution of military involvement .................................... 128

3.3 The embedding of Canadian reporters in Afghanistan ......................... 134

Conclusions ...................................................................... 140

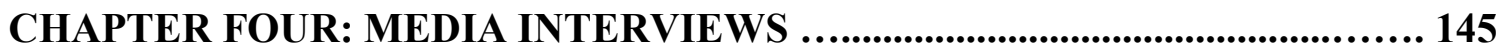

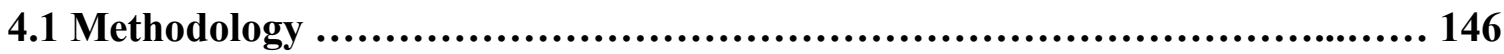

4.2 Results overview .............................................................. 149

4.3 Demographics ............................................................ 150

4.4 In their own words: the embedded, dis-embedded, or unilateral experience .. 151

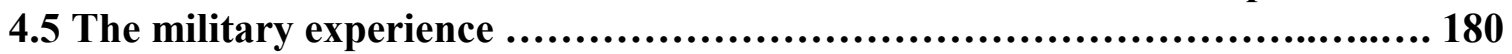

4.6 Media coverage ............................................................ 191

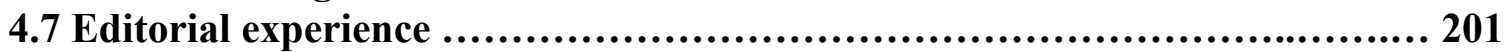

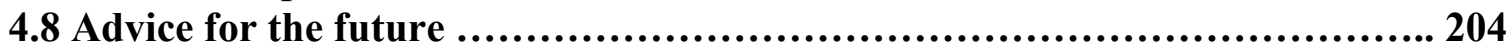

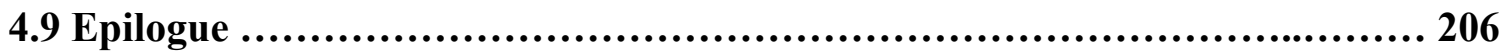

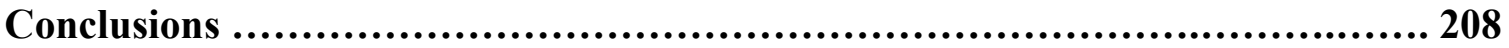


CHAPTER FIVE: MILITARY/GOVERNMENT INTERVIEWS ............... 213

5.1 Methodology ................................................................ 214

5.2 Results overview ................................................................... 217

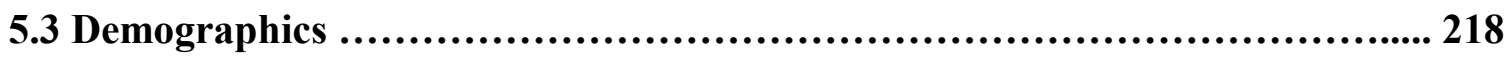

5.4 The other side of the coin: government and military officials speak ........... 218

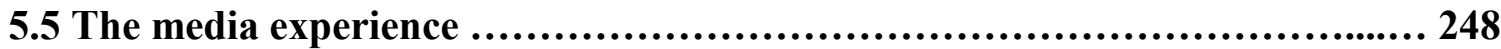

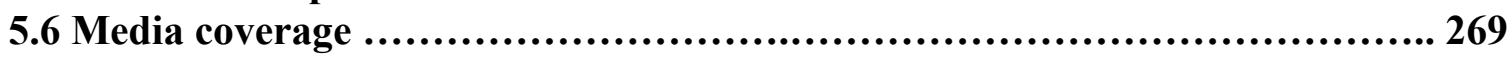

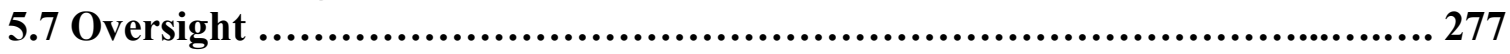

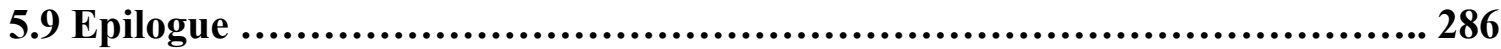

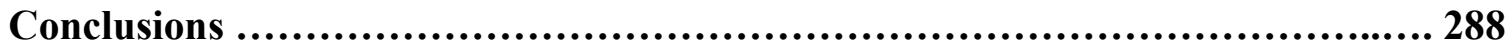

CHAPTER SIX: MEDIA COVERAGE ANALYSIS ......................... 292

6.1 Methodology .................................................................. 293

6.2 Findings ...................................................................... 298

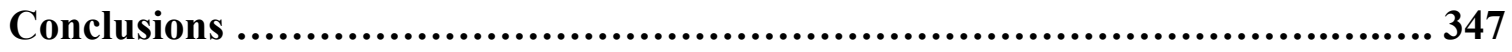

CHAPTER SEVEN: DISCUSSION AND ANALYSIS $\ldots \ldots \ldots \ldots \ldots \ldots \ldots \ldots \ldots \ldots \ldots . \ldots . \ldots . \ldots 33$

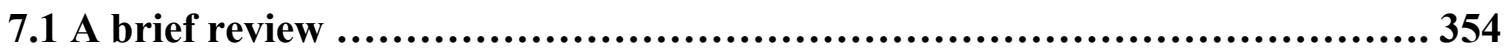

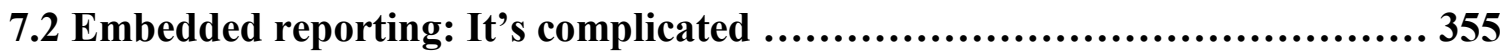

7.3 Dis-embedding ............................................................... 368

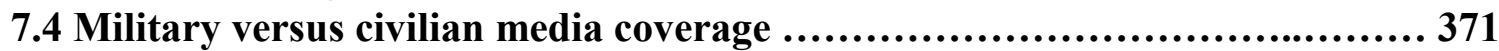

7.5 Message control from the motherland ....................................... 375

Conclusions .................................................................... 382

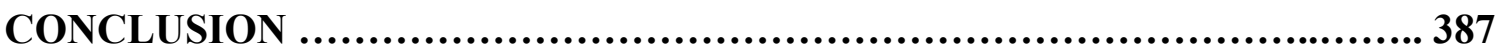

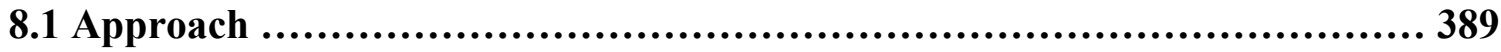

8.2 Key findings ................................................................ 390

8.3 Implications and recommendations ......................................... 395

8.4 Limitations and future research directions ................................ 397

8.5 Final words ............................................................... 399

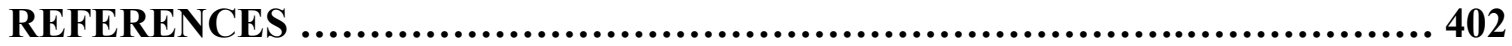




\section{LIST OF TABLES AND FIGURES}

TABLE 1:

Constructed Week Sampling, Oct. 2001 - Dec. 2011

TABLE 2:

Period one: October 2001 through to June 2003, Constructed Weeks ............. 299

TABLE 3:

Period two: July 2003 through to February 2006, Constructed Weeks

TABLE 4:

Period three: March 2006 through to December 2011, Constructed Weeks ........ 325

CHART 1:

Period one: October 1 - June 2003, Media Coverage, compared (hits) ............ 300

CHART 2:

Period Two: July 2003 - February 2006, Media Coverage, compared (hits) ...... 315

CHART 3:

Period Three: March 2006 - December 2011, Media Coverage, compared (hits) . 326 


\section{LIST OF APPENDICES}

APPENDIX A: Interviewee List, Media ......................................................... 430

APPENDIX B: Interviewee List, Military and Government Officials ............. 431

APPENDIX C: Carleton Ethics Approval (Media) .............................. 432

APPENDIX D: Introduction/Invitation Letter (English and French) ............. 433

APPENDIX E: Letter of Consent (English and French) .......................... 437

APPENDIX F: Questionnaire, Media (English and French) .................... 443

APPENDIX G: Carleton Ethics Approval (Military and Government) ............ 449

APPENDIX H: Questionnaire, Military and Government ...................... 450

APPENDIX I: Social Science Research Review Board Approval .................. 452

APPENDIX J: Canadian Forces Media Embedding Program: Guidelines, Ground

Rules and Documentation for Land-based Operations ........................... 453

APPENDIX K: Canadian Forces Media Embedding Program: Guidelines, Ground Rules and Documentation for Joint Task Force Afghanistan ................... 514

APPENDIX L: Questionnaire, Military, Revised ................................ 516

APPENDIX M: Map of Afghanistan ........................................ 529 


\section{INTRODUCTION}

When I was barely 19 years old, I moved to Guatemala for eight months. More eager for adventure than aware of practicalities, I found myself studying Spanish and teaching English in a country wracked by civil war. Media reports of the fighting were garish and full of upsetting details, unbound by more northern sensibilities. It was largely guerrilla warfare, frequently remote, so news reports would usually focus on the disappeared, bodies found - often showing signs of torture - grieving relatives, angry accusations, but rarely did the media explore reasons behind the strife. That experience sensitized me to how important the role of the media - domestic and international - can be during times of war, both as a check on possible abuses of power as well as a source of indispensable information for individuals on the outside trying to see within.

Flash forward in time to the weeks following 9/11 when the western world was in shock, and enraged, and normally placid nations like Canada agreed to send troops to a country few Canadians had heard of, and likely only because the Soviet Union had invaded it in 1979. Why did Canada become involved? There were at least three reasons: the first was an emotional reaction to the $9 / 11$ attacks that killed almost 3,000 victims, including 24 Canadians (Granatstein and Oliver 2011, 4); the second was a perceived need for a diplomatic and political response by the U.S.'s closest neighbor and largest trading partner; the third was a forceful military agenda designed to transform Canada's military while simultaneously increasing its profile, credibility, and influence. In early December 2001, Canada's Joint Task Force 2 (JTF2), an elite military unit charged with carrying out 
special operations, secretly entered Afghanistan (Stein and Lang 2007), followed by 750 Canadian soldiers from the Canadian Forces' 3rd Battalion, Princess Patricia's Canadian Light Infantry (3 PPCLI) Battle Group in January to February 2002, serving as part of a "stabilization force" working with the U.S. operation in Kandahar and reporting to the 101st American Airborne Division. The media soon followed, initially working directly with Lieutenant-Colonel Pat Stogran, who commanded the 3 PPCLI.

The Afghanistan War has been one of the latest, large-scale entries in the complicated relationship between western militaries and the media—ongoing since the late $19^{\text {th }}$ century, ${ }^{1}$ and alternating between adversarial and symbiotic, sometimes even simultaneously. A key factor in the evolution of this relationship has been the rapid pace of technological advancements; technologies used to conduct war as well as those used to communicate warfare. This dissertation will initially examine the historical evolution, practice, and effects of military/media communications strategies, with embedded reporting as the most recent - and possibly the most transformative - development. I will look back roughly 50 years in time at the military/media communication strategies that contributed to, supported, and flowed from several important conflicts: the Vietnam War (1955-1975), the Falklands War (1982), and the Gulf War (1991). ${ }^{2}$ I will then move forward the themes explored in these conflicts and apply them to the Iraq War (20032011), ${ }^{3}$ as well as the more recent Afghanistan War (2001-2014) in order to investigate how previous issues related to military-media relations are being played out in a more current context, specifically: my thesis will explore how official procedures that governed media coverage during the Afghanistan War - specifically, embedding policies by both 
Canadian media parent organizations as well as the military - influenced the resulting media coverage that Canadians received. I argue that embedding policies and practice changed both how war coverage was produced, as well as the content of what was produced. This was owing to two primary developments. First, the program was largely housed within the cultural confines of the military, a culture that has unsurprisingly and even rightfully formalized an information process that exacts compliance by participant journalists with a view to a number of objectives, particularly security and safety. Whether information control was an objective or a by-product of the design can be debated. Second, the component of Canada's embed program that distinguishes it from other countries' embed programs - the ability of journalists to dis-embed and re-embed upon request and arrangement - was rarely taken advantage of by individual journalists. This was due to a variety of reasons, most predominantly safety issues, media-parent directives, and a difficult physical and linguistic terrain "outside of the wire." The relative paucity of dis-embedded and/or independent reporting became even more conspicuous in the face of outstanding examples of media coverage that did go beyond within-wire stories, focusing on the multidimensional effects of the war rather than its often glorified means.

I will investigate this argument within the Canadian context cited above, using semistructured elite interviews and content analysis to demonstrate that the net outcome of structural and procedural limitations associated with the embedding process was a concession of the media's vantage point to the program's military hosts. Resulting media coverage focused heavily on the Canadian military - particularly on combat, injuries, 
casualties, and ramp ceremonies - at the expense of Canadian diplomatic and humanitarian efforts in Afghanistan.

In support of my research, I will integrate communication theory, journalistic practice and product, and military and government perspectives in order to better grasp both the overall patterns as well as the nuances of what I see as an ongoing "chess game" waged by the military and the media. While some scholars contend that embedded reporting when news reporters are attached to military units involved in armed conflicts - was used as far back as the Franco-Prussian War of 1870, and certainly there exist sporadic examples of "embedded reporters" throughout history, the policy of embedded reporting was not implemented in earnest until the 2003 Iraq War, and certainly never before on such a large scale. However, while Operation Iraqi Freedom saw more than 600 U.S. and foreign journalists embedded with and reporting from infantry positions, aircraft carriers, Special Forces units, and Marine divisions, the idea's genesis had occurred during and was accelerated by the Afghanistan War. ${ }^{4}$

The practice of embedded reporting has shifted military/media relations dramatically, perhaps permanently. This study will trace the threads of embedding reporting back through an approximately fifty-year period, 1960 to 2011. The Vietnam War not only provides the most glaring and perhaps footnoted example of a breakdown in military/media relations during the last century, but it also serves as a benchmark for military objections to the media's presence during times of conflict. I will then move forward through time, linking military strategies learned from Vietnam, subsequently 
applied in the Falklands War, honed by the Gulf War, and further evolved during the Afghanistan War, until an official program of embedded reporting was implemented in earnest during the 2003 Iraq War. As a result of the normalization of embedding reporting, the more traditional or independent form of reporting - in a war environment has become referred to as "unilateral" reporting, meaning outside of the embedded program. In the Canadian context, notably and uniquely, leaving/returning to the embed program temporarily to report from elsewhere is called "dis-embedded" reporting. This feature markedly distinguishes the Canadian embed program from that of other countries.

Following its first formal and large-scale inception during the Iraq War in 2003, there was a surge of attention paid to embedded reporting. Media scholars have been primarily wary and often critical of the practice (Brandenburg 2007; Brockus 2009; Carruthers 2011; Dadge 2006; Knightley 2004; Schechter 2003, 2006; Sylvester and Huffman 2004; Tumber and Palmer 2004). For example, two that looked at U.S. print and television coverage of Operation Iraqi Freedom (OIF) in 2003 (Pfau et al. 2004; 2005) found that embedded reporting provided positive relational cues through interviews with military personnel; Haigh et al. (2006) found that print coverage by embedded reporters of OIF was significantly more positive toward the military than those of non-embedded or unilateral reporters. Two studies that looked at British television coverage of OIF (Lewis et al. 2004; Lewis \& Brookes 2004) found a heavy focus by embeds on specific combat missions as opposed to broader issues; as well as coverage more favourable towards the government's position on the war, and twice as likely to represent the Iraqi people as welcoming the invasion rather than suspicious, reserved, or even hostile. Furthermore, 
Aday, Lingston and Hebert (2005) found that executives at media organizations such as Fox News Channel actively encouraged reporters and anchors to use first person plural words like "we" and "our" - when discussing coalition and U.S. forces. This is an important development because textual structures such as "I," "we," and "us" include both the reporter and the viewer in the unfolding events. Conversely, traditional reporting that uses third-person language - "he," "she," "they," and "them" - underscores the distance between the viewer and the event (Gerbner 1994).

The issue of lost objectivity has been one of the main criticisms of embedded reporting, focused on the psychological underpinnings of the relationship between soldiers and reporters. Concerns ranged from a form of "Stockholm syndrome," that is, the bonding between victims and captor(s) that can develop from a lengthy hostage situation (see Lindner 2009) to the non-captive "social penetration" theory of how normal human relationships develop, that is, as people get to know each other better, communication shifts from the superficial to more personal topics, eventually facilitating more intensity and intimacy. In the latter case, hot conditions - typical in combat - can lead to accelerated bonding, or what has been called swift trust (Hensley 1996) or amplified enculturation (Soeters 2000). The basic concern was that closer relationships with the soldiers facilitated through embedding would diminish objectivity.

Subsequently, studies turned to reporter attitudes and views on their own embedded experiences (Fahmy and Johnson 2007; Johnson and Fahmy 2009), finding that some embedded reporters did indeed find themselves in an environment where their loyalties 
were tested and perhaps divided. As American embedded journalist Gordon Dillow (Fahmy and Johnson, 2005) admitted: "I found myself falling in love with my subject. I fell in love with 'my' marines. Maybe it's understandable. When you live with the same guys for weeks, sharing their dreams and miseries, learning about their wives and girlfriends, their hopes and dreams, admiring their physical courage and strength, you start to make friends - closer friends in some ways than you'll ever have outside of war. Isolated from everyone else, you start to see your small corner of the world the same way they do" (303).

Distinctive reporting environments led to varied relationships and outcomes. In their study of the Iraq War, Fahmy and Johnson (2007) found that embeds and unilaterals were very aware of the effects of their different environments. Embeds explained that because they had more access to the troops they wrote primarily about the war and U.S. soldiers; unilaterals wrote mostly about Iraqi civilians wounded and killed, as well as their reception and perception of the U.S. military. While embeds attached to specific units were able to provide an intense and intimate snapshot of the war, their focus on the minutia, individual soldiers, and in-depth coverage of their assigned unit often resulted in a limited possession of the historical, political and/or social context and effects of the war. Conversely, "[the unilaterals] were able to convey the human tragedy element far more accurately. They did not have any pressures to send a story which would not be well accepted by or give 'bad publicity' to troops which they were sharing intimate time and space with over the weeks of the war" (108). In short, embeds were typically found to 
have an insider's or participant observer's perspective while unilaterals have an outsider's or more traditional perspective (Wasilow 2011).

Military analyses of and commentary regarding embedded reporting (Battaglia 2005; Beane, Jr. 2009; Holonen 2003; Stephenson 2005; U.S. Army War College 2004; to name a few) have been largely favourable of the cooperation demonstrated between the military and media, calling the media a valuable resource that should be leveraged with the goal of informing audiences, and noting its importance in strategic planning as well as a its placement in a mutually beneficial relationship with the military. It was not lost, as Lehman (2004) observed, that the effective employment of embedded media by an operational commander could be a "powerful asset" and gain American public support and counter enemy propaganda.

In addition, a number of media reports and more mainstream publications addressed journalists' firsthand experiences while reporting from the war zone - usually embedded - and tended to present first-person accounts (Chadwick 2004; Inskeep 2010; Junger 2010; Romano 2003; Rubin 2009), highlighting the "stories behind the stories" (Katovsky and Carlson 2003) and exploits such as "My Week at Embed Boot Camp" (Jacobs 2003). Thus the reporter often became the story, relaying not the news but insights about the process and their part in the process that produces the news. The telling of these tales is understandable because unlike other professions that are expected to function in harm's way - such as the military, police, or firefighters - journalists are not typically schooled 
in violence but are schooled in telling stories based on their observations and information gathering.

My study will examine the story of military/media relations in the Canadian context, using Afghanistan as my case study. I contend that, as key players in a game that is often not of their making, both the military and media strive to manage information flow during the conflict in question. Significantly, the two institutions live and breathe disparate ideologies - brought closer together through the embedding process, yes - but still distinct from one another, and at times in opposition to one another. By ideology, I refer to a "system of meaning that helps define and explain the world and that makes value judgments about that world. Ideology is related to concepts such as worldview, belief system, and values, but it is broader than those terms ... [referring] to the basic ways in which the world is defined" (Croteau and Hoynes 2000, 159). Approaches to information management reflect those ideologies: the media discourse of uncovering and distributing information versus the military/government discourse of protecting and/or withholding pieces of information. The embedding process situates these two ideologies in closer proximity than ever before, within the high-intensity environment of a war zone. This intimate juxtapositioning of two incongruent entities and approaches to information sharing initially benefitted military imperatives, which will be demonstrated. However, I argue that while early media coverage largely favoured combat operations and perspectives, later and unwanted media coverage focused on casualties, fatalities, and ramp ceremonies. 
This work posits that the CFMEP - by its very nature as a predominantly military construct - enabled the framing of issues that are beneficial to the host party - the military. Notwithstanding the approval and cooperation of the embedded process by partnering media organizations, and notwithstanding the experience and professionalism of individual journalists, the in-theatre conditions that enable, protect, and inform reporters also fundamentally create boundaries that restrict them as participants. While the ability to dis-embed that existed under CFMEP rules, which uniquely allowed Canadian journalists to go beyond "the wire" and interact with the Afghan people and their quotidian issues of importance, could have served to mitigate these boundaries, my research has found this capability was rarely utilized and/or present in the 10 years of media coverage that was analyzed.

\section{Methodology}

As the foundation of my qualitative research, I will use two methodologies to pursue my thesis: semi-structured elite interviews and content analysis. First, semi-structured elite interviews will weave together three unique perspectives on embedded reporting in Afghanistan: journalist, government official, ${ }^{5}$ and military personnel. The first perspective will be that of journalists who had first-hand experience of reporting from Afghanistan: as an embedded reporter, a dis-embedded reporter, or both; as a unilateral reporter; or in atypical cases, all three. The second and third perspectives will be those of military and government officials who had in-theatre contact with the media during the Afghanistan War. Interviews with journalists and military/government officials will 
elucidate the practice and effects of embedded and dis-embedded reporting - drawing from their on-site presence, observations, and participation in the processing of information for the Canadian public. As my research evolved, I discovered that my initial examination of the relationship between journalists and soldiers had in fact become an examination of four critical and interactive relationships, which further included: journalists and their home media organizations; the Canadian military and the Prime Minister's Office (PMO); and Canadian media organizations and the PMO. This will be further discussed later in chapters 4,5 and 7.

The second methodology will be content analysis of 10 years of media coverage by four media outlets, examining the effects of embedded reporting on Canadian war reporting during the Afghanistan mission. I will analyze media coverage of Canada's participation in the Afghanistan War from its initial military contributions in 2001 through to the end of troop deployment in 2011. Analysis will focus on reports by embedded and disembedded reporters - the first group much larger than the second - and compared when possible. An unexpected finding of my 10-year analysis of Canadian media by four prominent media organizations of the Afghan conflict was an absence of reporters who were operating completely unilaterally; thus, unilateral-produced media coverage is not addressed within my analysis, but several unilateral journalists will be interviewed in chapter 4 in order to gather their observations and insight. Yet another unexpected finding - the paucity of French-language media coverage of the war - will be addressed in chapter 6 . 
I will then triangulate the findings from all three chapters to better understand the introduction, development, practice, and influence of embedded reporting in a Canadian context. In other words, the second methodology of content analysis will examine what the embedding process actually produced, versus what the three groups of interviewees thought it could, should, and did produce. To my knowledge, this will be the first such scholarly contribution of its kind in Canada, and will help to position Canada's military/media relations within the larger context of western military/media relations.

\section{Literature}

As noted earlier, while embedded reporting has received a significant amount of attention (Aday, Lingston and Hebert 2005; Beane, Jr. 2009; Cortell, Eisinger, and Althaus 2009; Fahmy and Johnson 2005; Katovsky and Carlson 2003; Lehman 2004; Paul and Kim 2004; Pfau et al. 2004, 2005; US Army War College 2004; to name a few), and criticism (Lewis et al. 2004; Schechter 2003), most of that attention has focused on its use in Iraq (Carruthers 2011; Schechter 2006; Knightley 2004; Fox and Byungho Park, 2006). Very little research has addressed its use in Afghanistan (Edy and Meirick 2007; Rall 2010; Haigh 2014; Weisman 2015), much less so within the Canadian sphere of military/media relations (Price 2010; Hobson 2011; Bergen 2010) and some is astonishingly misinformed and biased against the media with little academic substantiation (Maloney 2005; 2009; 2011). My research will help fill this gap for communications scholars and others interested in this topic by building a baseline body of data the can be revisited, challenged, built upon, and adapted to future needs. 
Although I include in my study a review the literature on media effects - primarily agenda setting and priming, framing and indexing - it is the latter two that I argue are most applicable for my theoretical framework. Framing is a nuanced yet intrinsic component of a news report. "Frames reside in the specific properties of the news narrative that encourage those perceiving and thinking about events to develop particular understandings of them" (Entman 1991, 7). I primarily use framing theory to explore how war reporting has occurred and does occur, as first discussed by Goffman (1974), and subsequently built upon by Entman (1991; 1993; 2003), Scheufele (1999), Shah, Kwak, Schmierbach, and Zubric (2004). Further, I explore how news frames will highlight certain aspects of news and downplay others through selection, emphasis, exclusion, and elaboration (Tankard et al., cited in Capella and Jamieson 2007). As noted earlier, news frames are even more restricted within an embed environment such as the CFMEP. Thus, I investigate how framing theory, in conjunction with the very structure of the embed program, can jointly magnify limiting effects on media coverage. I draw in particular from Entman's work with issues of frame dominance; dominance representing onesidedness in the framing of a particular issue, such as battle objectives, and frame parity representing the existence of counter-frames or opposing views, which rarely exist within the embedding experience.

Communication frames are powerful tools because they affect the attitudes and behaviours of their audiences; media frames often mimic those used by politicians, other media outlets, or public groups (Entman 2004; Carragee and Roefs 2004), performing a 
powerful mediating role. In terms of foreign policy issues, for example, Entman (2004) has observed that frames originating with the administration shape the frames used by other elites such as the media and the public. Building upon research on media frames, Bennett's theory of indexing (1990; Bennett et al. 2007) contends that the media have a bias toward power and consistently present the agenda of the political elite. Indexing can be particularly influential in media coverage of foreign-affairs news, which I argue would include conflict reporting. Although indexing theory has been predominantly applied to domestic media coverage of foreign-affairs news — more specifically, the domestic American media's coverage of foreign affairs - I wanted to explore if and how this theory might apply to the Canadian embedded media's conflict news coverage. Ultimately, I found a lack of indexing as defined by Bennett (1990; Bennett et al. 2007), therefore this research project did not turn out to be an indexing study.

\section{Structure}

I will present several chapters that investigate my core question: how did official procedures that governed media coverage during the Afghanistan War - embedding policies developed and imposed by both Canadian media-parent organizations as well as the military - influence the resulting media coverage that Canadians received? I argue that embedding policy - the result of negotiations between the imperatives and constraints of the news media and those of the military - had a structural influence on the content and emphases of ensuing media coverage. More specifically, embedding policies and practice changed both how war coverage was produced, as well as the content of what 
was produced. The result was an overwhelming focus on the military - to the exclusion of diplomatic and humanitarian efforts - initially on combat and goals, subsequently on injuries, deaths, and ramp ceremonies.

First, given that embedded reporting as we know it today has its roots in a rich history of military/media relations, I will begin my examination of its evolution within that larger context. Chapter 1 will use a media-effects lens, particularly framing and indexing theories, to look at the influence of the political and military elite on the media through five conflicts that significantly contributed to major shifts in overarching military/media relations throughout a 50-year period: the Vietnam War (1955-1975), the Falklands War (1982), the Gulf War (1991), the Iraq War (2003-2011), and finally the Afghanistan War (2001-2014).

Once the historical antecedents of military/media relations have been presented, chapter 2 will focus on a review of the literature on media effects - primarily agenda setting and priming, framing and indexing - examining their similarities and differences in order to evaluate if they are cumulative, refined versions of one another or, rather, are more dependent upon factors such as placement in time, particular media ecologies, and/or specific cultures. As noted earlier, I primarily use the approaches of framing and indexing to explore how war reporting has occurred and does occur as I argue these two theories offer the most comprehensive approaches to analyzing why the media reports on international conflicts the way they do. 
Chapter 3 will outline the involvement, as well as reasons for that involvement, of Canadian military forces in Afghanistan following 9/11; their engagement is divided into three time periods that correspond to varied deployments and objectives in different regions of Afghanistan. This chapter will also address the development and formal implementation of the Canadian embedded-reporting program in 2006, as well as the evolution of Canada's involvement from a strictly military presence to a "3D" strategy of defence, diplomacy, and development projects following the release of an important milestone called the Manley Report (2008).

Next are three chapters that comprise the corpus of my original research and major contribution to the literature. In chapter 4, I will interview journalists with first-hand experience of reporting from Afghanistan: as an embedded reporter, a dis-embedded reporter, or both; as a unilateral reporter; or in atypical cases, all three. My questions were designed to provide a wide spectrum of insight into how embedded policies and practices have developed, perceptions regarding how the program operates and delivers, how participants perform and work together, what the outcomes are, and possible suggestions for change. Of note, I will let my interview subjects present their own narratives in this chapter, later condensing and analyzing their comments in the Discussion section. Finally, this chapter will go beyond the four media entities analyzed in chapter 6 - the Globe and Mail, La Presse, CBC, and Télévision de Radio-Canada (SRC) - to interview apropos journalists who reported form Afghanistan. A list of interviewees can be found in Appendix A. 
For chapter 5, I will interview military and government officials who had in-theatre contact with the media during the Afghanistan War. As with chapter 4, my questions were designed to provide a wide spectrum of insight into how embedded policies and practices have developed, perceptions regarding how the program operates and delivers, how participants perform and work together, what the outcomes are, and possible suggestions for change. As in chapter 4, I will let my interviewees present their own narratives, later condensing and analyzing their comments in the Discussion section. Of note, in order to secure Department of National Defence ethics approval of my questionnaire for military personnel, I agreed to remove the majority of my military oversight questions as they asked for opinions that required participants to "speculate about events, incidents, issues or future policy decisions" (DAOD 1998), which is prohibited by Canadian legislation. A list of interviewees can be found in Appendix B.

Next, chapter 6 will serve as a mirror of sorts, reflecting what embedded reporting actually produced in comparison to what the three groups of interviewees in chapters 4 and 5 believed it did or should produce. I will analyze a 10-year period of media coverage of Canada's participation in the Afghanistan War, from its initial military contributions in 2001 through to the end of troop deployment in 2011. I will compare English and French coverage: for print, I chose the Globe and Mail and La Presse, and for television, I chose the $\mathrm{CBC}$ and Télévision de Radio-Canada (SRC). Analysis will be conducted in two stages. First, I will use a method of data collection called constructed week sampling for the three military time periods I noted in chapter 3 . For example, Period one extends from October 2001 through to June 2003. I constructed a sample of three weeks of media 
coverage from October 2001 through to June 2003, from a total of 21 months, by selecting one Sunday from October 2001, one Monday from November 2001, one Tuesday from December 2001, and so on. The second stage, critical discourse analysis, "traces its roots backs to linguistics" and allows for detailed analysis of the 'semantics' and 'syntax' of the texts (Johnston 1995, 220) vis-à-vis the research question: quantifiable influence of embedded reporting. The units of measurement will be theme, a single assertion about a subject; presentation, if the journalist was reporting as an embedded or unilateral; and tone, observable choice of personalized or neutral language to report events. I will utilize these units of measurement to examine if and how framing and indexing of issues may occur.

Chapter 7 will reflect on the findings of my interviews and content analysis in order to establish what influence the practice of embedded reporting has played in the Canadian media's use of discursive practices to portray the Afghanistan War. I will analyze and discuss the results from chapters 4,5 and 6 and categorize key themes and issues identified through my research, incorporating perspectives from journalists as well as military and government officials, and evaluate how all of these elements support or reject my thesis claim and theoretical approaches.

Finally, drawing together pertinent threads from the previous chapters, I will detail how my research cumulatively supports my original argument: that embedding policy - the embodiment of priorities and limitations of two disparate cultures, the military and the media - had a discernible structural influence on the content and emphases of ensuing 
media coverage. I explore how, one, the very structure and housing of the program in conjunction with military prerequisites and within military confines - both reasonable conditions given issues of security and safety - as well as, two, the inability due to mediaparent dictates and/or unwillingness of many journalists to take advantage of the uniquely Canadian option of dis-embedding, combined to produce a military-centric rather than overarching perspective on the war, and largely dismissive of diplomatic and humanitarian efforts. There were of course individual exceptions in media coverage, but for the most part, analysis showed a discernible imbalance. I will also discuss how my findings fit into and contribute to the larger body of scholarly literature on military/media relations, the limitations of my study, and possible future research directions.

\section{NOTES}

${ }^{1}$ Some media scholars (Knightley 2004), trace the practice of war correspondence back to the Crimean War (1853 -1856), when The Times of London sent a general reporter, William Howard Russell, to report back; while others (Pfau et al. 2005), have traced the relationship between the media and the military back to the American Civil War (1861-1865).

2 This war is also called the "First Gulf War," the "Persian Gulf War," and "Operation Desert Storm." I will use "Gulf War." While the genesis of the Gulf War began with the invasion of Kuwait by Iraqi troops on 2 August 1990, the subsequent invasion by a UN-authorized coalition of 34 nations and led by the U.S. began on 17 January 1991. Thus, I use the year 1991. The invasion, “Operation Desert Storm," ended on 28 February 1991.

3 This war is also called the "Second Gulf War" and "Operation Iraqi Freedom." I will use "Iraq War" to help distinguish it from the shorter invasion of 1991.

${ }^{4}$ Embedding was also used on a limited scale for U.S. military deployments in Bosnia (1992 through to 1995), Kosovo (during 1999) and, as noted earlier, for pooled reporters during the Gulf War. Its success, according to Cortell, Eisinger, \& Althaus (2009), produced an expectation by news bureau chiefs that some form of an embedding program would be devised for the next military campaign.

${ }^{5}$ Government perspectives were not only valuable for their policy views, but a number of military and government officials were typically housed together during Canada's mission in Afghanistan and had experiences with the CFMEP as well as journalists reporting from Afghanistan. 


\section{CHAPTER ONE: HISTORY OF MILITARY/MEDIA RELATIONS LEADING TO EMBEDDED REPORTING}

In this chapter, I will trace the origins and development of what is today referred to as embedded reporting, while simultaneously examining its varied influence on the practice of conflict journalism. Although I will predominantly concentrate on five relatively recent conflicts that I contend have significantly contributed to major shifts in overarching military/media relations throughout a fifty-year period which have led to the de facto adoption of the embedded program by most western militaries, I will first briefly speak to the origins of embedded reporting that reportedly date back to World War I (1914-1918), if not earlier to the Franco-Prussian War of 1870-71. In this, it could be said that an embryonic form of embedded reporting is almost as old as the very practice of war reporting itself, which some scholars such as Knightley (2004) have traced back to the Crimean War (1853-1856). ${ }^{5}$ I will next focus on three conflicts: the Vietnam War (19551975), the Falklands War (1982), and the Gulf War (1991). ${ }^{6}$ I will map how and why military/media communication strategies contributed to, supported, and flowed from each of these conflicts while exploring the arguments used to defend or oppose them. Lastly, I will advance the themes explored in these previous conflicts and apply them to the more recent Iraq War (2003-2011) ${ }^{7}$ as well as the ongoing Afghanistan War (2001-present) in order to investigate how previous issues related to military-media relations are being played out in a more current context. 


\subsection{Tracing the roots of embedded reporting}

War is only a continuation of state policy by other means

- Prussian military strategist Carl Philipp Gottfried von Clausewitz, 1874 (2006)

Although the practice of embedded reporting seemed to "jump" into the public eye at the beginning of the Iraq War in 2003, that foray was simply the first large-scale official use of embedded reporters, the tendrils of which were rooted to various degrees in previous conflicts. In order to better appreciate the significance of today's embedded reporting, it is important to trace its development from the more traditional form of conflict journalism which is now referred to as "unilateral reporting" - to what has largely become the new norm for war journalism: embedding reporters into conflict situations in close proximity to the soldiers they will report on and whose protection they need. Following is a brief review of the practice's historical context.

\section{$\underline{\text { Franco-Prussian War (1870-71) }}$}

The period of time between the American Civil War (1861-1865) and WWI has been called the "Golden Age" for the war correspondent (Knightley 2004). The print press was gaining in popularity, literacy rates were growing, the telegraph enabled more rapid communication over greater distances, and the practice of censorship was not yet well organized. A “new breed” of mostly European reporters (Roth 2010, 127) used electric telegraphy and Cyrus Field's transatlantic cable, completed in 1866, to deliver speedy news reports to a public hungry for information, employing a more concise and crisp style 
of writing that stood in contrast to a more florid and descriptive style that was popularized by William Howard Russell during the American Civil War.

Some believe that the origins of embedded reporting, within the larger context of military/media relations, can be traced as far back as the Franco-Prussian War. Prussia took advantage of information lessons learned from the American Civil War, both in terms of movement - eventually fusing its railway, telegraphic, and aerial services under the name "communication troops" (Mattelart 1996, 203) - as well as the propaganda value of a friendly press. "Nothing will be more favourable for our political standing in England and America than the appearance, in the two most influential newspapers of these countries ... of very detailed accounts of our army in the field," said German Chancellor Otto von Bismarck to Minister of War Albrecht von Roon (cited in Knightley 2004, 47). Conversely, French authorities - prescient of American objections following the Vietnam War - forbid access by journalists of any specialty and nationality to French camps from July 1870 onward (Martin 2006, 73-74) due to the belief by French military strategists that leaked information had caused the defeat of the French army. Nevertheless, albeit removed from the grime and gore of battle, British reporter Archibald Forbes was allowed close access to both Bismarck and the King of Prussia as they awaited news of the battle at Gravelotte-Saint-Privat in August 1870, and subsequently recorded their emotional reactions to victory for his readers.

\section{World War I (1914-1918)}


A more unequivocal example of embedding can be found in arrangements that the British army made for six war correspondents during WWI (Knightly 2004, 84-85, 101-104, 531532). Prior to this arrangement, the press had been kept on tight lockdown by Britain, in an effort to prevent public awareness of military losses. The correspondents were embedded with the British Expeditionary Force in France, given the honorary rank of captain, wore uniforms, and were assigned orderlies, chauffeurs and conducting officers; however, their view of the war was limited to what the general staff felt they should see, and their subsequent writings were submitted to the censors, who passed them on to the War Office in London, which then forwarded the dispatches to various newspapers. Last but not least, all six correspondents were given Knighthoods for services rendered. The effective commandeering of members of the press to serve as a propaganda arm of the government and military was noted by Prime Minister Lloyd George in 1916: "The Press has performed the function which would have been performed by Parliament...." (cited in Mattelart 1994, 57).

British historian Ponsonby (1936), well-known for his observation that "when war is declared, truth is the first casualty," cited the example of a war correspondent - who had mentioned a chivalrous act committed by a German soldier toward an Englishman during fighting - subsequently receiving a telegram from his employer, chiding him: "Don't want to hear about any good Germans." That same correspondent, Sir Philip Gibbs, later wrote an account that seems prescient of words written by reporters embedded with the U.S. military during the Iraq War roughly 100 years later. "We identified ourselves absolutely with the armies in the field, and we wiped out of our minds all thoughts of 
personal 'scoops,' and all temptation to write one word which would make the task of officers and men more difficult or dangerous. There was no need of censorship of our dispatches. We were our own censors." (Gibbs 1923, 248). The resulting lack of neutrality in reporting, coupled with an abundance of false atrocity stories, led to a simmering anger with WWI English and French war correspondents - the latter just as culpable in ignoring the tragic blunders of its army - mitigated somewhat by a nascent resistance among American war correspondents to censorship attempts (Knightley 2004, $98,111,120)$.

World War II (1939-1945)

Although WWII began in 1939 when Germany attacked Poland, the U.S. did not enter the war until after the Japanese bombed the American fleet in Pearl Harbor, Hawaii, on 7 December 1941. While the U.S. military had disallowed reporters from the front during WWI, it largely welcomed them during WWII, considering the press to be part of the fighting forces. "Correspondents have a job in war as essential as the military personnel," wrote General Dwight D. Eisenhower in a memorandum drafted in the days before the Normandy invasion. "Fundamentally, public opinion wins wars" (Moeller 2006).

The line between soldier and journalist became blurred with the help of the U.S. Office of War Information - a government agency created by President Franklin D. Roosevelt on 13 June 1942 and that lasted until September 1945 - which was directed by Elmer Davis, a former New York Times journalist, and tasked with publicizing the American war effort 
both domestically and internationally (Knightley 2004, 299). WWII aptly demonstrated that war correspondents can become heroes if, one, it is a popular war and, two, they are seen as part of the war effort, as was the case with Ernie Pyle, Edward R. Murrow, and the CBS radio team in London known as "Murrow's Boys" (Kellner 2008, 302). Pyle, a columnist for Scripps-Howard, was likely the best-known journalist of the war. Like today's embedded reporters, Pyle told the stories of the ordinary GIs - the 'grunts' of the war. He initially convinced his editors to send him overseas for a six-month stint, but stayed for three years, living among the soldiers, filling his column with the details of their lives at the front. "Embedding is not new," according to war documenter Stephen Ives. "Reporters in World War II were embedded, but they had more freedom of movement. Ernie Pyle could go from one unit to another" (Ives 2003).

Canada had entered WWII in September 1939, initially supplementing the British Expeditionary Forces. Although Canada lacked its own version of Ernie Pyle, the Canadian Army had - like its Allies - more quietly promoted close ties between correspondents and military troops. In fact, correspondents received the status of honorary officers, wore military uniforms, and were subject to military law. According to Balzer, "correspondents were, in effect, part of the military, much more so than are recent 'embedded journalists"' $(2010,31)$. Although not a formal embed program, the underlying rationale was similar: journalists who saw themselves as part of an organization would likely refrain from writing negatively about it. 
If, however, there was any doubt about the patriotism of the reporter, organizations such as the Office of Censorship would oversee all civilian modes of communication, while the U.S. army and navy practiced "censorship at source" (Knightley 2004, 300). All war correspondents were required to sign an agreement to "submit for the purposes of censorship all statements, written material, and all photography intended for publication" (Roth 2010, 479-497). By the time the Allies stormed the beach at Normandy in 1944, the military was in the position to be able to select 28 writers and photographers as "assault correspondents," including famed war photographer Robert Capa, who was with the first wave (Riechers 2003). In summary, according to Knightley, correspondents during World War II practically functioned as propagandists for the allies. "It's best summed up by the American government censor, who at the height of World War II said, in relation to the press, "tell them nothing till it's over and then tell them who won" (McKew 2003).

In retrospect, the military/media relationship during the two World Wars could be labeled as symbiotic, largely due to what Brandenburg calls "voluntary compliance by journalists" $(2007,948)$ but also due to more systemic measures such as censorship. Following WWII, during the first six months of the Korean War (1950-53), military/media relations continued to be relatively cordial and censorship was applied only to issues concerned with military security, much like today's "operations security" (OPSEC). In 1951, however, when the U.S. press began to question the U.S. role in the conflict, criticized the conduct of the Syngman Rhee regime, and wrote embarrassing stories about frightened GIs, the military imposed heavy censorship on news media releases through General Douglas MacArthur's headquarters (Schoenfeld 1992). 


\title{
1.2 Technological advances used to conduct war as well as communicate warfare
}

I wish God damned television had never been invented

- Edward R. Murrow 1948 (cited in Hamilton 2009, 297)

\begin{abstract}
Although it is valuable to peer as far back as possible in history for the origins of the embedded program, I assert that it is especially worthwhile to examine more recent interactions between the military and the media, a trajectory of critical junctures that has led to today's fundamentally altered version of conflict journalism. Following is a condensed 50-year timeline that begins with the Vietnam War and continues through to the Afghanistan and Iraq Wars, presenting both journalistic practices as well as military perspectives and, when pertinent, introducing communication theory. I contend the five wars that I have chosen most clearly demonstrate critical military/media communications during this time period; however, I will also address key activities and interactions both during the conflicts as well as those between the conflicts, meaning the time period after one conflict and prior to another.
\end{abstract}

Vietnam War (1955-1975)

It is the "conventional wisdom" that South Vietnam was lost because of television (Hallin 1986, 105-6). Certainly Vietnam was America's first televised war, given that television was still in its infancy at the time of the previous Korean War, and not yet a major source of news. In retrospect, however, military/media relations during Vietnam were divided 
among at least three primary factions: adversarial, mutually beneficial, ${ }^{8}$ and convergent. ${ }^{9}$ Furthermore, variations of these three perspectives have continued to influence military/media relations during subsequent conflicts.

Politicians such as Lyndon Johnson and Richard Nixon, as well as the military establishment, represent the faction that had the most influence on subsequent military/media relations. Political and military authorities adopted an adversarial narrative of the journalist's role, contending that critical and uncensored presentation of American casualties during the Vietnam War undermined public support for the war (Reston 1972). Many point to a special 1968 report on the Tet offensive by Walter Cronkite of CBS in which he called the war a "bloody stalemate" and virtually impossible to win (Hallin 1986, 108). President Johnson, despite a close relationship with Cronkite, is reported to have said following the report, "it's all over" (Ranney 1983, 5).

Nixon also blamed television, for showing "the terrible human suffering and sacrifice of war ... the result [being] a serious demoralization of the home front, raising the question whether America would ever again be able to fight an enemy abroad with unity and strength of purpose at home" (Nixon 1978, 350). Some scholars support this view, noting that 90 percent of US households in the 1960s possessed a television set, which supplanted newspapers as American's primary source of news (Brewer 2009, 181), and that 60 percent of Americans got most of their war news from television (Knightley 2004, 451). That said, Knightley points out that “television's power seems to have impressed British observers even more than American" (452); for example, according to Air Vice- 
Marshal S.W. B. Menaul, director-general of the Royal United Service Institution, television reporting had "a lot to answer for [in] the collapse of American morale in relation to the Vietnam war" (cited on 452). ${ }^{10}$

The military perspective also falls within this narrative. General William C. Westmoreland, former commander of the Military Assistance Command in Vietnam, believed that the reporters' youth - some 51 percent of US reporters in Vietnam had been in their $20 \mathrm{~s}$ - inexperience, ignorance, and craving for professional advancement all contributed to a distorted image of the war. Westmoreland claimed that, eager to make a name for themselves, these novice reporters had done so in the easiest way possible: by criticizing authority. "Finding fault was one way to achieve the sensational, and finding fault with an Oriental regime with little background in or respect for Western-style democracy was easy" (cited in Thayer 1992, 91). Furthermore, complained the general, the coverage was blood thirsty, "almost exclusively violent, miserable, or controversial: guns firing, men falling, helicopters crashing, buildings toppling, huts burning, refugees fleeing, women wailing” (Westmoreland 1976, 420). It was not just the military that denounced press coverage: former Los Angeles Times reporter Robert Elegant lambasted his own profession for becoming "less objective than partisan" (Elegant 1981, 138) while New York Times columnist Cyrus Leo Sulzberger mused: "Imagine what Goebbels would have done for Hitler with TV as well as radio to hand" (Sulzberger 1970, 39).

Coverage of the 1968 Tet Offensive by the northern forces was particularly galling for the US military. While former reporter Braestrup explained that portraying Tet as a defeat for 
the allies (1984) was more of a sign of pervasive pessimism that hung over the press corps rather than an ideologically driven desire to undermine domestic support for the war, Westmoreland saw calculation and hostility: “[M]ost South Vietnamese units fought well, but it was not the 'in thing' in media circles to say anything good about the South Vietnamese. The media misled the American people by their reporting of 'Tet,' and even a number of officials in Washington were taken in" (Westmoreland 1979, 168). Apparently President Johnson was one of those officials, given that Cronkite's damning evaluation of the war as a "stalemate" on 27 February 1968 led to LBJ's decision on 3 March 1968 to not seek reelection as president (Hallin 1989, 170; Seib 1997, 19).

In short, the lesson the military and prominent politicians took away from Vietnam was clear: war correspondents who operated freely, wrote, photographed, and filmed what they liked, and mocked the military that protected them, could help "lose" a war. As I will address later, some contend that the British military subsequently constructed their Falklands media strategy based on the same belief - that the power of television had lost Vietnam (Knightley 2004, 452). ${ }^{11}$

A second, contrary faction or view of military/media relations is one of mutual support; that, until Tet, television news was "lopsidedly favorable to American policy in Vietnam" (Hallin 1988, 110). Just 22 percent of all film reports in the pre-Tet period depicted actual combat; around 24 percent contained shots of the dead or wounded, usually briefly; and less than 10 percent offered more than one shot of the dead or wounded (129-30). In addition, people may not have accurately self-reported the impact that television news 
had on them. Owning a television and watching network news during the mid-1960s were not one and the same; in fact, network news was watched by fewer than half of all television-owning households on any given night (Thayer 1992, 99).

A later study by Lichty (1984) found that fewer than one third of adults watched any TV news, and "only one percent of the 78.3 million American TV households watches CBS's Dan Rather as often as four or five nights a week" (158-9). Furthermore, due to the effects of selective perceptions, the media tend to reinforce people's already existing attitudes: a 1968 study found that 75 percent of respondents who considered themselves "hawks" also considered Walter Cronkite a "hawk," and even more thought Chet Huntley and David Brinkley were "hawks," while a majority of viewers who considered themselves "doves" also considered the three anchors to be "doves" (Lichty 1973). Finally, even though BBC commentator Robin Day's 1970 remark that "blood looks very red on the colour television screen" (Knightly 2004, 452) received a lot of attention, the fact is that a majority of American households did not possess a colour TV set until after 1972 (Brewer 2009, 181).

A third faction of military/media relations speaks to the surreal nature of a mediated war. Arlen (1969), for example, contends that television was in fact a paradoxical, contradictory force. On one hand, television served to "banalize" or "diminish" the war for its viewers by the very "physical size of the television screen" (8) and its disconnected black-and-white images of three-inch-tall soldiers trotting up hills or walking through tall grass - all observed within the cozy confines of the viewer's living room. On the other 
hand, while television did serve to facilitate revealing the horrors of war by using images and, to a lesser degree, sounds to tap into viewers' emotions, Arlen argues that television's true influence was demonstrated primarily through support of an alreadygrowing societal opposition to the war.

Taylor has expanded on this "reality/image gap," noting that there are two types of wars: the "real war" in which blood runs freely and combatants die gruesomely, and a "mediated" war in which the grim realities of conflict are "filtered" to a distant and nonparticipating audience. "Real war is about the sounds, sight, smell, touch and taste of the nasty, brutal business of people killing people. It frightens and appalls most people, so much so that they would be repelled by its reality. Media war, however, is literally a mediated event which draws on that reality but which, in and of itself, is confined to merely an audio-visual - and therefore inherently desensitizing - representation of it" (1995). This theme of a distant and social construction of death during war remerged and was intensified later during the 1991 Gulf War (Umberson 1992), a dissonance that will be addressed later in this chapter.

More vital for communication scholars than television's role in the outcome of the Vietnam War, however, was the development of theories about media "framing," "indexing," and information flow. The ideas of power-elite fragmentation and domestic contestation, which led to media divergence and critique, have had deeper resonance than the perception that television specifically or the media in general caused the loss of the Vietnam War. I contend that the media was instead fragmented in its approach to and 
coverage of the war - for example, ground-level journalists versus upper-echelon editors - and that the media by large were also swept along with the cultural, political, and draftweary tides of the time and more likely became emblematic of the war's loss in the public and military eye due more to the novelty of television than its actual influence.

Although I will further address theoretical approaches in chapter 2, it is important to introduce certain concepts now as they are pertinent to military and media developments covered in this chapter. The first is framing. Goffman (1974) was the first scholar to specifically define it as "the principles of organization which govern events - at least social ones - and our subjective involvement in them" (10). In short, framing is about packaging; for journalists, it is about how they choose to select, emphasize, interpret, and exclude aspects of a perceived reality. These choices have clear implications for, or framing effects on, the way an audience perceives, interprets and reacts to news stories.

Since its inception, the study of framing, its processes, and the context in which it can operate have expanded considerably (Entman 1993; Scheufele 1999; Shah, Kwak, Schmierbach, and Zubric 2004). Entman in particular has expanded on Goffman's original concept to elaborate on two issues: frame dominance, dominance representing one-sidedness in the framing of a particular issue, such as reasons for going to war; and frame parity, representing the existence of counter-frames $(1991 ; 2003)$. In order to achieve parity, news must present a "complete alternative narrative, a tale of problem, cause, [and] remedy" $(2003,418)$. However, an examination of military/media relations 
will demonstrate that, while it sometimes exists, "frame parity is the exception, not the rule" (418).

The concept of indexing emerged from the study of media coverage of the Vietnam War as a way to analyze government influence on the media (Hamilton 2009). Indexing essentially contends that the media have a bias toward power, and consistently present the agenda of the political elite. It is supported by analysis showing that coverage tends to follow the patterns of official views (Bennett 1990). "Once officials engage with news events, the story frames generated by journalists are then generally 'indexed' to the range of sources an viewpoints that reflect levels of official agreement and consensus" (Bennett, Lawrence, and Livingston 2007, 100). When consensus within the government is strong, as it was during the early stages of the Vietnam War, the range of views in the news media tends to be narrow. When the range of official views widens, as it did in conjunction with growing opposition to the war, media coverage tends to widen with it.

The media bias found within indexing is based on the erroneous assumption that authority figures, government experts, and elite informants know enough about a story and its associated issues to provide a complete picture, thereby forestalling additional investigation by a reporter. Indexing is particularly prevalent in the reporting of international news and matters of foreign policy - which certainly involve wars - as journalists are often hesitant to probe beyond government and military officials, who are habitually perceived as the most informed authority figures and experts. In addition, the executive branch of government has strong constitutional power in foreign affairs, and 
legislators typically defer to the president and the military in the midst of a national security crisis. The Vietnam War illustrates this tendency; in the early 1960s, the war was still a "back-burner conflict" and much of what the American public knew of it came from journalists in Washington, who in turn received much of their information from either the State Department or the White House.

Another factor lending great support to indexing influence during the Vietnam War involves a journalist's basic need for sources who can provide facts and views; in Washington these sources are predominantly elected and appointed officials who are knowledgeable, who make and implement policy, and are generally approachable when they want to be. Using sources outside elite circles in Washington is a more subjective call, and open to questioning by an editor and perhaps the public, especially if their views are nonconforming. However, if an official presents a dissenting view, it becomes more palatable and easier to process within the story, as happened after the Tet Offensive in 1968 when official consensus broke down. In retrospect, it can be said that journalists did not so much deviate from their professional norms and initiate the end of the war as they followed the lead of their capitol-based sources, who had reappraised the war effort in light of costs and casualties (Mueller 1973, 42-61), and this elite reappraisal in turn triggered an adjustment in media coverage of the war.

That said, indexing is not found in all reporting, political systems, or cultures. French journalists, for example, reacted to the Iraqi invasion of Kuwait by gathering reactions 
from notables and spokespersons from each of the various parties, such as the Communists on the left and the National Front on the right (Cook 1994).

To this day, theories and disagreements continue to abound regarding media coverage of the Vietnam War and its influence on the trajectory of that war. Again referencing the three narratives of military/media relations presented earlier-although some media historians, journalists, and military officials would like to claim an adversarial relationship, it would be more accurate to say that the media were cheerleaders of the war effort, at least prior to 1968 and the Tet offensive. ${ }^{12}$ Nonetheless, both the military and the media were merely the latest characters in the larger drama of colonial disintegration. As New York Times war correspondent David Halberstam expressed to Knightley: "The problem was trying to cover something every day as news when in fact the real key was that it was all derivative of the French Indo-China war, which is history. So you really should have had a third paragraph in each story which would have said, 'All of this is shit and none of this means anything because we are in the same footsteps as the French and we are prisoners of their experience.' ... in Vietnam I think we were haunted and indeed imprisoned by the past" $(2004,465-6)$.

Falklands War (1982)

While the invasion by Argentinian forces of the long-disputed Las Malvinas or Falklands Islands in April 1982 was small-scale in terms of military engagement, the conflict's primary importance vis-à-vis military/media relations is to demonstrate that the British 
Ministry of Defence (MOD) fashioned its restrictive Falklands press plan based on the firmly held belief that Vietnam had been "lost" on and by American television (Hallin 1986, 105). Several US military officials publically continued to complain that an 'uncensored war' had led to their defeat in Vietnam, a view championed by newly retired General Westmoreland while telling the New York Times "there should have been press censorship" (Ayres 1974). Television was perceived as the primary domestic antagonist and, subsequently, relations between soldiers and journalists were designed in openly adversarial terms.

The British were caught unawares when military dictator Leopoldo Galtieri ordered the invasion of a group of rocky and nearly treeless islands roughly 300 miles northeast of the southern tip of South America and 8,000 miles from Britain. The rapid deployment of British warships in response to Argentina's invasion - after London initially minimized Galtieri's threatening behavior - facilitated a minimization of media coverage: “... hardly ever have circumstances been more propitious for a censor than they were for the British in the Falklands" (Mercer, Mungham, and Williams 1987, 39). The mere handful of journalists -29 total - who joined the Task Force seemed themselves to expect a hasty victory, packing little more than a toothbrush and change of underwear (Morrison and Tumber 1988, 5-7). These reporters found themselves never without a military minder, their images and stories were "reviewed" by their minders (and sometimes again by the MOD in London), and they had to exclusively rely on military communications equipment to transmit copy back home (Carruthers 2011, 120-123). 
One of the 'mistakes' the British military was determined to avoid was allowing reporters unfettered access to the battlefield; consequently, both print and broadcast media were kept on a very tight leash during the 74-day campaign (Carruthers 2011). While the official MOD position was that no censorship was practiced, the imposed parameters or "guidelines" indicated otherwise. For example, "good news" coverage, such as a 23 May Sunday Mirror photograph (Taylor 1991, 95) by Tom Smith of a Falklands Islands family offering a Marine a cup of tea - "Cuppa for a Brave Para" portrayed what Brothers (1997) calls "a quintessential image of Britishness. The custom of tea drinking was projected as a hallmark of English culture, while the symbolic picket fence signaled ownership and domestication of this far-flung corner of empire, legitimising the campaign to re-establish sovereignty over it. The smiles of the village women and children expressed gratitude for a job well done, fitting effortlessly into the up-beat narrative of a conflict whose less pleasant aspects had been conscientiously expunged" (208). This image appeared only two days after the Task Force had landed at San Carlos, where photographer Martin Cleaver had recorded the HMS Antelope's explosion during battle — an image that was subsequently delayed for three weeks because it was judged to be bad for morale (Dodds $2005,225)$

Two television correspondents - Brian Hanrahan and Mike Nicholson - tried to work around these enforced parameters. The two pieced together stories from the work of print colleagues, had themselves winched from the Hermes to an auxiliary ship called the Olmeda, and used the latter's secure satellite phone system called the Marisat to file their voice reports (Harris 1983, 33). Film footage was shot, but then it had to be shuttled by 
helicopter or ship to Ascension Island, then by plane to Britain, constituting an average gap between filming and transmission of 17 days to reach London (Dodds 2005, 223). The result was essentially a radio report. In fact, the Falklands conflict was dominated by radio rather than television reports (Dodds 2005, 230).

On the domestic front, the war's primary importance was political - Margaret Thatcher's government was suffering the lowest popularity ratings ever recorded due to record unemployment - and the Falklands conflict allowed the Thatcher government to engage in post-colonialist chest-beating in the name of patriotism and British resolve. As battle lines were drawn, indexing effects became evident at national levels.

Self-censorship practices by media managers in the name of "good taste," issues of national security, and public opinion closely mimicked Prime Minister Thatcher's political discourse that was littered with patriotic fervor and references to "our boys," as well as hostility towards anti-war protesters, the BBC, the political left, and trade unionists. Most of the British media - with the exception of the BBC, the Daily Mirror, the Guardian, and the Financial Times - were clearly sympathetic to the government's decision to use armed force. The Sun, for example, used war rhetoric in their headlines such as "Stick It Up Your Junta" (20 April 1982) at war's outbreak and "Gotcha: Our Lads Sink Gunboat and Hole Cruiser" (4 May 1982) in reference to 1,200 Argentinians drowning, both capturing and intensifying the prevalent zeitgeist. In retrospect, government-led outrage against "the dangers of 'appeasing' dictators" (Dodds 2005, 227) and comments such as "We are fighting a battle against that type of aggression, and once 
again it is Britain that is fighting it" (House of Commons 1982, 70) seem suspect given that, despite British claims to sovereignty over the Falklands dating back to 1690 , the UK had denied full British citizenship to the islanders until after the war, when the government passed the British Nationality (Falkland Islands) Act in 1983.

Following the war, students of military history became invested more than ever in examining the power of "immediate mass communication," recognizing that "the news media can be a useful tool, or even a weapon, in prosecuting a war psychologically, so that the operators don't have to use their more severe weapons," wrote public affairs specialist Lieutenant Commander Humphries of the US Navy in a post-Falklands analysis 1983, 67). The key was to "control access to the fighting, invoke censorship, and rally aid in the form of patriotism at home and in the battle zone" (59) in order to "affect or help assure "favourable objectivity" (71). The biggest obstacle to achieving this goal was "a juvenile attitude by reporters, publishers and TV executives who are too often used to getting their way" (65) and pesky journalists that were "too cavalier with dangerous information because of naiveté, pressures of deadlines, self-righteousness, or political bias" (61-62).

In summary, media management for the Falklands War was premised on the idea that war in the television age could be "won" by imposing severe restrictions on television, which would in turn minimize the public's exposure to negative representations of the British forces. The regulations issued to correspondents with the Falklands Task Force in 1982 clearly outlined the military's perception of the military/media relationship, one of 
irreconcilable antagonism: "The essence of successful warfare is secrecy. The essence of successful journalism is publicity" (Harris 1983, 16). The Pentagon, in turn, tried to emulate the MOD's restrictions on the media during its later invasion of Grenada (1983) when it excluded reporters altogether, the invasion of Panama (1989) when it began to experiment with the idea of a "press pooling" system, and the Gulf War (1991) when it implemented media reporting teams (MRTs) or "press pools" to control what they called "unfettered journalism" (Mordan 1999). In fact, serving as a harbinger of the 1991 Gulf War, Washington Post reporter Tom Shales wrote mid-war in 1982 that the distant, and fairly bloodless conflict in the Falklands looked "almost like a video game, with so many graphs and maps and little blip-ships on the screen, and so little real evidence of combat" (cited in Carruthers 2011, 125).

\section{Gulf War (1991)}

As noted above, with its implementation of press pools during the Gulf War, the Pentagon emulated and enhanced previous Falklands media restrictions by the MOD. Humphries (1983) had noted that Mao Tse-tung's aphorism - "Power comes from the barrel of a gun" - needed to adapt to an age of near-instant communication technologies. "Power also bounces down a beam from a communications satellite and goes to the side which tells the story first," he wrote (emphasis added, 61). Humphries was particularly impressed by the Israelis' ability to "use strict censorship" while maintaining "not usually obstructive" media relations, and making sure that reporters' copy was dispatched with speed and that reporters were "given every possible assistance in the field" (61). While 
this approach may seem contradictory, it was in fact a basic blueprint for press pools and became an integral component of the US military's three-pronged approach to commodifying the war for the American public.

There appeared to be three new communications strategies employed during the Gulf War — percolating since Vietnam, building on the British success in the Falklands, and honed by the US during invasions of Grenada (1983) and Panama (1989). One, the war was aggressively packaged as a battle against Iraq's "naked aggression" that threatened US energy needs. Two, the position that technological advances would allow a war that could be fought with "smart" weapons that cleanly, swiftly, and unerringly hit their targets, thereby causing minimal civilian fallout. Three, the news media was 'managed' much better than in the past. ${ }^{13}$

The first strategic parry involved an unprecedented use of public-relations (PR) firms to 'package' the war; speed seemed to be of the essence, as did borrowing from history. Immediately following Iraq's invasion and subsequent occupation of Kuwait in August 1990, President George H.W. Bush compared it with the Nazi blitzkrieg in Europe during the 1930s, and Saddam Hussein with Adolf Hitler. In another historical throwback - to World War I, when British propagandists accused German soldiers of tossing Belgian babies into the air and catching them on their bayonets - atrocity stories began to surface. The most egregious, and effective, had Iraqi soldiers bursting into a Kuwaiti hospital and tossing premature babies out of their incubators so the incubators could be sent back to Iraq. Initial media coverage was bolstered by tearful testimony from a 15-year-old 
Kuwaiti girl called "Nayirah" before the Human Rights Caucus of the US congress in October 1990 about scenes she claimed to have witnessed in a hospital where Iraqi troops had thrown babies from their incubators in an orgy of looting. President Bush referred to her story six times in the next five weeks as an example of Hussein's offensive regime. During Senate debate in 1991 on whether to approve military action to force Hussein out of Kuwait, seven senators specifically mentioned the incubator-babies atrocity story, and the final margin in favour of war was just five votes, 52 to 47 (Knightley 2004, 487). In retrospect, the incubator-babies atrocity story provided decisive momentum in the larger campaign to prepare the American public for the need to go to war against Iraq.

Roughly two years later, the truth emerged. The story was a complete fabrication. Nayirah was the daughter of the Kuwaiti ambassador to the US. The emir of Kuwait and his exiled regime, through an organization called Citizens for a Free Kuwait, had hired the services of American PR firm Hill \& Knowlton at a cost of $\$ 10.8$ million (Carruthers 2011, 36) to campaign for US military intervention to oust Iraq from Kuwait. Hill \& Knowlton handlers had coached and rehearsed Nayirah for her appearance before the Congressional Committee (MacArthur 2004, 59). It also later emerged, due to investigative efforts by the Center for Public Integrity in Washington, that many of the company's executives had served in the Reagan and Bush administration and that one, Craig Fuller, the company's new president, had been Vice President Bush's chief of staff (Knightley 2004, 488).

In fact, the US administration had made heavy use of both Hill \& Knowlton as well as the Wirthlin Group to conduct opinion polls and engage in "issue development" (Carruthers 
2011, 36). ${ }^{14}$ Such conduct illustrates how war justification and preparations became a "branding" exercise, geared toward creating a palatable package that could be purchased by public consumers. It is important to note that this was only the beginning of a long and continuing relationship between the US administration and corporate PR firms: Hill \& Knowlton executive Victoria Clarke later became the Pentagon spokesperson for U.S. Secretary of Defense Donald Rumsfeld, as well as the reputed architect of the policy of embedding reporting. ${ }^{15}$

As a result, news coverage prior to the war closely mirrored US administration packaging of it. There was little questioning of the decision to send troops to the Gulf. News coverage concentrated on the build up of the military force and most prominent columnists and almost every newspaper editorial urged war (Knightley 2004, 486). In one analysis of American coverage of the crisis, Malek and Leidig found that "the press behaved more like a propaganda arm of the government promoting the idea of the inevitability of war in the Persian Gulf" $(1991,15)$.

In conjunction with the aggressive marketing of the Gulf War was a hyper focus on the "surgical" nature of air strikes on military targets: the cancer would be removed but the living flesh around it would survive. This second strategy can be viewed as the military's attempt to change public perception of the nature of war itself, to convince the mediaand thus public opinion - that technological advances would allow avoiding many of war's horrors. As BBC commentator Robin Day noted decades earlier, it wouldn't matter if blood looked very red on television if the military could serve up a bloodless war. 
Daily military press briefings followed a steady script of war sanitization: 'smart bombs' dropped with 'pinpoint accuracy' would take out only military targets; Patriot anti-missile missiles would protect Saudi Arabia and Israel from Hussein's Scud missiles; the war would be shortened and there would be few or no civilian casualties. Only they didn't say "civilian casualties," they said "collateral damage," and bombing military targets in the heart of cities was "denying the enemy an infrastructure," human beings were "soft targets," saturation bombing was "laying down a carpet," torture was "enhanced interrogation techniques." The rhetoric used also served to distance the image from the reality.

The military's grainy black-and-white video footage, gathered from the nose cones of missiles as they raced toward their targets, served to both define and sanitize the Gulf War. The missile targets, initially identified in the crosshairs of the imagery and then removed upon impact by a visual blip, became merged with computer-generated simulations to effectively dehumanize the very human effects of war: death and destruction. While Baudrillard's (1995) contention that the Gulf War did not take place was exaggerated for effect, his point was that the Gulf War was very much like the movie Capricorn One, in which the flight of a manned rocket to Mars - which actually took place in a desert studio - was relayed "live" to the rest of the world as reality (61). The end result was that the public's perceptions and understanding of the war, the reasons for fighting, and the very meaning of the consequences of hostilities were so fundamentally 
guided by the media's (and the Pentagon's) representations that for many the war became more symbolic than realistic.

As with the incubator-babies atrocity story, the truth about 'smart bombs' and a 'clean, high-tech war' did not emerge until after the war ended. According to General Merril McPeak of the United States Air Force, smart bombs accounted for just seven percent of the bombs dropped on Iraq (cited in Thomson 1992, 12). The rest were high-impact munitions like cluster bombs, designed to destroy a wide area rather than a precise target. Their use was largely kept from the media during the war. Many of the facts about these high-tech weapons came out during testimony before the House Armed Services Committee. For example, former Defense Department official Pierre Sprey said: “The country has been poorly served by shameless doctored statistics and hand-selected video clips of isolated successes that were pumped out to the media during the war in order to influence post-war budget decisions" (Sharkey 1991, 151).

The military's third communications strategy was the introduction of a 'press pool' policy for reporting from the war zone that was much more restrictive of media freedom than existed during the Vietnam War; Britain instituted a similar form of media management. This policy provided for a small group of reporters and photographers, representing the print and broadcast media, who would be chosen from a prepared roster to accompany the military and whose reports would later be shared, or pooled, by other media and their representatives. 
A 10-page 1990 Pentagon document called Annex Foxtrot, written by Captain Ron Wildermuth, chief Public Affairs Officer for U.S. Central Command, gave the Pentagon control over who could talk to troops and under what conditions, as well as control over much of what could be reported. Restrictions provided for prior restraint of material deemed dangerous to national security as well as censorship afterwards. "News media representatives will be escorted at all times. Repeat, at all times." Annex Foxtrot was one step in a long march of decisions that, by war's end, left the U.S. with a dramatically changed policy on press coverage of military operations. A limited number of correspondents were chosen for each pool, escorted by military officers to cover combat action as chosen by the military, and expected to make their subsequent reports available to colleagues not chosen for the pools. While there was some outcry against what was called censorship through the "power to define coverage," (Knightley 2004, 490), there was even more competition among journalists regarding who would be chosen, leading to subsequent animosity between the pooled and independent reporters. Here too was the origin of the term "unilateral," a military term for a reporter who did not want to join the pools but instead report independently.

Not only were the unilaterals treated harshly by the military - by mid-February, more than 20 had been detained or threatened with detention before being sent back to Dahahran in Saudi Arabia - but the pool system also served to pit the pooled reporters against the unilaterals. For example, Robert Fisk of The Independent related a story in which he was independently searching for stories during the battle of Khafji when he came across a formation of Marines and a pool of journalists. An NBC-TV reporter spotted Fisk, 
verbally assailed him, and then reported him to a Marine public-affairs officer who subsequently barred Fisk from gathering information (Fisk 1991). The incident became about turf between journalists, not the news fact that the Iraqis were still fighting in Khafji long after the western military claimed it had been liberated.

After some 38 days of air bombardment, the ground war began, lasting a mere 100 hours. The 'golden cage' of press pools proved vexing: many journalists found themselves far from any action, what $\mathrm{ABC}$ network vice president Walter Porges called "censorship by lack of access" (Fialka 1992, 6). The reporters were isolated instead of tapped in, stationed with units in the desert or in the rear of the main push into Kuwait, and further disconnected from information because during the ground assault the Pentagon had temporarily suspended its daily briefings that many reporters had come to rely on for information about the war's progress.

The combined effects of these three strategies led to a heavily endorsed, produced, and televised Gulf War, earning the nickname Video Game War. News coverage prior to the war closely mirrored U.S. administration packaging of it: the media concentrated on the build up of the military force, and most prominent columnists and almost every newspaper editorial urged war (Knightley 2004, 486). For the first time people all over the world were able to watch live pictures of missiles hitting their targets and fighters taking off from aircraft carriers. Allied forces eager to demonstrate the 'surgical' accuracy of their weapons were aided by journalists who were both transfixed by what Knightley (2004) calls the "Star Wars Nature" of the conflict and simultaneously lacking in the 
technological know-how to accurately translate and assess military claims. Knightley cites one Defense Department scientist calling most correspondents "pretty impressively ignorant about technology" (497).

One of the few kinks in the military pool strategy was the media savvy of Hussein himself. During the build-up toward the invasion, Hussein made Iraq accessible to western journalists, particularly CNN. Once the bombing began, Hussein allowed CNN's Peter Arnett to be joined by the BBC's John Simpson, and ITN's Brent Sadler in Baghdad. While the U.S. military was frustrated by the presence of high-profile reporters they could not control, and despite personal attacks on all three correspondents for serving as Hussein's collective mouthpiece, their film coverage of night skies alight with explosions and anti-aircraft fire, interspersed with breathless commentary about missiles going past their hotel window, served to grip the attention of western viewers and certainly contributed to presentation of the war as a surreal video game.

Accordingly, soon after the conclusion of the Gulf War, CNN and other mediators of realtime news footage found themselves in the spotlight almost as much as the news itself. The "CNN effect" became widely discussed, analyzed, welcomed, and criticized by scholars, political and military elites, and media personnel themselves. ${ }^{16}$ The discourse varied between the extremes of support for a globe-shrinking information tool capable of sharing western consciousness to the less fortunate in distant lands, versus disparagement of a medium that was said to undercut rational contemplation, encourage public emotionality, and force instant responses in situations that required careful decision- 
making. What has since become apparent, however, is that the CNN effect was highly selective - only some conflicts such as Somalia became regarded as conflicts worthy of reporting, while others such as Rwanda did not. At any rate, one could argue that the CNN effect has become supplanted by the Al-Jazeera effect, and perhaps even the YouTube (or citizen journalism) effect, a topic to be addressed at another time.

Between the Gulf and Afghanistan Wars, military and humanitarian operations in Somalia (1992), Haiti (1994), Bosnia (1995), and Kosovo (1999) each contributed in a limited manner to development of the embedded-press system. Following the Gulf War, representatives from major print-media organizations such as The New York Times, The Wall Street Journal, and Time petitioned the United States Department of Defense (DoD) to make substantial changes to wartime press access. The two sides were able to come to an agreement on all issues except that of security review, i.e. formal censorship (Paul and Kim 2004); in May 1992, the DoD adopted nine principles for guiding future military/media cooperation during all U.S. military engagements. ${ }^{17}$

However, some members of the press - in an effort to avoid a repeat of the stifling press pools during the Gulf War, and taking advantage of the announcement of an impending humanitarian relief effort in Somalia - arrived ahead of 30,000 U.S. troops deployed from 1992-93. The predominantly televised coverage began with American assault troops crawling up the beaches at night with TV crews crawling backwards ahead of them, and essentially ended with images of a dead American pilot being dragged through the streets by Somalis. During humanitarian efforts in Haiti from 1994-95, the press was once again 
able to gain access prior to the military's arrival, but given the relatively peaceful domestic situation and positive outcomes of the intervention, military/media relations were perceived as cooperative, "by far the most cordial and workable press-army relationship I have been involved in," according to Douglas Farah of The Washington Post (cited in Greenway 1999, 52). In fact, some reporters traveled with military units, in a fashion foreshadowing the future embedded system.

For Task Force Eagle in Bosnia during 1995, the reporters were embedded for almost a month; one week with the troops prior to deployment in Germany during December, then for another two to three weeks with their units (Moskos 2000, 24). There were 24 media organizations represented from the U.S. and nine more from Britain, France, and Germany_in all, 33 reporters were embedded with 15 different units (Paul and Kim 2004, 48). This early experimentation with embedding was more about facilitating a feature-type story than long-term coverage of the war. Referencing ongoing military operations in Bosnia, the Pentagon described embedding as a situation "where a reporter goes and lives with the unit for several days or a week and then writes a story about it" (emphasis added, DoD 1996a). Officials explained that "with embedded media the whole idea is that the reporter becomes part of the unit" (DoD 1996b). As early as 1997, a U.S. Army field manual went on to define embedding as:

the act of assigning a reporter to a unit as a member of the unit. The reporter eats, sleeps, and moves with the unit. The reporter is authorized open access to all sections of the unit and is not escorted by public affairs personnel. Rather, the unit is the reporter's escort. Reporters file their stories from unit locations and security is accomplished at the source, by establishing with the reporter what can be covered and reported on and what cannot be reported on, or when material can be reported. (DA 1997, 25) 
However, the idea of integrating journalists into military units for the duration of a war had not yet been considered.

Operation Allied Force in Kosovo during 1999 also hosted a small number of embedded reporters, however, the operation was almost exclusively an air campaign. Not only is news coverage logistically more difficult when so far removed from the ground, but the military was also highly concerned about operational security and pilot safety from Yugoslavian forces and had no qualms about limiting press access. The press then turned to information provided by Milosevic, which led to graphic reports of allied bombings. Albeit limited in nature, the Kosovo experience illustrated for the military that it would have a difficult time preventing the press from gaining access to information in the wake of technological advances.

Roughly two years later, on 11 September 2001, al-Qaeda attacks on the U.S. dramatically and likely permanently changed the landscape of military/media relations. On 17 September 2001, President George W. Bush used CNN to announce "we're going to find those evildoers, those barbaric people who attacked our country and we're going to hold them accountable and we're going to hold the people who house them accountable" (CNN 2001). On 7 October 2001, Bush declared war and the aerial bombing of Afghanistan began. 


\section{$\underline{\text { Afghanistan War (2001-present) }}$}

Political and military leaders customarily seek to justify launching an aggressive war in the loftiest terms possible; thus, most wars are crafted as a product of noble and altruistic reasons. Following 9/11, the U.S. administration justified its attacks on Afghanistan through two major themes: the threat of terrorism, as personified by Osama bin Laden and the Taliban; and saving Afghan women from the Taliban. This was done primarily by two means: one, methods of framing (Goffman 1974) that were supported by the indexing model of U.S. press behavior (Bennett 1990; Bennett et al. 2007), and two, facilitating psychological bonds between soldiers and journalists through the embedding process.

Both broadcast and print media perpetuated the post-9/11 frame that paired American outrage and sorrow over the attacks with a nation's resolution to wreak vengeance: for example, NBC gave its coverage the tagline "America Strikes Back" (2001), and the New York Times ran a daily section called "A Nation Challenged" until the end of 2001 that both reported the latest counter-terrorist developments as well as providing space for “portraits in grief” devoted to each one of the 9/11 victims (2001).

Just as the incubator-babies atrocity story used during the Gulf War was a historical throwback to British WWI propaganda of German soldiers spearing Belgian babies, so too did the 9/11 crisis present an opportunity for historical comparisons; more specifically, a warning. The U.S. military and the Administration paralleled the 9/11 attack with the Japanese raid on Pearl Harbour, Hawaii on 7 December 1941 (Miles 
2006). This comparison was repeated often, and as late as 2006, when Bush linked Pearl Harbour to his government's "fight against terror," represented by Osama bin Laden and the Afghanistan War, during his National Pearl Harbour Remembrance Day proclamation. "In the 21 st century, freedom is again under attack, and young Americans have stepped forward to serve in a global war on terror that will secure our liberty and determine the destiny of millions around the world. Like generations before, we will answer history's call with confidence, confront threats to our way of life, and build a more peaceful world for our children and grandchildren" (Bush 2006).

The high levels of alert maintained after $9 / 11$ also facilitated the 26 October creation of the USA PATRIOT Act (2001), the title standing for Uniting (and) Strengthening America (by) Providing Appropriate Tools Required (to) Intercept (and) Obstruct Terrorism. The Patriot Act dramatically reduced restrictions on the ability of law enforcement agencies to gather intelligence within the US, allowing, for example, extensive eavesdropping on private communication. ${ }^{18}$ A few weeks after $9 / 11$, and prior to the bombing of Afghanistan, Bill Maher, host of the talk show Politically Incorrect, said it was "cowardly" for the US to launch cruise missiles on targets thousands of miles away. White House press secretary Ari Fleischer denounced Maher, saying that "people have to watch what they say and watch what they do" (Schilke 2005, 135). The controversy led to many sponsors withdrawing their advertising, and $\mathrm{ABC}$ cancelled the very popular show at the end of that season, in an act characterized by some as payback. ${ }^{19}$ Furthermore, and prior to her support for embedded reporting, Assistant Secretary of Defense for Public Affairs Victoria Clarke would remind reporters that polling data 
showed that a majority Americans thought the media disclosed too much information and - by inference - should be better managed (Hess and Kalb 2003, 101).

At the same time the media were being warned about seeming unpatriotic (Hess and Kalb $2003,101)$, they were channeled into covering the administration's association of its "fight against terrorism" with "a fight for the rights and dignity of women" (Bush 2001). Much of the initial western media coverage adopted an Orientalist (Said 1978) version of Afghan history, implying that oppression of Afghan women had begun with the Taliban, and largely ignoring what essentially had created the Taliban: a rise of fundamentalism spearheaded by the mujahideen or "holy warriors" who were funded by the U.S. in order to resist the Soviet occupation, eventually leading to the 1989 departure of Soviets forces. Subsequent analysis (Fahmy 2004; Wasilow 2012) has shown that western media coverage of Afghanistan following 9/11 predominantly took its cues from the U.S. administration, seizing on the burqa as a symbol of Afghan women's rights and dignity that needed protection from the Taliban.

In hindsight, this focus on women's liberation in Afghanistan seems little more than a cynical ploy on the part of the administration to "sell the war to the US public" (Stabile and Kumar 2005, 766). Notwithstanding President Bush's praise for Afghanistan on 20 January 2004 for its "full participation by women" as well as the "men and women of Afghanistan [who] are building a nation that is free and proud and fighting terror" (Bush 2004), today's conditions for Afghan women are little if any better than when the war began. Roughly 80 percent of the country's population live in rural areas (World Bank 
2011); and poor, rural, and illiterate women continue to be particularly vulnerable to traditional ways that are often, yet erroneously, justified as required by Islam and Sharia law (UNAMA 2010).

The Afghanistan War contributed to the development of the embedded program, even though the program itself was not implemented on a first-ever, large scale until during Operation Iraqi Freedom in $2003 .^{20}$ News bureau chiefs were expecting that some form of an embedding program would be devised for future military campaigns (Cortell, Eisinger, \& Althaus (2009) due to the previous use of "pooling" during the Gulf War, and limited versions of embedding during U.S. military deployments in Bosnia (1995) and Kosovo (1999).

However, in 2001, at the outset of the Afghanistan conflict, the DoD still perceived the embedding process as inferior to press pools, the Pentagon's preferred mechanism. For example, in a briefing on 30 September (DoD 2001), bureau chiefs clearly reiterated their desire for embedding with U.S. troops, but Clarke was noncommittal. Then, several weeks later, on 5 December 2001, Marines confined pool reporters and photographers in a warehouse to prevent them from covering the return of wounded U.S. soldiers (Knightley 2004). This prompted outrage from the press corps, followed by a written apology from the DoD. Bureau chiefs used this opportunity to further press the DoD to use embedding for the Iraq conflict. 
Two other developments were simultaneously influential. Approximately 1,000 foreign and domestic media representatives were planning to cover the conflict. Frustrated by the Pentagon's attempts to create dependence on its own information flow, many of these unilateral reporters were making their own arrangements for independently entering Afghanistan and neighboring countries, often reporting on the war with the assistance of Northern Alliance troops. The Pentagon had previously demonstrated its contempt for and uncooperativeness toward unilaterals during the Gulf War, and now even more of them appeared on the war's horizon.

Another factor was the growing realization by military officials that advances in communication technology, particularly portable satellite-transmitting devices, had reduced the Pentagon's (and the MOD's) ability to control the dissemination of information from the battlefield. In other words, attempts to strictly control media access to the front lines did not in fact limit the media's ability to disseminate information about U.S. military actions, some of which clearly questioned military claims. Furthermore, alternate media outlets such as Al-Jazeera, which were out of the Pentagon's reach, were challenging the military's attempts to 'control the message.' In summary, the information environment surrounding the military/media relationship had become increasingly uncontrollable and a new approach was crucial.

While it is not clear if embedded reporting was introduced as a well-conceived military strategy from the beginning, or was haphazardly introduced and successively improved, the psychology that sustains embedding reporting is both effective and simple in its 
brilliance. Social penetration theory is a fancy way of describing how human relationships develop. As people get to know each other better, communication shifts from the superficial or party chatter to more personal topics, slowly moving beyond public personas. More contact leads to communication with greater breadth and depth, which in time facilitates more intensity and intimacy. Normally this process takes time, but can fast track in hot conditions - when uncertainty levels are high and circumstances are dangerous - which is typical in combat. These conditions can lead to accelerated bonding, or what behavioral scientist Hensley (1996) has called swift trust. This in turn can bias people's perceptions, an important consideration in the case of embedded journalists who are essentially reporting while in a crise-du-jour environment.

The drive to belong to a larger, encompassing group can also promote enculturation, which refers to a person's acceptance of a given organization's culture and values. As commitment to any organization - whether religious, academic, work-related, or social grows, people internalize attitudes and adopt behaviors that tie them to the group. While enculturation occurs in all organizations, military-culture researcher Soeters (2000) notes that its effects are especially magnified in combat conditions, when "there is a strong need for a so-called collective mind" (475). Practically speaking, the survival of the individual journalist within the combat unit depends on the adoption of collective and even seamless behaviour. Furthermore, just like in the case of swift trust, enculturation is accelerated in "hot conditions" (Pfau et al. 2005, 471) such as combat when - by design as well as necessity - embedded journalists and military personnel eat, drink, and ponder their mortality together. 
As noted by Entman (1991), frames are intrinsic to a news report: "Frames reside in the specific properties of the news narrative that encourage those perceiving and thinking about events to develop particular understandings of them" (7). What this means in practical terms is that, because embeds and unilaterals cover different aspects of the war, it is only natural that they frame the conflict differently. Embedded journalists are attached to specific units in order to provide an intense and intimate snapshot of war. Due to their focus on the minutia, individual soldiers, and in-depth coverage of unit activity, however, they are unable to provide a broad overarching view of military operations or a historical, political and/or social context to the war. Unilaterals, on the other hand, have less access to battle but generally more access to what happens outside of and after the fighting, such as citizens' reactions and casualties. In short, embeds have an insider's or participant observer's perspective while unilaterals have an outsider's or more traditionaljournalism perspective.

A recent comparison of the two approaches (Wasilow 2011) examined two different documentary films about the war in Afghanistan - one American, the other Canadian. Restrepo: Afghan Outpost is a 93-minute documentary made by embedded journalists Hetherington and Junger (2010) that chronicled the deployment of a 15-man platoon of U.S. soldiers to Afghanistan's dangerous Korengal Valley in 2007 and 2008. Restrepo is an exercise in cinéma vérité: the cameras never leave the soldiers, channeling their loneliness, deprivation, boredom, strain of constant threat of attack, then attack; there are no interviews with generals, politicians, or civilians. The documentary is full of 
unvarnished close-ups of the visceral sounds and sights of combat, including interviews with the soldiers three months after deployment, when many were suffering from posttraumatic stress. This was a conscious choice on the part of its creators, one of whom told Associated Press that the power of the interviews derives from the close ties that developed during combat and filming. "We were friends," said Hetherington. "We turned up not as military authority figures, not as the company shrink, but as friends who'd been through these experiences and, therefore, they opened up in a way that was pretty profound." While emotionally poignant, Restrepo is also notable for a lack of perspective on the larger war.

A completely different approach was taken in Afghanistan: Outside the Wire, a one-hour documentary made by unilateral journalist Taylor (2010), who had travelled to Afghanistan five times during three years, often alone, and always without military protection. Outside the Wire is an exploration of Afghan life outside of the heavily fortified Canadian base at Kandahar Airfield: addressing the complexities of a country with a history of strife dating back to Alexander the Great, extreme poverty, shady political maneuverings, corruption at the highest levels, an illicit drug trade, ethnic and tribal factions, warlord brutality, and lack of access to education, employment and equality for women. Taylor went beyond NATO troop activity and ramp ceremonies for fallen soldiers to speak face-to-face with tribal elders, warlords, would-be suicide bombers, local politicians, aid workers, foreign diplomats, but no soldiers. His intent was to expand coverage on Afghanistan beyond what he calls "far too narrow a sliver for us to base any kind of decisions" on the mission. 
Two different framing approaches to the war in Afghanistan; two different reactions that perhaps illustrate some of the divergences between embedded and unilateral conflict reporting. Restrepo invokes visceral feelings of fear and camaraderie with soldiers whose humanity is front and centre. Outside the Wire engages the viewer in an intellectual conversation about a complicated history, numerous contributing issues, and future prospects. Restrepo is unabashedly emotional. Outside the Wire is cognitively demanding. Although these two examples of conflict reporting took place in Afghanistan, the first-ever, large-scale implementation of the embedded program occurred during Operation Iraqi Freedom in 2003, which the next section will address.

\section{$\underline{\operatorname{Iraq}}$ War (2003-2011)}

Evocative of the Gulf and Afghanistan Wars, President G.W. Bush began using rhetoric such as "Axis of Evil" during his 29 January 2002 State of the Union Address in reference to Iraq, Iran, and North Korea, framing the conflict with Iraq, Hussein, and bin Laden in terms reminiscent of WWII and the original Axis comprised of Japan, Germany, and Italy (Western 2005, 195). Bush speechwriter David Frum (2003) described how his original term "axis of hatred" (subsequently changed to "evil") was used for Iran, Iraq, alQaeda, and Hezbollah because they "all resented power of the West and Israel, and they all despised the humane values of democracy" (262) and, accordingly, "formed an axis of hatred against the United States" (236). 
On 5 February 2003, Secretary of State Colin Powell told the United Nations there were Weapons of Mass Destruction (WMDs) in Iraq (Washington Post 2003). ${ }^{21}$ The media followed his lead, and there was a subsequent 30-point jump in the number of Americans who felt convinced of a link between Hussein and al Qaeda after Powell spoke (Gershkoff and Kushner, 2005).

The effusive media support given to Powell illustrates the power of indexing (Bennett 1990; Bennett et al. 2007), specifically, the ability of executive personnel to set the agenda, and linkages between media coverage and "the dynamics of governmental debate" $(1990,108)$. The Democrats failed to voice forceful opposition to the wars, passively contributing to a cacophony of support for military action. At the same time, the U.S. news media adhered closely in 2003 - as they did earlier in 1990, leading up to the 1991 Gulf War, and again in 2001 prior to the Afghanistan War - to dominant views espoused by the "triangle" of executive opinion inside the Beltway, reflecting the lack of balance demonstrated by policy elites instead of questioning it.

That said, when the proverbial 'carrot' didn't work, the Bush administration was notorious for 'bullying' behavior vis-à-vis reporters who were uncooperative during the build-up to the 2003 Iraq war, not entirely unexpected given Bush's comment that: "Either you are with us, or against us." Carruthers (2011) describes how the Bush administration sought to "domesticate" the media by rewarding sympathetic reporters with "leaks, background interviews, and seats on official flights" while freezing out those who didn't play along (39). Inside the Beltway, "where access is all, few wanted to risk 
losing it" (46). Not only were the chances of investigative reporting stymied, but the very foundation of reporting - sources who helped form the news - were considered bargaining chips in the name of cooperation.

The effects of indexing were also apparent in the UK. For example, despite reporter Andrew Gilligan's citation of an anonymous government-weapons expert (David Kelly, who later committed suicide) that Iraq's WMD holdings had been deliberately "sexed up" (Lewis and Brookes 2004, 283) by 10 Downing Street, and despite public opposition to the war resting at 75 percent of polled opinion, the two biggest circulation broadsheets The Times and the Daily Telegraph - as well as the most popular tabloid - the Sun favoured the official line on Iraq that was pursued by Bush and Blair (Couldry and Downey 2004, 274).

Back in the U.S., news coverage by former New York Times journalist Judith Miller of Saddam Hussein's alleged WMDs is often cited as an example of inaccurate reporting that helped to justify a war. Miller was subsequently criticized by the Times' ombudsman for basing several articles from the fall of 2001 to 2003 on faulty information, concluding that: "It seems to me that whatever the limits put on her, the problems facing her inside and outside the newsroom will make it difficult for her to return to the paper as a reporter" (Calame 2005). Still, the problem may go much deeper than a reporter who was too chummy with government officials and too accepting of their calculated leaks. At the time, Miller defended her reporting by saying: “[My] job isn't to assess the government's information and be an independent intelligence analyst myself. My job is to tell readers of 
the New York Times what the government thought about Iraq's arsenal" (cited in Massing 2004, 62). Miller saw her role as that of a relayer or messenger - an approach which places her firmly within the cheerleading narrative of military/media relations that existed during the Vietnam War prior to 1968.

Miller's perception of her messenger role was a far cry from the antagonistic role that journalists such as New York Times columnist Maureen Dowd advocates - to independently assess information, question sources, and analyze information before reporting it - noting that "investigative reporting is not stenography" (Dowd 2005). Which leads to several questions: was Miller's performance simply a reflection of how Carruthers (2011) suggests mainstream American media now defines news gathering: a barometer tracking the mercury of policy deliberation on Capitol Hill (41)? Have the U.S. news media become far too attuned to executive power in the "golden triangle" of the White House, State Department and Pentagon (Hess 1983), allowing access to official briefings and sources to become an excessively powerful news-management tool (Entman and Page 1994; Zaller and Chiu 2000)?

After all, news organizations are not compelled to follow the lead of executive power. In 2003, for example, mainstream media coverage could have drawn more from the opposing views of academics, liberal think tanks, anti-war activists, and even reporters infuriated by their treatment during the Gulf War. One of the few voices of dissent was Ambassador Joe Wilson (2003), but his dissention was an anomaly more than the norm and, to this day, questions surround the subsequent "outing" in the press of his wife, 
Valerie Plame, as a CIA agent. Carruthers (2011) ascribes this failure to protest to a "two way relationship of mutual need" (42). Her synopsis falls in line with Bennett's indexing theory, that the very nature of news reporting has changed to such a degree that the practice of ignoring or minimizing viewpoints outside of the inner circle of Beltway policy-making has become a self-fulfilling prophecy: "those outside that charmed circle remain beyond its circumference, while those at the core are duly empowered to police its boundaries" (42).

What is of particular interest for the purposes of this section is an examination of the mastery of discourse developed and set into motion by military-communications strategists at three different levels during the Iraq War. The first is the large-scale introduction of embedding reporting in 2003. As noted earlier, embedded reporting allows both physical limitations on reporters, as well as propaganda through camaraderie. However, as revealed in a 2008 New York Times article by David Barstow, "Behind Analysts, the Pentagon's Hidden Hand," embedding news media with U.S. troops was just one level of Pentagon strategy.

The second level involved 'embedding' hand-picked retired military officers as "message force multipliers" into TV and radio media to help shape public opinion without making viewers aware of their administration connections. Even before $9 / 11$, according to documents gained through a two-year battle with the Pentagon, Clarke had built a system to recruit "key influentials" - movers and shakers that included war heroes, military strategists and advocates, and defense-industry contractors and lobbyists - "experts" who 
could be counted on to generate support for U.S. Secretary of Defence Donald Rumsfeld's priorities. The result was a "Pentagon information apparatus [using military] analysts in a campaign to generate favorable news coverage of the administration's wartimes performance" (Barstow 2008).

The third level, improving on methods introduced during the Gulf War, involved highly produced media briefings from Central Command using multi-million-dollar theatrical technology - animations, film footage, archival stills, split screens, scrolling headlines, and music (Brockus 2009, 32) - to enhance "expert" commentary. It was as if the term associated with the Iraq War, "shock and awe"- that is often used to refer to a military doctrine in battle that uses crushing power, overriding maneuvers, and spectacular displays of force to paralyze an adversary's perception of the battlefield (Ullman and Wade, Jr. 1996) - was used to maneuver domestic media to the point of paralysis. Consequently, when embedded coverage of the soldiers' perspectives, while generally sympathetic (Lewis et al. 2004; Lewis and Brookes 2004; Pfau et al. 2004; Pfau et al. 2005), began to seem repetitive or micro-focused, raucous Pentagon briefings could digitally grab and fill the viewers' senses once again. In contrast, the more comprehensive coverage by roving or traditional reporters of the war's greater context seemed flat.

However, just as Hussein's media savvy was a thorn in the Pentagon's side during the Gulf War, the influence of Al-Jazeera during the Iraq War was likewise irritating. From its beginning, Al-Jazeera's coverage was rooted in Arab and Islamic cultures that are very familiar to the majority of its viewers (Barkho 2010), and was oppositional to the U.S. 
Operation Iraqi Freedom, instead referring to it as the War On Iraq. Given its origins in Qatar since 1996, Al-Jazeera was well placed to physically report from both Iraq and Afghanistan and had no qualms about showing horrific footage of maimed and dead civilians and Coalition soldiers, something the Pentagon was at pains to prevent. Some Al-Jazeera transmissions were picked up by western TV networks and rebroadcast, undercutting the efforts of Central Command to control the message and making the Coalition Commander, General Tommy Franks, look unreliable if not a liar.

Another key test of military/media relations related to the Iraq War was the 28 April 2004 disclosure on CBS's 60 Minutes that American guards had abused prisoners at Abu Ghraib in Iraq. Photographs supporting the story were taken by U.S. soldiers and Military Police (MPs), showing Iraqi men in an array of different postures, all degrading. Some photos also showed their tormentors, sometimes grinning and giving a 'thumbs up,' seemingly enjoying the degradations over which they presided.

This incident was relevant on several different levels. One, that these photos were taken by soldiers and MPs themselves must have been thoroughly shocking to a military so invested in controlling its image. Second, the expectation by some that these revelations would be so appalling to the American public that they would cease their support for Bush and the war (Hersh 2004; Charlie Rose 2004) turned out to be highly premature. Certainly there was an outcry by some Americans, but it was short-lived and far from unanimous. Undeniably there was outrage in the Muslim world, prompting Bush to issue an apology on two Arab television networks (although not Al-Jazeera), however, the 
response by many Americans was that the frustrated and stressed-out soldiers were just blowing off steam and their behavior was not so different from that of frat boys (Rush Limbaugh 2004).

Third, the Abu Ghraib incident seemed to once again demonstrate indexing effects. Some academics, notably Bennett, Lawrence and Livingston $(2006,2007)$ have argued that the U.S. press, and the Washington Post in particular, complied with the Bush administration's framing of the mistreatment of prisoners at Abu Ghraib as isolated actions of "a few bad apples" that was unconnected to a higher authority or policy. Constant avoidance of terms such as "torture," as well as the absence of "counterframing,' were interpreted as consistent with the indexing model of U.S. press behavior. Conversely, Porpora, Nikolaev, and Hagemann (2010) have argued that a "socially structured disinterest" in political communication and related disempowerment of the general public were more problematic for balanced coverage of Abu Ghraib than indexing.

While many espouse technological advances as a means of liberation for the news from traditional sources, events related to Abu Ghraib suggest otherwise. Even though journalists' possession of digital photos certainly allowed them to break the news ahead of authority commentary, the story ended up being passed over to government officials for official representation. This demonstrates a trend identified by Livingston and Bennett (2003) who, following an examination of eight years of international stories on CNN, found that even though new technologies have allowed a greater number of event-driven 
stories to appear, "officials seem to be as much a part of the news as ever" $(2003,363)$.

When officials engage with news events, the story frames generated by journalists once again become indexed to a range of sources and viewpoints reflecting official agreement and consensus (Bennett et al. 2007).

General consensus seems to support the model of framing at play during the larger issue of the Iraq War, albeit a more nuanced version (Entman 2003) of cascading frames in which the media is capable of offering and has provided counter-framing measures, thereby demonstrating a greater degree of independence from elite political opinion that Bennett's indexing model might acknowledge. For example, since 2003, numerous accounts have addressed the Bush administration's efforts to manufacture justification for a war against Saddam Hussein on the basis of WMDs, a connection between Baghdad and Al Qaeda, and Hussein's human rights records regarding the Kurds and others within his domain (Schechter 2003; Miller 2004; Dadge 2006; Schechter 2006). "Never before in the annals of contemporary American foreign policy was so much evidence accumulated so quickly that the assumptions leading to a war were so questionable," observed Dorman $(2006,12)$.

\section{Conclusions}

Our newsrooms are market-driven and profit-oriented, our staffs are poorly trained and dispirited. We dread being called liberal, we hate to be seen as unpatriotic. We fear making our readers unhappy, we don't want to insult powerful people - indeed, we seem to yearn for their favor. (Overholser 2003) 
As we can see from this chapter's relatively brief overview of more than 100 years of military/media communication, embedded reporting is not necessarily an isolated, timespecific component of conflict journalism. Although it is chiefly associated with a formal, large-scale implementation during the Iraq War, one could say that embedded reporting may in fact represent a decades-long, fundamental shift in the very nature of conflict journalism.

Perhaps as far back as the Franco-Prussian War (1870-71), and certainly World War I (1914-1918), elements of an embedded relationship between the military and media existed. The substance of that relationship has ebbed and flowed as the military and the media have waged a chess game of strategic moves and counter-moves in their efforts to influence public opinion. If we agree with the position voiced earlier by columnist Maureen Dowd of the New York Times, that journalists should adopt an investigative rather than a stenographer role - to independently assess information, question sources, and analyze information before reporting it (2005) - then it seems the media is currently losing the chess game when it comes to war coverage.

Multiple pressures beset journalism. Commercial demands exerted in the name of profit meaning that consumers must be entertained so that advertisers will be satisfied - has led to a commodification of news to such an extent that the phrase "war sells" has become a truism. Investigating the reasons for a war is not as sexy, profitable, or straightforward as reporting on the fighting. In addition, members of the media are often competitive with one another and, furthermore, divided internally between ground-level journalists and 
upper-level editors, publishers, and producers. Moreover, as Knightley (2004) points out, war correspondents tend to have short working lives and, as of yet, there does not seem to exist a tradition or "guidebook" for passing on their experiences. Despite seminal studies of propaganda techniques by figures such as Lasswell dating as far back as 1927, American journalists seem to vow after almost every war to never again be deceived. All of these pressures have likely contributed to the press's growing inclination to follow the lead of political elites.

To various degrees, the Gulf War (1991), the Afghanistan War (2001) and the Iraq War (2003) have illustrated the role that the media can and did play in shepherding public energies for war through framing political and foreign-policy issues in such a way that military force became the most plausible method for resolution. According to proponents of indexing (Bennett 1990; Bennett et al. 2007), media coverage is "indexed implicitly to the dynamics of governmental debate" $(1990,108)$. Given that the Democrats failed to voice forceful opposition to the wars, tacitly contributing to a chorus of support for military action, it is understandable why the U.S. news media had adhered so closely in 1990 (leading up to the invasion in 1991), 2001, and again in 2003 to dominant views espoused by the "triangle" of executive opinion inside the Beltway. In other words, both framing and indexing theories seem to be supported by media coverage that reflected the policy elites' near-unequivocal support, in each instance, for military action.

Conversely, the military is an excellent student and has spent considerable time, money, and person power analyzing what will and will not, what has and has not, worked in 
effectively relaying its message. "Wars are studied, lessons are learnt, systems are devised, tested and polished" (Knightley 2004, 484). The British Ministry of Defence has a manual called The Green Book (2010), updated regularly, which provides guidelines for working with the media during wartime. While it can be safely said that the military is more disciplined than journalism - perhaps to the point of rigidity - this trait serves it well in terms of consistency and focus. Moreover, the Pentagon has proved itself remarkably well attuned to developments in new technologies, as well as the utilization of public relations and psychological means to meet its coexisting goals of victory and image-enhancement. In summary, lessons learned from Vietnam, subsequently applied in the Falklands, honed by the 1991 Gulf War, and further perfected through the embedding process in Iraq and Afghanistan, have led to more nuanced while possibly more effective methods of influencing popular perceptions and attitudes among both the media and the public. Outright censorship ${ }^{22}$ has given way to "slanting news" in our new, overloaded information environment. Framing, indexing, "spinning" have replaced the infamous "blue pencil" that was once so liberally applied amid loud protests (Knightley 2004).

Certainly the practice of embedded reporting initially garnered a great deal of attention from media scholars as well as military analysts (Aday, Lingston and Hebert 2005; Beane, Jr. 2009; Cortell, Eisinger, and Althaus 2009; Katovsky and Carlson 2003; Lehman 2004; U.S. Army War College 2004; to name a few). However, discussion and analysis have waned. Furthermore, there remains a lack of consensus on whether the embedded-reporting program is a brilliant control strategy on the part of the military, 
merely a response to security and cost-saving considerations on the part of the media, or dictated by a public's need for emotionally riveting and entertaining war coverage.

One line of enquiry I hope to pursue is examining if the practice has become a psychological form of "indexing" from the ground up. In other words, instead of the media following a bias dictated by the upper echelons of power and tracing official or elite views in a discernible pattern, embedding has instead become a process by which frontline journalists follow a personal bias based on an emotional bond of camaraderie with their imposed peers, subsequently adopting and tracing soldiers' views of the war. And was it originally designed to do so? Regardless, embedded journalism has unquestionably made war personal, and that poignancy perhaps reflects its true value in our increasingly impersonal world, which is why this is not only a relevant area of research to pursue, but especially so within a Canadian context.

\section{NOTES}

${ }^{5}$ Knightley provides the example of The Times of London commissioning a general reporter, William Howard Russell, to report back from the Crimean War; other scholars (Pfau et al. 2005) have traced the relationship between the media and the military back to the American Civil War (1861-1865).

${ }^{6}$ This war is also called the "First Gulf War," the "Persian Gulf War," and "Operation Desert Storm." I will use "Gulf War." While the genesis of the Gulf War began with the invasion of Kuwait by Iraqi troops on 2 August 1990, the subsequent invasion by a UN-authorized coalition of 34 nations and led by the U.S. began on 17 January 1991. Thus, I use the year 1991. The invasion, "Operation Desert Storm," ended on 28 February 1991.

${ }^{7}$ This war is also called the "Second Gulf War" and "Operation Iraqi Freedom." I will use "Iraq War" to help distinguish it from the shorter invasion of 1991.

${ }^{8}$ A second faction or view of military/media relations is that they are mutually beneficial. Historical studies of war reporters (Knightley 2004) emphasize the public-relations nature of most conflict reportage that predominantly legitimizes government policies, strategy, and narratives. Regarding Vietnam specifically, Hallin (1986) challenges the myth that a proactive and critical media corps deliberately undercut U.S. military activity there: "for the most part television was a follower rather than a leader: it was not until the collapse of consensus was well under way that television's coverage began to turn around; and when it did 
turn, it only turned so far" (163). Indeed, the print media was rarely oppositional to the Vietnam War until after the Tet Offensive of 1968 when journalists joined a growing American tide of criticism.

${ }^{9} \mathrm{~A}$ third view of military/media relations is that it has converged to the point of becoming virtually indistinguishable; that the media now constitute the "spaces" in which wars are fought and are the major conduits through which audiences experience war (Thussu and Freedman 2003). The media construe a battleground where "there are fewer bodies to observe and less mess to clean up" (7). Taylor has notably expanded on this "reality/image gap," noting that there are two types of wars: the "real war" in which blood runs freely and combatants die gruesomely, and a "mediated" war in which the grim realities of conflict are "filtered" to a distant and non-participating audience. "Real war is about the sounds, sight, smell, touch and taste of the nasty, brutal business of people killing people. It frightens and appalls most people, so much so that they would be repelled by its reality. Media war, however, is literally a mediated event which draws on that reality but which, in and of itself, is confined to merely an audio-visual - and therefore inherently desensitizing - representation of it" (1995). This theme of a distant and social construction of wartime death is a pervasive undercurrent of today's use of drone warfare by the U.S. for counter-terrorism purposes along the Afghanistan/Pakistan border.

${ }^{10}$ Which is perhaps why the British military subsequently constructed their media strategy in the Falklands based on the same belief - that the power of television had lost Vietnam (Knightley 2004, 452).

${ }^{11}$ While it is doubtful - given society's increasing desensitization to the brutality of combat through media coverage as well as an entertainment industry that has become increasingly carnage-obsessed - that public reaction to wartime visuals in their living room would be as outraged today, there is certainly merit to military awareness of a lesson that needed to be learned: controlling the message can be key to domestic victory.

${ }^{12}$ For example, Harrison E. Salisbury's early, critical coverage of American activities in Vietnam for the New York Times was roundly criticized by both American officials as well as his own media colleagues external and internal to the Times, costing him a Pulitzer Prize in 1968 (Hamilton 2009, 392-403).

${ }^{13}$ That said, the Creel committee of 1917 certainly established a precedent for wartime propaganda efforts. Under the chairmanship of journalist George Creel, the committee tried to encourage enlistments for the war effort by promoting the official view of a "just and idealistic war," saturating media outlets with socalled "news" and promotional items, and - notably - recruited 75,000 "Four Minute Men" speakers to present short appeals between features at the nation's movie houses (Vaughn 1980, cited in Sproule 1987). See also Creel (1972).

${ }^{14}$ The Pentagon also used a private PR company called the Rendon Group to vet applicants to the embedding program during the later Afghanistan and Iraq Wars, which included examining their previous stories in order to gauge their outlook - favourable or not - on the military (Bamford 2005).

${ }^{15}$ Before joining the Pentagon, Clarke was a manager in Washington for Hill \& Knowlton, and also served as press secretary for the re-election campaign of President George Herbert Walker Bush in 1992. Clarke left the Pentagon in 2003, joining CNN as a political and policy analyst, then Comcast Corporation and, most recently, $\mathrm{ABC}$ as an on-air consultant and news analyst.

${ }^{16}$ The "CNN effect" is a communications theory of international relations that asserts that global television networks such as CNN and BBC World have become a decisive influence in determining policies and outcomes of significant events through their coverage of those events (Gilboa 2005).

${ }^{17} 1$. Open and independent reporting will be the principal means of coverage of U.S. military operations. 2. Pools are not to serve as the standard means of covering U.S. military operations. Pools may sometimes provide the only feasible means of early access to a military operation. Pools should be as large as possible 
and disbanded at the earliest opportunity -- within 24 to 36 hours when possible. The arrival of early-access pools will not cancel the principle of independent coverage for journalists already in the area.

3. Even under conditions of open coverage, pools may be appropriate for specific events, such as those at extremely remote locations or where space is limited.

4. Journalists in combat zone will be credentialed by the U.S. military and will be required to abided by a clear set of military security ground rules that protect U.S. forces and their operations. Violation of the ground rules can result in suspension of credentials and expulsion from the combat zone of the journalist involved. News organizations will make their best efforts to assign experienced journalists to combat operations and make them familiar with U.S. military operations.

5. Journalists will be provided access to all major military units. Special operations restrictions may limit access in some cases.

6. Military public affairs officers should act as liaisons but should not interfere with the reporting process.

7. Under conditions of open coverage, field commanders should be instructed to permit journalists to ride on military vehicles and aircraft whenever feasible. The military will be responsible for the transportation of pools.

8. Consistent with its capabilities, the military will supply PAOs with facilities to enable timely, secure, compatible transmission of pool material and will make these facilities available whenever possible for filing independent coverage. In cases when government facilities are unavailable, journalists will, as always, file by any other means available. The military will not ban communications systems operated by news organizations, but electromagnetic operational security in battlefield situations may require limited restrictions on the use of such systems.

9. These principles will apply as well to the operations of the standing DoD National Media Pool system. (DoD 1993)

${ }^{18}$ With minutes to spare before the Act's expiry, on 26 May 2011, President Barack Obama signed a fouryear extension of three key provisions: roving wiretaps, searches of business records, and surveillance of individuals suspected of terrorist-related activities but who are not linked to terrorist groups (Mascaro 2011).

${ }^{19}$ According to Maher: "I cleaned out my office a week later," he said in a subsequent interview. "We were always in hot water for one thing or another. That was just the straw that broke the camel's back" (Breznican 2002).

${ }^{20}$ At that time, more than 600 U.S. and foreign journalists were embedded with and reported from infantry positions, aircraft carriers, Special Forces units, and Marine divisions.

${ }^{21}$ A claim that he now repudiates as "one of my most momentous failures, the one with the widest-ranging impact" (Powell 2012, 223).

${ }^{22}$ With the exception of the Bush administration's ban on photography of coffins returning to the U.S. with the bodies of soldiers killed in action in Iraq and Afghanistan (Carruthers 2011), eerily echoing the Kremlin's insistence that Red Army soldiers' bodies returning from Afghanistan during its 1979-1988 invasion and occupation be sealed and bolted in zinc coffins (Alexievich 1992). 


\section{CHAPTER TWO: WHEN WORDS CAN LEAD TO WAR}

This chapter will begin with an examination of a theoretical understanding of the relationship between language and society that is called Critical Discourse Analysis (CDA). While discourse analysis refers to the study of discourses as combinations of ways of saying, ways of acting, and ways of thinking that express certain "versions of reality," critical discourse analysis investigates the social relationship of power and ideology through discourse. I will draw predominantly from the works of Norman L. Fairclough, Teun A. van Dijk, and Ruth Wodak - who are most commonly associated with, and whose works have profoundly contributed to, the development of CDA.

I will next address media effects - primarily agenda setting, priming, and framing - as well as indexing, examining their similarities and differences in order to evaluate if they are cumulative, refined versions of one another or, rather, are more dependent upon factors such as placement in time, particular media ecologies, and/or specific cultures. I will draw predominantly from Mawell E. McCombs and Donald L. Shaw's groundbreaking work on agenda setting, Shanto Iyengar, Dietram A. Scheufele and David Tewksbury's extensive writings on comparative differences and similarities among media effects theories, followed by Robert M. Entman's research on framing and political power, as well as W. Lance Bennett's work with indexing from 1990 onward.

I will focus on two theoretical approaches - framing and indexing - to explore how war reporting has occurred and does occur. I contend these two theories offer the most 
comprehensive approaches to analyzing why the media reports on foreign-policy issues such as international conflicts - the way they do.

\subsection{Language as a form of power: Critical Discourse Analysis}

Language, discourse analysis (DA), and critical discourse analysis (CDA) are separate 'units,' yet inextricably linked. As functioning members of society, individuals use language to reflect a set of experiential, relational, and expressive values (Fairclough 1992, 110). According to this perspective, there is a correlation between linguistic production and social variables. Simply put, language plays a crucial role in shaping how we experience our society and the world around us.

DA is the study of language-in-use. Different theories of DA offer a different set of tools with which one can analyze language-in-use; a tool being a specific question to ask of data. Each question assists the reader to look closer at the details of the chosen language in an oral, written, or visual communication (Gee 2011, x). Forms of communication can be complex and contextual, and analysis must adjust accordingly, becoming an exercise in what Gilbert Ryle calls “thick description” (lecture cited in Geertz 1973): for example, whether a twitch, wink, or parody.

Consider, he says, two boys rapidly contracting the eyelids of their right eyes. In one, this is an involuntary twitch; in the other, a conspiratorial signal to a friend. The two movements are, as movements, identical; from an I-am-camera, "phenomenalistic" observation of them alone, one could not tell which was twitch and which was wink, or indeed whether both or either was twitch or wink. Yet the difference, however unphotographable, between a twitch and a wink is vast.... The winker is communicating, and indeed communicating in a precise and special 
way: (1) deliberately, (2) to someone in particular, (3) to impart a particular message, (4) according to a socially established code, and (5) without cognizance of the rest of the company.... Contracting your eyelids on purpose when there exists a public code in which so doing counts as a conspiratorial signal is winking.

Still, yet another layer is possible.

Suppose, he continues, there is a third boy, who, "to give malicious amusement to his cronies," parodies the first boy's wink, as amateurish, clumsy, obvious and so on. He, of course, does this in the same way the second boy winked and the first twitched: by contracting his right eyelids [sic]. Only this boy is neither winking nor twitching, he is parodying... (6).

CDA is a yet deeper form of analysis. It enables an examination of "language in use" that is embedded in the larger context of political, social, and cultural issues (Gee and Handford 2012, 1). While some forms of CDA advocate intervening in these issues, my research will consist primarily of describing and explaining the impact that embedded journalism has had on Canadian war reporting, not in advocating one position or another. Furthermore, given that the validity of CDA can be questioned due to what might be considered poorly defined interpretation or scope, I will also use interviews with key members of the media and military/government to strengthen the context of my analysis of the use and effects of embedded reporting.

To understand both discourse and CDA, one must first understand how language, text, and power are inter-related, and how they may be used to construct the reality in which we live. While CDA is fundamentally about language, comparing discourse to language is like contrasting an orchestra with a flute. Discourse does much more than merely reflect events that take place in the world; discourse interprets those events, formulates 
understandings, and constitutes their sociopolitical reality. The concept of "language" cannot adequately account for the historical, political, and cultural allocation of meanings, nor their evolution, representation, and reproduction through a variety of practices. Unlike the noun of language, which seems merely a thing, "discourse" is both a noun and a verb, which helps to position discourse as both a thing and an act, given that "discourse is socially constitutive as well as socially shaped" (Fairclough and Wodak 1997, 258).

Notwithstanding their different roles, language is an important means by which discourse exists. In other words, the "role of language and communication is ... essential in processes of change, since it is through language that change is talked or written into being, that genres gradually change or drastically alter, that evolving, general societal discourses are voiced" (Wodak 2012). The constitutive dimension of language goes far beyond the mere telling of pre-existing and neutral phenomena, particularly where contentious issues are concerned. Language expresses thought, sentiment, and direction, creates a public space, and then places items for assimilation into that space. It facilitates relations among individuals and subsequently establishes shared meanings. Thus, "relations of power and property themselves are not possible without language; they are essentially realized in language" (Taylor 1985, 271).

CDA can be used to shift focus back towards the language and texts that create the meanings and stories used to interpret the events. Tracing its roots to the development of critical linguistics during the 1970 s to systematically analyze the political and social 
significance of text, contemporary CDA largely analyzes "opaque as well as transparent structural relationships of dominance, discrimination, power and control as manifested in language" (Wodak 1995, 204).

Given that language is a tool used to create meanings, one can argue that the very process of 'meaning making' - whether by the media, military, or politicians - is inherently political and ideological as it entails both the burden and the privilege of power relations that fluctuate in accordance with maneuvering, arguing, and negotiating the meanings at hand. Language was used to pose questions about the 'who,' 'what,' 'where' and 'why' of the Afghanistan War, as well as frame and position the responses to those questions. Both holding and manipulating the stage for discussion are themselves power plays that understand the potency of language, turning the process into discourse originating from selected positions and choosing a context design that will buttress those positions. In sum, language is much more than a transparent medium of human interaction that uses meanings we might presume to be stable and an accurate reflection of events. Journalists, military officials, government officials all create stories about events, and do so in order to support their standpoint.

CDA is not a specific direction or research, nor does it have one unitary theoretical framework; however, most kinds of CDA will represent a critical perspective, position, or attitude and ask questions about the way specific discourse structures are deployed in the reproduction of social dominance. Similarly, CDA is not as much a single theory or set of methods as it is an orientation to the study of language embedded within its social 
context, or language "as a form of "social practice"” (Fairclough and Wodak 1997, 258).

Fairclough's approach (1992) of "textually oriented discourse analysis" draws on

Bakhtin, Foucault, and Marx, seeking to understand how discourses reveal social practices, and how social practices are shaped through discourse (Fairclough 2003). Thus, CDA reflects a two-way relationship: discourse both has a significant effect on the shaping of society, and is also shaped by society. Given that discourse is "so socially consequential," this raises issues of power distribution: "Discursive practices may have major ideological effects - that is, they can help produce and reproduce unequal power relations between (for example) social classes ... through the ways in which they represent things and position people" (Fairclough and Wodak 1997, 258).

Power is about relations of difference, and particularly about the effects of differences in and on social structures (Wodak and Meyer 2009, 10). Language is a conduit of power in several ways: language indexes and also expresses power, and is likewise involved where there is contention regarding and a challenge to power. Power does not necessarily derive from language, otherwise the media in their communication capacity would often reign supreme, but language can be used as a tool to both establish and challenge power, to uphold or subvert it, to alter distributions of power in both the short and long terms. As noted earlier, due to their business of and daily dealings in language, media institutions comprise much of the playing field on which language articulates differences in power that support hierarchical social structures. 
In their discussion of how $\mathrm{CDA}$ is useful in disclosing the discursive nature of much contemporary social and cultural change, Chouliaraki and Fairclough (1999, 103-104) argue that the journalistic field be theorized as a specific form of "media capital." While media institutions often purport to be neutral, or engaged in "impartial interpretation" therein providing space for public discourse, reflecting states of affairs disinterestedly, and transparently presenting the perceptions and arguments of the newsmakers - the language choices of the media indicate otherwise. For example, when Bush declared a "war against terrorism" in the wake of $9 / 11$, that message was often unquestionably repeated and emotionally endorsed by media institutions against a backdrop of carnage. Politicians and journalists were performing as "symbolic elites" (van Dijk 1993a) - a group that also includes academics and writers - who are most often producers and reproducers of discourses of dominance, such as racism or other forms of prejudice, due to their access to public discourse. While Fairclough links textual analysis to social structures, van Dijk is more interested in the cognitive process and tried to analyze how meaning is created in people's minds, explaining their constructions of knowledge, beliefs, values, etc. (Reyes 2011).

As noted by Dedaić and Nelson (2003), when a particular framework of understanding is discursively declared, then other, possible understandings remain unsaid. For example, in reference to 9/11: “...it was rarely said, either by ordinary Americans on television or by their political leaders, that what had happened was primarily a criminal act [against New York or icons of capitalism]. The words of criminality were subsumed by those of war" (xiv). Further, heralding the approach of a war necessarily involves constructing an 
enemy: "an 'other' who is so foreign and distant that who becomes it. It can be tortured, maimed, slaughtered; who cannot" (454). Thus, the mass media repeatedly comprise a site of power, of struggle, and play a significant mediating and constructing role: “...struggles are enacted in the course of communicative interaction, and that communicative interaction is the discursive facet of the constitution (and reproduction) and reconstitution of the social, including the structuring of positions within and relations between social fields" (Chouliaraki and Fairclough 1999, 104).

Another important perspective in CDA related to the notion of power is that it is very rare that a text is the work of only one person. In texts, discursive differences are negotiated; they are governed by differences in power that is in part encoded in and determined by discourse and by genre (Wodak \& Meyer 2009, 10). Therefore, texts are often a site of struggle in that they show traces of differing discourses and ideologies contending and struggling for dominance. For example, the use of the terms "terrorist" and "freedom fighter" will have been differently applied - according to select ideologies, political contexts, and historical supremacy - to Che Guevara in Bolivia during the 1960s, the Contras in Nicaragua during the 1980s, al Qaeda since 2001, and the recently deceased Nelson Mandela throughout decades of political activity. Recognizing the influence of practices and values from the past, Wodak has developed a discourse-historical approach that investigates historical and political issues and texts by tracing discursive acts from the past to the present and their implications for the future (2012). Like Fairclough, Wodak recognizes the primacy of using language behavior to analyze "issues of social relevance" (1989, xv) but stresses the historical aspects of any approach chosen. 
CDA seeks to go beyond the obvious. While the examination of power is central for understanding the dynamics and specifics of control in modern societies, power is mostly invisible, which is why discourse analysis is designed to investigate the linguistic manifestations of it. Van Dijk $(2009,77)$ refers to this as the "incompleteness" of discourse meaning. Semantically speaking, a discourse is like the tip of an iceberg: only some of the propositions needed to understand a discourse are actually expressed; most other propositions remain implicit, and must be inferred from the explicit propositions. Van Dijk calls these presuppositions "mental models" that are implied but not asserted by the discourse (Ibid). For example, as part of the U.S. administration's use of the burqa as a symbol of Afghan women's rights and dignity that needed protection from the Taliban, President George W. Bush introduced the phrase "women of cover" in 2001 into the media's vocabulary prior to the Afghanistan war. The mass media was used to create a link between the opinions and directives of government leaders and public reception of that rhetoric. Bush's seemingly casual rhetorical play on the American feminist term "women of color" foreshadowed what would soon become an attempt to mobilize western feminism to support his war on terrorism (Wasilow 2012). Subsequently having Laura Bush "guest host" the presidential radio address to the nation served to support Bush's associations between the war on terrorism and "brutality against women and children by the al-Qaida terrorist network" (Bush 2001), exploiting the use of her gender to further reinforce the mental model previously outlined by her husband. 
These mental models are rooted in and reflect hidden and latent type of everyday beliefs, which often appear disguised as conceptual metaphors and captivating analogies, such as "women of cover," and "war on terror." In daily discussions at the proverbial water cooler, coffee shops, and on social media, certain ideas arise more commonly than others. Often these ideas stem from print, radio, television and online media coverage of current issues, regularly converging in their focus. Often people with diverse backgrounds and interests may find themselves thinking alike in disquieting ways, and thus, dominant ideologies appear as seemingly "neutral," holding onto assumptions that stay largely unchallenged (Wodak \& Meyer 2009, 8). Organizations such as governments that strive for and seek to maintain power will try to influence the ideology of a society to become closer to what they want it to be. When most people in a society think alike about certain matters, or even forget that there are alternatives to the status quo, we witness the Gramscian concept of hegemony (Lears 1985, 567). Regarding this concept of hegemony, van Dijk (1998) sees ideologies as the "worldviews" that constitute "social cognition." While van Dijk used the example of representations and attitudes that whites have about blacks, we could certainly substitute westerners for "whites" and terrorists for "blacks."

I will draw from three prominent critical discourse analysts cited above - Fairclough, van Dijk, and Wodak - to explore connections among language, cognitive processes, and social acts. I will use CDA in an effort to analyze and "decode" hegemonic discourses employed in media reports that effectively marginalize and "other" selected groups by influencing and skewing public opinion in favour of elite groups. I will primarily utilize one of the more comprehensive attempts toward theorizing CDA, Fairclough's Discourse 
and Social Change (1992), in which he constructs a social theory of discourse and provides a methodological blueprint for CDA in practice (see also van Dijk 1993, and Wodak 1995).

Fairclough provides a three-dimensional framework for envisaging and analyzing discourse.

One, discourse as text: in which the linguistic features and concrete examples of discourse are systematically analyzed, such as choices and patterns in word choices, and text structure. The use of first-person choices such as "we" and "our" that can be used in war reporting, for example, can have the effect of obscuring the influence of political processes through a focus on the individual in combat. Fairclough's attention to concrete textual features distinguishes his approach from that of Michel Foucault's (1972), who provided valuable albeit more detached insights on the influence of verbal and situational contexts on statements, and whose work is better reflected in Fairclough's second dimension.

According to Foucault, who concerned himself predominantly with the analysis of "discursive formations" in specific historical and socio-cultural contexts, a particular discursive formation is capable of maintaining its own "regime of truth." He argued that the dominant tropes found within the discourse of a particular historical period determine what can be known, therefore, constituting the basic episteme or knowledge of that age. While a range of discursive positions might be available at any given time, reflecting 
various determinants that were, for example, economic or political in nature, Foucault focused on the influence of power relations of particular interpretative communities deciding on issues such as law and money, thereby occupying a position of privilege and dominance versus other, more marginalized positions.

Correspondingly, Fairclough's second dimension is discourse as function: meaning something that is produced, circulated, distributed, consumed in society. Fairclough contends that that one cannot overemphasize the salience of language in major social changes in recent decades: "Many of these social changes do not just involve language, but are constituted to a significant extent by changes in language practices; and it is perhaps one indication of the growing importance of language in social and cultural change that attempts to engineer the direction of change increasingly include attempts to change language practices" (6). Adopting Fairclough's approach, I will investigate if the program of embedded reporting - through examination of its effects on reporters, military personnel, and media coverage - was structured in order to facilitate the creation of a particular discourse representation or language practice, creating a context that affects what is said or written, and how it is interpreted. As Foucault (1972) noted, the relationship between an utterance and its verbal and situational context is not necessarily a transparent one.

The third dimension is discourse as social practice: using theory that draws upon discourse to construct linkages among text analysis, discursive function, and ideological effects. Fairclough focuses on discourse as a process of hegemony, power that is achieved 
through constructing alliances and integrating classes and groups through consent, so that "the articulation and re-articulation of orders of discourse is correspondingly one stake in hegemonic struggle" $(1992,93)$. Certainly it can be argued that recognition of the increased importance of language in social life has led to a greater level of conscious intervention at multiple levels to control and shape language practices in accordance with economic, political, and institutional objectives. The interconnecting or networking of texts through speeches, media coverage, editorials, and interviews serve to legitimate official policy; as van Dijk (1998) explains, legitimation is a crucial social function of ideology which often manifests as "a complex, ongoing discourse practice involving a set of interrelated discourse" (255). Fairclough calls this systematic process of intervention the "technologization of discourse" (55): whereby discourse itself has become widely subject to the technologies and techniques Foucault identified with the modern workings of power.

In summary, CDA is a method of systematically examining the structures and functions of text and talk in their social, political, and cultural contexts. When applied to the study of mass communication, and particularly the media, CDA allows researchers to pay detailed attention to the structures and strategies of relevant discourses and to the ways these relate to both institutions and audiences. As we will see in the next section, power is not restricted to simply the influence of the media on their audiences, but also involves the role of the media within a broader framework that includes the social, cultural, political, or economic power structures of a given society. 


\subsection{Media effects research: refined with time}

I will next examine three media-effects models: agenda setting, priming, and framing. I will briefly review each of the three models, examine how they are related, and explain why the construct of framing - in conjunction with the concept of indexing - are best suited as the 'prism' through which I will proceed with my chosen area of study.

Media-effects research inhabits an important corner of the world of communications theory. As noted by McQuail (1994): "The entire study of mass communication is based on the premise that the media have significant effects" (327). The mass media serve as a system for communicating messages and symbols to the general population (Herman and Chomsky 1988). This system of values, beliefs, and codes serves to integrate individuals into the larger institutional structures of society. McQuail posits that scholarly discussion of media effects can be divided into four stages during recent decades.

The first stage, from the turn of the 20 th century to the late 1930 s, was dominated by the influence of strategic propaganda that was utilized during World War I, which in turn led to a significant fear of the influence of media messages on attitudes and beliefs. The second stage, ending in the late 1960s, up-ended the paradigm of strong media effects in favour of personal influence that became considered as the main influence on attitude change. For example, Klapper (1960) contended that campaigns and opinion leaders did not influence people as much as they reinforced existing attitudes. The third stage, beginning in the 1970s, was dominated by a search for new strong media effects, shifting 
from changes in attitudes to more cognitive effects of mass media (Beniger and Gusek 1995). It includes the original offering of agenda setting. The fourth and current stage, which began in the early 1980s, is characterized by "social constructivism," and includes the concepts of priming, framing, and indexing. The description of media and recipients in this stage combines elements of both strong and limited effects of mass media. On one hand, mass media can have a strong impact by constructing social reality, that is, "by framing images of reality ... in a predictable and patterned way" (McQuail 1994, 331). On the other hand, media effects can be limited by an interaction between mass media and its recipients (Scheufele 1999).

\section{Agenda Setting: When Gatekeepers Ruled}

Agenda-setting research in political communication was propelled into the academic spotlight during the 1970s by McCombs and Shaw (1972):

In choosing and displaying news, editors, newsroom staff, and broadcasters play an important part in shaping political reality. Readers learn not only about a given issue, but also how much importance to attach to that issue from the amount of information in a news story and its position. In reflecting what candidates are saying during a campaign, the mass media may well determine the important issues - that is, the media may jet the "agenda" of the campaign (176).

In other words, agenda setting contends that there is a strong correlation between the emphasis that mass media place on certain issues - through relative placement or amount of coverage provided - and the importance attributed to these issues by mass audiences. For example, it is like an "above the fold" scenario; historically, top issues of the day are 
always placed on the top half of the front page of a newspaper. Likewise, the more the media covers an issue, the more important the public perceives it to be.

Even though the term is largely associated with McCombs and Shaw, roughly a decade earlier, Cohen (1963) had noted that the press was amazingly successful in guiding its readers' attentions, without manifestly telling them what to think:

The press may not be successful much of the time in telling people what to think, but it is stunningly successful in telling its readers what to think about.... The world will look different to different people, depending ... on the map that is drawn for them by writers, editors, and publishers of the papers they read (13).

In short, if - in the choice and presentation of information that is then used by citizens to make informed life decisions - the media draws from a restricted menu, so too will the scope of information presented to and consumed by the public be restricted. It would seem that Shaw and McCombs (1989) tempered their theory with time, acknowledging that news is not simply factual information; rather, it is an act of creative constructivism. In other words, just as history is composed of events that have been selected and recorded - case in point, the Bible - so too are news issues and events classified or delineated by the words chosen to record them. This will be addressed later along with the term secondlevel agenda setting.

During the 1980s and early 1990s, the approaches of priming and framing were developed, based on the idea that the mass media had potentially strong attitudinal effects, but any effects depended heavily on predispositions, schema, and other audience 
characteristics that influenced how recipients processed messages (Scheufele and Tewksbury 2007).

\section{Priming: Cueing the Mind}

Priming is often understood as an extension of agenda setting, and its theoretical approach is frequently used in research on media violence. Originally referred to as cue theory (Berkowitz 1965), testing showed that media portrayals can contain particular symbols and, when these symbols appear in a person's real life, they can 'cue' the person to remember the media portrayal. For example, Berkowitz found that when violent portrayals in the media contained weapons, these weapons became powerful cues to people in real life. Subsequently, when people saw a particular kind of weapon in real life, it triggered memories of the media portrayal and those memories were likely to lead to aggressive behavior.

When priming is applied to the media, "priming refers to the effects of the content of the media on people's later behavior or judgments related to the content that was processed" (Roskos-Ewoldsen, Roskos-Ewoldsen, and Dillman Carpentier 2002, 74). In political media coverage, for example, priming occurs when news content suggests to news audiences that they should use specific issues as benchmarks for evaluating the performance of leaders and governments. Evolving from cue theory, memory-based models of information processing assume that people form attitudes based on considerations that are most salient when they make decisions: "memory and judgment 
will be directly related when the judgment was based directly on the [smooth] retrieval of evidence information" (Hastie \& Park 1986, 258). In other words, judgments and attitude formation are directly correlated with "the ease [emphasis added] with which instances or associations could be brought to mind"' (Tversky and Kahneman 1973, 208), resulting in "systemic biases."

As noted earlier, some researchers have argued that priming is a temporal extension of agenda setting (Iyengar \& Kinder 1987): by making some issues more salient in people's mind, i.e. agenda setting, the media can also influence factors that people consider when making judgments about news items such as political candidates or issues, i.e. priming. In other words, the temporal structure of agenda setting and priming assumes that the media can make certain issues or aspects of issues more accessible - meaning, easily recalled for people and thereby influence the standards they use when forming attitudes about issues such as candidates and political issues (Scheufele and Tewksbury 2007).

\section{Framing: Establishing Mental Parameters}

Framing differs significantly from agenda building and priming. It is based on the assumption that how an issue is characterized in news reports can have an influence on how people develop a particular conceptualization of an issue or perhaps reorient their thinking about a given issue. The major premise of framing theory is that an issue can be viewed from a variety of perspectives and be interpreted to have multiple implications. Some researchers, such as Capella and Jamieson (1997) and Iyengar (1991), contend it is 
not in fact the presence of an issue in the news that is important, which is the main thrust of agenda-setting research, but the way that issue is framed.

Sociologist Erving Goffman (1974) was the first scholar to specifically discuss framing as a process of deconstructing the individual's "organization of experience," and defining it as the "principles of organization which govern events - at least social ones - and our subjective involvement in them (10-11). Goffman proposed that framing occurred because individuals cannot understand the world fully, and constantly struggle to interpret their life experiences and to make sense of the world around them. Goffman conceptualized the idea of a "primary framework" as the first point of the organization of personal experience. In order to efficiently process new information, he argued, individuals will apply interpretive schemata or "primary frameworks" $(1974,24)$ to classify information and interpret it meaningfully.

The psychological origins of framing can be found in experimental work by Kahneman and Tversky (1984), in which they examined how different presentations of essentially identical scenarios can influence people's evaluations and subsequent choices of various options presented to them. While their work was largely economic in nature - assessing how loss aversion leads to risk aversion - it cast light on the importance of how framing a transaction as a loss or a gain can influence a person's ensuing calculations. In his 2011 update, Kahneman was not optimistic about people's ability to resist framing. 
Todd Gitlin (1980) introduced the concept of framing to mass communication research in his classic examination of how CBS trivialized a major student movement during the turbulent 1960s. Contrary to Cohen's assertion $(1964,13)$ that the press was "stunningly successful in telling its readers what to think about," Gitlin argued that the media's power lay in exactly the opposite direction—ensuring what the audience does not think about. Yet even prior to Gitlin's research, the roots of framing can be seen in both psychology and sociology (Pan \& Kosicki, 1993).

Some researchers suggest that not only are agenda setting and framing related, but that framing is an extension of agenda setting (Scheufele 1999). They use the term secondlevel agenda setting to describe the impact of the salience of characteristics of media coverage on audiences' interpretation of these news stories. For example, McCombs, Shaw, and Weaver (1997) contend that, whereas agenda setting is concerned with the salience of issues, frame setting is concerned with the salience of issue attributes. Put another way: "The first level of agenda setting is ... the transmission of object salience. The second level of agenda setting is the transmission of attribute salience" (McCombs, Llamas, Lopez-Escobar, and Rey 1997, 704).

Certainly there is merit in refining the original agenda-setting hypothesis. It has been criticized for being simplistic, and overly focused on linkages between broad-issue categories in media coverage and public-opinion surveys. A more accurate perspective on agenda setting and framing would be the one adopted by Price and Tewksbury (1997): Agenda setting looks on story selection as a determinant of public perceptions of 
issue importance and, indirectly through priming, evaluations of political leaders. Framing focuses not on which topics or issues are selected for coverage by the news media, but instead on the particular ways those issues are presented (184).

Another criticism of agenda-setting is that what may have been a discernable and powerful gate-keeping process at one time, has simply become less influential - at least for many technologically advanced nation-states - in today's raucous internet version of the "Wild West," the omnipresence of smart-phone technology, the immediacy of 'Twitterverse,' and high social connectivity that is facilitated by numerous social-media outlets. I believe that Scheufele and Tewksbury (2007) touched on this last point when noting the distinction between accessibility and applicability effects. As accessibility effects, priming and agenda setting are grounded on memory-based models of information processing that enable 'easy recall,' are largely temporal in nature, and thus, more sensitive to the passage of time. This is distinctly different from framing as an applicability effect, wherein a message has the outcome of a connection between two (or more) concepts such that, after exposure to the message, audiences will accept the concepts are connected. "If a person thinks that Attribute A belongs with Issue B, that belief will likely persist until some countervailing information is encountered. An accessibility effect is much more easily reduced by the flow of time" (16). I contend that an accessibility effect is also significantly minimized by the cacophony of voices and alternate media choices that are much more prevalent today than they were in the 1970s.

In summary, agenda-setting effects assume that the power of effect lies with the heightened accessibility an issue receives from its placement in the news world (Price and 
Tewksbury 1997). Thus, it is not so much that information about the issue has the effect; rather, it is the fact that the issue has received a significant amount of processing time and attention that carries the effect. Priming can be viewed as a temporal extension of agenda setting (Iyengar \& Kinder 1987). While agenda setting is said to occur when the media makes certain issues more salient in people's minds, priming is said to occur when news coverage establishes certain content cues for subsequent behavior or suggests to news audiences that they should use specific issues as benchmarks for evaluating or making judgments related to the content that was processed. In contrast, the framing approach assumes that the power of effect lies within the description of an issue or the label used in news coverage about the issue. The primary effects of a frame rest within the accompanying interpretive schemata that are pertinent to the issue at hand. In other words, the key difference between agenda setting and priming, on the one hand, and framing, on the other hand, is whether we think about an issue versus how we think about it. While the former continues to have merit, it is the sophistication of the latter that warrants close attention, particularly as it has become increasingly used to design scenarios that draw western nations into conflicts on the other side of the world.

\subsection{Using Discourse to Frame a War}

Framing theory is a discourse analysis approach that is principally concerned with dissecting how an issue is defined and problematized, and the effect that this has on the broader discussion of that issue. Framing shares many of the building blocks of CDA exploration of the construction of meaning, and a belief in the potential for discourse to 
affect action beyond the text - but is primarily focused on linguistic interplay, or what Fairclough would call his first dimension. While people clearly learn from news, what they learn can be both explicit and implicit. And what they learn depends to a great extent on how information about their greater world is framed.

Goffman (1974) wrote that "we tend to perceive events in terms of primary frameworks, and the type of framework we employ provides a way of describing the event to which it is applied" (24), thereby rendering "acts of daily living ... understandable because of some primary framework (or frameworks) that informs them" (26). He differentiated between "natural" and "social" primary frameworks that help people make sense of "what is happening' around them. Natural frameworks "identify occurrences seen as undirected, unoriented, unanimated, unguided, "purely physical,"' such as those found in the physical and biological sciences. Social frameworks, on the other hand, "provide background understanding for events that incorporate the will, aim, and controlling effort of intelligence, a live agency, the chief one being the human being;" otherwise known as "guided doings" (22).

The current study is concerned with the design and impact of the news frame, which Tuchman (1978) argues “organizes everyday reality, and ... is part and parcel of everyday reality" (193). News frames include strategic, conflict, personality, issue, and episodic frames. They are always about a topic and usually carry substantive information within their particular frame (Chong and Druckman 2007). News frames highlight certain aspects of news and downplay others through selection, emphasis, exclusion, and 
elaboration (Tankard et al., cited in Capella and Jamieson 2007). News frames activate constructs, invite certain inferences but not others, and cue internal connections in news receivers as a function of the content, style, and presentation of the given news story.

For Entman (1993), essential elements of the event interpretation process are selection and salience: "To frame is to select some aspects of a perceived reality and make them more salient in a communicating text, in such a way as to promote a particular problem definition, causal interpretation, moral evaluation, and/or treatment recommendation" (52). The intent is to present information in a way that resonates with existing underlying schemata among an audience (Shoemaker \& Reese, 1996). It is not my intention to claim that most journalists will try to spin a tale or purposefully deceive their audiences. In fact, framing can serve as a necessary tool to reduce the complexity of an issue, given the constraints of day-to-day media operations, whether than be deadlines, news holes, or airtime (Gans 2005). In reference to presenting relatively complex issues, such as an examination of the history, culture, geopolitics, and religious elements of the Afghanistan War, frames can be used to present these issues efficiently and in a way that makes them accessible to lay audiences because they play to already existing cognitive schemata. In short, the framing and presentation of events and news in the mass media can systematically affect how recipients of the news process and understand these events (Price, Tewksbury and Powers 1995, 4).

The construction of news media frames is an interactive process in which journalists actively attempt to find a narrative "fit" between incoming information and pre-existing 
media frames. While the scope of incoming information is limited by both internal and external circumstances, such as technology, the incoming information as well as its sources have an important influence on the construction process. Additionally, the professional and political culture found within each news medium can play a significant role in this procedure by guiding the search for related and relevant information as well as defining the range and tone of existing frames that can be applied to a given story, conflict or issue.

Authorities such as government sources have important advantages over alternative sources such as critics in the promotion of their frames to the news media (this will be covered more in-depth later under indexing). The political power of government or military sources can be translated into cultural power through their ability to socialize journalists, and through their ability to plan, package, and deliver events in ways that resonate within the professional and political culture of the news media. At the same time, the news media are able to access their own variety of in-house frames, often depending on the timing and development of issues, and can choose to counter-frame attempts by authoritative sources. In this respect, the news media is capable of playing a critical role - more of "watchdog" than "lapdog" - by originating or legitimating existing oppositional frames that allow a voice and power to alternative perspectives.

While framing can be understood in both positive and negative terms - one, a strategy to manipulate and deceive individuals or, two, a learning process through which people acquire common beliefs around a social norm (see Chong 2000) - framing in the public- 
opinion field often has a negative connotation. This is because framing effects suggest that the circulation of public preferences is arbitrary and mercurial in nature, and that power elites can manipulate popular preferences to serve their own selfish interests. Or as Entman (2010) writes: “...assuming coercion isn’t an option, exerting power to affect behavior in a democracy requires framing - 'telling people what to think about' - in order to influence the attitudes that shape their behavior" (392).

I argue that framing effects are necessary for the development of informed public attitudes and opinions; that public-opinion formation necessarily involves the selective acceptance and rejection of competing frames that contain sometimes conflicting information about issues; and that discussion and debate regarding the appropriate frames for conceptualizing an issue ultimately lead to common perceptions and judgments about the pros and cons of a given policy. However, this latter perspective pre-supposes a certain degree of informed awareness, and further assumes that framing effects are a liability only if individuals fail to develop an ability to discriminate among frames and thus remain vulnerable to certain representations of issues.

By their very nature, news frames present a partial view of the world and the news media play a large role in the mediation of those views. For example, the threat posed to Afghan women's rights is largely a distant and remote issue for a western public, much more so than women's rights in North America. Thus, it became much more of a mediated issue. Public awareness became predominantly limited to a US-administration call for the 
liberation of "women of cover," to images of burqa-clad women, and to reports of atrocities against women that were carried out by foreign terrorists in a far-away land. While these pronouncements/images/reports may be jarring and even disturbing, they are in fact of little personal relevance to the viewer/reader as they have little impact on their daily lives. According to Iyengar (2007), when attributions of responsibility for distant and remote issues and events such as terrorism - and I would suggest Afghan women's rights - are associated with poorly understood disputes in distant locales and with ideological conflicts, attributions of responsibility tend to be highly responsive to the framing of those issues and events.

The set of dimensions that affect an individual's evaluation of a given issue constitute an individual's "frame in thought" (Chong and Druckman 2007). For example, if an individual believes that women's rights dominate all other considerations in deciding whether a certain group has the right to impose restrictive laws on females, that individual's frame in thought is women's rights. If, instead, he or she gives consideration to women's rights, religious beliefs, cultural sensitivity, and the effect of the laws on the community, then his or her frame in thought consists of this mix of considerations. Clearly, an individual's frame in thought can have a significant impact on his or her overall opinion. For example, a women's rights frame would incline someone to oppose laws considered restrictive of those rights. It is for this reason that politicians, and the public-relations behemoth at their disposal, will attempt to mobilize the public behind their policies by encouraging them to think about those policies along particular and preselected lines. This is accomplished by highlighting certain features of the policy, such as 
its likely effects, cost, or relationship to important values (Jacoby 2000). When doing this, the speaker is invoking a "frame in communication." For example, if a speaker claims that a terrorist group's actions construe "a women's rights issue," then he or she invokes a women's-rights communication frame.

\section{Framing effects}

Communication frames are powerful tools because they affect the attitudes and behaviors of their audiences. Politicians often adopt communication frames used by other politicians and the media (Riker 1996); likewise, media frames sometimes mimic those used by politicians, other media outlets, or public groups (Entman 2004, Carragee and Roefs 2004); and citizens may also adopt frames encountered in discussions with other citizens (Walsh 2003). Much of the communication and political science literature, however, focuses on how communication frames by political, media, and interest-group elites can influence citizens' receiving communication frames and resulting attitudes. This process is typically called a framing effect.

As noted earlier, unlike agenda setting, framing is not simply concerned with the presence of news topics but with how topics are treated in the news; thus, framing effects are subtler than agenda-setting effects. Framing effects occur when changes - for example, small changes in wording - in the presentation of an issue or an event produce changes of opinion, sometimes very significant changes. Sniderman and Theriault provide the example of asking members of the public whether they would favor or oppose 
allowing a hate group to hold a political rally; 80 percent of respondents were in favor when the question was prefaced with the suggestion, "Given the importance of free speech," while only 37 percent were in favor when the question was prefaced with the phrase, "Given the risk of violence" (151-153, 2004).

Bush's use of alternating feminist and terrorist rhetoric to create support for the impending war was able to successfully situate framing within the democratic process that guides us: using the mass media to create a link between the opinions and directives of government leaders and public reception of that rhetoric. A framing effect can only occur if a given consideration - such as women's rights in the context being under attack by a previously identified terrorist group, and linkages with terrorist responsible for the 9/11 attacks on American soil who were hiding in Afghanistan - has been stored in memory and is available for retrieval and use (Chong and Druckman 2007).

The successful use of framing to rally people to support racism or xenophobia - for example, decrying the eroding effects of illegal Mexican immigration, heralding America-only "freedom fries," and the more recent call to ban all Muslims from entering the U.S. - demonstrate there is nothing inherently superior about a strong frame other than its largely emotional appeal to audiences. In other words, strong frames should not be confused with intellectually or morally superior arguments; in fact, these frames are often built upon exaggerations and outright lies that play on the fears and prejudices of the public. As Chong and Druckman (2007) have noted, strong frames often rest on symbols, endorsements, and links to partisanship and ideology rather than on substantive 
information about a proposed policy.

Framing is not a hypodermic needle, however, and framing effects may transition with time. While most framing studies assume that leading communicators are members of the elite - such as politicians, the media, experts, and other opinion leaders - and that the recipients of the communication are the general public (Walsh 2003), this influence may not necessarily be exclusively and indefinitely unidirectional in nature. As Chong (1996) points out, frames are created with a particular audience in mind, therefore the preferences of that audience may very well have a reciprocal bearing on the position taken by elites. In terms of foreign policy issues, for example, Entman (2004) has observed that frames originating with the administration shape the frames used by other elites such as the media and the public. However - and as evidenced by public reaction to casualties of American soldiers during the Iraq war - the public's reaction to the initial frame can be fed back to the media and other elites, who may then influence and lead to a revised administration view. This process may lead to a debate on a given issue — debate defined as competing frames. In this respect, Entman takes into account the potential role of multiple actors who can influence and even anticipate one another in their creation of contesting frames.

\subsection{Indexing}

Several scholars have built upon Goffman's work on framing (Entman 1991; 1993; 2003; 2004; 2007; 2010; Scheufele 1999; Shah, Kwak, Schmierbach, and Zubric 2004). I will 
predominantly be employing and pivoting from Entman's discussion of frame dominance as it segues neatly into the concept of indexing, which emerged from the study of media coverage of the Vietnam War as a way to analyze government influence on the media (Hamilton 2009). As noted in chapter 1, frame dominance signifies one-sidedness in the framing of a particular issue, such as definitions of terrorism, who constitutes a terrorist, and reasons for going to war; frame parity represents the existence of counter-frames or alternate views (Entman 1991; 2003). In order to achieve parity, news must present a "complete alternative narrative, a tale of problem, cause, [and] remedy" (2003, 418). As the history of military/media relations can demonstrate, while it sometimes exists, "frame parity is the exception, not the rule" (418).

A dominant slant or "news frame" will not simply reflect agreed-upon facts, according to Entman (2010). "Slant characterizes individual news reports and editorials in which the framing favors one side over the other in a current or potential dispute" (Entman 2007, 165). He contends that elites are mindful players in the pursuit of sourcing power: when competitive elites sense weakness, it emboldens them to attack. "This alters the distribution of opinion readily available on the reporter's network of sources and potentially sets off a downward spiral whereby negative slant feeds perceptions of weakness and unpopularity, fomenting further assaults from elites" (395). Even when elites do agree or perhaps remain silent for strategic purposes, he notes, "the news is even more likely to slant in favor of a single interpretation of any facts - the apparent elite consensus - just as suggested by Bennett's indexing model with respect to foreign news" (395). Entman does not necessarily perceive one-sidedness as a negative: in the case of 
climate-change issues, for example, he critiques journalists who pursue and confer equal treatment on a competitor who provides asserted facts that hardly any knowledgeable source would accept, and points to insightful work by Boykoff (2008), who dissects "climate contrarians [who] have developed competing discourses that challenge top climate scientific evidence" (15).

Furthermore, seeking journalistic 'balance' may be uniquely perceived in different countries, even those with similar cultures. As Dimitrova and Strömbäck (2005) point out in their comparison of media coverage of the Iraq War, U.S. journalists seem to have an understanding of the term 'objectivity' by which "US journalists become more dependent on their official sources, and ... when no dispute is perceived, they let the official sources set the media agenda" (403). On the other hand, according to Patterson (1998), for a majority - 58 percent - of Swedish journalists, objectivity means "going beyond the statements of the contending sides to the hard facts of a political dispute." This would suggest more of an 'activist' than 'neutral' role, as journalists thus decide what the 'hard facts' are. Conversely, among American journalists, only 28 percent adhere to the same perception of journalistic objectivity in favour of "expressing fairly the position of each side in a political dispute" (22).

According to indexing theory - first introduced by Bennett (1990) and further developed by Mermin (1999) - the U.S. media tend to harmonize their reporting to the views of the political elite and other official sources. "Once officials engage with news events, the story frames generated by journalists are then generally 'indexed' to the range of sources 
and viewpoints that reflect levels of official agreement and consensus" (Bennett, Lawrence, and Livingston 2007, 100). When there is consensus among elite sources, the likelihood that journalists will further investigate an issue and push for answers is low; consequently, the media's agenda is directed by government officials rather than by journalists or editors (Bennett 2004, 2012; Entman 2004; Hallin 1986; Schudson 2003).

This media bias is based on two assumptions. One is an affinity toward those perceived to hold power; Entman calls this "a tendency to slant news favorably toward the side regarded as most powerful, popular, and unified" $(2007,167)$. The second is the belief that authority figures, government experts, and elite informants know enough about a story and its associated issues to provide a complete picture, thereby forestalling additional investigation by a reporter. Furthermore, journalists have a basic need for sources who can provide facts and views; in Washington these sources are predominantly elected and appointed officials who are knowledgeable, who make and implement policy, and are generally approachable. Using sources outside elite circles in Washington is a more subjective call, and open to questioning by an editor and perhaps the public, especially if the source's view is nonconformist.

One of the first studies to document this pattern was Hallin's (1986) study of media coverage of the Vietnam War. During the 1960s, much of what was known about the Vietnam War came from journalists in Washington, who received much of their information from either the State Department or the White House - institutional sources that were relatively unified in their support of the war. However, consensus broke down 
after the Tet Offensive in 1968, official views widened, and public opposition grew. Correspondingly, media coverage expanded its tone because, as Entman (2003) points out, "open discord among American leaders usually breaks out before the news deviates significantly from the White House line" (421). Accordingly, it can be said that journalists did not so much deviate from their professional norms and initiate the end of the Vietnam War as much as they followed the lead of their capitol-based sources, who had reappraised the war effort in light of costs and casualties (Mueller 1973, 42-61), which in turn triggered an adjustment in media coverage of the war.

This same indexing theme continued through subsequent conflicts, such as the Falklands War (1982), and the Iraq War (2003-2011). As noted in chapter 1, the British media largely mimicked Prime Minister Thatcher's political discourse - in the name of 'good taste' and issues of national security - that was littered with patriotic fervor and references to 'our boys' as well as hostility towards anti-war protesters, the BBC, the political left, and trade unionists. Another example is when, as the invasion of Iraq began, U.S. Secretary of State Colin Powell asserted the existence of Weapons of Mass Destruction (WMDs) in a speech to the United Nations (Washington Post 2003) on 5 February 2003. The media repeated his claims, and there was a subsequent 30-point jump in the number of Americans who felt convinced of a link between Hussein and al Qaeda after Powell spoke (Gershkoff and Kushner, 2005). Powell now calls the WMD claims "one of my most momentous failures, the one with the widest-ranging impact" (Powell 2012, 223). 
Indexing seems to be particularly relevant to conflict reporting and terrorist issues given that journalists are often hesitant to probe beyond government and military officials, who are habitually perceived as the most informed authority figures and experts. In addition, the executive branch of government has strong constitutional power in foreign affairs, and legislators typically defer to the president and the military in the midst of a national security crisis. For example, New York Times journalist Judith Miller justified her reporting of erroneous claims that Saddam Hussein possessed WMDs by stating: "[My] job isn't to assess the government's information and be an independent intelligence analyst myself. My job is to tell readers of the New York Times what the government thought about Iraq's arsenal” (cited in Massing 2004, 62). Miller saw her journalistic role as that of a messenger.

As noted earlier, consensus - or lack thereof - is key. Bennett (2003) outlines 10 factors that converged to create a "perfect storm" of media complicity with government propaganda pertaining to the Iraq War, with a special entry called "Where were the Democrats?" He writes "the [media's] failure to report on the antiwar movement was due to the dependence of the press on official opposition or partisan engagement of institutional processes to elevate grass roots voices to regular members of the news cast." Carruthers (2011) more pointedly criticizes mainstream American media for defining newsgathering as a barometer tracking the mercury of policy deliberation on Capitol Hill (41). In other words, activity within a very small area of real estate - the "golden triangle" of the White House, State Department, and Pentagon (Hess 1983) - has become an overly powerful news-management entity via access to official briefings and sources (Entman 
and Page 1994; Zaller and Chiu 2000). Carruthers (2011) claims this "two-way relationship of mutual need" has become self-sustaining: "those outside that charmed circle remain beyond its circumference, while those at the core are duly empowered to police its boundaries" (42).

Bennett (2003) has also remarked on how U.S. "press ethnocentrism" lends itself to "cultural-patriotic story-telling" while remaining "remarkably closed to world opinion," and at best, adopting a "condescending tone for discussing the din of international criticism." One of the few comparative studies of the coverage of the Iraq War (Dimitrova, Kaid, Williams and Trammell 2005) found significant differences in war framing between U.S. and international news websites: foreign sites were more likely to include the responsibility frame, where the "emphasis is on the party/person responsible for the event" (32), while the American sites were more likely to focus on military conflict. One of the goals of my research will be to investigate where the Canadian media's war coverage falls on this framing spectrum.

There are three powerful lines of criticisms regarding indexing: one, that its effects are predominantly limited to foreign-policy issues; two, many of its insights pre-date $9 / 11$; and three, it makes few allowances for countering voices. First, while it is true that much of indexing research has focused on foreign-policy issues, I contend that research on both military/media relations, and its sub-category of media response to and treatment of conflict issues, fall within the purview of foreign-policy matters and media coverage of them. Thus, I have few concerns with this criticism. Second, while Entman (2003) was 
certainly correct at one time in his position that indexing was based mostly on events before 1991, and "cannot account fully for changes in international politics and media behavior since the end of the Cold War" (416), I contend that indexing is still a valid measure of how the American media responds to and reports on foreign matters, perhaps even more so today than in years past when media outlets had dedicated foreign reporters on their payrolls and were less dependent on beltway sources. And if news reporting immediately following 9/11 showed anything, it was how closely aligned the media was to official and patriotic sentiment during times of emotional upheaval. The question I will address in my study is if and/or how embedded Canadian media have followed and reproduced a perspective that can be tied to entrenched power structures.

The third criticism carries more weight. While Entman admits that "indexing quite convincingly emphasizes elite opposition as a vital determinant of whether the news will deviate from the White House line," he is also correct that "it does not explain fully why leaders sometimes choose to contest the White House frame and other times keep quiet, or just how much elite opposition will arise. Nor do previous models delineate comprehensively the public's role in the larger system of communication...." $(2003,416$ 417). Entman's cascading network activation model is a useful tool for helping to explain how interpretive frames activate and spread from the top level of a stratified system such as the White House, down to a network of non-administration elites such as experts, and further to news organizations, their reports, and then the public ... as well as how interpretations may feed back from lower to higher levels. In this model, as with the indexing model, the media as conduit are more likely to create counterframes to the 
original, preferred frame when officials at the top levels are not united, but Entman's model adds additional counterframing factors such as midlevel, readily available sources with alternative frames.

The Abu Ghraib prison story can expand upon this third criticism. On 28 April 2004, CBS's Sixty Minutes disclosed that American guards had abused prisoners at Abu Ghraib in Iraq. Photographs taken by U.S. soldiers and Military Police (MPs) showed Iraqi men in an array of degrading postures, sometimes along with their tormentors who were grinning and giving a 'thumbs up.' Some academics, notably Bennett, Lawrence and Livingston (2006; 2007) argued that the U.S. press, and the Washington Post in particular, followed the Bush administration's framing of the prisoners' mistreatment as abuse, not torture, and the isolated actions of "a few bad apples" that were unconnected to guiding authority or policy. Washington Post Executive Editor Leonard Downie explained his rationale: "Abuse is obvious from the information and images we have, and is serious in its own right. Torture is more loaded term and its use requires more information about whether the abuse constitutes torture" (2004). Nonetheless, Bennett et al. (2006) claim media coverage followed a predictable pattern of indexing: "lacking any consistent counterframing by high-level officials, the national media declined to challenge the administration" (481).

Conversely, in a follow-up paper with a different methodology, Porpora, Nikolaev, and Hagemann (2010) counter-argue that Bennett et al. (2006) understated the strength and consistency of Washington Post coverage, which did in fact engage in considerable 
counterframing even in the absence of elite political opposition. Claiming that the 2006 study's exclusive coding with single words served to compromise validity, Porpora et al. concluded that their use of more extended frames of reference did not in fact support the indexing model by Bennett (1990), but rather the cascade model by Entman (2004) "in which the press exercises more independence of elite political opinion than the Indexing model admits" (254). This valid criticism is one of the reasons that I will be utilizing both word coding as well as an examination of the context within which the words are utilized. On a related note, Porpora et al. also remarked that a perhaps more fundamental problem with building toward an informed public is a basic lack of audience interest in national, and especially international, news in the U.S. (269).

\section{Conclusions}

Many leaders throughout history owe their fame (or infamy) at least in part to their ability to use language as a means to manipulate their followers. "The prototypes [of leaders] are also great orators, such as Churchill, or Roosevelt ... or Hitler. For the inspiring orator can also lead a people, or rather mislead them, into believing that the narrow self-interests of the governing party are actually the interest of the people as a whole" (Joseph 2006, 13). Likewise, elite politicians and/or their staffers are experts at utilizing language in order to have their message resonate with the voting public or, as Fairclough (2002) writes, to "naturalize" their political goals. More often than not, the media is the conduit by which these messages and policies are relayed. As Reese and Lewis (2009) write: "Of 
course, that's why so much work goes into labeling policy in the first place; choosing the words that the news media must rely on controls the discourse at a basic level" (784).

Political speeches are almost always planned discourse (Ochs 1979) and are fundamentally acts of persuasion. As noted in chapter 1, following 9/11 and in conjunction with the launch of the Afghanistan War, Bush repeatedly utilized the phrase "women of cover" to refer to the Taliban-decreed burqa. It is doubtful the term haphazardly mimicked the term "women of colour;" in fact, it was no doubt chosen to tap into support by women for Bush's rally to war in Afghanistan. Much more than just another folksy Bushism, the phrase had likely been proposed by a member of the White House "spin doctors" team, analyzed, massaged, tested, and once green lit, incorporated into a presidential speech by a professional writer. Effective politicians understand and endeavor to harness the power of language - with the media as a messenger - to explain and/or justify their acts in order to garner the people's support.

Discourses are power relations; establishing social sense through ideological struggles between competing discourses, such as political and military control of information versus media gathering and release of information. Critical discourse analysis (CDA) can be used to shine a spotlight on the linguistic processes used by the privileged to gain and maintain power. It can also be used to analyze the subsequent flow and possible reification of constructed messages by the media. Yet, discourse analysis - when all is said - remains but one piece in a larger academic puzzle that includes an understanding of practical, day-to-day operations of the media. 
The media and the government often function as "intertwined cogs of an elaborate machine" (Hamilton, Lawrence, and Cozma 2010, 93). The press will often rely on administration and government officials - particularly when it relates to foreign policy and war, to establish a roster of stories and sources. The government, in turn, pays close attention to managing the subsequent news flow. From a practical standpoint, relying on officials is efficient and lends authority to the news (Tuchman 1978) and credibility to the news medium. From a democratic perspective, a press that reports what a nation's elected officials are saying and doing may well serve the public. "Governmental definitions of reality are supposed to be, after all, the best approximation of that bedrock of political reality, responsible public opinion” (Bennett 1990, 109).

The agenda-setting hypothesis posits that it is the media that determines which elements of the public discourses the audience notices or ignores, contemplates or neglects. While this concept likely had more sway during its initial development by McCombs and Shaw (1972), McCombs (1976), Shaw (1979), and later by Lang and Lang (1981), it holds less resonance in an era during which information and opinion can travel instantaneously via Twitter or smart phones, effectively bypassing national boundaries and official gatekeepers, as witnessed during the 2011 "Arab Spring" protests and more presently in the 3 a.m. tweets of an American president. Much of the research on priming is rooted in network models of semantic memory, which propose that concepts are associated in memory; this would mean that triggering one concept, such as a gun, can activate another related concept, such as gun-related violence, and will additionally influence later 
information processing (Carpentier, Roskos-Ewoldsen and Roskos-Ewoldsen 2008).

While priming continues to possess merit, particularly regarding political issues and candidates, research has shown that priming effects may be limited to, at a minimum, 15 to 20 minutes, and at a maximum, 24 hours, which may make it more applicable to issues such as elections rather than long-term decisions such as military activities and obligations.

That said, the media may still possess a certain degree of agenda-setting power - whether through primary initiation of coverage or secondary tracking of official statements where agenda-setting is defined as successfully performing the first function of framing: defining problems worthy of public and government attention (Entman 2007). Furthermore, it might be said that the effects of framing can only have an impact of audience members' interpretations and preferences through priming, by highlighting certain ideas worthy of audience attention, and activating schemas that encourage these audiences to think, feel, and decide in a particular way (Price, Tewksbury, \& Powers, 1997). The point is, agenda setting, priming and framing may yet be tied to one another even if the saliency of certain models have waned with time and technological advancements. The end result remains that framing is a process of culling a few elements of perceived reality and assembling a narrative that highlights connections among them to promote a particular interpretation (Entman (2007).

Like the process by which wages are indexed to changes in the cost of living, the news, according to indexing theory, reflects changes in levels of consensus or competition, 
agreement or conflict, among government officials (Hamilton 2010). More precisely, given that official sources play a vital role in the construction of news, increases in levels of consensus among elites will likely precipitate the adoption of certain news frames over others and diminish instances of frame contestation (Bennett et al. 2006; Entman 2004). Power, or the perception of power, is the deciding factor: journalists tend to calibrate the range of viewpoints they present in the news to reflect their reading of the balance of power among official elites. Indexing and framing are linked by a common factor: news sources (Groshek 2008, 315).

While the indexing hypothesis - which argues that national news framing tends to correlate with and is limited to the range of debate among the political elite - has been shown to apply to the American media, particularly regarding foreign-issues coverage, the question exists: does it apply to news systems outside the U.S.? Or do other variables, such as national interests, specific national journalistic culture and editorial policies of each news organization, as well as and the broader political and social context, better explain the factors that influence news framing? A comparative investigation of elite press coverage of 9/11 in the U.S., Italy, France, and Pakistan (Archetti 2008, 17) found that it cannot be applied outside the American context. I will investigate if this holds true for Canada.

For this study, I will utilize critical discourse analysis (CDA) of Canadian media coverage of the Afghanistan War and also conduct interviews with media and military/government personnel. I will investigate the interplay of power relations between two specific 
discourses: the media discourse of news and the military discourse of dominance. I will focus on two theoretical approaches - framing and indexing - to explore how war reporting has occurred in a Canadian context: why the media uses the sources they do, construct the stories they do, and ultimately report on international conflicts the way they do. I will investigate if embedding reporting has become a successful framing tool designed to rally the media and, by extension, the public in support of the Afghanistan War. A detailed methodological approach will be provided within the next three chapters. 


\section{CHAPTER THREE: CANADA'S INVOLVEMENT IN AFGHANISTAN}

Afghanistan, "Graveyard of Empires” (Bearden 2001), is an unlikely candidate for the world's focus, let alone Canadian troop involvement for roughly 10 years. This overview will seek to explain why and how a war on the other side of the world cost Canadians at least $\$ 18$ billion (Globe and Mail 2014), caused the deaths of 158 military personnel, and still requires Canadian troops to protect the Ambassador and staff at the embassy in the capital, Kabul. Following are several key fundamentals of Afghan history, culture, and governance that briefly describe the environment into which Canadian military personnel were introduced in late 2001, accompanied by select geopolitical and domestic factors that influenced Canada's decision to join the conflict, what that involvement entailed, concluding with a brief examination of the embedded media program during the war.

Located in Central Asia, the landlocked and mountainous nation of disparate tribes, languages, and religions is roughly the size of Manitoba and slightly smaller than Texas. While blessed with natural riches - such as a robust agricultural production of fruits and nuts, and more recently recognized reserves of minerals and natural gas (Chossudovsky 2013) - a history of conquest dating back to Alexander the Great in 330 BC, up to and including invasions by the former Soviet Union in 1979, and again by the United States and its allies in 2001, has contributed to today's extreme poverty, shady political manoeuvring, corruption at the highest levels, an illicit drug trade, ethnic and tribal factions, warlord brutality, and a lack of access to education, employment, and equality for women and girls. 
The dominant ethnic group is the Pashto-speaking Pashtuns, who account for roughly 42 percent of the population (CIA World Fact Book 2014) or 12 million; perhaps just as importantly, more than twice that number of Pashtuns live in neighbouring Pakistan, a factor that will be further addressed in the final chapter. Afghan Persian (Dari) is spoken by roughly half of the country's citizens, Pashto is spoken by 35 percent, predominantly in the south, while smaller groups throughout the country speak more than 70 other languages and dialects. The Pashtun "nation," which can trace its warrior heritage back to the days of Alexander the Great, is comprised of roughly 350 to more than 400 tribes and clans. Pashtuns are predominantly Sunni Muslims and their religious code, called Pashtunwali, is rooted in Mosaic Law and adheres to a decentralized form of governance, meaning that no single person can rule and/or interpret the Word of God.

Roughly 80 percent of the country's population lives in rural areas (World Bank 2011), essentially rendering Kabul politically impotent in terms of exercising control over tribes in the countryside. As a result, power is often shared on a de facto basis. Pashtun government is based on the collective wisdom of the men of the jirga, an assembly of tribal elders called to render tribal or intertribal decisions. For major or far-reaching issues, such as adopting a constitution, a loya jirga or grand council is consulted. For example, during recent negotiations between Afghanistan and the U.S. on the Bilateral Security Agreement (BSA) - a document designed to extend access to U.S. forces to military bases in post-2014 Afghanistan - Afghan President Hamid Karzai consulted with the loya jirga in Kabul. ${ }^{23}$ 
Prior to 2001, Canada's involvement with Afghanistan was limited. Diplomatic relations were first established in 1968 to help coordinate humanitarian and development work in response to a series of natural disasters. These diplomatic ties were severed when the Soviet Union invaded Afghanistan in 1979 (Phillips 2008). Following the Soviet withdrawal from Afghanistan, the Canadian military shared its expertise in land-mine detection and clearance to a limited degree between 1985 and 1991, while the Canadian government provided humanitarian and food assistance through both international and domestic agencies between 1990 and 2001 (Pigott 2007, 79). Prior to September 2001, not only were Canadians advised to avoid travelling to Afghanistan, any problems that might have arisen were directed to the Canadian High Commission located in Islamabad, Pakistan, the closest official Canadian presence.

\subsection{Why Canada became involved}

As noted in chapter 1, soon after 9/11, the U.S. invaded Afghanistan and coordinated warfare efforts with members of the Northern Alliance ${ }^{24}$ to remove the Taliban regime, which had allowed al-Qaeda to operate training camps within Afghanistan. By the end of 2001, the Taliban regime had lost control of most of the territory it had held since 1996 and its leadership was presumed dead or to have had escaped across the border into Pakistan's tribal areas. U.S. forces and NATO allies such as Canada remained in Afghanistan to support the then-fledgling regime of President Hamid Karzai, a Pashtun of 
the influential Popalzai clan who hails from a family that has royalist sympathies (Pigott 2007, 61).

Post 9/11 events have led to new geopolitical efforts for control and influence in the region (Cooley 2012, 53). Many commentators have compared these political machinations to the Great Game that was played out by the Russians and British in the $19^{\text {th }}$ century, or described them as part of a continuing or New Great Game with revised and occasionally additional players (Klass 1987; Rashid 2002; Edwards 2003; Menon 2003; Kaylan 2008; Ivens 2010; Songh 2010; Walberg 2011). One could even hypothesize that a previously imperialistic Great Game has evolved into a more complicated international jockeying for energy resources, military positioning, and constant maneuvering for strategic advantages between the world's "superpowers" and emerging regional powers. Perhaps a better moniker than "Great Game" is now needed.

Why did Canada respond so positively and relatively quickly to the American call to arms in a post 9/11 world? There were at least three reasons: one, an immediate emotional reaction to the 9/11 attacks that killed almost 3,000 victims, including 24 Canadians (Granatstein and Oliver 2011, 4); two, a perceived and pressing need for a diplomatic and political response from the U.S.'s closest neighbor and largest trading partner; and three, a subsequent military agenda conceptualized and forcefully promoted by General Rick Hillier, who was determined to transform Canada's military while simultaneously increasing its profile, credibility, and influence. 
First, Canada's post-9/11 domestic mood was both outraged and sympathetic. Vigils were held across the country (Lennox 2009, 91). Prime Minister Chrétien decided, against the strong advice of his own security officials, to hold a massive outdoor rally on Parliament Hill in Ottawa so that Canadians could demonstrate their sympathy for the U.S. Three days after the attacks, the prime minister, Governor General Adrienne Clarkson, U.S. Ambassador Paul Cellucci, and other dignitaries joined roughly 100,000 people in an emotional remembrance ceremony (Goldenberg 2006, 261)

On 2 October 2001, NATO Secretary-General Lord Robertson invoked Article 5 of the Treaty of Washington - which states that any attack on a NATO nation launched from outside that nation shall be interpreted as an attack on all NATO nations - meaning that the 9/11 attacks justified a military response. Previously, Chrétien had gone on record before any other leader in calling for Article 5 to be invoked (Goldenberg 2006, 263). Canada's position was that "countering the terrorist threat, by foreclosing the regression of Afghanistan as a haven again for terrorists, is plainly one objective" (Manley 2008).

The second reason is that Afghanistan constituted a pivotal shift in Canadian thinking towards security. Prior to 2001, an emphasis on United Nations-related peacekeeping for which Lester B. Pearson won a Nobel Prize in 1957 - was a major component of the blueprint of "human security" that was heralded and pursued by Canadian Minister of Foreign Affairs Lloyd Axworthy from 1996 to 2000. In conjunction with these activities, Canadians came to see themselves as a "moral superpower" (James 2012, 6), a leader in efforts such as land-mine removal. However, it became increasingly clear during 
operations in Somalia ${ }^{25}$ and Bosnia in the early 1990s, where "peace building" and "peace making" were required rather than "peace keeping," that notable discrepancies existed between the demands being placed on the Canadian Forces (CF) and CF capacity for meeting those demands.

The American reaction to 9/11, President George W. Bush's call for a global War on Terror, loudly framed the attacks as an incipient assault by radical Islamists against all free nations of the world, particularly western nations. Notwithstanding the underlying causes of 9/11 that could be traced to years of imperialistic arrogance and interference by the U.S. in the Middle East, the attacks did constitute a very real and destructive threat to western nations, particularly those aligned with the U.S. Thus, moving into step with a War-on-Terror response not only rendered Canada's prior focus on "human security" as secondary to its more endangered need for "national security," but the subtlety of Canada's prior geopolitical approach to sustaining peace had become a luxury difficult to sustain during more imperiled times. Furthermore, without national security there could be no human security (James 2012), at least until the former was regained.

Beyond joining the international-support movement for the U.S. and overhauling its own approach to security, Canada also had domestic interests to consider and protect, most notably its trading status with its closest neighbor that is also a superpower. Canada and the U.S. share the longest international border in the world, about 300,000 people cross the border every day, and various estimates put the value of trade on the order of $\$ 1$ million per minute (Pigott 2007, 81). Canada's agenda from 9/11 onward focused on 
keeping that border open (Stein and Lang 2007, 6). Immediately following the attacks, there was a brief border closure, and a number of American politicians loudly asserted that the hijackers had used a porous Canadian border to further their plans. Certain domestic constituencies as well as the Canadian economy in general would have suffered considerably if the border were closed for any significant length of time.

The third reason for Canada's quick response is related to long-held beliefs that Canada's "human security" focus had served to minimize its military operations, and that Canada's foreign policy had neglected the fundamental purpose of the CF. Developments cited as particularly troublesome were traced back to the mid-1960s: "unification, budget cuts, personnel reductions, bilingualism, social engineering, and a failure to renew equipment [that] gradually broke down morale and sapped professionalism" (Granatstein 2002, 42223). The CF were seen by many as more bureaucratic than a fighting force at any respectable level of readiness. As noted previously, Hillier was a major proponent of the need for fundamental changes in the CF: "The army and the rest of the Canadian Forces after decades of training, few operations, a Cold War, government inattention and being on the back burner in Canada - were becoming a bureaucratic organization, just another department of the Government of Canada, administered by managers, not leaders" (Hillier 2009, 47).

In short, Canada's profile was perceived as lacking the clout it deserved. While from a national perspective, Canada had made significant troop contributions to operations in Bosnia and Croatia during the mid-1990s, those troops had been so buried in 
multinational maneuvers that from an international perspective, Canada's contribution was almost invisible. According to Hillier: "We never did get full credit for those contributions because of the way we put them out the door. We did not have a decisive influence or decisive effect that led to a good influence for Canada in the Balkans. We had no major leadership positions, we did not have a chair at the table in defining how the Balkans would continue to be developed or what the international community was going to be doing there and it was very frustrating to all involved at the time" (Hobson 2006, 1). Hillier was very clear in his determination to change the status quo. "What we're looking for is the chance to have sufficient profile and therefore, with that, sufficient credibility ... that then gives us the opportunity to get leadership appointments and to influence and shape regions and populations in accordance with our interests and in accordance with our values" (Hobson 2006, 1).

Altogether, Afghanistan provided a window of opportunity to change Canada's reputation - at least among those who weighed Canada's military and spending and commitments against those of the U.S. - as a "free rider" (Stein and Lang 2007, 13). Canada's participation in fighting would allow "full engagement in international affairs in a manner befitting Canada's status as a member of the G8" (Sjolander 2009, 83), and also counter both domestic and foreign criticism of Canada's military (Welsh 2004, 15). 


\subsection{The evolution of military involvement}

The Canadian Forces' involvement in Afghanistan can be roughly divided into three time periods, albeit with some overlap due to the complexity of transitioning military missions and sometimes intersecting operations. Period I extended from the official beginning of the Afghanistan War during October 2001 through to June 2003. Period II extended from July 2003 through to February 2006 when Canadian troops were primarily stationed in Kabul. Period III began in March 2006, when the CF was primarily stationed in Kandahar province, up to December 2011, by which time most CF troops had withdrawn from Afghanistan, with the exception of Kabul.

On 20 September 2001, Minister of Defence Art Eggleton authorized CF members on military exchange programs to participate in operations responding to $9 / 11$; at roughly the same time, specific units began to receive warning orders about possible and imminent deployment to Afghanistan (James 2012, 17). On 7 October 2001, Chrétien ${ }^{26}$ announced Canada's support for Operation Enduring Freedom $(\mathrm{OEF})^{27}$ - an effort involving both the U.S. and the U.K., which began that same day - through Operation Apollo's contribution

of air, land, and seas forces. Politicians of all stripes generally agreed: in Parliament on 17 October 2001, a motion supporting international actions against terrorism passed 212 to 10 (Pigott 2007, 83; Government of Canada 2001).

Even though the Taliban were quickly routed from power in the late fall of 2001, maintaining security and rebuilding a nation proved much more difficult than expelling a 
misogynistic group of zealots who seemed to rapidly transform into more effective insurgents than leaders. According to Hillier $(2009,244)$, Canada had taken on more than it perhaps realized: "The government had so little understanding of things military that I don't believe it truly comprehended the mission to which it had just committed our soldiers, our first combat mission since the Korean War."

Operation Apollo officially began in October 2001 and lasted through to October 2003. In early December 2001, Canada's Joint Task Force 2 (JTF2), an elite military unit charged with carrying out special operations, secretly entered Afghanistan (Stein and Lang 2007, 11). The 40 soldiers worked in conjunction with the U.S. Task Force K-Bar to capture and/or kill Taliban and Al Queda fighters near Kandahar (Pigott 2007, 86). In January to February 2002, 750 Canadian soldiers from the Canadian Forces' $3^{\text {rd }}$ Battalion, Princess Patricia's Canadian Light Infantry (3 PPCLI) Battle Group became the first official Canadian Task Force to serve in Afghanistan (Pigott 2007, 88), part of a "stabilization force" working with the U.S. operation in Kandahar and reporting to the 101rst American Airborne Division.

From January 2002 through to July 2002, Lieutenant-Colonel Pat Stogran commanded the 3 PPCLI in Kandahar, Afghanistan, as part of the U.S.-led Task Force Rakkasan for a tour of duty that included hunting al-Qaeda terrorists in the mountains of Paktia, Zabul, and Kandahar provinces. After an operation to the infamous caves of the Tora Bora region in eastern Afghanistan, the first Canadian casualties occurred at the hands of two F-16 American pilots on 18 April 2002 during a botched training exercise at Tarnak 
Farm, once home to Osama bin Laden and subsequently used for training by Coalition forces: four 3 PPCLI soldiers were killed (Blatchford 2007, 43). This event had two profound effects on Canadians: one, it put Canadians on notice that Afghanistan was a war zone as opposed to a traditional peacekeeping mission; and two, it fed into a Canadian stereotype of Americans as trigger-happy (James 2007, 27). Although it is difficult to know for certain what impact this "friendly fire" incident had on ensuing Canadian decision-making - given that genuine concerns had been raised about the sustainability and training of CF forces - a month later, on 21 May 2002, the Chrétien government announced it would be bringing home CF troops that July and that they would not be replaced.

As Pigott $(2007,84)$ has pointed out, there have always been two distinct forces operating in Afghanistan: the American-led OEF, focusing on the routing of the Taliban and the capture of bin Laden, and the "coalition of the willing," which became the International Security Assistance Force (ISAF), the command of which was rotated among different nations on a six-month basis. Despite wariness of further commitment of CF troops to Afghanistan, Canada was even less interested in deploying troops to Iraq, a conflict that neither Chrétien nor the Canadian public seemed to support. Sentiment at the time was that "the Canadian government would do anything, commit troops anywhere, on almost any kind of mission, as long as it meant we could stay out of Iraq" (Hillier 2009, 262).

In September 2002, Canadian Defence Minister John McCallum learned that the U.S. wanted Canadian forces back in Kandahar (Stein and Lang 2007, 43). Although he was 
not yet Chief of the Defence Staff (CDS), and despite his deep concerns with the readiness of the troops and the sluggish decision-making process between Ottawa and the battlefield, Hillier (2009, 257-260) supported this choice. In a surprise to CF command, however, McCallum announced to the House of Commons in February 2003 that Canada would lead the ISAF mission in Kabul (CBC 2003), providing 1,900 troops and subsequently joined by the Department of Foreign Affairs and International Trade (DFAIT) and the Canadian International Development Agency (CIDA). Thus, the Canadian mission in Kabul represented a change in the previous trend toward a greater combat role (James 2007, 29), instead providing assistance to civilian infrastructure such as well-digging and repairing local buildings. NATO then took over responsibility for the ISAF mission on 16 April 2003 (Stein and Lang 2007, 95).

Period II corresponds roughly with Operation Athena, the official name of Canada's support given to both peace and combat missions ${ }^{28}$ under the auspices of NATO's ISAF operations in Afghanistan. While Operation Athena began in July 2003 and lasted through to October 2005, I have extended Period II until February 2006, which is when Operation Archer began in the Kandahar region. ${ }^{29}$ In Canada, Paul Martin (Liberal) became Prime Minister on 12 December 2003 (until 6 February 2006). In Afghanistan, while CF forces served as part of the NATO-led Kabul Multinational Brigade (KMNB), a new constitution was developed and then ratified (January 2004), and elections were held from 2004 to 2005: in December 2004, Hamid Karzai was inaugurated as President of the Islamic Republic of Afghanistan, and in 2005, delegates were elected to the national parliament and provincial councils. 
On 4 February 2005, Martin appointed Hillier as CDS; Hillier both embodied and stimulated "an important psychological shift both within the Canadian Forces and in the government's view of the military (Stein and Lang 2007, 157). On 13 February 2005, Defence Minister Bill Graham announced that Canada would move its forces from Kabul to Kandahar (James 2012, 31). That same month, ISAF initiated efforts to extend operations beyond Kabul with a focus on developing the country's government institutions, especially its national security forces, and joining with government and nongovernment organizations in rebuilding shattered communities. CF efforts focused once again on Kandahar province in the south, but with what was called a "Three-Block War" approach: military forces conducted humanitarian, peacekeeping/stabilization, and combat operations simultaneously on three separate city blocks (Dorn and Varey 2009). Canada also took command of the Kandahar Provincial Reconstruction Team (KPRT) during 2005.

Period III corresponds roughly with the launch of Operation Archer, the sequel to Athena, extending from March 2006 (Horn 2010, 22) as the CF both provided security and helped with reconstruction in Kandahar province, through the 2010 "surge" of American troops, and up to December 2011, by which time Canada had withdrawn the bulk of its troops from Afghanistan. ${ }^{30}$ Period III comprises the most complicated and wide-ranging of the three periods. Also in February 2006, Steven Harper (Conservative) became Prime Minister on 2 February. 
There were two major elements of importance to note during Period III: first, the presence and efforts of Canadian forces in Kandahar comprised the nation's first combat mission since Korea; ${ }^{31}$ second, the Canadian government also initiated and pursued what it called a "whole of government approach." These foci were governed by the over-arching "Afghanistan Compact," an agreement made by the Afghan government, key ministries and organizations with coalition forces operating in Afghanistan (NATO-led ISAF and $\mathrm{OEF}$ ), which was designed to enhance security, governance, and economic development in the nation according to prescribed goals or benchmarks (NATO 2006).

In terms of the first component, from February to November 2006, Brigadier-General David Fraser was in charge of a major offensive called Operation Medusa that began against insurgents in Kandahar province. Numerous Canadian casualties led to parliamentary debate, followed by the establishment of an independent examination of the war by former Liberal deputy Prime Minister John Manley, which led to the "Manley Report" $(2008)^{32}$, a key document that changed the course of the mission. One of its recommendations was that Canadian military focus should shift gradually from combat to training Afghan national-security forces. Shortly afterward, a confidence motion was passed in the House of Commons to keep Canadian soldiers in Kandahar only until 2011. ${ }^{33}$ As part of its final adieu to Afghanistan, Canada committed to conducting Operation Attention from 2011 to 2014, involving the maintenance of 950 CF military trainers and support personnel in the country to provide training and professionaldevelopment support to the national security forces of Afghanistan: the Afghan National Army (ANA), the Afghan Air Force (AAF), and the Afghan National Police (ANP). 
These operations largely shifted from Kandahar back to the relative safety of Kabul (NTM-A 2009).

The second component is related to another Manley Report recommendation, that of "integrated planning," the foundation of the previously mentioned "whole of government approach" that incorporated diplomats, development workers, law enforcement and corrections officers, and other civilians from the military, Foreign Affairs, the Canadian International Development Agency, and the Royal Canadian Mounted Police to aid in security and rebuilding efforts. The project was directed from Ottawa by a special Cabinet Committee on Afghanistan led by Foreign Affairs Minister Lawrence Cannon and encompassed several localized initiatives, some of which appeared in subsequent media coverage: the KPRT, which extended from August 2005 to August 2010; ${ }^{34}$ Task Force Kandahar, which extended from January 2006 to June $2011,{ }^{35}$ and the Operational Mentor and Liaison Team (OMLT), which operated from August 2006 to June 2011. ${ }^{36}$ As a result, three signature projects, carried out by PRTs, have continued past the departure of CF troops and are called "intended principal legacies" (James 2012, 55): the Dahla Dam and irrigation system, polio eradication, and education.

\subsection{The embedding of Canadian reporters in Afghanistan}

Despite Canada's international service record of, and national pride in, its peacekeeping abilities, the 1990s represented a difficult decade for the CF due to both military and public relations fiascos, which were accompanied by repeated cutbacks in government 
funding. In 1993, the murder of a Somali teenager by members of the Canadian Airborne Regiment as well as findings of a subsequent cover-up by Department of National Defence (DND) officials (Maclean's 1996) led to the disbanding of that unit. Low public esteem was further eroded by Canada's inaction during the Rwandan genocide in 1994; even though other countries had also failed to react, perhaps none held their peacekeeping abilities in such high esteem as Canada and, thus, were not as conspicuous (James 2012, 9). In 1995, the CF was once again rocked by reports of violent hazing incidents, and more serious reports of sexual assaults of CF members (Doyle Driedger et al. 1998).

Following 9/11, as noted earlier, members of JTF2 secretly entered Afghanistan in early December to hunt Taliban and al-Qaeda leadership, followed by regular CF troops in early 2002. Growing media and public interest in the movement of Special Forces and regular soldiers, as well as the large-scale relocations of navy, air and other equipment, meant that DND was attracting attention - certainly more positive than in recent years and needed effective public-affairs policies in place to manage that attention properly. According to DND Public Affairs officer Don Roy, author of the original CFMEP rules, public-affairs strategy had not been updated since the late 1980s, and in 2001 there existed no official policy for dealing with media in-theatre (cited in Price 2009, 40). In short, the Afghanistan War provided both an opportunity to improve the CF's previously sullied reputation while simultaneously allowing for the development and implementation of an embedded-reporting program. 
Initially, DND handled reporters on a case-by-case basis, and offered temporary placements when available and upon request (Roy, cited in Price 2009, 40). Given DND's limited but positive experiences with hosting journalists in Bosnia during the mid-1990s (Hobson 2007,7), CF military commanders were reportedly "quite open to doing so again in Afghanistan" (Janzen 2004, 43). Chief Public Affairs Officer Lieutenant-Colonel Christian Lemay explains that when the CF began to embed journalists with forces in 2002, it wrote the embedding agreement based on the American blueprint. Later, in 2003, when Canadians reporters were stationed with CF troops in Kabul, he said they "took the ISAF ground rules and Canadianized them" (Hobson 2011, 7). The rationales supporting the creation of the CFMEP rules ${ }^{37}$ were related to organizational, security and legal issues, journalists' safety and cost effectiveness for media organizations, and correction of "bad information" from secondary sources (Roy, cited in Price 2009, 42). Also according to Roy, the primary focus of the CFMEP guidelines was to ensure "operations security" or OPSEC (Price 2009, 43). In fact, OPSEC later turned out to the major bone of contention for embedded reporters.

From February to August 2002, the CF hosted approximately 20 to 30 Canadian journalists in Kandahar (Hobson 2007, 8), several months that correspond roughly with Period I as described earlier in this chapter. Reporters were initially given little access and even less information, according to Toronto Star Mitch Potter, writing "military officials ... are keeping us on a short leash" (2002). Restrictions were loosened, however, under the influence of 3PPCLI Commander Stogran who supported keeping the public informed and gave reporters access to his soldiers and operations. Shortly afterwards, the "friendly- 
fire" deaths of four Canadian soldiers due to U.S. F-16 airmen captivated both media and public attention for succeeding weeks, followed by Chrétien's declaration that CF troops would return to Canada in July 2002 and not be replaced.

Months later, as noted earlier, Chrétien announced in February 2003 that CF soldiers would be deployed to Kabul for Operation Athena. CFMEP rules were being updated by the Judge Advocate General in Ottawa, so embedded reporters were informally processed at Camp Julien in Kabul, according to Lt-Col. Lavoie (interviewed by Price 2009, 52). Media interest was at its peak during late August and early September 2003, when eight journalists representing five different agencies were embedded (Janzen 2004, 46). On one hand, some reporters were unhappy with their treatment, including Chris Wattie of the National Post:

Certain elements in the Prime Minister's Office, Privy Council Office, and Director General Public Affairs, both civilian and uniformed, opposed embedding from the beginning. Documents were delayed, our arrival on base was pushed back several times, and approvals were slow to arrive. After more than a week of stalling, the reporters actually organized a revolt.... (cited in Hobson 2007, 10).

On the other hand, Hobson critiqued media performance - both at Camp Julien and back in Canada - for concentrating on immediate physical elements of the mission as opposed to more strategic or theoretical concerns, such as "mission creep" - the expansion of a project or mission beyond its original goals - and its sustainment $(2007,10)$.

Defence Minister Bill Graham's announcement in February 2005 that Canada would double and move its forces in 2006 from "risk aversion" Kabul to Taliban-heavy 
Kandahar signaled the transition from Period II to III (Pigott 2007, 102-103). The move also triggered a new wave of interest in embedding, and the CFMEP was formally established in 2006. A visit by Harper and his entourage in March 2006 increased the number of Canadian reporters in Kandahar from 30 to almost 50 (according to PAO Rob Frank, cited in Price 2009, 57); and between January 2006 and mid-April 2007, 230 journalists embedded with the $\mathrm{CF}$, bringing the total to 40 different media outlets that had embedded reporters with the CF (Hobson 2007, 12). The CFMEP was once again revised for Joint Task Force Afghanistan, becoming more specific about what information could be released or not. The information considered sensitive for OPSEC included: specific details on troop strength and equipment, names of military installations or specific geographic locations of military units, information on ISAF or coalition special operations units, information regarding force protection measures, and the identity or specialist trades of soldiers who killed or injured anti-coalition militants. ${ }^{38}$

Transitioning into Period III of CF military engagement, there were two major developments vis-à-vis the embedded program. Previously, rules on independent transportation had been eased, treatment for unilateral journalists improved, and embedded journalists were allowed to terminate and reactivate their embedded status to cover events that did not involve the CF (Hadaway 2006, 128). This process was called "dis-embedding" (almost always followed by "re-embedding"). It was this last component, flexibility regarding embedded journalists' ability to disengage and re-engage from the program to cover non-military events, which greatly differentiated the Canadian program from its American counterpart and perhaps helped to provide greater context to 
resulting media coverage. While this development was largely due to a shortage of available vehicles in which members of the media could accompany patrols, it had the effect of allowing for greater independence in that embedded reporters could find their own drivers and "fixers." ${ }^{39}$ If they chose to dis-embed, reporters were simply required to inform their news desks in Canada as well as the public affairs team at the Kandahar Air Field (KAF), contact their fixer, and arrange for pick-up and private transportation out of the airfield. Once the gates closed, the reporter was considered to have dis-embedded and, upon return, re-embedded (Price 2009, 59).

The second development concerned growing frustration with the definition and implementation of OPSEC by military officials. On one hand, (DND 1997, 7), PAO policy states: "The public has a right of access to all unclassified information concerning the objective and activities of the army. Security should never be used as a reason to hide unclassified but embarrassing information." However, according to Hobson $(2011,6)$, "part of the problem stems from the fuzzy definition of operations security." In an interview with Hobson $(2011,6)$, Ottawa Citizen reporter David Pugliese agreed: "they should come up with one definition of operational security and stick to it. That's not what they're doing. The government invokes operational security it seems when they don't want to answer embarrassing questions." Canadian Press reporter Murray Brewster concurred: "The OPSEC rules have been a moving stick. Either you accept what they ask you to do, or you challenge it and you basically dare them to dis-embed you or to discipline you." He described his "first helicopter assault operation and the major who was leading it ... [who] gave us a little scrum. The public affairs officer was standing 
beside him. The pilot was very good ... very quotable and it was a lovely story and he was talking about how his mother was a holocaust survivor and how very proud she would be of his military service. This [PAO] captain interrupted this major and said, 'that's OPSEC. You can't talk about your family"' Hobson (2011, 7-9).

As Operation Archer extended into 2006 and beyond, suicide bombings and the use of improvised explosive devices (IEDs) by militants increased dramatically as the Taliban seemingly adopted terror tactics used by neighbouring Iraqi insurgents: in 2005, there were 21 suicide attacks, and in 2006 there were 141 suicide attacks, causing 1,166 casualties; similarly, there were 530 IED bombings in 2005 and 1,297 in 2006 (Ware 2014). These events had several consequences: military casualties caused the Canadian public to become painfully aware of the "warrior" rather than "peacekeeper" nature of the mission in Afghanistan, and to question what Canada was doing in Afghanistan in the first place; many reporters became more hesitant to venture "beyond the wire" of KAF and consequently focused much of their coverage on "ramp ceremonies" of soldiers lost in battle; and Canadian officials became increasingly frustrated with the media's focus on battle events versus reconstruction efforts that were underway at significant Canadian taxpayer expense - all of which will be addressed in further detail in chapters to follow.

\section{Conclusions}

The intent of this chapter was to provide an overview of the international, geopolitical, and domestic factors that led to the involvement of Canadian military forces in 
Afghanistan from 2001 to 2011, trailing through to 2014, as well as the development and implementation of the embedded program during the Afghanistan War. Such an overview is crucial to understanding how and why Canada became invested in such a distant and foreign country that most Canadians had even not heard of - other than in association with 9/11, al-Qaeda, Osama bin Laden, and the Taliban - when JTF2 forces were initially deployed in December 2001. The Canadian government and military involvement in Afghanistan led to hosting of Canadian journalists, first on a case-by-case basis and then housed predominantly under the auspices of the Canadian military's CFMEP - the latter scenario producing the bulk of media coverage that is the focus of my thesis.

I contend that the cumulative information provided in chapters 1, 2 and now $3-\mathrm{a}$ historical review of the origins and development of embedded reporting, a theoretical perspective on CDA, framing, and indexing, and a review of the realities of Canada's military and media involvement in Afghanistan - will serve to establish a firm foundation upon which I will build the remainder of my research. As noted, I have chosen to divide $\mathrm{CF}$ involvement into three periods, as these will cumulatively set the stage for an in-depth examination of: first, Canadian military/media relations during a critical decade in Afghanistan; second, the perception (and use) of embedded reporting that evolved from suspicion to acceptance and even expectation; and third, an evolving impact on media coverage of the war. I will conduct interviews with pertinent media, military, and political personnel in order to construct an insider's view on the embedding program's development, progress, and impact on individuals and policies most closely associated with it. I will also examine 10 years of media coverage, analyzing the impact the 
embedded program may have had on journalists' relaying of the war's details and

developments. The following three chapters will examine military/media relations in

Afghanistan from 2001 through to 2011 by focusing on, respectively: Canadian media

perspectives (chapter 4), Canadian military/government perspectives (chapter 5), and

Canadian media coverage (chapter 6).

\section{NOTES}

${ }^{23}$ The loya jirga voiced unanimous support for the signature of the BSA document, a recommendation that Karzai essentially ignored, but that is another story (Zimmerman 2014).

${ }^{24}$ While the Soviet-backed communist government struggled to maintain control in Kabul from 1989 to 1992, various mujahideen groups battled for control of the remainder of the country. In 1992, a coalition of seven mujahideen groups called the Mujahideen Government of the Islamic State of Afghanistan formed the government (Marsden 1998, 42). This mujahideen government in 1992 would later form the Northern Alliance, which fought a defensive war against the Taliban government.

${ }^{25}$ Furthermore, in 1993 Canada was rocked by the "Somalia Affair," a military scandal also referred to "Canada's national shame" (Valpy 2009). Two Canadian soldiers participating in humanitarian efforts in Somalia beat a Somali teenager to death - a crime documented by grisly photos - followed by charges that the armed-forces hierarchy tried to cover it up. The affair led to the disbanding of Canada's elite Canadian Airborne Regiment, greatly damaged the morale of the Canadian Forces, and scarred the previously stellar domestic and international reputation of Canadian soldiers.

${ }^{26}$ Jean Chrétien was the Liberal Prime Minister from before 11 September 2001 until 12 December 2003.

${ }^{27}$ There were always two separate yet conjoined forces operating in Afghanistan: the American's OEF, which was focused on the capture of Osama bin Laden, and the "coalition of the willing," which subsequently became the International Security Assistance Force (ISAF). Command of ISAF was to be rotated among different nations on a six-month basis.

${ }^{28}$ The Government of Canada designed Operation Athena as the military component of a "3D" engagement - Defence, Diplomacy, and Development - in Afghanistan that coordinated military and civilian efforts in an overseas missions for the first time (Lemay 2013).

${ }^{29}$ Canadian commands: From July to December 2003, Brigadier-General Peter Devlin commanded ISAF's KMNB. In August 2003, Major-General Andrew Leslie became Deputy Commander of ISAF in Kabul. From February to August 2004, General Rick Hillier commanded the NATO ISAF in Afghanistan. From January to July 2004, Brigadier-General Jocelyn Lacroix led the KMNB.

${ }^{30}$ By December 2008, the number of Canadian soldiers killed in Afghanistan increased to more than 100, becoming an issue that increasingly eroded Canadian support for the military mission.

${ }^{31}$ From February to November 2009, Brigadier-General Jonathan Vance served as Commander of all Canadian and NATO forces with Joint Task Force Afghanistan. From February to November 2009, Colonel Roch Lacroix served as Deputy Commander of Canadian and NATO Forces in Kandahar Province, working 
alongside Brig.-Gen. Vance. From November 2009 to May 2010, Brigadier-General Daniel Ménard was Commander of Task Force Kandahar until his removal for fraternization with a subordinate. During the interim, Brig.-Gen. Vance returned to command Task Force Kandahar until September 2010, when Brigadier-General Dean Milner became Commander of Joint Task Force Kandahar, and also supervised the winding down of Canadian operations there until July 2011. From July to December, Brigadier-General Charles Lamarre commanded the remaining Canadian Forces members in Afghanistan under the auspices of the Mission Transition Task Force (MTTF), responsible for concluding all aspects of the Canadian military mission in Kandahar Province by December 2011.

32 The Independent Panel on Canada's Future Role in Afghanistan- appointed by Harper in October 2007 to evaluate options - was led by former foreign affairs minister John Manley. Its evaluation becamse know as the Manley report, and made five recommendations (2008, 37-38):

1. Canada should assert a stronger and more disciplined diplomatic position regarding Afghanistan and the regional players. Specifically, Canada, in concert with key allies, should press for:

a. Early appointment of a high-level civilian representative of the UN Secretary-General to ensure greater coherence in the civilian and military effort in Afghanistan;

b. Early adoption by NATO of a comprehensive political-military plan to address security concerns and imbalances, especially the need for more troops to bolster security and expedite training and equipment for the Afghan National Security Forces;

c. Forceful representations with Afghanistan's neighbours, in particular with Pakistan, to reduce the risks posed to regional stability and security by recent developments in that country; and d. Concerted efforts by the Afghan government to improve governance by tackling corruption and ensuring basic services to the Afghan people, and pursuing some degree of political reconciliation in Afghanistan.

2. Canada should continue with its responsibility for security in Kandahar beyond February 2009, in a manner fully consistent with the UN mandate on Afghanistan, including its combat role, but with increasing emphasis on training the Afghan National Security Forces expeditiously to take lead responsibility for security in Kandahar and Afghanistan as a whole. As the Afghan National Security Forces gain capability, Canada's combat role should be significantly reduced.

- This commitment is contingent on the assignment of an additional battle group (of about 1,000 soldiers) to Kandahar by NATO and/or other allies before February 2009.

- To better ensure the safety and effectiveness of the Canadian contingent, the Government should also secure medium helicopter lift capacity and high-performance Unmanned Aerial Vehicles (UAVs) for intelligence, surveillance, and reconnaissance before February 2009.

3. Canada's contribution to the reconstruction and development of Afghanistan should be revamped giving higher priority than at present to direct, bilateral project assistance that addresses the immediate, practical needs of the Afghan people, especially in Kandahar province, as well as longer-term capacitybuilding. 4. The Government should systematically assess the effectiveness of Canadian contributions and the extent to which the benchmarks and timelines of the Afghanistan Compact have been met. Future commitments should be based on those assessments.

5. The Government should provide the public with franker and more frequent reporting on events in Afghanistan, offering more assessments of Canada's role and giving greater emphasis to the diplomatic and reconstruction efforts as well as those of the military.

${ }^{33}$ While the Canadian combat mission ended in July 2011, the Mission Termination and Transition team took over that same month, executing "close-out" activities until December 2011 (Lemay 2013).

${ }^{34}$ The KPRT concentrated on three specific projects: the Dahla Dam and irrigation system, education in the province, and eradication of polio. Note that PRTs were American in origin, once called Coalition Humanitarian Liaison Cells, that were established the U.S. military forces in early 2002 as part of OEF (Pigott 2007, 135). The Canadian PRT in Kandahar brought together elements from the Canadian Forces (CF), Foreign Affairs Canada (FAC), the Canadian International Development Agency (CIDA), and the Royal Canadian Mounted Police (RCMP). 
${ }^{35}$ The focus of Task Force Kandahar was on the localized development of Afghanistan's national security forces, and maintaining a safe and secure environment for development and capacity-building work to exist.

${ }^{36}$ The OMLT was comprised of multi-disciplinary NATO/ISAF soldiers who provided training, mentorship and liaison services to members of the Afghan National Army (ANA).

${ }^{37}$ There appear to be three sets of CFMEP rules: the Canadian Forces Media Embedding Program: Guidelines, Ground Rules and Documentation for Land-based Operations; the Canadian Forces Media Embedding Program: Guidelines, Ground Rules and Documentation for Her Majesty's Canadian Ships; and the Canadian Forces Media Embedding Program: Guidelines, ground rules and documentation for Joint Task Force Afghanistan. The Naval documents is not available, the other two are provided in the Appendices.

${ }^{38}$ According to personal correspondence with Chief PAO Lemay (25 April 2014): Task Force Afghanistan was a subordinate unit to Canadian Expeditionary Force Command (CEFCOM) - the unified command responsible for all CF international operations - and would have written their own tactical implementation plan based on higher orders/guidance, turning those into their own plan, order. "But it was always based on the Land embedded programme and also must have incorporated ISAF HQ specific things like reporter accreditation, access to camps, etc., also dictated by ISAF." (Still trying to acquire a copy.)

${ }^{39}$ In the context of foreign correspondence, especially in a hostile environment, a "fixer" is that person usually a local - who will set up interviews, interpret conversations, and provide links and leads to people and stories. 


\section{CHAPTER FOUR: MEDIA INTERVIEWS}

In order to gather real-world insights on the practice of embedded reporting, I conducted a series of interviews with journalists who had first-hand experience of reporting from Afghanistan: as an embedded reporter, a dis-embedded reporter, or both; as a unilateral reporter; or in atypical cases, all three. These interviews allowed me to collect an important body of material that prioritized the views of those most directly affected by the embedding process. Accordingly, I have chosen to let my interview subjects present their own narratives, briefly summarizing their comments at the end of this chapter, and later condensing and analyzing their comments in chapter 7. This approach has provided a means of obtaining what Fairclough (1992) calls "judgements about aspects of discourse samples in the corpus from 'panels' of people who are in some significant relation to the social practice in focus" (227) - in other words, comments from people who have 'walked the walk.' Their views complement interviews with members of the military and Canadian government personnel in chapter 5, and analysis of Canadian media coverage of the Afghanistan War in chapter 6, helping to elucidate my core query concerning the influence of an embed policy negotiated by two disparate cultures - the military and the media - a policy which ultimately favoured the military perspective, but not always in a manner the military appreciated. Finally, while chapter 6 concentrates on media coverage by representatives of print media (the Globe and Mail and La Presse) as well as television media (CBC and Télévision de Radio-Canada (SRC), this chapter goes beyond those four media entities by seeking out unilateral reporters who proved largely absent within that 
main body of analysis. A list of all interviewees for this chapter can be found in Appendix A.

While several studies have examined press coverage by embedded versus unilateral reporters, and fewer studies have allowed journalists to assess themselves, their reporting, and the reporting system, to my knowledge no studies have addressed long-term media coverage of the Afghanistan War by Canadian reporters, nor examined the framing of issues to the degree this research does, nor provided an opportunity for self-assessment of performance, particularly regarding issues of censorship and/or self-censorship. I also gathered information on several demographic characteristics, personal ideologies, experiences with military policy and personnel, general attitudes toward war reporting, and suggestions for the future. These elements were included in order to provide a broader assessment of key influences on the embedding process and outcomes, and furthermore to allow for insights regarding future developments. Finally, this chapter helps to fill a gap that exists regarding personal testimony from predominantly Canadian reporters who participated in, or observed from "outside the wire," the most comprehensive embedded program ever designed and maintained by the $\mathrm{CF}$.

\subsection{Methodology}

I interviewed 16 journalists who had covered the Afghanistan war from a story-telling perspective. Nine were print reporters (one also worked as a photojournalist), four delivered television news, and three worked in both print and television. Fourteen 
journalists worked in English media, one worked in the francophone media, and one worked in both official languages. Of the 16 who agreed to be interviewed, one journalist had been based in Washington, D.C. and had more of a policy or political orientation, while 15 had first-hand experience of reporting from Afghanistan: as an embedded reporter $(\mathrm{n}=2)$, an embedded/dis-embedded reporter $(\mathrm{n}=1)$, a unilateral reporter $(\mathrm{n}=3)$; both embedded and unilateral reporter $(n=5)$; or in some cases, all three $(n=4) \cdot{ }^{40}$ Three of the 16 remain posted overseas while the remainder reside in North America. Notably, of the $17 \mathrm{CBC} / \mathrm{SRC}$ reporters and anchor that I contacted for an interview, only seven agreed to be interviewed; of the remaining 10 , one noted that he had never directly covered Afghanistan, one declined for reasons of memory, one did not wish to "risk critical relationships with the military needed for future reporting," while the majority did not respond to my queries. On average, each interview lasted a minimum of one hour, and all were conducted between December 2015 and March 2016.

I utilized semi-structured interviews as well as partial transcription of the interviews: taking notes and making general observations throughout, but also taping the interviews in order to 1) maintain the accuracy of direct quotes and 2) keep a record of what was said for data-verification purposes. For telephone and Skype interviews, I took detailed notes on my laptop while also recording the interviews using Call Recorder. For in-person interviews, I took detailed notes on my laptop while recording the interviews using a personal mini-recorder or HT Recorder. In the two cases of email exchanges of questions/responses, the email responses serve as their own records of commentary. 
My initial contact list of journalists was gathered through analysis of media coverage of the Afghanistan mission, and further expanded through personal contacts, recommendations, introductions, document review, and presentation/conference attendance. First contact was an invitation email/letter, previously approved by the Carleton University Research Ethics Committee (Project number 103585), followed by two reminders, if necessary. If my invitation was accepted, I then sent a consent letter outlining the respondent's four quotation choices, which also required their signature, as well as a copy of my questionnaire for reasons of transparency and their preparation. Copies of each of the above documents are in the Appendices: Carleton research ethics approval (C), invitation letter (D), consent letter (E), and questionnaire (F).

Interviews either took place at the participant's choice of location or via Skype/telephone and, in two cases, via email. The consent form, in accordance with tri-council ethics regulations, confirmed that comments made in the interview would be attributed to the individual and/or their organization in the final dissertation, according to their quotation selection. Two individuals requested anonymity. All participants in this work agreed to their comments being used in the dissertation and signed the consent form. Participants were provided the option to stop the interview at any point or to request that any comments made be struck from the record. As the interviewer, I clarified that my research interest was to explore embedded reporting within a Canadian context in order to understand its use and development in Afghanistan as well as its placement within the larger framework of war/conflict journalism. Although an interview guide was developed, it was not adhered to strictly in each case as some themes and questions were more 
relevant in some circumstances than in others, and in some cases the respondent wished to digress. Interview questions were largely open-ended, allowing for participants to share their most pertinent insights and experiences about the experiences with and/or observations of embedded reporting.

\subsection{Results overview}

As noted earlier, I have chosen to allow the journalists to present their own narratives. I have included editorial commentary with each section, and will provide a brief analysis at the chapter's end, once the reader has had the opportunity to absorb the quotes. Further analysis will be provided in the Discussion chapter. As the reader will see, the majority of respondents supported the concept, design, and implementation of the CFMEP. The ability to dis-embed from the CFMEP - meaning, embedded journalists were allowed to terminate and reactivate their embedded status to travel "outside the wire" to cover events that did not involve the $\mathrm{CF}$ - was almost universally lauded as both a valuable component that allowed reporters to cover non-military issues of the war, and a feature of the program that positively distinguished it from other countries' embed programs. However, as noted in chapter 5, many government officials were highly disappointed that resulting non-military coverage rarely included civilian-supported diplomatic or development projects elsewhere in the country. A majority of journalists relayed positive experiences with the military during their embedded, dis-embedded and unilateral reporting; that said, response existed on a continuum ranging from effusive to distrustful. The main contention, as noted by Hobson $(2011,6)$ was the occasional "fuzzy definition of 
operations security." While operations security (OPSEC) was formerly laid out in military doctrine, a number of on-site reporters disagreed with its in-theatre interpretation and enforcement. The reporters' assessment of Canadian media coverage was mixed: the overall opinion was good, yet many felt there was too much emphasis on military operations instead of the wider effects of the war on Afghans; nonetheless, Canadian coverage was perceived as superior to that found in other countries. Interestingly, none of the reporters I spoke with felt their media organization provided excessive input regarding story direction or content, yet a number of military and civilian respondents in chapter 5 felt that reporters were mandated by their Toronto bosses to provide a "death watch," meaning, concentrate their reports on soldier fatalities.

\subsection{Demographics}

The majority of the respondents were between 45 and 75 years of age; only three were in their thirties. Three of the 16 journalists were female, 13 male. When disclosed, personal political ideologies ranged from "left of center" to "small C conservative," with "pragmatism" being mentioned more than once. Education ranged from high school $(\mathrm{n}=1)$ to college $(\mathrm{n}=1)$ to university $(\mathrm{n}=14),{ }^{41}$ which included five master's degrees and one honorary Ph.D. Respondents possessed a wealth of media experience, ranging from nine to $50+$ years of reporting, a majority of which comprised foreign-news and conflict reporting, and covering wars zones that extended from Northern Ireland to Somalia, from Yugoslavia to Afghanistan, and from Iraq to the ongoing war in Darfur. 


\subsection{In their own words: the embedded, dis-embedded, or unilateral experience}

Following are the responses given by 16 Canadian war correspondents to questions regarding their reporting experiences while covering Canada's role in the Afghanistan mission. As noted earlier, I have tried to insert myself at a minimum, instead letting the journalists present their own narrative. One more housekeeping note: while the CFMEP was formally established in 2006, several reporters were closely housed with the CF as early as 2002, when then-prime minister Paul Martin ordered Lt.-Col. Pat Stogran to lead Canada's first contingent in Kandahar Province.

\subsubsection{To embed or not to embed?}

Postmedia's Mathew Fisher (personal communication, 5 February 2016) is Canada's longest serving foreign correspondent and "has embedded far more than any other Canadian journalist in Afghanistan." The Canadian military formally launched its embed program in Kandahar in 2006, and according to Fisher, "from 2006 ... to 2007 and 2008, between 10 and 15 journalists were always embedded in Kandahar to chronicle Canada's first major combat mission in half a century" (Fisher 2011). "Everyone wanted that stamp in their passport as a foreign news reporter, but quite quickly those numbers started to drop off, to eight or 10, then five or six, and then two by 2011" (pers. comm.). This was due to several reasons, the most influential of which were safety concerns for the reporters and the Canadian public's perceived lack of interest. 
Paul Watson, who Fisher calls “the Toronto Star's famously intrepid and incisive Pulitzer Prize winner" (Fisher 2011), is less enthusiastic about the concept of embedded reporting. "I was only embedded in 2010 briefly because the Toronto Star had asked me to go back to Afghanistan," he said (pers. comm., 8 March 2016). "The whole game [of embedding] was to get journalists locked into a system so they will just behave and tell the stories the government wanted to be told. There was so much more to be told, and still is."

Graduating in 2006 from the political studies program at Queen's University, Matthieu Aikins began reporting from Afghanistan in 2008 for Harper's Magazine, Rolling Stone, The New Yorker, The Atlantic, The Walrus, and the Globe and Mail. "In my case, I did both embedded and unembedded reporting, so it was easier for me to grasp the trade-offs of those arrangements," he said (pers. comm., 9 February 2016). "My experiences were quite different form the vast majority of reporters in Afghanistan. Most journalists travelled there as apart of the embedded program but I did not. I was living there, and I would embed only to report on certain stories [that required that approach.]"

At a further distance on the spectrum is journalist, writer, and producer Edward Girardet, author of Killing the Cranes: A Reporter's Journey through Three Decades of War in Afghanistan. Girardet began reporting from Afghanistan in 1979, just before the Soviet invasion of the country and, while he never formally embedded with a military force, he would speak with soldiers through chance encounters during his travels. "I have nothing against embedding as long as journalists go beyond and cover the war from the civilian point of view because you need to go and cover all sides of the war," he said (pers. 
comm., 27 February 2016). "You have a lot of restrictions with the military and understandably you are with people like yourself, so you are really seeing the war from the same perspective. I know that some people would embed and then go outside to cover other issues and I think that's the way to do it, to cover a war from both sides." Girardet also "embedded" or travelled or with the mujahideen during his time in Afghanistan and wryly noted the greater comfort levels that military embeds enjoy.

\subsubsection{Preparations}

Despite being embedded with a trained military unit, reporters are still at risk and according to veteran $\mathrm{CBC}$ reporter Brian Stewart, insurance companies are insisting on pre-embedding "boot camp" for reporters (pers. comm., 8 December 2015). Participation in a Hostile Environments and Emergency First Aid Training (HEFAT) course can last from two days to a week - covering a curriculum that might include instruction on risk assessment and planning, emergency first-aid, vehicle accidents, improvised stretchers and carriers, weapons and ballistics, risk reduction in terrorist and targeted environments, personal safety against sexual assault and hostile mobs, improvised explosive devices (IEDs), landmines and terrorist attacks, ordnance and combat hazards, checkpoints, evasion and escape, interrogations, kidnapping and surviving captivity - and with a price tag ranging from roughly $\$ 1,000$ to $\$ 3,000$. That cost is why journalists like Naheed Mustafa, an award-winning freelance broadcaster and writer, called the boot camp almost too expensive for freelancers (pers. comm., 26 January 2016). 
Apart from boot camp, some journalists engage in heavy research. "It is a constant," said Fisher. "I read almost every morning, four hours on international news, particularly regarding conflict zones, and have done so for many, many years." Girardet believes that both on-site absorption as well as preliminary work are crucial. "Before I left for a place like Angola, I would set aside time in a place like Geneva for two or three days so I could interview people at the Red Cross, the UN Human Rights Council or the WHO, collect readings, arrange meetings with local NGOs, etc. so that by the time I got to the field I would have all that information and conversations set up." He believes that the Soviet War in Afghanistan "was really the last war to do reporting properly, because when you went into Afghanistan at that time you were travelling and collecting a lot of information in your notebooks for up to six weeks, and so you had time to think and write." Today's immediacy of reporting has largely replaced that practice of reflection, he said, often leading to less depth and context in reports.

\subsubsection{Story wish list}

Some reporters went into Afghanistan wanting to cover certain stories, others expected the stories to present themselves. "I'm more of an on-the-ground guy," said Stephen Thorne, previously with the Canadian Press during the Afghanistan mission and now an Ottawa-based photographer (pers. comm., 24 January 2016). "But one of the stories I carried with me all the time was Afghanistan's recovery and Afghans' resilience." Similarly, CBC senior correspondent Susan Ormiston would have a wish list, "things I wished to explore depending on the temperature and the times, but always I would leave 
with a longer list” (pers. comm., 5 January 2016). "A huge benefit of greater experience on the ground is that your understanding grows exponentially, sometimes that list becomes unachievable, and you can sometimes want so much more than your editor does," she said.

Conversely, reporters like Christie Blatchford - formerly with the Globe and Mail and now the National Post - knew her "focus was not about Afghans but mostly about soldiers. I was aware that the purpose of the embedded program was to introduce the Canadian public to our soldiers" (pers. comm., 22 February 2016). Likewise, Mustafa and Stewart had a fairly clear idea of their story choices. "Typically my stories are either features or documentaries, so a lot of it is in place before I leave ... for example, interviews and locations," said Mustafa. Stewart would spend many weeks in advance on research and setting up appointments. He knew that he "wanted to see how the war was run, how the military was getting on with the government. I wanted to explain to the public how wars come about." He credited his former beat as a foreign affairs and military specialist with giving him an advantage in his preparations.

\subsubsection{Reports that were told}

"I was able to tell in an amusing fashion about the absolute boredom that comprises soldiering, driving around, bullshitting and talking," said Blatchford. "But also I was in a three-day gunfight in which a Canadian soldier was killed practically in front of my eyes, and I wrote about that too. I certainly came to understand what it was like to be really 
frightened." Aikins noted that it was natural that when a reporter embeds, "the stories you are able to tell best are the ones from the military's perspective; in that sense you are kind of restricted in the stories you are able to tell. I think it's understood that embedding comes with certain costs and restrictions. You know you don't know certain things, but you don't know what they are ... it takes time and experience with the embedded program to know what you're missing out on." More to the point, said Patrick Brown, reporting for both $\mathrm{CBC} / \mathrm{SRC}$ in Afghanistan and now an independent documentarymaker, "if you're embedded, you're stuck" (pers. comm., 3 February 2016). "You can't go to the hospital, you can't [investigate] the government, you can't go look at the drug trade, you can't say, 'oh, there's a big meeting with the tribal leaders.' But if you are not embedded, then you can't get close to the military. To embed and dis-embed is much better, but that doesn't always work in a battlefield situation."

Ormiston felt that while embedded she "was well briefed on the bigger picture, but what I wasn't getting was the nuance of the other side." Leaving the base with independent transportation and fixers allowed her and her team to "cover stories not related to the 'bang bang' and more related to 'whole of government' story. We got to talk to Kandaharees, which you can't do when you are embedded." Ormiston's view is shared by Michel Cormier, of Radio-Canada/CBC: "Les sujets sur les sources des conflits et ceux qui les vivent et en sont victimes sont toujours plus pertinentes que les récits des combats" (pers. comm., 22 February 2016). 
Outside the wire existed opportunities perceived as missing within the protective confines of embedding. "I was best at hanging around with tribal elders for three-hour tea sessions and figuring out some of the things that the military didn't know, or was reluctant to tell us," said one former Globe and Mail staff correspondent who did not wish to be identified (pers. comm., 31 December 2015). Watson concurred: "The best stories about Canadians in Kandahar were when I broke free and went to schools, for example, and documented how the money Canada was investing was basically being stolen by contractors, and the Canadian public didn't know this was happening to their tax dollars."

\subsubsection{Challenges recalled}

"It turned out that I am a coward," said the former Globe staff correspondent. "I disliked the bang-bang aspect of war reporting. Other people loved the adrenaline, but I was never one of those brave souls. So I found the front-line stuff a bit challenging." Even for those well entrenched within the fighting, "it was tough to report some of the stories that wouldn't reflect well on the guys," said Thorne. It was also tough speaking with Afghans with armed soldiers at your flank, Aikins noted: "speaking with Afghans while embedded doesn't really work because it's like going to a school and trying to talk to a class with the principal next to you."

Another issue was what Stewart called difficulties obtaining the truth from the base administrator in Kandahar when he pressed for information about firefights, maintaining that the Canadian public had a right to know about the dangers their soldiers were facing. 
In an article written after a Taliban rocket was fired into the Kandahar military base, he questioned the overly abundant use of OPSEC by the Harper government (2010). ${ }^{42}$

While acknowledging the use of what he called "stage-managing," David Common, currently host of CBC's World Report, said "going out with the soldiers led to 'raw' stories and there is value in that" (pers. comm., 11 December 2015). But in 2006 or so, he said, the CF decided they were not going to report fatalities of soldiers. "We had an incident and certainly some were wounded and/or killed, but suddenly no one got hurt anymore, so we were wondering what was going on. They would say there that nothing happened. Certainly there was a lack of information, and the message was very carefully managed. We knew of instances of the PMO and PCO trying to coordinate the message, not the [Afghanistan] Task Force ${ }^{43}$ simply because of the coordination of the message."

Beyond the conflict itself, daily life in Afghanistan presented challenges. "Everything moves much more slowly there," explained Canadian Press journalist Murray Brewster (pers. comm., 6 January 2016). "You can’t call someone when a bomb goes off, institutions are very weak, it's a completely different process of getting things done, and there were challenges related to our ability to move around because of the security concerns, which made it much more difficult to cover things. Also, from the military perspective, there was a vested interest in putting the best face on their activities, and if you asked uncomfortable questions they might eventually answer but as the war went on, there seemed to be much more political control and managing of the messaging." 
Watson agreed: "The politics of southern Afghanistan are complicated," he said. "There were clearly dirty deals done between Canadian Forces and civilians and local warlords, which - if Canadians fully understood - they would not be proud of." He referenced a recent article by Aikins (2016), which detailed a 16-year-old interpreter's relationship with U.S. Special Forces that helped turn him into an Afghan trucking-company owner earning more than $\$ 160,000,000$ during several years while contracting for the U.S. military. "Realists may tell you that you have to do deals in Afghanistan, but having spent a lot of time with Afghans, I know they are incensed with the level of corruption that came about after western influence grew. There was corruption before but it's through the roof now. Say what you will about the Taliban and how they treat women and their strict codes, but they don't tolerate corruption. We needed a lot more reporting on the corruption and less on the rah-rah storytelling of military escapades. Not to say Canadian soldiers were not brave, they were, but we needed to tell more about the local life of Afghans."

Not that dis-embedding or reporting as a unilateral would guarantee success. As Cormier noted, challenges included "la logistique, la difficulté de cueillir l'information; la fiabilité de l'information sur la situation générale du conflit, la préoccupation d'être fidèle au sujet, aux drames et qu'il soient compris de l'auditoire." Ormiston called it a constant challenge of "balancing risk versus reward. What is the importance of the story, its relevance to my audience, and the risk associated with it? You always ask yourself, should I stay 15 minutes longer, because that's a risk. Should I contact another person for an interview? That's a risk." 
Adding to an already complex environment, Afghan views and wants were often divorced from reality, explained Mustafa. "There's a certain kind of thinking, for example, when you talk to women - especially those who are poor and have little education - and you ask 'what do you see for your children in the future?' And they will ask for almost magical things, like I want them to be a doctor or an engineer. This makes it difficult to get at the real understanding of what a thing is. Nowadays people are more often saying that nothing can be salvaged, which is yet another extreme. What we really need is to be real about who is doing well and who is not doing well; just because it's not perfect doesn't mean there is no hope. However, I do believe there have to be local solutions, I think the 'pet project mentality' [such as Canada's signature undertaking, the Dahla Dam] has to end, and we have to make success about something originating from the [Afghan] ground up."

\subsubsection{Personal trials}

A number of reporters felt that practical matters such as logistics were their greatest personal challenges. "How do you get where you're going, who do you talk to, how do you file it?" said Fisher. "My first question is always about not where I'm headed or how am I going to get there, my first consideration is how am I going to file this story." Brown said that security and endurance could also test an embed's personal limits. "If you are a doctor, you see misery, an aid worker [poverty], as a reporter you see an ugly side of humanity. Problems began when we started to have relatively inexperienced people join 
in because they thought it was important for personal career enhancement and then they found themselves getting shot at and were not able to handle it."

There are also very real physical demands. "The time zone difference is a factor," said Brewster. ${ }^{44}$ "Your day begins there at 7:30 a.m. and your editors are not starting work until 5 p.m. your time, and you're dealing with questions until one in the morning, and if you do that seven days of the week, it's exhausting mentally and physically. It was an endurance test for me and my colleagues." Watson cited the physical impediment of a weak left hand that made travelling on forays difficult. "To travel with the troops you need to be physically fit and so I couldn't go out with the troops as often as I wanted in case something like an attack occurs and there is a need to escape," he said.

4.4.7 Does embedding facilitate micro-coverage at the expense of a broader view?

Canadian reporters who embedded seemed mindful of its limitations, and provided various perspectives on how they countered. "I was well aware of the narrowness of my view," said Blatchford. "The only danger of my kind of reporting is when you forget that you have the blinders on and that very few people are going to be straight with you. But I wasn't there to write the big picture of Afghanistan, I was there to write the story of the first conflict since Korea." While Fisher understood that a lot of journalists wanted to know the Afghan view of the war, he consciously chose to avoid that path. "In my opinion the Canadian public wanted to read about the Canadian soldiers; I could tell this from the feedback I received from the readers," he said. "The reality was that people are 
parochial, and the Canadian public was interested in what Canadian soldiers were doing and their interest was not about the suffering of the Afghan people."

"I felt that the embedding program was specifically designed to present the view of the ordinary soldier day to day," said Brewster, "designed to make the Canadian public fall in love with the Canadian soldier. The military wanted you to get out with the troops whether there was a story or not, but was not always sharing information regarding what was going on in other parts of the country. And you needed the military to cooperate with you if you wanted to tell the bigger picture; sometimes they did and sometimes not, so ... you could lose sight of what was going on."

"Basically you are a message in a bottle for as long as you are with them," observed Brown. 'It's just like MPs on Parliament Hill who don't have their peccadillos reported on if they have a good relationship with the media; reporters and politicians are together on the plane, at dinner, in the bar, etc., essentially you're embedded with each other and so there is this difficulty of turning yourself into an objective reporter because you are quite close to the people. I think the danger is that when you are committing yourself as a reporter to embed, you are dedicating yourself to a very narrow view of events, it gives you the illusion of being up and close and personal but really you have tunnel vision."

"I was naturally inclined to be patriotic, which is troubling to admit," said Watson, "but when you're with brave Canadians, and they are very brave people, walking patrols in Kandahar province, the tendency is to want to write about brave Canadians. Yet the 
danger of that is losing sight of what is not working, and more broadly, why the overall western military mission in Afghanistan was misguided or a mistake. It's simply human nature, not internal pressure - especially for a country like Canada because this service was so different for our country - to want to report on the bravery."

"You have to remember," added Aikins, "that while on the base you have no contact with the public, translators, the Afghan army, the police, only rarely with civilians, etc."

"It was crucial to dis-embed for this reason," added a current Globe and Mail correspondent who wished to remain anonymous. "Leaving the base really provided a much better understanding of the overall situation. For example, there was a day when the coalition force bombed a village that seemed to be full of innocent civilians, and I went to the hospital and interviewed people, which you could not do if you were sitting on the base all the time. The Canadians seemed to give more freedom to the journalists." Ormiston said that the media's relationship with the CF changed for the better over time. "Perhaps their change in tone came about because of experience, [or maybe] the military was learning what kind of beasts we were."

Two reporters who never embedded shared their perspectives. "What I observed was that some staff reporters were almost just following the Canadian military and weren't able or willing to get out and see other things like Graeme Smith did," said Mustafa. "This was partially because the security situation changed with time; it deteriorated, and then more limits were placed on reporters, then reporters started pooling resources, and so the 
reporting became uniform. Sometimes when I came back with a story, it was a challenge to pitch the story to editors [because] they had no sense of Kabul while the CF was in Kandahar, but the reality was that most of the country was safe. Furthermore, with the CF, there was a lot that didn't get reported, as the CF did a lot of things that made Afghans angry, so it was incomplete reporting, but almost certainly logistics were involved with that."

"I do have concerns that embedded reporters lose perspective," said David Halton, former foreign affairs correspondent for the CBC. "The hybrid option - embedded and disembedded - is probably the best option. That doesn't mean a good correspondent can't be at Kandahar Airfield and do good reporting, like Graeme Smith did, but there are additional pressures" (pers. comm., 18 December 2015).

\subsubsection{Dis-embedding without constraints}

None of the reporters I spoke with felt constricted in the stories they could address when dis-embedded from the CFMEP. "Yet you still had to be vigilant, careful, and follow strict protocols and not vary from them," said Brewster. "For example, depending on the security in town, you would go in with your fixer, and if the security situation was OK, you had your pre-arranged interview to do. You never show up on time, either 15 minutes before or half an hour later because someone might be waiting to kidnap you, because maybe someone has told a member of the Taliban about the interview, and afterwards 
maybe you stay for 20 minutes to an hour, and then leave regardless of whether you have got the full interview or not."

"In my opinion dis-embedded still means embedded, because you've signed an agreement," observed Ormiston. "It wasn't that we were able to report more critically but more accurately. And we were still under the umbrella, using their internet, for example. The big ugly question was 'what happens to the reporter who gets kidnapped, and what does the CF do about it?' The CF had no control over who we saw and what we heard; some of us might be influenced by people outside who were telling us inaccurate and biased information. A reporter still has to sift through the fog that exists on both sides."

Blatchford said she didn't feel particularly safe outside of the wire as a woman with blonde hair. One time she left to do a story but had to remain in the car for about 25 minutes, parked near a Ferris wheel, waiting for her fixer. By the time the fixer came back, the car had been surrounded by a group of males, ranging from boys to adults, and the mood had become menacing.

Speaking as an outlier among the journalists I interviewed, Fisher believes the Canadian military made a "huge mistake" by permitting dis-embedding. "They allowed some journalists to use the Kandahar airport as a hotel," he said. "They would eat military rations, stay in heated/air-conditioned tents, with the military providing water, shower and washing facilities, free cleaning of clothes, etc. They availed themselves of all of this and then went out and did reports from the perspective of the Taliban. I agree with the 
American approach of, when you are embedded, then you are embedded. Or if you have another way, like living in Kandahar and reporting from there, then you should do so. I think every journalist should be free to do what they want, but not to take advantage of the military systematically."

4.4.9 Exiting and re-entering the base

None of the reporters I spoke with felt that it was difficult to leave and then return to Kandahar Airfield. "I spent time with military forces from several countries, and was impressed by their hospitality, but the Canadian military stood above the rest because of its uniquely open system of embedding," wrote former Globe and Mail reporter Graeme Smith in The Dogs Are Eating Them Now. "Journalists could eat breakfast with the troops, walk off the base and have lunch with insurgents, then get back to the military mess hall for dinner. The fact that the Canadian military remained so helpful to journalists - in the face of political backlash - was a remarkable choice of principle over expediency" (Smith 2013, 289)

"In the early years, [embedding and dis-embedding] was really easy," added Brewster, "but the longer the war went on, and especially after the Americans came during the surge, it became much more difficult."

4.4.10 Danger "outside of the wire" 
"You are at the mercy of whomever you run into on the road," said Brown. "And frankly, military units have very little regard for journalists who are outside of their perimeter. There is a great deal of carelessness in the heat of a military movement and they don't really care about who is down there, reporter or otherwise. Your job [as a soldier] is to attack the enemy and protect yourself, and the complications of military-age men and women who may or may not be reporters is not really a main concern."

\subsubsection{Self-assessment of performance}

The majority of reporters I spoke with had few regrets about their performances. "I stayed as long as I could tolerate it," said Thorne, "but you're working seven days a week, I was burned out, and I missed my wife. You adapt to the idea that you have to watch where you walk, but it takes its toll on you." Brewster added that the quality of reporting "depended strictly on the year," he said "The longer I was there, the more institutional knowledge I had, and the more savvy I became about the stories I was covering and my ability to cover them and ferret out information."

\subsubsection{The unilateral perspective}

Those reporting as a unilateral strongly felt a greater sense of freedom to address stories. "Dans certaines situations, il est intéressant d'être intégré, par exemple pour raconter de l'intérieur la vie d'un soldat ou que la situation est tellement dangereuse qu'il faut la protection de l'armée," said Cormier. "J'ai toujours opté pour travailler indépendamment 
de l'armée. Je n'ai jamais non plus accepté de vivre sur les bases militaires. Cela nous donne une plus grande autonomie, une plus grande variété de sujets, un plus grand rayonnement dans le pays, et une indépendance par rapport à l'agenda de l'armée.

"Absolutely, and a greater responsibility also to protect myself," said Brown. "There are challenges too of running into combats, as none of these wars are single sided; you don't have two sides, you have multiple factions." Conversely, some reporters felt safer at a distance from the troops. "When you travel with the troops you are a target, the Taliban are looking to take you out," said Brewster. "When I was outside the wire, I felt a greater sense of security because I felt I had a little more control over my destiny."

"The very word 'unilateral' drives me nuts," said Watson. "Journalists need to be honest about this: the only reason you want to do this [job] is to tell the truth, and can you tell the truth if you sign a document that gives away your right to be a journalist? If I want to question the story about whether this western military intervention is succeeding in Afghanistan, or whether we are building a better country and winning hearts and minds, the answer is no, but it's very difficult to tell that truth when you are embedded."

\subsubsection{The importance of fixers}

Reporters I spoke with were almost unanimous in their view of the fixer as unsung hero. “The word 'fixer' really doesn't do justice to the role of Afghan journalists working with foreign media," said the former Globe staff correspondent. "They are the brains of the 
operation. It's a collaboration, but the international journalist is usually the minority partner."

“A fixer doesn't do much for you when you are embedded but they are essential when you are independent," said Aikins. "[They are] critical, in some ways the antidote to the embedded program," added Common. "Fixers are translator, guide, cultural advisor, our liaison with the community, whether ordinary people or the officials, and we couldn't have done our job without them," said Brewster. "The idea that a Canadian reporter who is not fluent in [Pashto and/or Dari] can go into a country like Afghanistan with its complexities and without a fixer is just ridiculous," said Brown. "Absolutely fundamental, I am nothing without the local people I have worked with," agreed Watson.

Blatchford recalled that one of her fixers was a medical doctor, "but he made more money as a fixer than as a doctor," she said. "I would think it would be very, very hard especially as a woman - to function without a fixer. Only once could I work without my fixer - a lovely afternoon interviewing Afghan women - because he was male."

"I think that fixers are particularly important for TV, but I would often prefer to do my own 'fixing,"” said Girardet, "because no matter what you do, get a visa, or drink tea, you are always learning something that could be useful. Sometimes I would find a local journalist who wanted to get out with me, and they would help with language or friends or local contacts and it would also serve as an ongoing training program for them." 
On the other hand, not everyone was fan. "I thought many of the fixers were untrustworthy and not very good, didn't understand journalism, and perhaps working with, or some were clearly in the pocket of, the Taliban," said Fisher. "I think that perhaps some of my colleagues were seduced by their fixers, plus, they were taking risks, and that's why I avoided most of them like the plague."

4.4.14 Would the journalists have changed anything?

"J'aurais tenté d'aller encore plus loin hors des sentiers battus pour raconter des histoires de vie de ces conflits," said Cormier. Similarly, Brewster wishes he would have "gambled a little more. There [were] some stories I wish I would have gone after," he said. "For example, we knew a lot more about what was going on with the corruption in Kandahar and other sorts of political things that we never got the chance to tell. I admire Graeme Smith, and I would follow that guy to the end of the earth because Graeme had the guts on at least two occasions - the detainees and the drug stories, two signature stories - to go out and just do it." Fisher wishes he would have pushed harder to leave Kandahar; he would have spent more time in Kabul, Helmand province, Kunduz, Herat, in order to "to get a better and bigger picture of the war."

Stewart wishes the system had been more transparent. "Very frequently officers and others would relay the terrible feeling that war was being run out of the PMO and not the Defence department," he said. "Requests for interviews with CF personnel always had to 
go through the PMO for approval ... the 'no dead bodies' rule probably came from the PMO too. ${ }^{\circ 5}$

"I wouldn't have risked my life like a fucking idiot," said the former Globe staff correspondent. "I'd have spent more time having long conversations far away from the front lines, and less time anywhere near the stuff that's exploding."

\subsubsection{How the CFMEP differed from other countries' embed programs}

"There was no formal embedding program when I first went out there in 2002," said Thorne. “They introduced one in Kabul but they didn't keep it very long as there weren't too many reporters going over there to cover [the troops]. The Americans were ramping up for Iraq. It was a different system, assigning reporters to different units, joining that unit in the States, and staying with them throughout their deployment. They were stuck with that one unit, no matter what, even if that meant being on an aircraft carrier for the whole time. The Canadian program was so very different. You probably had more opportunity to see action with the Americans, because you were assigned to a unit and that was where you stayed, whereas the Canadian system was more haphazard. But with the Canadian program, there was probably more freedom, as you could come and go."

The former Globe staff correspondent agreed. "The key difference [was] flexibility to embed and dis-embed at any time, sometimes several times a day," he said. "I probably wouldn't have been able to do my job without their flexibility. They knew it wasn't 
always in their best interests to have me walk off camp and talk to people they weren't thrilled with, but I said it's better than not having me report on them and what they were doing. Some nations were very restrictive, for example, the Dutch wouldn't allow full names of the soldiers to be used, and videos were checked before they left."

"[It seemed] our armed forces were less experienced than the Americans in dealing with the media," observed Ormiston. "The CF were pitching stories, for example, that we had already done, [they] were initially somewhat naïve and unaware of what we would consider good stories."

"I would suggest the Canadian program was far more open, less restrictive, and less managed," said Brewster. "[Until] things were going bad in 2007 and 2008. ${ }^{46}$ We saw the soldiers come in, but [officials] would present an insanely optimistic perspective of what was going on, partly for political reasons. They were horribly conscious of how unpopular the war had become [at home]; they had a lot to prove - that they weren't just peacekeepers, they knew how to fight - and any suggestion that things were going less than swimmingly was not tolerable."

“The Canadian program had a much more stable group of reporters," said Aikins, "a permanent rotation, slots for major media companies such as Canwest, Postmedia, Canadian Press, Globe and Mail, CBC, etc., so they all had someone there more or less all the time. Whereas the American programs would let a reporter come in for a set period of weeks and then go back to the U.S. As a result, the Canadians had people there for 
longer, they built a better knowledge of the military, a rapport with the Canadian military. I think this had pros and cons: people were maybe more knowledgeable about military operations, and probably had more support from their institution for being there; however, this arrangement built up a coziness between the embedded media and the military, kind of a group-think mentality that allowed for assumptions that weren't really challenged, what the mission was doing and how it worked. The program was also Kandahar-centred, and while that was important, it was just one part of the country."

"I can't compare [the programs]," said Blatchford, "but I think the CFMEP was terrific and gratifying. Canadians know little about their military. Most Canadians in urban Toronto have virtually no experience with the army, none at all. I found that soldiers are interesting, remarkably capable people, unlike us 'wusses' in Toronto ... imagine, they could fight and cook dinner over a crappy stove in the middle of the desert."

"In some ways [the CFMEP] was better, and worse," said Fisher. "It was better compared to the Brits; the British were very controlling, they wanted to see every story and video before published, or sent some on up 'for security reasons,' and the few civilians they had doing this for the Ministry of Defence didn't understand journalism. The Americans controlled far more than the Canadians, they were extremely rigid, and they objected very strenuously to the Canadian version of the embedded program, saying 'we give [the reporters] two weeks and that's it.' Their colonels would say to me, 'how do you get away with this, we give out two weeks, and you've been here for years?' But I think you need that time to see all the different aspects of aviation, ground, medical, etc. 
[Conversely,] the Canadians didn't really want you out in the field for long, most of the missions were only about a week at a time. Another reason Canadian reporters did not spend much time in the field was because they were on a 'permanent death watch,' and if you were out in the field you couldn't cover ramp ceremonies. But back in Canada, this turned the public against the war. The soldiers essentially died over and over again, in the field, loaded onto the plane at the ramp ceremony, on the road of the heroes, their own funeral ... each of those guys died four or five times. The Americans didn't allow journalists to attend ramp ceremonies, and they didn't think the Canadians should either."

\subsubsection{Whether or not the CFMEP should be continued}

The clear majority of reporters I spoke with felt the CFMEP should be continued. "Oui," said Cormier, "parfois, c'est la seule façon d'avoir accès à des zones de conflit. "Absolutely," said Blatchford. "I don't think that the news media should rely on it to tell the only story, but it's a useful framing." Akins agreed: "When the Canadian military has operations overseas, the media organizations have an obligation to report on those programs, but I don't think it's a substitute for independent reporting at all." Furthermore, added Mustafa, "there needs to be more transparency for embedded journalists in terms of what they are or are not allowed to report."

"The hybrid solution is the best option," said Halton. "You often have to get out of the embedded situation if you want to take an objective look or analysis of what is going on. 
Often you can see things that your army press officers do not want you to see or report on, such as civilian casualties, but it can be extremely dangerous for the reporters."

"The advantage of being embedded or accommodated is that it's very useful in terms of logistics, accommodations, transportation, etc.," said the current Globe and Mail correspondent. "If you can stay with the troops, it's helpful - and safer - but this can depend on the war. As a journalist, the ideal option is to have as much freedom, access, and movement as possible, but every military organization is going to try to limit you in some ways. Still, I didn't feel that restricted as I could get out of the wire. However, most of the other media - like CBC and CTV - did not go outside of the wire, they did not talk to victims, analysts, act as experienced observers outside. They said they did not do that because their bosses said it was too dangerous, 'you could get shot, so you have to stay on the base unless you go out with the troops.' [For example], when I went to interview survivors of a bombing, no other Canadian journalists went to the hospital, which meant they didn't get the full picture. I was struck by the fact that CBC and CTV reporters were mostly waiting for a debriefing from the military."

"The program should be continued because most other news agencies wouldn't cover wars unless they had an embed program," noted Watson. "But if they are going to run a program like that, they need to allow more self-responsibility on the part of the journalists. The journalists are there to cover a war; if some journalists prefer to stay in a tent, that's their choice, but if others prefer to go out, then let them go." 
"If another conflict came along like Afghanistan," opined Brewster, "I hope they would do it again, but I wouldn't hold my breath. The program in Kandahar did serve a purpose, telling how much [the soldiers] bled, and the conditions they lived in, it restored the reputation of the CF and took away the stain of the Somalia scandal. Now that the country loves the military again, they don't necessarily need us (the media) anymore. I used to joke with the soldiers that 'one day, you're going to be happy that there's a crazy-ass reporter in your corner and don't forget that.' Now look at the veterans' stories that are coming out now. I told them, 'remember that what I do for a living is one of the reasons you are over here fighting, you want the Afghans to have the rights that I have in order to report on you."”

"I'm really on the fence about this question," said Ormiston. "In some respects, it was the only way to reasonably get to the front lines for a large number of journalists. If you were to do that independently, you would have had to negotiate every single time, and that might have been unworkable. However, I see two issues. One, many, many journalists took the responsibility of only covering the stories that the military allowed them to. And two, the existence of an embed program - as well oiled as it was - meant that my editors could say that we were covering the Afghan War. But I would say, no we were not, we were covering the Canadian military in the Afghan war. There is a convenience in saying we were covering the war, but to do that effectively, you have to cover all sides. The embed program can provide some perspective, but I am pleased that I made the decision to operate unilaterally when I did." 
4.4.17 How journalists think the CFMEP should be changed

"I would devolve more decision-making to the media officers in the field," said the former Globe staff correspondent. "It was embarrassing how often they needed to wait for instructions from Canada. It was unclear, sometimes, where the orders were coming from." Thorne agrees: "I think their command on the ground should be in charge," he said. For the three deployments I was there for, I got to see three different modes of operations, and each command is very different from each other."

"It's really a matter of access," said Ormiston, "there was too little access to stories that, when told, can make a difference. Some reporters would spend weeks and weeks just on the base. Also, there was a fear of missing the story about casualties, I think that covering casualties had too much importance."

Watson had suggestions for all militaries, not just the CF. "I think it would be helpful to train whoever is in charge of permits or approving off-base trips so that they understand what journalists do," he said. "There is a sophisticated and unsophisticated way to work with the media; a more sophisticated way is to allow journalists to get the stories they want and for you to get the message out that you want. Let smart officers and smart soldiers talk to the journalists. The bureaucracy makes it too easy to just say no."

Brewster noted that everyone seemed to be in silos. "The British covered the British, the Canadians covered the Canadians, etc.," he said. "When the the Brits came into 
Kandahar, they said they had no idea of the numbers of casualties the Canadians had sustained. You have to be able to give the overall picture."

Blatchford believes the program should expand, and even have a domestic angle. "There should be more people coming through it," she said, "more people on ships, more people covering activity with ISIS. Maybe we should even have embedding with soldiers who are helping with the flooding of Red River in Manitoba."

"The program should not be continued in the way it exists now," countered Fisher. "It should be changed to have reporters strictly embed with the troops, so the public understands you are with the military, just like on a campaign bus. Also, the rules should be enforced. Some journalists reported on stuff they shouldn't have, and got second and third chances, and this should not have happened. There should also be vetting in terms of suitability, such as experience and mental-health status. War reporting is at the deep end of the pool; if people can't swim, they shouldn't dive in at the deep end of the pool."

Stewart suggested a post-conflict meeting between soldiers and journalists. "We need a detailed, lengthy post-mortem where people can list grievances and go over them," he said. "The Americans did this with their embed program and the media closely followed this issue, but to my knowledge the Canadians have not done this."

"Why not have a global program helping to send journalists out to cover both the military but also civil society as well?" asked Girardet. "You have a global fund for HIV, why not 
have global funding for bona fide journalists to cover conflicts? The idea is try to improve foreign reporting."

"I think that there should have been more of an organized attempt to do something for the local fixers and journalists in the program," said Akins, "who were kind of cut loose when the program came to an end. They weren't offered a place in Canada or education opportunities. For example, some of them went on to university programs in the U.S. because some media organizations in the U.S. helped them afterward, but that didn't really happen on the part of the Canadian media organizations."

\subsubsection{Summary}

As the preceding comments have illustrated, safety and mobility issues in a country like Afghanistan - which are genuine concerns and not just a matter of convenience and comfort - largely drive support for the CFMEP, both by reporters and media organizations. That said, journalists are hardly a homogenous group, as evidenced by the variety of views I encountered. Those who had embedded, and occasionally disembedded, perceived the CFMEP as a valuable tool in the arsenal of a reporter's handbag versus unilateral journalists who were more sceptical of perceived close ties between reporter and soldiers and the impact those ties might have on reporting contrary to military preferences. As noted by several respondents, the more experienced reporters would tend to dis-embed more than the less experienced reporters. Furthermore, it would seem that less experienced reporters - officially sent to Afghanistan as a reprieve for 
those reporters working that "hardship" posting and unofficially as part of a time-limited training program - were most at-risk of developing unobjective, even fawning, relationships with the soldiers - to the point of sometimes adopting military clothing and cultural perspectives. While every reporter I spoke with had considerable respect for and appreciation of the jobs that solders were required to do as part of the Afghanistan mission, there was also an underlying understanding by many of the need to maintain the emotional distance required to do the job the reporters were sent to do: report on the war, not just the military operations conducted during the war.

\subsection{The military experience}

\subsubsection{Expectations}

"Hollywood doesn't really prepare you for war," said the former Globe staff correspondent. Blatchford said she fully expected the experience to be scary: "It was far more frightening than I thought," she said, "but you suck it up and do the job." Ormiston called her time in Afghanistan "better than I expected, and my experiences had a 10-fold influence on my storytelling," she said. "The amount of ground truth that you can pick up when you are over there cannot be overstated."

4.5.2 Pros and cons of embedding with the $\mathrm{CF}$ 
The dominant pros cited by reporters were the flexibility of the CFMEP program, the security it afforded, and access. "The ability to travel to places you might not otherwise report on," said Ormiston, "and when you are with the military, you get that insight of what is happening at the moment." Common agreed: "access to a part of the story that Canadians are interested in," he said, "attachment to a very powerful and majestic force, where all your needs, such as medical care, are taken care of."

"If you are a reporter and you have a message to get out," said Brewster, "you've got a pipeline working for you right there. The obvious con [for the military] was that you do not control what the media write; this really grated on the nerves of some commanders, public affairs officers (PAOs), and strategic personnel.”

"The only con is if a media organization would use it as a sole form of reporting," emphasized Blatchford. "Its usefulness is less about portraying a conflict in its whole glory or tragedy, its usefulness is to introduce Canadian soldiers to members of the public. Its purpose sought to celebrate, and let ordinary reporters engage with, ordinary soldiers."

The major con cited was restriction. "A con is having your access restricted to any degree," said Common. "Stockholm syndrome, and wasting time," said the former Globe staff correspondent. In addition, added the current Globe correspondent, "there were agreements signed previously, and so you felt legally obliged to follow their orders," he said, "because it could have an impact on the paper's ability to embed reporters again." 
Embedded reporters such as Geoffrey York felt the Canadian military did try to steer coverage (Sheppard 2006): “The military control was greater than I expected," he said. “The censorship was tougher and more arbitrary than I had expected." During his onemonth stint in Afghanistan in May 2006, he recalled, "I experienced two clear attempts at censorship. The first case was a relatively unimportant story and I was able to write about it eventually. The second case was the attempt to suppress the photos of Canadian soldiers with Taliban prisoners. This was in my view a fairly important issue. I believe that Canadians have a right to see how their soldiers are detaining prisoners, because of the human-rights issues involved. But in this case ... we rejected the military's attempts to suppress the photos ... and we published the photos within a few hours. This actually shows that the military does not have full control of journalists, even in an embedded situation."

\subsubsection{Pros and cons of reporting as a unilateral reporter}

"When unilateral, you are able to get perspectives from the people you are trying to help much more readily and it's unfiltered," said Brewster. "For example, when you're embedded you're with the soldiers, in flack jackets and helmets, you're talking to local people and you will hear how great things are. But maybe you come back the next day unilaterally, and you will get a much different picture, one that's more honest, more direct." He relayed a story connected to a Canadian-led offensive in 2006 in Kandahar Province called Operation Medusa. "We followed people back to their homes after [an 
initial visit with CF soldiers,]" he said, "and they told us the commander had basically threatened them that if the Taliban came back, they (the villagers) would be punished."

"If you're stuck inside the wire, you are dependent on what they tell you in briefings, which can be limited and misleading," added the current Globe correspondent, "but if you are unilateral, you have much more freedom." Nonetheless, while unilaterals clearly valued the different perspectives and freedom that accompanied information gathering away from the $\mathrm{CF}$, none of them claimed this scenario would guarantee them the full and complete truth either.

\subsubsection{CFMEP policies}

"There are always problems with the way people interpret a policy," said Brown. "I was told all sorts of things were 'super secret,' which was complete nonsense, but there is only a limited amount that you can argue with them."

"It was a constant moving of the yardstick where OPSEC was concerned," added Brewster. "A quick example was when they tried to stop us from reporting where firefights and casualties had taken place. They told us we could only give the name of a place the size of New Brunswick because the Taliban might use the information, even though obviously the Taliban knew where they had fought. Later on they did not want us to report on casualties at all as they were trying to sanitize the war." 
"Definitely there is a policy to restrict journalists from controversial subjects and to redirect journalists to success stories," said Aikins. "There is always a tug of war, and at the end of the day the military could control where you could go. I remember trying to write about counter-insurgency and I wanted to go to an area of active combat operations, but they wanted me to go to a more pacified and secure area, like Deh-e-Bagh, where they can present the image they want to present." Pronounced "Dee-bah" and situated south of Kandahar, it was the poster child for the "model village" approach advanced by Brigadier-General Jonathan Vance, commander of the Canadian-led Task Force Kandahar for most of 2009 and again in 1010. The approach was a new kind of counterinsurgency action, embracing rural communities willing to receive enhanced security and small-scale community reconstruction, with the hope of enticing other communities to request similar improvements in exchange for a pledge to not protect insurgents. The CF was very proud of the project; journalists were largely skeptical because they felt they were being spoonfed an unrealistic version of Afghanistan.

\subsubsection{Personal difficulties due to OPSEC}

"OPSEC is the thing that is used both in reasonable situations," said Common, "and in situations where they don't want something known. OPSEC is a giant blanket the military can use to throw on things, because they define what it is. Sometimes it's very clear, sometimes it's not, sometimes it's ridiculous. For example, at Kandahar Airport, the camp was on one side and the Taliban would send rockets into the camp from rocks high above on the other side, using a timer, and 95 percent of the time it hit nothing. The one 
time it hit the mess tent, they didn't want us to report it because they argued it could help target the mess tent in future, but this was ridiculous because the Taliban literally set the rocket against a rock, put a timer on it, and ran away." ${ }^{, 47}$

Thorne concurs. "I understand that with OPSEC, you're talking about people's lives," he said, "but sometimes they would muddy the waters between OPSEC and politics. Back in 2002, it was the Canadians and Americans, and OPSEC could refer to how the Canadians would be perceived by the Americans and their relationship with them." He relayed one example when several American engineers were killed and, hearing the helicopters fly in, he took some photos but was detained and taken to the public relations tent. He then went back to his own tent and transmitted the photos to Toronto. "The next day they kicked me off the base," he said. "The American commander was furious there was a picture of an American in a body bag. Up to that point you only saw flag-covered coffins, but I had sent a photo of four field medics carrying a body bag."

Brown believes that transmitting certain information has the potential to be harmful. "The policy itself has to be that journalists and cameras do not have complete rein in a hostile environment," he said. "Nowadays these guerrilla units can get on the internet and see those photos, so we do have to understand security concerns, and most grown ups realize this point."

\subsubsection{Self censorship for any reason}


None of the reporters I spoke with engaged in what they would define as self-censorship.

"My inclination is to always push the envelope, but you still wake up in the morning and face the people you are living with," said Common. "There were probably times where I omitted some small detail, but the public always got the main story." Brewster spoke similarly: "The last thing you want to do is get someone killed," he said. "Did I ever keep verifiable, quotable information out of my stories because I was concerned? No. Did I play sometimes with the timing of the release of my stories because of someone's life? Most definitely." Blatchford recalled one time when she debated writing a story. "It was about an officer who had abandoned his troops under fire," she said. "I didn't want to write it, because I knew it would piss some people off, and it did, but I had to write the story. And the soldiers did talk to me about it."

"You were aware of OPSEC due to entering the program, and you had to respect it," observed Aikins, "but OPSEC also seemed to become sort of a privilege for certain reporters, to learn about things that were OPSEC. These reporters seemed to be given more access, so it almost divided the team of reporters. More conservative or pro-military reporters got a lot more access and got to speak with generals on the condition that they not speak about it. So OPSEC became a kind of currency. The military's definition of it became very broad, and it became almost internalized by some reporters in the program. This shows how embedding can require you to internalize various concepts." 
Blatchford seemed to be the only journalist I spoke with who faced no difficulties in having soldiers speak to her on the record: "Nope, not a one, they all spoke to me," she said. "A surprising number of people spoke to me about the [officer who had abandoned his troops under fire] and I didn't hang them out to dry.” This aligned with Geoffrey York's finding that "despite all the stonewalling instincts of their Ottawa masters, the Canadian soldiers were unable to suppress their own sincerity and honesty - their genuine belief that they were doing good work for humanity and the media should be allowed the freedom to see it" (2006).

Many of the others I spoke with encountered reticence if not outright distrust. "They almost all had to be approved by the PAOs," said Ormiston. Fisher believes that "Canadians are modest and shy and don't really want to talk that much, Americans are just more forthright by nature," he said. "Some soldiers also thought they were operating at top secret and couldn't talk about it." Aikins found that "soldiers were wary of the media, it wasn't easy for them," he said. "It was never exactly clear what the ground rules were, they would sometimes say you always had to have a PAO present, but that would be impossible in the field. Then if you were embedded and maybe built a rapport with a soldier and they commented to you on something, while you could publish off-the-record comments, if they went against OPSEC they could kick you out of the program." Brown believes that reticence is universal, "not everybody wants to stick their neck out," he said. "But it's not really so different than, for example, a factory-in-Mississauga story that might have problems getting workers to speak frankly." Watson's general feeling was that 
soldiers just didn't like journalists. "One of the most fundamental reasons is that the base is their home, and it's a culture, and you're not of that culture or tribe," he said. "People don't like being watched by outsiders, and nobody wants to get into trouble."

Cautiousness was similar if not intensified for unilateral reprorters. "Les militaires sont souvent méfiants des journalistes," said Cormier. “C'est un des désavantages de ne pas être intégré, les soldats ne nous connaissent pas."

\subsubsection{Working with PAOs}

Responses, and experiences, varied. "It was mixed," said Blatchford, "by and large pretty good, one guy was exceptional, a couple were dolts, one guy with the RCMP was terrific." Ormiston agreed: "It varied hugely by person, some really got it and were transparent and up front," she said, "others operated strictly by the book and did not understand the needs of a journalist." Brown noted that some individuals were "persnickety, but the same could be said about public relations people at the PMO or a large corporation," he said. "There's always a bit of an adverse relationship, we want to film everything and they don't want us to, they have their purpose and we have ours."

\subsubsection{Did PAOs provide sufficient information to reporters?}

"No, their job is often to prevent journalists from getting the whole story-and they did that, with smiles on their faces," said the former Globe staff correspondent. "I never 
blamed them." Watson agreed. "My suspicion is that they withheld a lot of information," he said, "and they certainly don't volunteer a lot of information."

"It depended on the tour," said Brewster, "and on the level of experience of the PAO as well as how they saw their role. You could have facilitators of information versus a tendency to want to dictate the story or protect the institution, meaning they were very guarded." Fisher said "the only people I would sometimes have problems were the junior PAOs because they were extremely risk-adverse."

"PAOs often had a limited view of the country," said Aikins, "because the reality was they were often people who never left the military base, they didn't speak the language, probably didn't know the culture, so what are they going to tell you?"

4.5.10 Did CFMEP policy rules match in-theatre practice?

"My feeling was that rules were briefly read once before going to Afghanistan and then Ottawa-led access took precedence," said Stewart. “'Sorry' and 'no' were the most common words I heard. Certainly the military can become 'soft tyrants' unless this is addressed properly, for example, OPSEC could be pulled down like a curtain."

"The application of the embed agreement changed over time," added Ormiston. "The scope of the embed program became so huge, and [reporters] who had no experience 
arrived, and you really didn't know them or how dependable they were. Having a surge of media can make for huge demands."

\subsubsection{Embedding with the U.S. military}

"American reporters are sometimes able to embed with U.S. Special Forces, which is never allowed in Canada - that's a big advantage for the Americans," said the former Globe staff correspondent. "But a huge disadvantage for an American embed is that you can't just walk off the base and conduct independent reporting. You're stuck with the Americans the whole time." When asked if reporters embedded with the Americans faced more restrictions on what they can report than those with the CFMEP, he responded:

"They were not so different from each other, both aimed at providing a lot of information about boring things, also about things that were crucial. Lying means you may get caught, that's a risk, but that's very different from not saying something."

\subsubsection{Summary}

As with most joint ventures, it is the people within the organizations that can make or break any given project. The military and journalism have very different cultures: one is extraordinarily structured, rule-oriented and often secretive, the other is anti-secrecy, must be able to adapt to and work within multiple scenarios, and takes pride in breaking or at least bending many rules. These differences are why the military/media relationship can be extremely fractious and why embedded reporting is often perceived with scepticism; 
the two ideologies are often diametrically opposed and so housing them together is fraught with risks. Nevertheless, some reporters developed particularly close relationships with soldiers and, frankly, viewed that as part of their job of reporting on Canadian soldiers for the Canadian public. Others saw the military as a participant in a professional relationship that naturally involved their withholding certain information, which was to be expected, and worked around if possible. None saw the CF as a nefarious force hellbent on conning reporters and/or manipulating them to do their bidding. All had profound respect for the soldiers. As briefly mentioned earlier in this chapter, and noted by several respondents, the largest speck in the eye of the embedding program seemed to be OPSEC: what existed in policy or print was not always interpreted by military personnel on the ground as reporters (and some government officials, as noted in chapter 5) thought it should be. Ultimately, the CF held the upper hand, as embedded reporters were housed on the base and had to adhere to rules that were prearranged. This would, of course, be irksome for individuals who had cut their journalism teeth on, and firmly believe in, questioning authority.

\subsection{Media coverage}

4.6.1 Canadian media coverage of the Afghanistan mission

Assessment of Canada's media coverage among the reporters I spoke with ranged from mixed to critical. "It was good," said Thorne, "but some political issues tended to get in the way of some of the coverage of that we were doing." Common also had a mixed 
opinion: "Sometimes it was superb and other times rather pedestrian," he said, "and I probably did both myself." Girardet thought the Toronto Star and Globe and Mail produced good reporting, "but you could see the restraints," he said. "Canadian reporting is pretty good, but still going downhill, and journalists are aware of this. Reporters have much more limited time to create stories. One of my main critiques is that mainstream media is too rushed and the quality of reporting has really gone down."

"I think Canadian coverage of the mission was generally good," said Aikins, "but the war was being covered without context, mostly just military operations. I don't think the general public really understood the whole picture because the media coverage wasn't really varied, with the exception of Paul Watson and Graeme Smith." Ormiston said she paid a lot of attention to media coverage, "and my opinion of Canadians' reaction to the Afghan war was that it was surprisingly small," she said, "and there was little debate among the public. There seemed to be a deliberate quieting of discussion from the government and, further, I think it's an unfair complaint from some quarters that the media only did a death watch.”

"My opinion of the coverage was that the Canadian public was well served in the first half of the war, but as events started to pile on one another, and we had the kidnapping of Melissa Fung and the death of Michelle Lang, the editorial restrictions imposed by Toronto - the media capital of the country - changed," said Brewster. "They started to become restricted to the point that it became very difficult to do anything other than the death watch at Kandahar Airport. From 2006 to 2011, the military will say there was too 
much ramp coverage. But not exactly; there was a lot of ramp coverage of the war but mostly by broadcast because very rarely did they get outside of the wire. For example, after Michelle Lang was killed, the $\mathrm{CBC}$ hire a security consultant in Toronto who would have to give permission to people back in Kandahar to go outside the wire."

Early in 2011, speaking on The Agenda with Steve Paikin, Fisher called a lot of the media coverage of Afghanistan "a disgrace ... with the notable exception of Christie Blatchford" (2011). His opinion has changed little: "Generally I was underwhelmed by it, I would call it pack journalism," he said. "Most of the journalists brought no understanding of military culture to the war and brought none of it back, they often didn't understand the different levels of officers, and many journalists were incurious of such things as the counterinsurgency operations (COIN) doctrine. ${ }^{48}$ So many of them had been trained on Parliament Hill and in 'gotcha journalism' and when they weren't doing that, it was very soft, gee-whiz journalism. They did not provide a compete picture for the Canadian public, and to this day the public hasn't been given a complete picture."

"We sucked a lot of the time," said the former Globe staff correspondent. "Security conditions were terrible, especially later in the mission, so that restricted coverage. Budgets were also reduced over the years, which tended to limit media operations."

"A lot of it was pretty superficial and simplistic," said Stewart, "with the exception of two reporters, Graeme Smith and Murray Brewster. “There wasn't enough big-picture or contextual reporting." 
Mustafa agreed. "In general terms, I thought it was pretty poor," she said. "It was too narrow a focus and didn't really tell us about what was going on in the country, except for people like Paul Watson, Murray Brewster, Graeme Smith, and Steve Chao. We still don't have any definitive accounting of the war, for example, 'how much did the war cost us?' 'How much is it going to cost veterans in terms of the price they are paying?' 'What have we left behind in Afghanistan?' Could we seriously say that we left things better?"

Mustafa added that it's all about messaging: "Whose job is it to counter what the government says?" she asked. "If media institutions are not willing to give an accurate picture of the reality of conditions in Afghanistan, or challenge the government's version, then who is going to do it? I understand the difficult logistics of reporting in Afghanistan, but I don't think most Canadians understand that the fighting was just a small component of what was happening in that country, and even today we don't really want to talk about the veterans. I think a lot of public opinion is top down, most people don't know there's a problem, and how are they going to know or understand that if you're not reporting on those problems?"

Watson was also critical of previous and current coverage. "I think Canadian journalism failed in Afghanistan, and has failed even worse after Canadian soldiers left," he said. "If you want to know what's going on in Afghanistan today, you have to read the New York Times. There just doesn't seem to be any coverage of Afghanistan now. Canadians died 
there, hundreds of millions of taxpayer dollars were spent there ... if you cover it, these issues will occur to people.”

\subsubsection{Print versus television media coverage}

"There was obviously a difference," said Ormiston. "It's definitely easier to cover war as a print journalist and describe your experiences, whereas with television you need to see. Afghanistan was a smorgasbord of beautiful pictures, and it was inherently frustrating that we couldn't jump out of the car and take an amazing picture, but it was too risky. The more you did it, the more you became a target." Ormiston related one time when she and her team were covering a market story, choosing one with openings at both ends for security reasons. "I literally jumped out, took off my burqa, did one take, and got the hell out of there," she said. "In times of conflict, 15 minutes of exposure is almost too much. This happened in Syria as well, I became quickly uncomfortable because you knew people were phoning in our location."

"There is always a difference," said Blatchford. "Lisa LaFlamme (with CTV News) was there and I thought she did an exceptionally good job. But I think that print almost always does a better job. When TV arrives, they don't just arrive, they change the air of where they are, whereas print never changes the air."

Halton believes that print coverage had a greater scope for nuance than television, "and reporters have a greater incentive to be embedded because of the visuals involved," he 
said. Stewart believes that " $\mathrm{CBC}$ and CTV documentaries were just as good as anything produced in print, [but] it's just more difficult to move around with equipment, it makes me more of a target." The former Globe staff correspondent agreed: "You can't wander into Kandahar with a big TV camera and maintain any semblance of a low profile," he said. "Print reporters can blend into the crowds a little more easily."

"TV is always a little more superficial," said Fisher. Thorne also thought that print was superior to broadcast. Both Mustafa and Watson noted that the only investigative work in Afghanistan seemed to be done in print. "TV can be very frustrating," observed Girardet. "TV producers are often very well informed but they have time constraints of one minute and 22 seconds."

\subsubsection{English versus French-language media coverage}

The greater number English-speaking journalists covering Afghanistan had a discernible impact on the quantity of coverage generated. "Beaucoup plus de journalistes de langue anglaises s'y sont rendus," noted Cormier. Brewster added: "Unless the Van Doos were in town, there was essentially no French coverage," he said.

In a 2011 commentary written on the Canadian media, Fisher remarked:

As for the French-Canadian media, they have shown as little interest in the Afghan war as they did in Canada's participation in the First World War, Second World War and the Korean War.

Although two French-Canadian generals have directed Task Force Kandahar, another French-Canadian general ran the war in the South in 2008, and three Van 
Doo battalions supported by other Quebec-based regiments have fought and died here, only a handful of French-Canadian journalists have shown up and none has stayed very long.

The almost total absence of journalists from Quebec throughout Canada's nearly decade-long involvement in Afghanistan is something that has deeply disappointed the French-speaking troops. They have often bitterly remarked that almost the only interviews they have ever given here have been in English, while networks such as Radio-Canada have spent years spending small fortunes covering events in Europe and the Middle East.

In terms of content, Thorne said that "by its nature, Quebec coverage is more questioning than English coverage." Fisher also noted differences: "The Ottawa pack was obsessed to try to find differences [in opinions] between a general and the ministers back home," he said. "The French would only cover the French units, they got close to people, and produced more intimate portraits."

4.6.4 Canadian media coverage over the duration of the Afghanistan mission

"The tone changed as people realized things weren't going well," said Halton. "As the casualties went up it became more negative. There seemed to be lots of bloodshed for freedom's sake, and then the Taliban came back after a while so it seemed almost pointless in terms of the deaths."

"Il y a eu deux phases," explained Cormier. "Le début de la guerre et la mission à Kaboul où il était relativement sécuritaire de travailler sans être intégrés et la mission à Kandahar où il fallait être intégrés. La première partie a donné du journalisme plus diversifié sur le 
pays alors que la deuxième partie s'est concentrée sur les combats et la vie sur la base ou un peu à Kandahar."

"There was a lot more coverage earlier than later," Fisher added, "and its tenor was out of whack with what was actually happening. The bad years were 2006, 2007, and 2008. I don't think the media really knew what Canada had done before, when Pat Stogran was there in 2002, and then the peace keeping mission in Kabul, and the training at the end."

"As the war became more taxing, in terms of death and the wounded, coverage became more skeptical," said Thorne. Ormiston agreed: "Coverage become more analytical and critical as time went on, and the lack of obvious positive results in terms of the big picture. Coverage also became more difficult as the government restricted information flow even further, they would not acknowledge negative news, and people tuned out because they had made up their minds in the last year or two that the war had become a futile effort." It was unclear if criticism preceded greater government restrictions on information flow, or vice versa, she said.

"Security concerns freaked everybody out," said the former Globe staff correspondent. "Friends died or were kidnapped. We all got a bit jaded." Blatchford thinks both the media and the Canadian public get tired and cynical about things that last more than a week. "We get bored first and then we ensure the public gets bored too," she said. 
"I find that international coverage overall has gotten much poorer and that goes for everybody but especially the CBC," said Brown. "So many of the reports are produced by people who are not actually in the place they are reporting on, largely due to the dwindling ability of mainstream media organizations to manage their economic plights. Mustafa said that coverage became more and more narrow. "Toward the end, $\mathrm{CBC}$ didn't even have a reporter there but just a videographer, who was certainly qualified but not a permanent reporter presence," she said.

4.6.5 Assessment of own media coverage of the Afghanistan mission "I'm very proud of what $C P$ did," said Brewster. "We were able to continue to tell the story all the way to the end. The breadth of our coverage was much more consistent than any other media organization in Canada because we were there all the time. Although we could have focused a little less on the day-to-day experiences or commodity news, and taken more chances with bigger stories, and deeper and long-term analysis, like Graeme Smith did.”

Both the former and current Globe reporters were content with their paper's performance. "The Canadians were closer to the front lines whereas most American organizations were operating out of Kabul bureaus that were farther from the action," said the former Globe reporter. "We did better than people who didn't even go there, and definitely better when we were able to get outside of the wire," added the current Globe reporter. 


\subsubsection{The reporters' reporter}

Graeme Smith was the journalist most often lauded for his reporting on Afghanistan, someone Stewart called "a classic example of becoming immersed in a country." Patrick Brown's work was likewise admired. Also, “Jojo was an amazing Afghan cameraman for CTV news, until he was killed," said the former Globe staff correspondent.

\subsubsection{Summary}

War reporting during a 10-year period is very likely going to be mixed, ranging from "superb" to "pedestrian," as one journalist called Canadian media coverage of the Afghanistan mission. Thematically speaking, there was a general awareness that much of the coverage became heavily military oriented - largely due to the environment within which the embedded reporters worked and were housed and transported - and this bothered some reporters more than others. Several thought it was simply the nature of the embedded program, and that an effort could be made to balance embedded reporting with alternate reporting - although who would coordinate this effort was unclear - that covered other aspects of the war such as its day-to-day impact on Afghans, diplomatic and development work, and local and international politics. Several found the military emphasis very disturbing because, one, it minimized a wider context deemed necessary for the Canadian public to understand why Canada had committed thousands of soldiers and millions of dollars to a country on the other side of the planet, and, two, it allowed 
participating media organizations to claim they were covering the Afghan War when, in fact, they were covering the Canadian military in the Afghan war.

\subsection{Editorial experience}

\subsubsection{Editorial support of reporters}

None of the reporters I spoke with seemed displeased with their media organization's support. “J'avais carte blanche puisque j'étais sur le terrain," said Cormier. Common covered the court marshal of the pilots that killed the CF soldiers in 2002. "Interest was extremely high at that point and I could do almost any story and it would get on the air," he said. "That evolved. When CF forces were moving large contingents, we followed their manoeuvres, and then when the warfare model changed to smaller, four-vehicle squads, the interest became a bit more body-count oriented."

4.7.2 Editorial interest in particular types of stories

The majority of the reporters I spoke with said they were not directed to cover particular stories. Cormier's editors were interested in "tout ce qui touche aux victimes de la guerre, à l'aspect humain du conflit," he said. Blatchford said "one of the great blessings of being in a war zone is that your editors can't reach you, and they don't try."

4.7.3 Which type of reporting could best criticize CF action? 
The reporters I spoke with were divided in opinion regarding which type of reporting embedded, dis-embedded, or unilateral - could best criticize CF action.

"Probably embedded because that's the only way to see what is going on," said Fisher. "If you are dis-embedded, it's very hard to report on something you've taken yourself away from, and the same is true in terms of being unilateral. I would say that both embedded and unilateral are vital, but to understand the military you have to be part of them, although it does give value to your reporting to be a unilateral and to hear what others are thinking and doing. But there are at least two issues with reporting as a unilateral: one, using fixers who were not professional and trustworthy, and two, it became hugely dangerous later on because the Taliban became much more dangerous, they would have killed you in 2006 just because you were white.” The former Globe staff correspondent agreed: "You almost needed to embed if you were going to criticize the CF because from the outside because it's hard to know if any particular action was CF or NATO."

"I would say dis-embedded because you have that freedom to go get the other side of the story, and only if you've heard all sides do you have the ability to criticize because you have an understanding of all or at least more of the issue," said Brewster. "Neither embedded nor unilateral and their specific vantage points will have the whole picture." Brown added that "access is key to all journalism, whether inside or out," he said. "There are certain kinds of military action that can only be criticized from the outside, like its 
impact on civilians, but there are also certain actions that can only be reported on from the inside, for example, the disbanding of the Canadian Airborne Regiment. ${ }^{\text {"49 }}$

"The best option would be a unilateral who has had experience reporting as embedded," said Mustafa, "so someone free enough to tell the story but who has also spent time up close." Watson agreed: "Without question, independent/unilateral reporting," he said, "but in order to fairly report about the CF you need to have access to them to test your assumptions. For example, misbehaving in villages would need be reported first from the Afghan side, and then you need to go to that unit and get their response." "Les unilatérales ont plus de latitude mais parfois moins d'information.," added Cormier.

\subsubsection{Summary}

The majority of the reporters I interviewed believed that a combination of insider and outsider perspectives were necessary to fully and accurately criticize CF actions and/or decisions. None of the reporters I spoke with felt they were directed by their front offices to cover soldier fatalities, dismissively referred to by some in the military as a "death watch." Certainly reporters noted a reduction in their mobility and therefore story outreach due to restrictions imposed by Toronto - what one reporter called "the media capital of the country" - following events such as the kidnapping of CBC's Mellissa Fung in 2008 and the increasing use of improvised explosive devices (IEDs), one of which killed Calgary Herald reporter Michelle Lang in 2009. There was no one type of reporting placement comprehensively viewed as superior: a number of reporters noted 
that both embedded and unilateral reporters have specific vantage points or access to sources and that both are needed for a whole picture: as one reporter said, "access is key to all journalism, whether inside or out" of the system.

\subsection{Advice for the future}

"My only comment is for those who consider embedded reporting: definitely do it," said Blatchford.

"There has to be a mix," said Ormiston, "the embed program has to be open enough ... in terms of access, but there also has to be another way of covering a war, it's not enough just to have embeds." Brown believes that both embedded and unilateral reporting are necessary. "As an organization, I think we have to do both," he said. "CBC has a constitutional duty to cover deployments, but for the audience, you also have to have people reporting independently as well as from the other side, in this case the Taliban. I think the uproar about [embedding] is nonsense, so-called consorting with the enemy. What could be more useful is having Canadian reporters reporting on all sides; I certainly did." Common also thinks a mix is best. "There is value to embedding as well as disembedding and unilateral reporting," he said. "However, embedding does not give you the same level of experience as a unilateral. For example, I would have trouble or pause to think about going into an active war zone with someone who has only been embedded because so much is taken care of for you, and experience in war reporting is something you acquire through living it." 
"A reporter should have the ability to get outside of the wire for a time," said the current Globe correspondent, "and not be dependent all the time on information that is just given to them. Being embedded certainly gives you a valuable perspective on the soldiers and patrols, but sitting in a tent and waiting for a briefing is not going to give you a good story. You need to go out and observe, think, and analyze. Embedding cannot be the only form of reporting, it's important to either dis-embed or also have unilateral reporters for balance." Thorne concurs: "Go out and do, don't just sit in the camp. And stop listening to briefings about operations that are already over, go see and do as much as you possibly can. I think that when it's feasible, you've got to press them all the time and never let them forget you're there, never let them relegate you to the sidelines in any way."

"Anybody who is going to go to a conflict zone and spend time with the military has to be very conscious of the relationship they are getting into," cautioned Mustafa. "They also need time away from the military, to get a sense of the broader picture outside of and around the military." Girardet also believes that if a reporter decides to embed, "at least try to find some time to get out and do some local reporting."

"There's only one thing you need to know to be a good war correspondent: all militaries lie," advised Watson. "If you're only going to write down what you're told, you're just a stenographer for propaganda. You need to question everything you're being told. There's no point being there if you're not going to report on all of it." "Il faut éviter le plus 
possible d'être intégrés," recommended Cormier. "Si on le fait, il faut maintenir une distance par rapport à l'agenda des militaires."

Both Stewart and Fisher felt that a stronger dedication to pertinent and prior research was needed. "Study the subject, military and war, just like politics if you're going to Ottawa as your beat," said Stewart. "There should be a 'war course' beforehand, as well as an intellectual interest in the subject." Fisher advised reporters to "try to find out what the hell you are doing before you get there," he said. "Most journalists never asked me for help or information, the only one who did contact me was Michelle Lang, asking what it was like in Afghanistan. Whether you are covering native issues, transportation, the environment, you should be prepared - this fundamental rule of journalism was ignored for Afghanistan. Many didn't go there to report the war, but to cover it as a political story, thinking 'what can I write that will have an impact on politics back home?' The truth is, [many] were out of their depth and sphere and comfort zone."

"Don't do it," said the former Globe staff correspondent. "Find a better job. I hear accountants live healthy long lives."

\subsection{Epilogue}

There were three commentaries that I believe deserve a separate mention. Below is a small portion of a three-hour interview with reporter Matthew Fisher that describes life on the base: 
In the beginning there was great enthusiasm, and then things soured. Most journalists didn't understand the danger they were getting into. In 2006, there were about 60 or 70 volunteers who badly wanted to get there, by 2010 only 4 or 5 went as volunteers, but others were strong armed by their companies. In 2006, they were all young and keen, by 2010/2011, these young and keen ones had pretty much disappeared.

I would guess I embedded 25-30 times, most everyone else six or 10 times, 290 embedded in total during the war, maybe 80 percent of them never came back a second time, even less a third time. After Michelle Lang's death in particular it became very hard to get journalists to go there, and some would only go out on combat missions if a helicopter would bring them [separately]. The whole embedding program was 'war journalism light.' You had a secure place to sleep, it was very comfortable, great communications, I had a wide-screen TV, four meals a day. We had a choice of six free restaurants - Burger King, Subway, Pizza Hut, TGIF, etc. - gymnasium, rowing machines, treadmills, shower facilities, plus 24-hour wifi and a telephone back to Canada that you could use if you wanted to. There are so many other ways to do it that are much tougher. So many journalists that went there thought they were war journalists but not really, the military treated them phenomenally well, and in fact created a culture of dependence. A lot of them thought that 'this was what war journalism is' and it's not ... it's about going out every day, and filing stories, finding out where the fighting is, etc. A lot of journalists would only take advantage of stories that were offered to them but would not go out and get the stories themselves. I'm saying many of the other journalists there didn't really know the realities of war journalism.

Naheed Mustafa on the media's legacy:

The practice of embedding in general serves a particular purpose, if you are reporting on troops then you have to be part of that program. My only criticism is how media programs used the program for reporting on the country and that was all they would do. I understand that journalism is a business, and there is a real cost associated with it, but it never felt like there was a serious conversation regarding the presence of media in the country. We have never talked about 'what is the legacy of the Canadian media presence in Afghanistan?' Frankly, the media presence itself was very thin. If you're going to be a country that invests in a war effort, then the media needs to really be there and not just at the mercy of the military.

Paul Watson on what seems like a forgotten war:

In my view, Canada is still invested in Afghanistan, we lost a lot of good people and spent a lot of money there. I'm frustrated that the media doesn't seem to care 
anymore now that the troops have left. I think this is partially because they only wanted to work with the care and protection of the military.

\section{Conclusions}

The intent of this chapter was to present the views of those with first-hand experience of reporting from Afghanistan: embedded reporters, dis-embedded reporters, those who did both, unilateral reporters, those who did all three. Sixteen interviews with a wide array of talented, experienced, and thoughtful reporters allowed me to collect a valuable body of material that has not heretofore existed. The testimony from these interviews comprises a significant part of this thesis' contribution to the literature.

The variable nature of journalism is simultaneously its strength and its conundrum.

Journalism means different things to people: a skill set, a craft, an art, a job, a pay cheque, a career, a calling. Someone who is content to cover a frivolous entertainment or fashion beat for a bi-monthly paycheque is going to have a very different perspective on the essence of journalism than someone who admires and wishes to emulate Hemingway's experiences as a reporter during the civil war in Spain. Foreign-news reporters are largely respected as a different breed of journalist - conflict reporters even more so. Watching a war unfold on the small or big screen is a very different experience than trying to perform as a professional reporter while contending with the piercing sounds, seeping wounds, pungent smells, and raging levels of cortisol that accompany warfare. In other words, the contributions of invested conflict reporters - whether embedded or not - provide us with important and necessary windows to pieces of a world most of us will never experience 
first hand; important and necessary to witness and possibly understand because wars happen when humanity fails to allow reason to rule hate.

I draw the distinction between an invested and experienced conflict reporter and those who are not because this was a subtle undercurrent that wove through a number of responses I received for this chapter, underlying several more major themes that will be discussed further below. As noted in this chapter, reporting from Afghanistan could be a gruelling, and dangerous, venture. There came a point when experienced reporters needed some form of respite. Reporting from Afghanistan was also perceived by some as a plum assignment, a proverbial feather in their journalistic cap. These two very different scenarios converged and led to an influx of inexperienced and/or under-qualified reporters into the CFMEP. As a result, according to several respondents, these reporters were less inclined to dis-embed, to seek alternative perspectives outside of the wire, to deeply probe or even question the stories provided to them by military sources, and more inclined to adopt the values and perspective of their military hosts. In short, they may have gone through the motions of textbook journalism but they did not genuinely attempt to delve beneath surface facts and report the whole picture.

On a more readily apparent level, there were several key themes that arose. The first was an acute awareness of the positive and negative attributes of embedded reporting. A minority of the reporters I spoke with were wholly accepting of the restricted scope of embedded reporting, with respect to primarily reporting on military matters and Canadian soldiers, firmly believing that this perspective was most important for, and wanted by, the 
Canadian public. A greater number of respondents felt that embedded reporting was an important tool in a reporter's handbag of many tools that could be buttressed by alternate forms of reporting. This commonality of acceptance was partly professional, employing available resources to provide the audience with what it was perceived to want, and predominantly practical, given the dangers of reporting from a country like Afghanistan. Embedding was a safer form of reporting from a war zone. Those reporters who were most suspicious and/or wary of embedded reporting tended to be more independent by nature, belonging to a critical school of thought that questioned authority much more readily than accepted it, and both accepted and prepared for the dangers of unilateral reporting.

Another key theme concerned the practice of dis-embedding from the CFMEP. A majority of reporters who responded were in favour of the practice, their support ranging from fervent to circumspect, which indicated an appreciation for the ability to seek out greater context, find different perspectives, and investigate the impact of a war on lives outside of the wire. Only one reporter was opposed to the practice of dis-embedding, and his objections seemed more about what he saw as taking advantage of military-provided comforts while 'consorting with the enemy' rather than providing that outside viewpoint.

Another theme of commentary concerned OPSEC. Commonalities included a general awareness and acceptance of the need for OPSEC, given that all parties were operating in a war zone, which necessitated caution in the name of security. However, commonalities devolved into differences when definitions of, and justifications for, restrictions became 
issues. A small but intense group of respondents felt that in-theatre interpretations of OPSEC were not always warranted. These differences in particular support my underling thesis argument concerning the in-theatre structural effects of a clash of two cultures: a journalistic desire to report events versus a military desire to enforce doctrine.

Praise for Canadian soldiers was another strong theme. Among the journalists I spoke with, there existed sincere respect that avoided descent into fawning. In fact, there was criticism, both muted and scathing, of those reporters who left behind their journalistic impartiality and became caught up in the exhilaration of battle. These differences point to the influence of a journalistic code held by the more experienced or, at the very least, those more strongly schooled in the concept of objectivity.

One last point, as I noted in my first chapter: contrary to the military's practice of analyzing what will and will not work, what has and has not worked, in effectively relaying its message, war correspondents do not seem to have a tradition of or 'guidebook' for passing on their valuable experiences. I find this somewhat peculiar, given journalism's very foundations in communication. In fact, it is unclear if any "debriefing" session or post-combat reporting program exists for war reporters, both in terms of sharing, analyzing, and learning from their experiences, let alone for dealing with any form of post-traumatic stress syndrome (PTSD) than can affect journalists and soldiers alike. 


\section{NOTES}

${ }^{40}$ Note: an embedded reporter is one who has signed an embed agreement, is living with the troops on base, and occasionally travelling with troops in convoys; a dis-embedded reporter has left the base, usually in the company of a fixer, and with the option of returning to the base or re-embedding; a unilateral or independent reporter has not signed an embed agreement, is not reporting from within the base or on a convoy, and almost always is working with a local fixer.

${ }^{41}$ Undergraduate journalism programs at Carleton and Ryerson universities were most often mentioned $(\mathrm{n}=7)$.

42 According to Hobson $(2011,1)$, the Department of National Defence defines Operations Security (OPSEC) as "the principle of safeguarding the integrity of a military operation or activity, and/or the safety of CF members and other personnel involved in the military operation or activity."

${ }^{43}$ The Afghanistan Task Force was responsible for inter-agency/department coordination and cooperation on Canadian diplomatic, deployment, and aid mission to Afghanistan. The task force was located within the Privy Council Office (PCO), and headed by former Foreign and Defence Policy Advisor and Associate Deputy Minister of Foreign Affairs David Mulroney. The task force was responsible for coordination between the principal departments of Foreign Affairs and International Trade (now Global Affairs), National Defence, and the Canadian International Development Agency in addition to other departments and agencies with some form of involvement, including the Royal Canadian Mounted Police and Correctional Service Canada.

${ }^{44}$ Kandahar is 8.5 hours ahead of Ottawa, Ontario.

${ }^{45}$ Stewart was referring to the Canadian government's decision to ban the media from covering the return of bodies of soldiers killed in the line of duty. Many in the media perceived this decision as a duplication of the Bush administration's ban, of images of the arrival of flag-draped coffins containing the remains of soldiers killed in Iraq, due to concern that such photographs would lower public support for the military campaign.

${ }^{46}$ Brewster was referring not only to the allegations that first arose in 2007 that the Canadian military was handing detainees over to the Afghan military without first making sure that they would not be abused, but also the high number of CF fatalities that occurred in $2007(n=30)$ and $2008(n=32)$, out of the total 158 fallen soldiers during the Afghanistan mission.

${ }^{47}$ Reference " 2 Canadians hurt in Kandahar rocket attack" (Common 2006).

${ }^{48}$ The COIN doctrine, also championed by U.S. General David Petraeus, views terrorism as a tactic rather than as a group's defining characteristic and, as a response, advocates an integrated and comprehensive military/economic/political strategy to delegitimize insurgent groups and prevent them from achieving their objectives (Kertzer 2008).

49 The Canadian Airborne Regiment (CAR) was disbanded in 1995 after the "Somalia Affair," a 1993 military scandal later dubbed "Canada's national shame." Plagued with problems even before it was sent overseas, the CAR's reputation was permanently stained following the discovery of the brutal beating to death of a Somali teenager at the hands of two Canadian soldiers participating in humanitarian efforts, followed by cover-up attempts. 


\section{CHAPTER FIVE: MILITARY/GOVERNMENT INTERVIEWS}

For this chapter, I interviewed military and government officials who had in-theatre contact with the media during the Afghanistan War. Eliciting their perspectives and experiences allowed me to compile a unique and important body of commentary from individuals responsible for developing and implementing the embed program, and/or working with reporters, embedded or otherwise, in a war zone. As in the preceding chapter, I have chosen to let my interview subjects present their own narratives, briefly summarizing their comments at the end of this chapter, and later condensing and analyzing their comments in chapter 7 . While embedded reporting has received both academic and popular attention, rarely has a spotlight been shone upon military and government officials working with embedded reporters. This chapter complements interviews with members of the Canadian and international media in chapter 4, as well as an analysis of Canadian media coverage of the Afghanistan War in chapter 6, to collectively provide a three-pronged perspective on the design, implementation, and results of the embedded program. This chapter further helps to elucidate my core query regarding the influence of an embed policy negotiated by two disparate cultures - the military and the media - a policy which ultimately led to an overwhelming focus on military rather than diplomatic and humanitarian activities, and particularly on military injuries, deaths, and ramp ceremonies. A list of all interviewees for this chapter, as well as their affiliations, can be found in Appendix B. 
As noted earlier, although several studies have examined press coverage by embedded versus unilateral reporters, and fewer studies have allowed journalists to assess themselves, their reporting, and the reporting system, to my knowledge, no studies have systematically addressed Canadian military/government perspectives on military/media relations, or more specifically, the structural influence of the embedding policy during the Afghanistan War on the content and emphases of ensuing media coverage. I also gathered information on several demographic characteristics, assessment of media coverage, and suggestions for the future. These elements were included in order to gather a broad spectrum of perspectives on the embedding process and outcomes, and also allow for insights regarding future developments.

\subsection{Methodology}

I interviewed 13 officials in total: seven current and former government officials, and six current and former military officials, all of whom had first-hand knowledge of and/or experience with the embedded program during the Afghanistan war. Their responses are merged in this chapter as the two professional Canadian contingents most likely to encounter and work with embedded, dis-embedded, and/or unilateral journalists during the mission. Five of the seven government officials who shared their views with me still work in government in one form or another, in Canada or abroad, ${ }^{50}$ one works with an international nonprofit, and one has moved to academia. Three of the six military officials are now retired, one remains in the military, one has moved to academia, and one has 
moved to media. On average, each interview lasted a minimum of one hour, and all were conducted between December 2015 and April 2016.

I utilized semi-structured interviews as well as partial transcription of the interviews: taking notes and making general observations throughout, but also taping the interviews in order to 1) maintain the accuracy of direct quotes and 2) keep a record of what was said for data verification purposes. For telephone and Skype interviews, I took detailed notes on my laptop while also recording the interviews using Call Recorder. For in-person interviews, I took detailed notes on my laptop while recording the interviews using a personal mini-recorder or HT Recorder. In the one case of an email exchange of questions/responses, the responses serve as their own record of commentary.

My initial list of government personnel and military officials to contact was gathered through analysis of media coverage of the Afghanistan mission, and further expanded through personal contacts, recommendations, introductions, document review, and presentation/conference attendance. Initial contact was an invitation email/letter, previously approved by the Carleton University Research Ethics Committee (Project number 103586), followed by two reminders, if necessary. If my invitation was accepted, I then sent a consent letter outlining the respondent's four quotation choices, which also required their signature, as well as a copy of my questionnaire for the purposes of transparency and their preparation. Copies of each of the above documents can be found in the Appendices - Carleton research ethics approval (G), invitation letter (D), consent 
letter (E), and questionnaire (F) - are located in Appendices. In addition, notice of CF research ethics approval is noted in Appendix I.

Interviews either took place at the participant's choice of location or via Skype/telephone and, in one case, via email. The consent form, in accordance with tri-council ethics regulations, confirmed that comments made in the interview would be attributed to the individual and/or their organization in the final dissertation, according to their quotation selection. Two government officials requested anonymity. All participants in this work agreed to their comments being used in the dissertation and signed the consent form. Participants were provided with the option to stop the interview at any point or to request that any comments made be struck from the record. As the interviewer, I clarified that my research interest was to explore embedded reporting within a Canadian context in order to understand its use and development in Afghanistan as well as its placement within the larger framework of war/conflict journalism. Although an interview guide was developed, it was not adhered to strictly in each and every case as some themes and questions were more relevant in some circumstances than in others, and in some cases the respondent wished to digress. Interview questions were largely open-ended, allowing for participants to share their most pertinent insights and experiences about their experiences with and/or observations of embedded reporting. 


\subsection{Results overview}

For the most part, I have chosen to allow the government and military officials to present their own narratives. I have included editorial commentary with each section, and will provide a brief analysis at the chapter's end, once the reader has had the opportunity to absorb the quotes. Further analysis will be provided in the Discussion chapter. As the reader will see, a clear majority of respondents believed that the purpose of the CFMEP was to simply report on Canada's mission in Afghanistan to the Canadian public. However, the definition of Canada's mission could be interpreted differently: although three formal components to the mission evolved, often called the 3D's - diplomacy, development, and defence - the last two received the majority of media coverage and, of the two, military-based stories certainly outweighed civilian or government official-based stories. While many journalists in chapter 4 highly valued the ability to dis-embed from the CFMEP to report from outside the wire, a number of officials - more government than military - were frustrated that few reporters seemed to take advantage of this option and, when they did, the resulting stories rarely included civilian-supported diplomatic or development projects elsewhere in the country. Both government and military officials also noted the effects of varied media experience on in-theatre behavior and treatment of civilian and military personnel, and on resulting media coverage. The majority of officials observed that media coverage sharply declined, along with the presence of media personnel, toward the latter part of the mission and that the accompanying tone became more critical and focused on ramp ceremonies. French-language media coverage was perceived as negligible, predominantly dependent on the presence of francophone troops. 
Several officials also cited frustration with Ottawa-based, top-down interference in the sharing of information by Afghanistan-based officials with the media-frustration directed at both CF public affairs and especially communications personnel in the PMO.

\subsection{Demographics}

The majority of the respondents were between 40 and 57 years of age; only one was in his thirties, and two were in their sixties. Four of the 13 officials were female, all government-employed while in Afghanistan, the remainder and all of the military officials were male. Education ranged from college $(n=1)$ to university $(n=12)$, including four master's degrees and one Ph.D. Respondents possessed a significant amount of experience working with the media in various capacities, ranging from 10 to 30 years.

\subsection{The other side of the coin: government and military officials speak}

Following are the responses given by 13 Canadian government and military officials to questions regarding their experiences working with members of the media - whether embedded, dis-embedded, or unilateral - covering Canada's role in the Afghanistan mission, as well as their views on the CFMEP. As in the previous chapter, I have tried to insert myself at a minimum, instead letting the officials present their own narrative.

\subsubsection{Perceived intent of the CFMEP}


The majority of the officials I spoke with, civilian and military, said the purpose of the CFMEP was simple: inform the Canadian public about Canada's mission in Afghanistan.

"The intent was to allow improved access to the mission, thereby improving reporting on the mission, therefore informing the Canadian public about the mission to a higher standard," said General Jonathan Vance, chief of defence staff, and former commander of the Canadian task force in Kandahar in 2009 and 2010 (pers. comm., 18 March 2016). "Transparency of the military to improve the accuracy of reporting was a theme."

Lieutenant Colonel Christian Lemay accumulated in-depth experience working with both domestic and foreign reporters as chief of public affairs from 2008 to 2012 with the Canadian Expeditionary Force Command (CEFCOM), the unified command responsible for all CF international operations, and subsequently as chief of public affairs and senior communications advisor at the Canadian Joint Operations Command (CJOC), which replaced CEFCOM in 2012. "I have managed all aspects of the CFMEP," he said, “implementing, adapting and coordinating the embedding and ensuring media ground rules were applied. In my view, the number one principle is to provide information to the [Canadian public about their] troops so it can better understand what the Canadian Armed Forces are doing on their behalf. By bringing reporters to live amongst the soldiers /sailors /airmen and to be part of operations, convoys, foot patrols, helicopter drops and anti-terrorist /piracy patrol at sea, we [offered] reporters the chance to witness the action instead of getting the story after the fact from someone who has been there during a technical briefing" (pers. comm., 6 February 2016). 
Katherine Heath-Eves was posted in Afghanistan from 2009 to 2010 with the Department of Foreign Affairs and International Trade Canada (DFAIT), which became Global Affairs in 2015. She was first based at Kandahar Airfield (KAF) and then the Kandahar Provincial Reconstruction Team (KPRT), ${ }^{51}$ the latter one of 25 provincial teams throughout Afghanistan designed to "facilitate delivery of reconstruction and development aid from a variety of international donors or contractors" (Cox 2007) to Afghans for local projects. "The embedded program is a really smart idea, designed to control the message on the part of the CF," she said. "It is the best way to bring in journalists to gain exposure to the mission, to showcase what they want to showcase, and to do it all safely. It allowed us civilians to have access to those embedded reporters, and to make inroads that we wouldn't have had otherwise" (pers. comm., 8 January 2016).

What soon became apparent during the interview process was discord regarding the very definition of the "mission" in Afghanistan. For many of the officials, there were two components to the mission - military and civilian - and the former often received media coverage in lieu of, or at the expense of, the latter.

David Mulroney, former deputy minister in charge of the Afghanistan Task Force, and secretary to the Independent Panel on Canada's Future Role in Afghanistan, which was led by former foreign affairs minister John Manley, is now president of the University of St. Michael's College at the University of Toronto. "I had a lot to do with communications strategy," he said. "I became very familiar with [the program] in 
Afghanistan. I worked with embedded reporters during 15 trips to Afghanistan over the course of two and a half years. Its intent was a very sophisticated effort to ensure that reporters could see for themselves conditions on the ground, and could acquire some firsthand knowledge of efforts - particularly military efforts - in Kandahar" (pers. comm., 22 December 2015).

Adam Sweet was originally posted to Afghanistan for two weeks in 2009 with the Canadian International Development Agency (CIDA), but ended up staying for several more months to work with Canadian Ambassador Ron Hoffman as a public diplomacy officer (PDO). "I was in focus groups when [the CFMEP] was originally designed," he said. "The objective was to help Canadians understand the military effort and support the program. It was very similar to the U.S. program, but I think it morphed over time because the military understood the need to foster understanding of the value of a "whole of government' approach, and that humanitarian efforts needed to be prioritized." At roughly the same time, however, he said the media began to focus more on the soldiers. "The media wanted to cover less of the civilian angle and more of how life was tough for the soldiers," he said. "They got better ratings when they could cover ramp stories, so there was an over-focus on ramp ceremonies rather than development work, and that was a disservice to those soldiers and others who gave their lives, because they believed in giving Afghans a chance to have a better life” (pers. comm., 4 January 2016)

A senior public diplomacy officer posted to KAH for 14 months from 2008 to 2009, now a political counsellor in Africa, concurs that the embed program evolved with time. "One 
of the reasons I was employed in this role was because the nature of our deployment was taking on more of a civilian aspect," he said (pers. comm., 15 February 2016).

'I think that the reporters' mandate was to report on the military operations ongoing in Afghanistan," said Colonel Roch Lacroix, who served as deputy commander of Canadian and NATO Forces in Kandahar Province during 2009, now retired. “I don't think they ever met the mandate that was written for them of reporting on the collective efforts of our 3Ds mission in Afghanistan: diplomacy, development and defense. They focused on defence predominantly. I told Matt Fisher I didn't understand why he wasn't covering diplomacy and development efforts, and he said, 'we send our articles to Canada, but the editors don't think it sells papers." Lacroix paused: "Editors have the purview to make choices" (pers. comm., 29 January 2016).

Still other views on the CFMEP's purpose stretched across the the spectrum.

"From the military perspective, it was to tell their side of the story, or the story, to facilitate the flow of information from the military to the public, with the media as a conduit," said David Harmes. He worked with journalists from 2003 to 2004 as a member of CF public affairs, ${ }^{52}$ and is now a professor of public relations at Conestoga College Institute of Technology and Advanced Learning (pers. comm., 29 December 2015).

Emma Welford, originally with DFAIT, was very familiar with the CFMEP. She worked in 2008 with the Afghanistan Task Force in Ottawa, was then posted to Kandahar and 
Kabul until 2011, and is now with the International Republican Institute in Morocco. She agreed with Harmes: "The intent was to structure media access to the conflict zone in Afghanistan, to ensure the safety of journalists, and without question to improve the coverage of the military side of the conflict," she said (pers. comm., 25 February 2016).

Scott Taylor was an infantry soldier with the Princess Patricia's Canadian Light Infantry (3PPCLI) until 1986, is the publisher of a Canadian military magazine called Esprit de Corps, and in 2010 produced the documentary Afghanistan: Outside the wire. "When embedding began en masse in 2003, that's how you knew that the Americans thought Iraq was going to be a cake walk," he said. "The last thing you want is an observer to a disaster. The intent of the Canadian program was to mirror that of the U.S. They realized that if you could contain and control the media, it was all a bonus. As long as you are on the gun side, you are going to take in the same view you are being given" (pers. comm., 30 December 2015)

\subsubsection{Advantages and disadvantages of the CFMEP for authorities}

"Information management can be decisive," said Colonel Pat Stogran, commanding officer of the first Canadian soldiers in Afghanistan from 2001 to 2002, subsequently becoming Canada's first Veteran's Ombudsman in 2007, now retired (pers. comm., 8 December 2015). "The program was designed to get the media to where the activities were. At the ground level, they had the best exposure to the activities, but they only had one side of it. Embedded media could become blind to the flaws that exist because that 
warm fuzzy allows for bias, and journalists like Mathew Fisher and Christie Blatchford drank the Kool-Aid."

"Certainly as information is regarded as one of the domains of conflict, its management is going to be part of the conflict," added Harmes, "so getting the perspective of the military front and center is one of the program's advantages."

"To a great extent, the military has got the media inside the cocoon, and everything is marvelous," said Taylor. "It's very adrenalin pumping for journalists to be with the soldiers in a military situation, they think these people are great. It's kind of a Stockholm syndrome, and they expect you to fall in love with the soldiers."

Protection for the journalists was an advantage cited by several respondents.

"The program avoided having media in the conflict zone while unidentified," said Welford, "in that media were not coming in and out of the country and possibly ending up in harm's way, not just from the Taliban but also from friendly fire, kidnapping, IEDs, etc. Because the CF had to go in and save these guys, and risk their own lives, there was a great advantage to having a structured and disciplined method of control. It also allowed control over the reporters, over what they saw and reported: you could put the reporter in a tank and let them report, take them to a specific base and have them report on a specific issue by having physical authority over them. Thus, it also allowed them a certain control 
over ... reports that might threaten OPSEC. But [remember,] this was a CF embed program, not a government of Canada program."

Heath-Eves agreed. "Access was important," she said, "and protection for reporters. Plus, they control the message; they literally generate the content for reporters to cover unless the horrible happens and someone dies, but even that is very tightly controlled when it takes place."

Utilizing the media to inform the public about the mission was clearly an advantage.

"The military had an opportunity to tell their story in a way that allowed them to explain it at length, to garner the benefit of the doubt," said Sweet. "Like my mom would say: 'truth leads to trust and trust leads to respect.' You may not always agree with them but you will have time to build that trust."

"Even before the journalists departed via Trenton, bound for Kandahar, there were very thorough briefings about our engagement where we could provide as accurate a picture at that time," added the senior public diplomacy officer. "It gave us an opportunity to listen to questions and areas of specific concerns, talk about their time frames, etc.

"The program's intent was to inform and educate Canadians," said Renee Filiatrault, previously a senior public diplomacy officer during 2009 to 2010 with Task Force Kandahar, under now Chief of Defence Staff Gen. Jonathan Vance (pers. comm., 7 April 
2016). She is currently director of communications for Defence Minister Harjit Sajjan. "It was clearly a good thing to bring ground truth back to Canadians in Canada."

"The advantages are more accurate reporting, a better connection between the Canadian public's understanding of the mission and what the mission actually is, and [recognizing] the context of the mission as a whole," said Vance. He gave an example in which he was travelling to a $\operatorname{shura}^{53}$ in the Dand district of Kandahar province, and his convoy was hit by a rocket-propelled grenade, prompting him to declare: “"If we keep blowing up on the roads, I am going to stop doing development. ${ }^{, 54}$ Rather than saying he was going to stop development work in Afghanistan, he said his remarks were directed to the need for community members to become active stakeholders in their own security, and he explained that to reporters on site. "I would say this improved situational awareness," he said. "You can report individual episodes but if you can't put it into a wider context, they're just stand-alone events, and they might be sensational events. If that's what you're after, then OK, but if you're after accurate reporting on Canada's global effort in Afghanistan then you needed to hear the context."

The senior Canadian civilian envoy in southern Afghanistan from 2008 to 2009 identified another fundamental advantage of the CFMEP: "I'm not certain that the media would have otherwise gone to Afghanistan," she said (pers. comm., 9 March 2016).

A disadvantage cited by the media in chapter 4 , and again here, was the quality of reporters that sometimes rotated through the program. "The media generally understand 
what the rules are and how things work, and to not run afoul of them," said Harmes. "Unfortunately ... a lot of junior people wanted to report on everything and anything and use whatever they learned in journalism school." Sweet agreed: "You could get the wrong type of people, who just wanted to pad their resumes," he said, "people who came over just to say they had ATIP'd (make an access-to-information request); they didn't want to work the shoe leather, to actually get out there and report." Welford added that the rotational nature of the program made coverage unbalanced: "Because it was rotational, reporters came in for six weeks, not long term," she said, "so you ended up with a very uncertain level of competency in the levels of reporters participating, sometimes they were excellent and sometimes they were in over their heads."

"There was nobody questioning the overall picture," said Taylor. "Reporters were wrapped up in the minutiae, and there was no bigger picture being reported. If you were eating four meals a day and sleeping in a bed on the base, are you really in Afghanistan? Are you really talking to people in the village? Will villagers really talk to you when surrounded by armed soldiers as you travel together? The [embedded] media are not going to get an objective opinion from villagers, and this means the army will breathe their own exhaust and believe what is reported by embedded reporters."

Another disadvantage, said Filiatrault, was the "siloed" nature of the reporting that it facilitated, even encouraged. "Every country had embedded programs with the intent to inform their domestic audiences," she said, "but this focused the stories just on their publics, only on their country that they were coming from and speaking to, so [missing] 
the panoramic view of the 50 nations involved. One of the first things I noticed when I got there, even with all my understanding and years in the Minister's office, was how many nations were involved in the effort, but it does not look like that from the embedded journalist's view."

Finally, another often-mentioned disadvantage of the program was the overwhelming military focus of media coverage. "Even though the civilian mission had significant activities going on," said Welford, "the embed program highlighted military-force activities, which made it very difficult for political diplomacy and development activities to get coverage."

5.4.3 Advantages and disadvantages of the CFMEP for the media

The majority of officials I spoke with cited safety for journalists and access - the latter defined in different ways - as key advantages of the embedded program.

"Embedding is definitely safer," said Taylor. "Afghanistan is a very hostile environment, so no question about it." Sweet noted Afghanistan's extremely low ranking on the international Human Development Index,${ }^{55}$ saying “[journalists] were given an opportunity to see some amazing work in some of the world's harshest conditions."

"Safety and security for the journalists was key as nothing in Afghanistan is predictable," agreed Filiatrault. "Embedding is still dangerous but it came with some protection, 
whereas unilateral journalists had no security, their security was on them. Also, ready access to decision makers like General Vance who would be ready to brief or speak with them." Embedding offered a service, added the senior public diplomacy officer. "Journalists had a relatively safe place to sleep, eat, and report from, and they were provided with organized deployment in and out of theatre."

"Certainly an advantage is getting up close to some parts of Canada's mission in Afghanistan," said Welford, "travelling by helicopters, or a light-armoured vehicle with security forces around you. They also got direct access to the mission commander and civilian officials, as the media tent in Kandahar was directly next door to the HQ offices."

"If Canadian soldiers are dying in the field, the Canadian public is going to demand the right to know what's happening and why," added Mulroney. "I think the program was a very good response to the legitimate recognition that, if you're going to send troops into harm's way, you've got to explain to Canadians constantly what you're doing and why and whether you are succeeding or not."

"It gave journalists an absolute feel for the nature and challenges of the mission," said Vance. "If you want to write about something, you've got to know the facts, and to know the facts, you've got to be dealing with the experts, who were in theatre. Of course they could criticize the mission, but I said 'don't criticize the mission that isn't, here's the mission, go ahead and criticize that.' It didn't make much sense to criticize those things that we weren't even trying to achieve." 
Vance took umbrage at reporting he felt was Ottawa-centric as opposed to missioncentric. "Sometimes it sounded to me like they weren't even talking about the mission that I was on," he said. "If you were only looking at it through the lens of the headlines around ramp ceremonies, the mission just looked like soldiers being killed, hapless victims, and there was no success, no progress, nothing good got done, we just killed people. That was a clear line of reporting back here in Canada."

Lacroix said that, despite becoming a component of any operation, journalists' professionalism would prevent them or their objectivity from becoming affected by that closeness. "And they did not always report just our best," he said. He recalled one example of two Afghan children who were killed by an explosion on a training ground. Embeds quickly reported on this, using information garnered from local villagers and rumours, which proved incorrect. "Jon Vance had to meet with the embeds to give out facts, and even correct ministers back in Canada who had also spoken out without knowing the facts."

Another perceived advantage of the program, often mentioned by reporters in chapter 4 , was the ability to dis-embed from the CF. Lemay explained that reporters only needed to inform their news desk and provide a probable return time, after which they could fly to Kabul or other locations in Afghanistan/Pakistan to conduct interviews and/or work with fixers. He said that embedded media would often be directed by their Canada-based news desk to cover a certain angle or to follow up on a story not directly linked to combat 
operations in Kandahar province. "I personally encouraged [embedded] reporters to venture on their own or with fixers to get the smell and feel of the street," he said. "For example, an Al Jazeera reporter [dis-embedded] from the task force to meet with a Taliban representative at the request of his front desk. He would not have been able to conduct such activity while embedded and escorted by soldiers."

Two disadvantages for the media most often cited was, one, the perceived control of media content by the CF, whether through limits on exposure or withholding of information, and two, a loss of objectivity through proximity to soldiers.

"You are still beholden to the CF in terms of what you see and how you see it," said Mulroney. "I think the other disadvantage is that as you live alongside people and see them and sympathize with them, it may become more difficult to criticize where criticism is necessary. I think journalistic professionalism can overcome this, and Canadian reporters generally rose to that, but I think that some of them became captive to a military point of view, which is a disadvantage for the media and the public. The public is best served when the media remains as objective as possible."

"Reporters were suspicious that they were only getting good news," said Welford, "and they didn't get to choose what they saw, because the military had control over the transport options. The military world is very structured, and it was difficult for reporters because this order is not in their nature and people don't have the time to sit down and explain things to you." 
"Typically there was the impression that if you were embedded, then your pen, your voice, your coverage was controlled," said Filiatrault. "If there was ever any attempt to guide a journalist's writing as a result of being embedded, there was an immediate response to that, and it didn't happen in my view." However, there sometimes were "difficult conversations" concerning OPSEC. She recounted one example where a journalist wrote about a VIP travelling in theatre and, as a result, that person became compromised, a "soft target," and had to change their agenda.

"You may feel like you lose a bit of your journalistic independence because you are reliant on the bandwidth of being able to report back," said Vance. "[For example,] if we took a casualty, the embed could not report on that casualty until the next of kin were notified. If there was interest in getting a story out fast, regardless of the feelings of the next of kin, we would shut down their ability to communicate that as a safeguard." When asked about reporters' ability to maintain their objectivity despite living in such close proximity to soldiers, Vance replied: "I would imagine that criticism or concern is levied by those whose job it is to guard or comment on journalistic integrity and/or by those who had never experienced embedded reporting. My personal experience was that they stayed objective. They were limited as to what they could see by their ability to stay mobile, a lot of their mobility was with us unless they chose alternate means of transport, but that was at their own risk." 
"Embedded reporters [were] prevented from covering a wide range of stories," said Heath-Eves, but not necessarily by the military. "There were a number of reporters that I worked with who wouldn't take the risk to come out to the KPRT from KAF to cover the civilian side of the story. They claimed it was their editors who said they could not travel. Certainly reporters could dis-embed, but the ones who did were far and few. I was really impressed with those reporters who went out [of the wire,] it was a lot work and some risk. Most were there for the program that the CF laid out for you: trips around the area with the general and senior officials, and while these were extremely valuable, it made it easy to look like you were working hard when you took advantage of junkets." She added that there were few reporters who were as hard working and valuable as Matthew Fisher.

The senior public diplomacy officer agreed that a few journalists developed expertise. "There were some journalists who spent a lot of time in theatre and became knowledgeable and had a deeper understanding of what we were doing," he said. "Matthew Fisher, for example, invested a lot of time and effort from very early days in Afghanistan." But the length of stay depended on the parent organization, he said, and in order to maintain a continuing roster of reporters, some stayed for only short stints. "It was more about their knowledge level than quality of reporting," he said. "I think you can spend two months on an issue and do a good job, but if you come in and then leave for 12 months, a lot can change while you are away."

Harmes added that one negative byproduct of spending so much time on the base was a growing fixation with casualties. "This type of activity set up a bad dynamic," he said, 
"they were waiting away and watching around the medical bases, it gave a kind of bad feeling, even though they could report that ambulances were going by."

\subsubsection{The CFMEP basics}

Journalists wishing to join the CFMEP needed to be accredited and possess documents identifying them as journalists (APPENDIX J, Introduction, 4). "It is the media agencies that submit their reporter, cameraman, photographer, field producer, etc.," explained Lemay. "The living accommodations for media were limited to 16 spaces at KAF and five at the KPRT. On a rotation basis, media agencies - Canadian and international would be given access for a period of three to four weeks." Although the CEFMP agreement clearly states that "participation in the CFMEP is based on the understanding that journalists will primarily cover CF and Government of Canada activities ...," (APPENDIX K, CFMEP Guidelines, 7c) the reality was that media coverage of military action was much more prominent.

"Between 2005 and 2006, when the CF moved from Kabul to Kandahar," said Welford, "even though the civilian mission had significant activities going on, the CF embed program highlighted military-force activities, which made it very difficult for political diplomacy and development activities to get coverage. Because it was rotational, reporters came in for [several] weeks, not long term, so the rotations were unbalanced; you ended up with a very uncertain level of competency in the reporters participating, sometimes they were excellent and sometimes they were in over their heads." 
"It was very expensive over the course of time," observed the senior public diplomacy officer, "months and months on end would run into a hefty bill, especially if you're talking about a prolonged stay." He recalled that there were reporters present from smaller organizations, but he suspects it became prohibitively expensive for them to maintain a long-term presence.

"Embedding would have been coordinated through the public affairs network," said Taylor, "and clearly they had their favourites. They got really upset with Graeme Smith who used to leave and get independent information and they hated that, even though he was still permitted to dis-embed and then re-embed."

\subsubsection{CFMEP operations}

"When I was there [from 2001 to 2002]," said Stogran, "I thought that informed reporters were the best scenario. I gave reporters the same deal: no names, no locations, no ID, off the record ... I saw the media's worth to the bigger picture. In the old days, I expected the soldiers to speak freely to the press but within their lane. The embedding process in the beginning was very different than what it became later on because of the political pressure from above, because the Harper government was so preoccupied with controlling the message." 
Taylor said only a few reporters were sent back to Canada for not observing CFMEP polices. "Even if the military didn't always like his coverage, Graeme Smith had the Globe and Mail backing him, and he did not have entirely negative coverage," he said.

For the most part, officials thought their relationship with the media was harmonious.

"Certainly some of the reporters got all Rambo'ed up," said Welford, "It is a very intoxicating environment, and very easy for a reporter to feel like they are one of the boys. But there are rules against wearing camouflage, or in any way appearing to be part of the CF, or carrying a weapon. It was a safety issue, the reporters were not part of the offensive force, there were some 30,000 people on the base from many different countries and organization, and you wanted to know who was who." Mulroney recalled that sometimes the military would get upset with journalists for reporting on Camp Mirage ${ }^{56}$ in Dubai, even though it was clearly on the flight path to Kandahar.

\subsubsection{Fairness of CFMEP policies to the media}

The clear majority of officials I spoke with felt that CFMEP policies were fair, particularly regarding journalists' safety within a conflict zone. "When you've got people's lives on the line, and there are a lot of moving parts in theatre, the rules are structured so that safety is paramount," said the senior public diplomacy officer. "I don't think the rules themselves met with too much push-back from the media." 
"As an outsider looking in," said Mulroney, "I think the military did their best to respect reporters' freedom. There will always be an attempt to show them what you want them to see, there will always be tension, but I think the military did their best to show reporters what they needed to see." Welford agreed: "I think the media were able to get real information about what was going on and still maintain the appropriate balance between doing their job and maintaining OPSEC. Remember that it was not mandatory to embed, and there were reporters who did not embed but went to Kandahar to report."

"I think the policies assured them of safety and compliance with OPSEC such that they could meet what they needed to do while still letting us do what we needed to do," said Vance. "[The policies] may not have allowed them to be as free as they liked, but I think that the embed policies were far less restrictive than some of their own editors' policies about were they could go, and when they could leave. Like the pool camera, for example, you could never go anywhere, you had to stay [on site] in case there was a casualty and shots were needed of the ramp ceremony. I know that lots of journalists kind of chafed under the restrictions, they would have like to have gone out more."

"It's a difficult task," added Taylor, "it's like taking people into a construction site, you have to have rules."

5.4.7 Were significant changes made to the CFMEP after its inception? 
"In the 10 to 20 years leading up to Afghanistan," said Lemay, "the CAF mainly reached out to Canadian national, regional and local media and escorted them on sponsored tours to visit our deployed land and air units, as well as navy ships." He said that PAOs would often receive requests from conflict correspondents to visit operations in places such as Somalia, Haiti, Rwanda, and Bosnia.

"But moving freely in war-torn countries became more and more difficult and dangerous after the first Gulf war," he explained. "[Journalists] who had become more influential ... exposing war atrocities ... were often [regarded] as high-value targets by battlefield opponents, captured as hostages, and/or lost their lives covering NATO, UN and coalition conflicts. Media agencies then began reaching out to NATO and the UN to be included during troop deployments and provided with access to military camps for overnight protection. We remained in step with our allies and went from sponsored media short trips to a very solid embedded program." He added that the CF has since adapted their Kandahar model for sea operations, called the Canadian Embarked Media Program.

"One of the unintended effects [of embedding] was that it allowed soldiers and military personnel to gain better knowledge of the way that journalism and journalists work," noted Harmes. "There is a traditional kind of misunderstanding between these two groups. Military personnel learned that journalists are not there to trip you up. Journalists learned the military is not always trying to withhold information. This is why the embedded program has benefitted both sides. Also, once journalists become familiar with the way the military works, it's not that hard to find your way around it, especially those 
journalists that came more than once. With experience, they understood what could and could not be done."

"I certainly saw changes in the level of interest in the program, and level of interest in Afghanistan period," said Filiatrault. "I went in for six weeks in 2008 when someone was on leave, and the media tent was full. When I went in for my posting proper in $2009 / 2010$, there were dwindling numbers of media in the tent. I suspect it was partially because of issue fatigue in Canada, as well as some considerations surrounding risks journalists undertook or could undertake. When I was first in Afghanistan, I didn't hear 'Oh, I'm not allowed to do a convoy movement, I can only move in helicopters,' but I heard that almost immediately when I went there in 2009/10. That created a dynamic: if you have one helicopter seat and two convoy seats, if someone only had permission to move in a helicopter, that effectively relegates the other journalists to the convoy in perpetuity, which is obviously more dangerous."

5.4.8 Did CFMEP policy rules match in-theatre practice?

A majority of officials felt that CFMEP policies were consistent from print to practice.

"I'm familiar with the argument that OPSEC could be used for everything on a day-to-day basis," said the senior public diplomacy officer. "As I came to understand what framed OPSEC, and how that reflected rules and decisions, I think the rules were meted out in a way that was utterly justifiable, but this was and is a debatable point. From where I was 
sitting, I believe there was a free and open discussion between the program and the media. Sometimes if [the media] had a point, stumbling upon an inconsistency, for example, there was dialogue and discussion on specific issues or points of dissent."

"There is always a trade off between safety and access, especially when the danger levels are high," said Mulroney. "And there is always a trade off, especially for some of the small media outlets, between access and expense. I honestly think [the CF] tried to give as much as possible the most access and highest level of safety to reporters."

"I think the policy rules stayed very consistent," added Vance. "The policies allowed access to the commander, and different individuals took it differently. I made certain the media could see the terrain with me so I could describe what was going on. I'll give you an example: if you said Kandahar City in 2009 to most Canadians and even most media, people would have this vision of constant fighting, death lurking around every corner, a really scary place. So when I would bring media through, I would show them the market, the palace, a really great coffee shop, there's mom and dad out for a stroll, etc. Yes, it was dangerous, no question about it, but it was also a bustling metropolis that was trying to maintain an economy, trying to survive, [and this] gave people a sense of 'why we were working so hard at this."”

5.4.9 Comparison of the CFMEP with other countries' embed programs 
Analogous to media commentary in chapter 4, the majority of comparisons of the CFMEP were made with the U.S. and, to a lesser degree, the British embed programs.

Stogran strongly believes that the American model of embedding used in Iraq in 2003 was, in fact, predicated on the Canadian example in Afghanistan prior to that time. "Certainly this was the case at the grassroots level," he said. "Someone who was a battalion commander in Iraq during 2003 told me he used a lot of our stuff, and U.S. General David Petraeus used to associate with him. Remember this was a time when we were trying to shed our peacekeeper image, which we had at the beginning. And we were winning there in the beginning: we were working closely with the local people, but headquarters would not approve money for schools, and so the soldiers stepped up and collected materials and were working on schools, and then drilling wells, etc." Lemay confirmed that CFMEP was initially set in Kandahar in 2002 under Operation Enduring Freedom, the U.S.-led coalition, and evolved until it officially began in 2006.

"I'm more familiar with U.S. model," said Harmes, "but would say it's purely a matter of scale: where we tend to have one brigade, they have many, so they can tell more stories via their embedded reporters." The U.S. also allowed embedding with their Special Forces, observed Sweet, which the CF did not allow. Furthermore, added Heath-Eves, Canada allowed more flexibility, such as dis-embedding.

"I dealt a lot with the American embedded program, and my American counterparts," said Filiatrault. "During the time that a surge was being considered for the south, there were 
some very high-temperature public debates, and a lot of attention on what level of resources were needed. The Americans were often saying there was nothing in the city, and this was very frustrating to us when we had Canadians in the city who were holding down the fort. This goes back to how the Americans were there to cover their guys, and we were there to cover Canadians, and it became very 'siloed."'

"My experience was with my colleagues at the British embassy, and they were much more involved from the diplomatic side in their embed program," said Welford. "The weight of the British embassy seemed to be taken into more consideration than we did in the Canadian system. This was partially a cultural thing, because the British Foreign Office is very prestigious and on the same power level as their military structure; that is not the case on the Canadian side. Also, our civilian side was much smaller, so perhaps our authority was perceived as proportional, perhaps it was even an afterthought."

\subsubsection{Whether or not the CFMEP should be continued}

Opinions ranged from dismissive to supportive. "The program should not continue as it exists now," said Stogan. Conversely, "now that it has started, it would be pretty difficult to stop it," added Taylor. The majority of officials fell within the latter category.

"If there is no other way for the media to report," said the senior Canadian civilian envoy. "The idea of it is a good one. We created an enabling environment so that the media could communicate reports of what was happening with Canadian taxpayer funds in a far- 
off place, in particularly challenging environments, and particularly if the media wouldn't have otherwise gone in with security risks. But there are always questions about things like [media] independence, and diversity of stories and voices. It can also create challenges for those of us as public officials living in that environment: for example, 'are we on the record or off the record?' There is the immediacy of it as well; it is unclear sometimes of how to respond to questions in times of stress or crisis."

"I certainly don't see any reason why it should be stopped," said Harmes. "Journalists would often talk about the dangers of being unilateral, such as kidnapping, so it's good because it allows them access, and from the military perspective it allows for their story to get out." The senior public diplomacy officer concurred: "I always saw the intent as a genuine desire to better inform Canadians through the media, and it's always beneficial to report on what Canada is doing farther afield," he said.

"Absolutely," added Welford. "It is imperative for reporters to have access during conflicts to what is happening in real time, with attention paid to security concerns. While there are judgement calls to be made, I think the advantages outweigh the disadvantages." She quipped that it was difficult for a civilian to pitch a story that was sexier than riding with a tank, and that seems to have been the most frustrating aspect of the program for her. "I could spend two weeks trying to talk to reporters about aid workers helping with voting in the election, and wouldn't it be nice if Canadians became aware of it, but no." 
"Absolutely, even with all of its headaches," agreed Heath-Eves. "The arrangement means that you are beholden to [the military's] will but you are also part of things when they happen in real time, so you are aware of them. The program allows Canada to tell its story, but it is also a brilliant PA idea to control the message."

Vance believes that the program should continue, dependent on the mission's ability to accommodate it. "At Kandahar we had a relatively secure platform," he said, "Kandahar airfield, a nation that allowed media presence, we had the infrastructure and the mass, but not every mission is like that. On some missions, you're in countries where the media is not authorized, sometimes you're in a place where you can't take care of them properly, feed, house or offer them the kind of communications that they would need to sustain their own work. Like in Iraq or Kuwait right now," he added, "it would be very difficult to embed media at this juncture."

"I think it should continue but be subject to a fairly rigorous 'lessons learned' review," said Mulroney. "This could involve reporters themselves or some pool or syndicate having a greater say in terms of the prevailing rules, what they get to see and do, to be sure that it doesn't descend into a sort of a public-relations exercise for the sponsoring [host.] For example, when reporters travel with the PM, they organize themselves into pools, and decide who is going to represent them, for better access or different conditions on behalf of all the participating journalists. Journalists are pretty good at organizing themselves and representing a common front." 


\subsubsection{How officials think the CFMEP should be changed}

There was a discernible, albeit not exclusionary, distinction between programimprovement suggestions by government versus military officials.

"Over the course of the four years I worked on the Afghanistan Task Force, the "whole of government' approach was strengthened every year, and if reporters were interested, we would do a pre-embed briefing with them on our five priorities, in person or on the phone," said Welford. "I think making that a permanent, reflexive component would allow them to have some context before they got in there. We didn't always get people who had a background in defense, so it helped them get up to speed, and it also allowed us to ask for assets in advance and do some forward planning."

Both Sweet and Heath-Eves agree there could have been more "whole of government" coordination. "It really needs to have a 'government of Canada' approach in terms of policy at the Ottawa level that allows for government engagement with the media," said Sweet, "because when you create different lines of responsibility you will have inconsistencies." Heath-Eves believes there should be improved coordination with civilians, NGO staff, and other actors who are working toward the same objective: "The embedded program had really limited reporting on other issues because of military scheduling," she said. "The Dahla Dam and schools were good examples of stories, but while it was Canadian engineers who were building schools it was also foreign affairs people, NGO staff, etc. involved and that would be missed." 
"[The program could be changed so] that the costs can be controlled for some," suggested the senior public diplomacy officer. "I was also struck by the interest from small- and medium-sized communities in Canada. I would suggest finding a way to bring more local journalists into the program; some of the reasons they couldn't were related to cost, so enabling this would improve access to the program."

"The reality is that a lot of the media are broke," added Filiatrault. "I think that embedded programs need to take into account the fact that many journalists are struggling to keep their jobs, which could affect the success of any program, so making it as cheap and accessible as possible is important." When asked who would then pay, Filiatrault replied that the $\mathrm{CF}$ tries to be as cost-effective as possible, making use of what she called "standing military assets" such as a bunk on a ship. "Those opportunities do present themselves, and we try to make them happen," she added.

"One of the things I've seen with embedded reporting is its heavy national focus," said Harmes, "but these missions are often international and/or multinational in nature. Something that would improve the quality of coverage would be if journalists looked at the overall mission instead of just focusing on Canadian perspectives." Lacroix referred to this as necessary support and understanding from the top down: "I'm talking about major media news outlets, in concert with Ottawa," he said. "Remember that the military doesn't ask to go into war, the government decides to send the troops into harm's way. So the media should better understand the mission. Don't say 'the military wants to go to 
war.' The military is eager to do its part, and we provide options when asked, but the government decides on what options are going to be implemented."

"It's up to the media to recognize that embedding is only one piece of the jigsaw puzzle," said Taylor. "Yes, it's a valuable insight into the lives of soldiers in combat but it's only one perspective." He called the ability to dis-embed a "positive," although less safe. "Changes have to come from the media side," he added, "through possessing knowledge of the conflict, through the questions they can ask ... the media has to take charge, and know that they need to give a bigger picture."

"This whole freedom of information process is a charade," commented Stogran. "I think anything not to do with 'national security' should be transparent and available. Instead of a journalist having to prove it shouldn't be redacted, they should have to prove that it should be redacted. I think they use 'secret' for things that are 'politically sensitive."'

\subsubsection{Summary}

As the preceding comments have indicated, military and government officials worked side by side during the Afghanistan mission, with a focus on the 3D's: diplomacy, development and defence. All of the individuals I interviewed possessed a very strong sense of pride in the work they attempted and accomplished in Afghanistan under very physically, mentally, and environmentally trying circumstances. Although the CFMEP was developed, housed, and supported by the military - which meant it had de facto 
control over the program - it became evident that a majority of government officials were displeased with the relegation of their efforts to a distant second place in terms of media coverage by embedded reporters. While a handful of respondents believed that the military had made a calculated effort to contain the media and manage the resulting message, many others faulted members of the media for becoming far too enthusiastic with the adrenalin rush of becoming part of a battle unit, "one of the boys," even if peripherally. As in the preceding chapter of media interviews, concerns were raised about the uneven and uncertain levels of competency of certain reporters that rotated through the CFMEP; less experienced reporters seemed to comprise the majority of those who "Rambo'ed up," as one respondent observed. Finally, a handful of respondents voiced concerns that close proximity to soldiers could hamper objective reporting, but also felt that dis-embedding could alleviate this and that, fundamentally, the advantages of the CFMEP such as safety for reporters far outweighed the disadvantages of perceived military rules and rigidity.

\subsection{The media experience}

5.5.1 Experiences with embedded or dis-embedded reporters

"I was generally very impressed with what I saw," said Mulroney. There were a few reporters, however, whose behaviour frustrated him. "Sometimes reporters got into almost-contests about who was exposed to the most danger, a real pecking order which I found unprofessional and unhelpful, that if you weren't exposed to fire you didn't have 
any credibility. They were caught up in the glamour and excitement of being posted, saw themselves as wannabe soldiers, lost their objectivity, became crusaders, and felt that they could therefore criticize others in the theatre of operations. They used to say disparaging things about civilians, and underappreciate the contributions that civilians made, so people in foreign affairs or development were perhaps not as respected. Thus they could be overly negative about civilian efforts, and also uncritical of some of the problems associated with the military campaign ... almost a Stockholm syndrome, [in that] they identified with their captors. But people serving in Kabul and elsewhere in Afghanistan all experienced dangers, and all had insights to share, and they were all worthy of respect."

"I had two advantages," said Welford, "one, I had worked as a political staffer on Parliament Hill previously, so two, I had relationships with national reporters beforehand. One disappointing experience was when reporters wrote the same kinds of stories, for example, 'Oh my god, there are women in the military.' These were often reported during the first week of embedding. Then there would be the story about the food, either too good or too bad, and inevitably a kitten story. Now if this had been balanced out with civilian coverage that would be okay, but we [mostly] got only military or the above/cute stories, not so much about the civilian or Afghan-experience stories."

"The embedded reporters gave much more of a produced story," added Sweet, "and tied to the Canadian agenda. One of the fundamental problems with coverage of the Afghan mission is that the reporters coming into KAF wouldn't be allowed to come out with the 
KPRT without approval from their head office, due to insurance concerns. But I was also told unofficially they had to be close by in order to quickly cover a ramp ceremony if there were casualties. Some reporters told us they could only travel by air, not ground, and this was a challenge because you couldn't see any of the development work that way, the schools being built, the dam work, etc. unless you came out with us."

Filiatrault concurred. "I was genuinely surprised at how difficult it was to get journalists outside of the wire," she said. Difficulties included the levels of conflict, safety and security concerns for journalists, logistics and resources needed for convoy or helicopter transportation, and exigencies of their home desk. "It's important to point out that was often to the great frustration of the journalists themselves," she added. Another surprise was the lack of delegated authority from Ottawa to civilians on the ground in Afghanistan. "On the civilian side we had an approval process - even for press releases that was enormous and cumbersome," she said. "It compromised our ability to meet deadlines and take advantage of opportunities. For example, if a journalist had a question about how many bags of wheat seeds we had and were handing out, the actual development person handing those out knew how many they had, but still had to confirm with and get that number back from Ottawa, which makes no sense.”

"I found that the more junior a journalist was, the more likely they were embedded," observed Harmes, "whereas the more senior, the greater chance of reporting as a unilateral. That greater experience obviously made a difference in the quality of their 
reporting. Also, the network of contacts the experienced journalists developed was better, they had secured local fixers to guide them around, etc."

5.5.2 Experiences with unilateral reporters

Few of the officials I spoke with had had experiences working with unilateral reporters.

As Harmes noted earlier, Welford said: "They tended to be reporters who probably had a little more experience, and were not willing to make that balance within the embed program," she said, "and they were often men, who had previous experience in conflict zones or difficult areas.”

"On occasion, some would show up at Kandahar airfield, looking to interview superiors," said the senior public diplomacy officer, "and I managed those relationships in much the same way as embedded reporters. I don't think we treated them very differently. It didn't happen that often, to be honest."

"They would swing through every now and then," said Vance. "They were usually operating under their own restrictions, working with fixers, and their access was only as good as their fixers' access. They saw things from a different angle, [as] it's a different world when you are not driving around in an armoured vehicle. Some of these reporters were equally valuable but oftentimes did not have the context. [For example], they could talk to a family who had just experienced the results of a raid, [and] if you reported just 
through the eyes of a family who had lost their child or their house as a result of western military action, you could be quite critical, saying 'you've just created new enemies.' It looks bad from the victim's perspective. But what they didn't get sometimes was that that family or community was housing Taliban who were actively killing citizens of Afghanistan, or attacking the coalition, or setting IEDs that were just as likely to kill a family in a station wagon as they were to kill us in an armoured vehicle."

During our interview, Vance often brought up the notion of context, feeling strongly that it is fundamental to understanding any given situation, particularly during a mission as complicated as Afghanistan. "Sometimes unilaterals could be accused of not having objectivity because they only showed a very, very tight shot and didn't necessarily put it in context of "why?" he said. "We never took action against families. We looked at the Taliban: where were they, what were they doing? Certainly there were parts of the population colluding with the Taliban, lots of civilian casualties that were reported were not innocent noncombatants, a lot of them were active in facilitation of the Taliban. My sense was that you needed to constantly put things in context to understand what the struggle was about; if you went too tight, you might have gotten a human-interest story but you probably weren't reporting in a context that made some coherent sense."

"You didn't always know what the reporters were going to do, and/or report on," said Sweet, "sometimes it made for better quality, sometimes it didn't." One article he praised was by Aikins (2009), "an amazing drug-trafficking border piece that information ops subsequently gave to all of their guys." 
Another unilateral journalist who was praised was Graeme Smith, working for the Globe and Mail, although technically, he reported at different times as embedded, dis-embedded and unilateral. "I thought Graeme was one of the best reporters in theatre," said Mulroney. "Graeme was a rarity, he was there longer and he understood how the country worked, whereas our generals never really did," concurred Taylor. "It's largely because of the job, they have to obey their orders without question. When you have a mandate, such as 'control this area of Kandahar,' it's never up to you to question orders. It's almost that you have to develop blinkers, maintain an 'arc of fire,' a defensive position to carry out your orders. That is why it's so important for the media to question everything because the military cannot."

5.5.3 Did embedded reporters effectively relay stories?

The majority of the officials I spoke with answered "yes," with certain caveats.

“They effectively relayed the Canadian story," said Filiatrault. "I don't believe they could effectively relay the entire-coalition story simply because their eyes were focused on the Canadian element. I think there were challenges in terms of resources towards the end, and challenges in the fact that they couldn't always go outside the wire. In the earlier days, you had two or three people from the same network, or rotating in on a regular basis, but towards the end there just wasn't enough of them and their primary role was to cover potential VSAs (short for Vital Signs Absent, meaning a casualty).” 
"They did a remarkable job of bring home to Canadians the reality of the campaign in Afghanistan," said Mulroney. "I think they did a better job on the military campaign than civilian efforts, and that is because the military was much freer to report on what they were doing and to work with reporters. Civilians were under strict orders not to talk to reporters without permission that was rarely granted. In those [few] instances, if there was any mistake, the retribution was severe and vindictive and that meant people became very, very reluctant to communicate because they were so afraid of reprisals from the political level. As a result, and not surprisingly, there was scant coverage of the civilian effort and often it was very critical because the reporters were so frustrated by the roadblocks put in front of them when it came to gathering information." Mulroney noted that the Manley Panel (2008) helped to loosen restraints.

"Up until the Manley Panel the constraints were onerous, to put it mildly," he said. "If anybody gave an interview that was considered negative - and you can't always control the way an interview is going to be conducted or reported on - even if the headline was negative, there would be a witch hunt in government and great unpleasantness would ensue as people were hauled on the carpet. It was only after the Manley Panel that we began to engage journalists, but by this time it was very late in the day, people's impressions were already pretty much set in stone. The military was much more creative and insightful when it came to engaging journalists, but on the civilian side we had this strange circumstance where we were not allowed to speak, and then got hauled before some committee of Cabinet and browbeaten by ministers because the communications 
results were so unsuccessful. I think that the failure to communicate effectively was one of the things that most hampered the campaign in southern Afghanistan by CIDA, Foreign Affairs, police trainers, and others. That control," he added, "came from the communications team in the PMO."

A number of officials also mentioned the restraints and demands that were purportedly placed on reporters by their head offices back in Canada, the one most often cited was the ghoulishly named "death watch:" covering slain Canadian soldiers.

"Certainly the Canadian reporters seemed to have restraints put upon them by their senior managers about what they could and could not do, what they could and could not report on, and what kinds of stories the Canadian public was interested in," said the senior civilian envoy. "Let's say a military representative and a civilian went down to the media tent and said 'you can either go out with the battle group and see a military operation or accompany a civilian member to go to see a development project or come to a meeting.' Well, they would not pick the development projects. When I asked why, they responded that 'our editors are telling us to be available for ramp ceremonies.", 57

"Like any news story written at home or by deployed reporters, these are always edited by their national desk," said Lemay. "Home office gets the pulse of their readership and TV audience. They will give directions and angles to be covered. If for example, an Afghanistan-related report was publicly released in Ottawa on Monday, it meant that embedded reporters, covering military operations, were directed to conduct immediate 
interviews with field commanders or diplomatic staff to explain and/or comment on that to meet the late evening news at home. National politics is a reality no one can escape and it will always trump military success and progress reports. In my opinion, I would say that 80 to 90 percent of the reporting was adequate. The balance of stories was often scripted and although [ostensibly] reporting 'live from Kandahar,' the content was nationally based, politically charged, and could have been done from Canada."

"The fundamental problem was that maybe 50 percent of the reporters viewed their posting as being an extension of Ottawa," added Sweet. "Not understanding that, despite some comforts and familiar processes, it was a war zone with a different set of rules. There was also a fundamental failure with the government trying to control messages from above. The Afghanistan Task Force did make things happen faster, but they still had to go through a chain of command."

"A definite disadvantage was that the embed program was rotational," added Welford, "so by the end of the mission, there were only a handful of reporters who had consistently come back to Afghanistan to cover all aspects of the mission: Matthew Fisher, Paul Workman, Murray Brewster, and Graeme Smith.”

"We did our best to try and provide perspective on our activities in Afghanistan, with the premise of informing the Canadian public," added the senior public diplomacy officer. "But there are inherent limitations within the industry and I'm not sure all of what was 
happening in Afghanistan was captured by the media. Ultimately the media couldn't be the only vehicle, the message needed different venues to reach the Canadian public."

5.5.4 Dis-embedded and unilateral reporting on the bigger picture

The officials I spoke with had varied opinions on how Canadian reconstruction efforts, the war's effects on Afghans, etc. were covered by reporters outside of the wire.

"I think they were better because they saw more and were less beholden to the military and less reverential in their coverage of the military," said Mulroney, "but only a few people would be willing to face the danger that that entailed."

"Reporters covered the war with an eye toward accuracy, and what the embedded reporters covered was accurate," said Filiatrault, "but the unembedded journalists would have that piece, and then they would go out to Helmand province and get that piece, and talk to Afghan farmers and get that piece, and talk to the governor of Kandahar and get that piece ... unilateral journalists got more pieces of the coverage."

"They were able to get closer to the Afghan population," said Vance, "and they could sometimes get a really good, unfiltered view of, and be able to report very accurately on, the feelings of Afghans. But I think if the reporter had a particular angle, like accentuating the harm of war, they wouldn't necessarily balance it with what we were trying to achieve. [For example,] the Afghan family who complains about our presence because 
we're dangerous also didn't want us to leave because of the Taliban. So the reporter might report the first part of the sentence - 'I want the coalition or ISAF to leave, but not right now' - but they wouldn't report the "not right now." Vance said this happened more than a few times.

"Reporters who dis-embedded were kind of cut from a different cloth," said Heath-Eves, "like Susan Ormiston. The quality of her reporting was excellent, and even though some of her reporting made Canada look bad, you could tell she did the leg work."

"Those who dis-embedded were the most experienced field correspondents, crews, and freelance photo-journalists," said Lemay. "They would join up with local fixers and live among the population in secured villas in Kandahar, in hotels in Kabul, or with tribes in remote areas. Evidently they were able to get a different perspective and obtain details which [might have been] different than the narrative provided by ISAF and troopcontributing nations." Still, Lemay has doubts that the "bigger picture" was ever captured. "I don't think that either the international community or the huge number of reporters who deployed to Afghanistan were able to fully grasp and maintain contact with the bigger geopolitical picture. Asymmetric/guerrilla-type fighting was happening all over the country, the enemy was blending amongst the population, al Qaeda and Taliban fighters were nomadic - conducting cross-borders activities and retreating in safe-haven zones where ISAF could not access, non-state organizations and other non-NATO states acted as back-door influencers, while all the time the UN and international community were 
conducting diplomatic efforts with influential bordering countries and establishing a democratic government in Kabul."

While reporters did not need to dis-embed to cover Canadian provincial reconstruction efforts or war effects in the Kandahar province, the senior civilian envoy noted that reporters nevertheless rarely made that choice. "There was [previously] criticism that civilians didn't talk to the media, however, that changed in 2008 and still that opportunity was not often seized, and that's an important lesson for all of us," she said. "The civilians were available but those stories were not chosen. Development stories are more complicated, it takes time, it's not the same as going into a particular area to facilitate the Afghan army coming in, with a beginning-and-end narrative.

Lacroix was less certain that dis-embedded and unilateral reporters understood the bigger picture: “I just don't think that they took the time to understand Canada's mission, the overall purpose of the mission from a strategic and historical perspective," he said. "Their myopic 'picking fly shit out of pepper with boxing gloves' was a distraction. If only they had understood the bigger picture: the Taliban used men and women and children to do their dirty deeds. There was too much focus on how many civilians were dying because of the military and not because of the Taliban, which was six to seven times higher. We do not deliberately target civilians, but they do, so stop coming up with reactive stories." 
Few respondents spoke of witnessing strife between authorities and reporters.

"I would sometimes see reporters chafing at restrictions during political visits," said Mulroney, "and arguing with political or media handlers, but that was infrequent."

"I recall some difficult conversations," said Filiatrault, "but I think there was a lot of good faith on both sides. The detainee issue was our most lightening-rod issue, and it was a very difficult issue to manage on an almost daily basis. It was certainly a healthy debate, as Canadians expect us to follow the laws of our own conflicts."

5.5.6 How warranted the use of operations security (OPSEC)

The embedding ground rules state: "The goal of OPSEC is to prevent the adversary from obtaining information that is essential to our mission. This objective allows for the safeguarding of some information that has an operational impact on our mission, while permitting Canadians $t$ know as much as possible about their soldiers, sailors, air personnel, and the civilian members of the deployed 'whole of government' team" (APPENDIX K, CFMEP Guidelines, 12). The majority of officials who spoke with me felt that the use of OPSEC was warranted, and did not venture into censorship.

"We would never review copy," said Vance. "We would restrict the ability to report on the death of a Canadian until we were sure the next of kin was notified, but that's not censorship. We would allow them to take video and hold it in the can until an embargo 
was lifted for the purposes of OPSEC. And we would insist that they not name places, particularly those with ongoing activities, because that could key the enemy onto us. If they violated that, they could be warned or dismissed from the mission."

"OPSEC covers disclosing locations, taking photos, etc.," said Welford. "There is such a high level of technical sophistication out there, both bad and good guys can follow Twitter feeds, read your blogs, etc. In 2008 we were being rocketed around eight times a day by some bad dude and I am totally okay with making it more difficult for this guy to maybe kill me or my colleagues."

Harmes, Sweet, Heath-Eves, and Lacroix - government and military officials - all felt strongly that OPSEC was warranted.

"I think there's an impression that OPSEC is used as a line to try and avoid embarrassment or not answer the question," said Filiatrault, "but I think that the best way to get accurate coverage is to just answer the question. However, having been in this environment for a time, and having worked for a previous Minister of Defense, there are circumstances where holding information - such as identification of special-forces operators, or information related to a soft target, or embargoes in order for someone to stay safe - is absolutely required. Outside of mistakes that were made, I never saw a journalist deliberately break OPSEC for the sake of a story. Ultimately they wanted to make sure that no one was put at risk as much as we did on the communications side. But there is an impression in Canada that when you say you can't answer a question due to 
OPSEC, it's an effort to avoid embarrassment. I can tell you, in my entire 15 years, I've never seen OPSEC used to try and avoid embarrassment.

"As the first deployed CF PAO in Kandahar in January 2002, sent to run the Kandahar Coalition Press Information Centre," said Lemay, "I ensured that all 40 or more media representatives read, understood, signed, and respected the Coalition media ground rules laid out during Operation Enduring Freedom. One evening, I was approached by CNN reporter Marty Savage, who informed me that there was a ground rule breach. One of the reporters on camp had voluntarily broken the ground rules and CNN was asking me what I was going to do about it. Since the individual was a Toronto Star reporter, and because I was Canadian, there could have been an ethical issue had I not kept my word, applied the rule to the letter, and expulsed that reporter from camp the next morning." He added that, had there been ethical concerns about the use of OPSEC, as noted within the embed agreement, Canadian and international news agencies, editors, and reporters would have balked at participating in and signing the embedding media ground rules.

"The use of OPSEC depends on the circumstances," observed the senior civilian envoy, "and it was a challenging environment. Although government in general does tend to over-classify things, especially where mobility and security are concerns.”

"OPSEC is real," said Mulroney, "but there is also a real danger that it will be misused, and I think that sometimes it was misused." Taylor agreed: "They do play that card too much, for sure," he said, "and they can control things with its use." 
5.5.7 Would you have changed anything about the way that embedded, dis-embedded, or unilateral reporters were treated?

"I think we could have given them more regular, predictable access to our stories," said Welford, referring to civilian activities, "like a meeting every day to talk about items." Harmes added: "I always thought it would have been nice to have them stay longer," he said, "as our projects often took months to come to fruition and only snippets were reported because of the length of the journalists' stay."

"I think we would want to have a more deliberate program of getting them access to what they wanted to have access to," said Vance, "putting the resources in place, [like] more transport support. We probably would need to be more deliberate at helping reporters get out; I like to think we were getting better at supporting reporters and their desire to access the civilian population. I wasn't the CDS back then ... I would have met with editors/publishers so they knew what the embedded program was about, what it meant, [what] we could manage, provide in terms of logistics and access. We would want to take the lessons from Afghanistan and say, 'hey, is there anything we did wrong?",

"There were two issues with dis-embedded and unilateral reporters," said Mulroney. "One, if the coverage were negative, and two, coverage coming from someone who was engaging in negative behavior that might involve [the military] if that person got into trouble. I think there was a tendency to see Graeme Smith as an opponent because his 
coverage - including his coverage of detainees - was so strong. But there were also legitimate worries. When Melissa Fung was kidnapped, that absorbed a huge amount of effort and resources and attention. People who were out there freely might say, 'well it's up to me,' but if they got in trouble, it would trigger a huge deployment of resources to get them out again.”

"I thought we treated them all well, and fairly," said Lacroix. "We trusted and respected them, and we were honest with them. Once you lose trust and reciprocity, it's time for someone to go home." Stogran agreed: "It's important to enhance trust, and the only way you can have trust is if it's mutual. In my case, I allowed the media to see everything but I said, 'please don't burn me.' The military has to be transparent, but this goes against the culture." Stogran added that a lack of transparency contributed to his departure from the military in 2007. "They are risk averse to transparency but not to putting soldiers in harm's way. A general would not risk getting shit from Stephen Harper because a reporter stepped out of their lines, and people at the senior levels were not ready to take a career risk by being honest with reporters and telling them the truth."

\subsubsection{Ease of speaking freely to reporters}

"I could not, the opportunities were few and far between," said Mulroney, "it was only during the post-Manley period that I got to do that on a regular basis. Prior to Manley, some of my worst experiences in government were getting browbeaten by Cabinet ministers who were being briefed and scripted by PMO officials. I can recall on one 
occasion having a series of Ministers rip into me, and they were actually reading notes that had been given to them by a smirking group of PMO officials who were sitting behind them in the Cabinet room. It was very disillusioning," he recalled. "It was General Natynczyk and I. They wanted to criticize our communications efforts. What was really frustrating was that the constraints we were facing were ones that the PMO had imposed, but they were feeling under pressure and they had to blame somebody."

"There was a very restrictive approvals process to speaking on the record to reporters, coming from the PCO," agreed Welford. "The reality was that I didn't speak on the record very often to reporters, only on two occasions. I think I had good judgement: working with straightforward facts and no comments with political implications. Once there was a little pushback, but I knew it was the right thing to do." She recounted that, after an attack in Kabul, she reported that there were no Canadians killed. "This was a fact," she said, "it was not necessary to check with a department half a world away. Problems could come up when we had a government system where officials would not respond promptly, leave us for hours, or not respond at all, or they didn't understand the theatre, really didn't have a lot of understanding of the communications world, and 'no, please don’t take hours to just correct my grammar."”

5.5.9 Did military and government personnel provide thorough information to reporters?

"The CF has quite clear rules about who can say what to whom, and it relates to 'direct experience' only," explained Harmes. "No speculation, only opinions on what you've had 
experience with. For example, if you are digging ditches in the hot sun, you can have an opinion on that, even if it's just 'it sucks."'

"Upcoming operations were briefed under embargo when possible," said Lemay, "[and] media joining the operations witnessed everything - good or bad. Reporters remaining behind at camp received operational technical briefings, when the information was available, after each phase of the ongoing operation."

Lemay readily acknowledged that some aspects of the mission were perceived as less appealing or less newsworthy. "Logistic and support units barely got covered and PRT/Government of Canada rebuilding projects needed more deliberate actions [by] the respective military and civilian chains of command and communications personnel in order to attract attention. Timing was everything when came time to offer a less attractive story. You can't 'sell' that story if some 'hot' kinetic action is on-going somewhere else." Lemay explained that Canadian civilian PDOs, such as Sweet, were under some pressure to demonstrate progress and improvement. "This was in no way an easy task when compared to ongoing combat operations," Lemay said. "Governance programs and nation-building projects were often under reported and in the shadow of more tangible combat operations."

"Yes we did [provide information,]" said Welford, "and maybe sometimes it was incredibly boring, but if you wanted to check your facts, I could give you numbers of vaccinations, schools built, etc. Sometimes they wanted more opinion than we could give 
$\ldots$ and there is no doubt the previous government's approach to communications created a less-is-more chill.”

"The military simply put more resources into it than we did or could," added Mulroney. "The Kandahar mission was seen as an ability to remake the image of the CF as peacemakers, to be an elite combat force, and they put a lot of effort into telling that story. They were very thoughtful in terms of how they told their story, and how very actively and aggressively they courted the media, it was a sophisticated communications campaign.”

5.5.10 Did the CF treat reporters differently than the U.S. military treated reporters?

"From the perspective of someone taking journalists out on patrols," said Harmes, "I didn't see any difference in how the reporters were treated. Lemay added: "It was not a matter of treatment, but of policy and approach," he said.

\subsubsection{Summary}

Military and government officials had different experiences with embedded reporters, and still fewer experiences with unilateral reporters. While numerous respondents observed that many embedded reporters did not want to leave the confines of the CFMEP, the reasons provided for this were divided: civilian efforts were unappreciated and/or disparaged, reporters had to be on site in case of soldier casualties, overriding safety and 
security concerns for journalists, home-desk restrictions based on editorial decisions, less seniority and/or experience with combat reporting, and a desire to link the war with a domestic agenda rather than the Afghan environment.

When embedded reporters did leave the wire, it was often with the protection of, and a focus on, CF soldiers. Few respondents encountered unilateral reporters, but remarks from those who did - while largely respectful of the need to provide an Afghan perspective - ranged from sceptical to disgruntled: reporting from outside the wire could be biased, it did not guarantee a view of the bigger geopolitical picture, and it still tended to focus on the military in one form or another. As two government officials noted: even after the Manley Report (2008) made it much easier for civilians to connect with reporters on diplomatic and development efforts, reporters still did not seize those opportunities. ${ }^{58}$

The issue of context was raised several times; however, context seemed to mean something different to someone with a military or civilian perspective. In the case of the former, it often meant sharing and understanding reasons for, or providing background on, military manoeuvres and objectives. It was particularly irksome to several military respondents that atrocities committed by the Taliban seemed underreported in contrast to much strong scrutiny of CF actions. Context to a government official meant sharing the nuts and bolts of a development project that might not possess the triumph of battle or a clear beginning-and-end narrative, but could nonetheless have an impact on many lives. 
Finally, in contrast to the views of several reporters in the previous chapter, most officials felt that OPSEC was fairly interpreted and exercised.

\subsection{Media coverage}

\subsubsection{Canadian media coverage of the Afghanistan mission}

Opinions ranged from mixed to critical.

"I think our media certainly became far more aware of the military," observed Taylor. "It was almost a bonding process; they got inside that world and reflected it. People began to know the difference between gunner and sapper, etc., and both the media and the public loved it. There was definitely more informed coverage of the soldiers."

"Given the complexity of what was going on at ground level, the parameters within which we were all operating, and the complicated nature of the mission, overall I found the reporting relatively accurate," said the senior public diplomacy officer, "but the quality was different on any given day." Welford agreed. "It was sporadic," she said. "The mission happened at exactly the same time as when the Canadian media went through a big change: beat reporters and generalists became more prominent whereas foreign reporting becoming more diminished. It was much better when we worked with reporters with the latter experience, but when dealing with mid-market reporters, the quality decidedly dropped off." 
"Given my role, I certainly paid attention to media coverage," said the senior civilian envoy. "Some people did extraordinary work, it's a very difficult environment to live and work in, but I think coverage could have been wider. I don't think the civilian aspects were reported at all, we could have done it better." Mulroney echoed this sentiment: "It was pretty accurate, but it might have been different had the civilian side of government been more able to tell more of their side of the story, and talk about what they were doing. You saw this in Murray Brewster's book,${ }^{59}$ how hard it was to find out about water coming from the Dahla Dam because no one would really talk to him. People were so scared of reprisals and retribution that they had stopped communicating."

"Generally speaking, they were doing a good job," said Harmes, "but still, they tell only a piece of the story when they focus on the Canadian perspective and not the multi-national aspects of it. For example, when humanitarian aid workers were killed in August 2008, it sounded like only two Canadian workers were killed but not the third, an American, and I knew her personally so this bothered me."

Filiatrault praised the coverage generated by reporters like Murray Brewster and Graeme Smith "that was top quality, partly because they relentlessly went into Afghanistan and became extremely good at covering events and developing a good situational awareness over the course of years and several battle-group rotations and several ambassadorial rotations," she said, "versus journalists who came in on a one- or two- or six-week embed." 
"I paid very close attention to it and did not think it was always top quality," said Vance.

"There was a disconnect sometimes between what was being reported and what the nature of the mission was. That said, if you read and watched and sampled widely within the Canadian media realm, you would have very balanced view of the Canadian mission, but if you relied on a particular news agency or just headlines and the first paragraph, you probably would not have a very good sense of the mission."

"Every single day I paid attention to media coverage, and it was terrible," said Sweet. "Those that came over did their best but unfortunately they often brought a lot of homeagenda items with them." Heath-Eves concurred, adding: "I would not say it was very good," she said. "There have been a lot messages out there about our failures, but I think we did make advances, we helped Afghans have better lives, there are more children in schools by a landslide, civil society is better, the Afghan people have more tools at their disposal ... but all too often the message has been critical." Lacroix believed that "internally, within the Task Force it was done well," he said, "but outside the area and back in Canada, it was poorly done."

Stogran was also critical, explaining: "It was tainted, biased, fixated too much on media lines and embedded journalists who were being led around," he said. "Mathew Fisher, bless him, became highly assimilated by the Borg, a case of Stockholm syndrome." 
A number of respondents noted the more nuanced nature of print coverage versus the more emotional reach of television through visuals.

"Certainly there is a difference between the 30 -second sound bite with television and deeper print reporting," said Lacroix. "Print coverage was, generally speaking, more thorough, more nuanced," added Vance. "Print coverage tended to be more nuanced, because they had the time and the depth to do that," agreed Mulroney. "Obviously with print you have more detail," noted Taylor, "but in terms of overall coverage, the "rah-rah support for the troops' reporting was similar."

"Print is able to get into issues in a little more depth," said the senior civilian envoy, "particularly if a reporter came back [more than once] and over a period of time. Television provided more of a snapshot view." Stogran added that "television was very much about sound bites. Articles will allow you to 'peel the onion a bit. Also, television coverage was not so much about critical questions, they were almost like cheerleaders."

"I don't think the difference was a result of one being better than the other," said Welford. ' $\mathrm{TV}$ is much more emotional, it is more poignant when the cameras are showing things like ramp ceremonies, and of course they have to cover that. But the end of the mission, there was one pool camera, which meant it could never be more than half an hour away from a possible ramp ceremony, and so that massively reduced the scope of television coverage of the mission." 
"War is very visual to report, very explosive, and from a broadcast perspective, in many cases, riveting," said Filiatrault. "I found that right or wrong, journalists would want to capture that kinetic element, but so much of what Canada did was not kinetic, like education for girls."

"As a professor, I would say that the quantity of detail that gets put into print reporting is at the highest level," said Harmes, "whereas television reporting is at the other end of the spectrum. Television reporters need visuals and audio and several takes and this was logistically problematic for them, and had an impact on the stories that were told." $\mathrm{He}$ added that how much news organizations were willing to invest in news coverage would also make a significant difference in reportage: "For example, one news organization would have one reporter and that would give one perspective, whereas other organizations would have more reporters in various ways and thus they reported more broadly on what was happening in the country."

5.6.3 English versus French-language media coverage

Most respondents noted that francophoe media coverage was almost always correlated with the presence of French-speaking troops.

"If the Van Doos ${ }^{60}$ or French troops were present," said Lacroix, "you would get more French coverage, but if there wasn't that troop presence, you didn't get much coverage, 
except perhaps for fatalities." Welford agreed: "The reality was that there was very little French influence in the embed program, and it was almost always related to French soldiers' presence," she said. The senior public diplomacy officer also witnessed the same discrepancy: "There were many more anglophone than francophone reporters."

Several officials thought that, even though their numbers were low, the quality of Frenchlanguage reporting was high. "The French reporting was of a better quality," said HeathEves, "they had a better handle on how the military worked with civilians, a better grasp of the bigger picture, and how different pieces of government worked together." Vance recalled that “there wasn't as much French coverage, they didn't have as many embedded reporters, but the ones they did have were good." Filiatrault added that "detainee issue aside, French coverage tended to focus more on human rights."

\subsubsection{Canadian media coverage over the duration of the Afghanistan mission}

Several officials noted the sharp decline in numbers of media personnel covering the war from the inception of the embed program toward the latter part of the mission.

"In the beginning you had a full media tent, toward the end only six or seven in the tent, and that changed the nature of reporting," said Filiatrault. Welford concurred. "Coverage was very different, from 2008/2009 when the media tent was full, about a dozen or so, to 2011 when there were about three or four reporters," she said. "Both the media and public lost interest, and the death of Michelle Lang hit everyone really hard." The senior civilian 
envoy, who watched media coverage very closely, said "the coverage peaked from 2006 to 2009 , there was less coverage post 2009 , and then dropped off toward the end of the mission."

"From 2006 to the pull out, the focus was all defense, casualties, ramp ceremonies, both in theatre and in Canada," added Lacroix.

"It's probably accurate to say that some media organizations stopped reporting accurately and started to portray the mission in a particular way," said Vance. "When the country decided it was going to stop its Kandahar mission and change its focus to [Kabul,] the reporting changed and that was too bad because it was the exact moment when Kandahar was beginning to settle down. The reporting focus became about us leaving, there was a definite sea change in reporting that we were not long for the mission."

Several respondents suggested that growing antagonism between the media and the Harper government may have contributed to the tenor of media coverage, that as the country became politically opposed to PM Harper, the criticism of the mission increased. Conversely, Stogran believes that as the mission lengthened, media coverage "became media lines from the $\mathrm{CF}$, it became very much centrally controlled, and there was a huge disconnect between reality and the CF propaganda for the Canadian media," he said.

5.6.5 Top Canadian reporter on the Afghanistan mission 
Matthew Fisher was the journalist that a majority of officials most often praised for his reporting on Afghanistan, someone that Lacroix said "understood military operations, he's been doing it for decades, he understands the strategic, operational and tactical, and has been elsewhere like Bosnia and Haiti.” Graeme Smith, Murray Brewster, Michelle Lang, and Matthieu Aikins were likewise admired for the quality of their reporting.

"The international reports were also interesting," commented the senior civilian envoy. "Media organizations like the Financial Times and the BBC also came out, they reported differently on the mission. The British tend to follow international development much more in depth than Canadian reporters."

\subsubsection{Summary}

As noted in the previous chapter, it is difficult to paint media coverage during a 10-year period with one stroke of the brush. Assessments ranged from good to tainted, with various explanations given and concerns raised. The overall glaring omission, as stated elsewhere in this chapter, was sparse attention to civilian development efforts versus an abundant focus on military aspects of the Afghanistan mission. Another issue raised was the 'siloed' nature of media coverage: a hyper focus on Canadian activities - and many other countries' embedded media did this as well - meant that the panoramic view of the roughly 50 nations involved in the war was lost. Still others felt that the message was either overly critical of Canadian military and humanitarian efforts in Afghanistan or far too accepting of military narratives. Numerous military and government officials noted 
the pronounced decline in media personnel covering the war from the CFMEP's inception toward the latter part of the mission, the media's growing focus on casualties and ramp ceremonies, and a particularly acute decline in presence and coverage after Calgary Herald reporter Michelle Lang was killed in 2009. Finally, a number of respondents suggested that growing antagonism between the media and the Harper government may have contributed to the increasingly negative tenor of media coverage of the Afghanistan mission.

\subsection{Oversight}

5.7.1 Administrative support of working with reporters

Responses varied. On one hand, according to Welford, "they were supportive, we needed to communicate what we were doing," she said. "The problem is that bureaucracies are not nimble, supportive but not nimble."

On the other hand, said Heath-Eves: "It was pretty bad, I am grateful that nothing negative happened while I was there," she said. "The control by the PMO was so tight that it made my job very difficult in working with reporters. Sometimes I would ignore those rules and talk with reporters using past decisions as a 'work around' to answer their questions." She recalled one example of having worked for weeks to set up a trip for a Canadian Press reporter, then receiving a last-minute email telling her to cancel the trip 
because Ottawa wanted another event to receive media attention without any interference. "But I called them out on it and they recanted," she said.

"Looking at my PA officers, I would say the military higher-ups were not as supportive as they could have been," said Lacroix. "At times the PA department back in Ottawa could sometimes become more of a problem than help."

\subsubsection{Official interest in particular types of stories}

The senior public diplomacy officer said that one of the reasons his position was created in the post-Manley period was to better inform the Canadian public about what was happening in Afghanistan by providing information to the media. "We also created another position at the PRT in Kandahar City," he said, "so me at Kandahar Airfield, and another in Kabul. Three full-time PA assets focused on telling better stories, much of it modeled on the Manley report, that is, recommendations on civilian engagement in the field and in Ottawa, focused on a 'whole of government' approach."

"My superiors were not overly focused on signature projects," said Lacroix, "they were more worried about the military operations being conducted, detainees, etc."

"The ultimate story was Rick Hillier," remarked Taylor. "He was able to enchant the media, a good old Newfoundland boy. He took [comedian] Ricker Mercer over in 2006, and built a floor-hockey arena for half a million dollars at the military base. The stuff we 
built for ourselves, and the expense! The cost was unbelievable, and around us we had Afghans just living in tents."

Vance reflected on stories that he wishes had been reported. "I would have liked more written about where the population was recovering, or trying to recover from conflict," he said, "where the results of our work could be seen and felt in the daily lives of the population. I would have liked more reporting on the parts of Kandahar province that were coming back to life: cottage industries, family homes where the lights turned on, where water was running again, and the kids were going to school. There were some successes, not just because of us, but because we set conditions for other departments and Afghans and ministries to get some things done. And in that, there was room for criticism, criticism of the Afghan government, failure to tie worldwide resources to the problem at hand - these are all legitimate areas to report on. Sometimes we would try to set conditions and fail to do so, or in trying to set conditions, we made things worse. So there is lots of room for objective reporting and criticism but I would have liked it to look more closely at the kind of results we were trying to achieve within the population we were trying to secure."

5.7.3 Unwarranted attention on certain stories in the media

"This is one of the major failures for [the military,]" said Lacroix. "We wanted to change the media and public narrative from death and military narratives to the mission itself, which was to help Afghans. But the media focused more on the deaths than what we were 
doing over there; 90 percent was focused on the military and maybe 10 percent on everything else. I think the editors failed us back in Canada."

“It wasn’t just because the journalists were not covering the development stories," said Mulroney, “we didn't enable the reporters. From 2007 onward, we did see stories about the Dahla Dam, building schools, polio immunization and other vaccinations, changes to the justice system, etc. I wish we had told a better story about the great changes we made to the detainee system. I asked a reporter about this and he said 'that story is over, no one wants to hear that story anymore."”

"I think the living conditions at Kandahar Airfield or the PRT received more coverage than warranted," said Welford. "I grew up on military bases, and I thought it was a bit cheap to criticise that there was a Pizza Hut on base that would deliver to soldiers' tents. A lot of those soldiers needed to rest and recuperate. That was one of the disadvantages of the media being trapped on base and covering a lot of day-in-the-life-of stories."

5.7.4 On whether certain stories should have received more attention

"Without question, the efforts done on the civilian mission," said Welford. "I think Canadians have no idea that we trained police, that we worked with human rights in prisons, that we helped set up border crossings, and that we helped with the collection of taxes." Many activities related to diplomacy and development were carried out, added the senior civilian envoy, such as "our work with the Afghan police, corrections officials, 
municipal and provincial changes, advancing human rights, promoting law, all this in addition to development work on health and other issues."

"There were a lot of great stories that weren't being told," agreed Harmes. "The casualtyrelated stories definitely received far more coverage than others, and while they were important to friends and families back home, in terms of the percentage of what was going on, the coverage was overdone."

5.7.8 Preference for working with embedded, dis-embedded, or unilateral reporters?

"[Officials] are human and no one likes to be shown in anything than the best light possible," said Sweet. "From a PR standpoint, they preferred the embedded reporters because they knew them, and who they were dealing with."

"It was more about the convenience of working with the embeds," said Lacroix, "they were part of the team, they were enablers, they could help us out or sink us. I felt that embeds could be trusted as long as they followed our rules; I think that Matt Fisher understood that. But unilaterals did not have to report to us, and we weren't a source of information for them. I don't think they did us any harm or good. They weren't there for Canadian interests, they were there for other stories, and not necessarily from a Canadian perspective. Their motives were different from the embeds' motives, which were soldier oriented. I think the two different methods can absolutely complement one another." 
5.7.9 If unilateral reporters were more prone to criticize military action

“They were more prone to give a fuller picture," said Sweet, "and a fuller picture of any action and/or use of power will inherently involve criticism of it." Lacroix concurred: "I didn’t work with them," he said, "but based on what I read, I would say yes."

"They were looking at other aspects than military gains or losses," said Welford, "so they were in a better position to comment on the impact of it all on civilians. Harmes added that they may not have been more prone to criticism, "but they would have had different contacts and sources, and this would have affected their coverage."

Lemay pointed out that embedding does not mean always agreeing with the military, and always reporting positive stories. "Embeds who were with the troops saw the good and the bad," he said, "and as such could often criticize military and civilian actions and inactions."

\subsubsection{Summary}

Disclaimer: in order to secure Department of National Defence ethics approval of my questionnaire for military personnel, I agreed to remove the majority of my Oversight questions (see Appendix L) as they were deemed to pose a risk to respondents given that they asked for opinions that required participants to "speculate about events, incidents, issues or future policy decisions" (DAOD 1998), which is prohibited by Canadian 
legislation. ${ }^{61}$ Only one military criticism cited was that PA officials in Ottawa could be more of a hindrance than help. Government officials were generally more vocal, lamenting the control by the PMO and PCO that often made their work with reporters difficult. Editorial control back in Canada was also criticized for focusing more on military deaths than Canadian accomplishments in Afghanistan.

5.8 Advice for the future

Suggestions ranged from the practical to the more philosophical, notwithstanding a government or military background.

"The embedded program needs a 'lessons learned' exercise or review just as much as many other programs or developments or decisions coming out of Afghanistan do," said Mulroney.

Respondents suggested pre-mission training and learning the rules. "Part of it is making sure that our staff has training, know how to engage in a conversation with the media, and I would certainly encourage background sessions or discussions prior to going," said the senior civilian envoy. "Staff going into extremely challenging environments need specialized training, for example, understanding how to navigate interpersonally in those very close quarters. Certainly there is better dialogue that can be held before, during, and after." Heath-Eves suggesting gaining "a very clear understanding of the rules of your job, such as the rules controlling the message out of the PMO," she said. "Learn how to work 
around them when necessary, as sometimes the rules certainly got in the way of communicating stories."

Several said access and information were imperative. "Give them lots of access, time, speak with them, answer questions, and offer context," said Vance. "One technique I used was giving non-reportable background briefs, explaining in fairly candid detail what we were trying to achieve. Most new arrivals got that pitch from me." Filiatrault agreed that access and availability were key. "You have to give people in the field delegated authority to provide access to journalists," she said, "not just facts, but also discussion and dialogue. Trust in the people on the ground to coordinate. You have to let the seriousness of the enterprise dictate coordination, break down silos, and don't try to run activities from Ottawa." She repeated a phrase a departing journalist once told her: "Trust in the truth.” Lemay similarly suggested enabling other government-department communications staff to share their whole-of-government stories with embedded reporters. "Canadian embedded reporters stopped reporting on overall Canadian objectives and benchmarks because civilian communicators could not meet in-theatre deadlines," he said.

Remembering the humanity of all participants was essential, said others. "Having a mutually respectful relationship with journalists prior to going into a conflict zone is incredibly helpful," said Welford, "because things move so fast due to combat, or a thousand other things can happen." Harmes agreed, suggesting that public affairs personnel could perhaps arrange for fostering relationships with journalists in Canada 
before going into the theatre of operations. "Remember that everybody is working under difficult conditions," added the senior public diplomacy officer. "Even before I landed there, I decided to take the approach of dealing with people in the most respectful and professional manner possible. You're living in cramped quarters and working seven days a week, 15 hours a day, hearing rockets go off at different times, and it can be difficult." Sweet added: "every kind of relationship only works if there is communication," he said. "You don't have to be disagreeable to disagree. Remember that you are both doing your jobs: you are a representative of the decisions of the state, the media is there to question those decisions, so don't take it personally."

"Harmonization, cooperation, and transparency are necessary," said Stogran. "There was such a disconnect between the higher ups and what was wanted or needed at the ground level. CIDA and DFAIT had imposed their projects form above, they did not speak with the villagers and learn what they wanted. Hillier never harmonized military activities with DFAIT and CIDA. If we would have harmonized the campaign more than we did, it could have been more successful." Lacroix added that "trust, mutual respect and honesty are key. You can give them all the information you want, but if you don't have those three you won't have a good relationship." Lemay praised those journalists who put their lives at risk to cover the mission. "War correspondents spend more time on dangerous assignments at one time than any soldier," he said. "They are often sent on their own without any intelligence, support or any armed escorts. Reporting the news and putting the military operations in context is in my own view their number one role; reporters must 
report what they see and the military must help them understand. Openness, transparency and access are three objectives I have championed."

\subsection{Epilogue}

Similar to chapter 4 , below are five commentaries that deserve a separate mention as they went beyond the scope of my questions.

Colonel Pat Stogran has rarely shied away from speaking his mind:

Although military force is thought to be decisive in a battle, it's not. It's the will of the people, and winning is about eroding the will of the people who are opposing you, or setting the conditions for this to happen. When I went back to Afghanistan in 2010, an elder said to me: "You used to talk about human rights, and yet everyone knew about what was happening with the detainees." Another time they wanted to talk to me about "democracy," although everyone knew about Karzai's dishonesty. Even though you may have political "wins" back home, the Afghan people know what's going on and you've already lost with them. That's why they will go with the devil they know, the Taliban.

Lacroix addressed at length the challenge of developing model village Deh-e-Bagh:

There was a lack of coordination by all government departments and DND in telling the narrative of Afghanistan. The PCO Afghanistan had a responsibility of telling the story of Afghanistan in coordination with other departments and the media, but I don't think there was ever a time Mulroney sat down with all the editors and said, "this is what we are doing in Kandahar." General Jonathan Vance and Brigadier-General Fred A. Lewis were in sync with what we doing in Kandahar, but it was not supported by the PCO group because it wasn't their idea. It was developed by the military, written and carried out by the military, but we worked hand in hand with the civilians over there. We saw the necessity of shortterm security that would allow for a long-term mission. But it was a turf war with the PCO, there was a lot of friction.

We launched in June 2009 after the PCO group gave support and it was very successful. The PRT assigned a political advisor to work with the district governor and find out what the people wanted. The PRT hired locals to do the 
work, filling in holes, working on roads, building schools, etc. and by September 2009 we were walking in the streets without flack jackets. The villagers were in control of their own destiny, a normal life for around 1200 people, where before there had been high unemployment, poverty, fear, etc. The men were working for a living and supporting their families, they took care of security, made sure people didn't come in with weapons. We tried to get the media to come down and show them around to talk to the villagers; they would sometimes cover it but their mandate was focused on the military side more than the collective efforts of our mission. Matt Fisher did write a beautiful feature on Deh-e-Bagh.

Lemay on how the program can adapt, but never be a single solution to reporting war:

The CFMEP officially began in 2006. Before that, we had reporters signing Coalition/ISAF ground rules. From 2006 on and after my arrival at CEFCOM in 2008 , the program was continuously adjusted, incorporating reporter and foreign editors' feedback and adapting to the type of operations and support [the forces] able to provide.

In the beginning, we had three Canadian TV crews (CBC, CTV, Global) and a wide representation of agency/print reporters rotating through. In 2008 or so, the TV crews agreed amongst themselves to pool their resources and rotate on a quarterly basis. We saw less experienced reporters showing up. It became a comfortable grooming ground for Canadian reporters who had never set foot on a battlefield. The program now, although very much limited, has been adapted to the Kabul mission and our operations at sea.

Filiatrault on the bureaucracy of war:

From a communications perspective, there wasn't enough delegated authority in the field, or clear lines of authority or coordination. For example, there was a healthy tension at the time between CIDA and the CF. Let's say there was a dirt road, with potential for IEDs. A soldier that needs that road would want it paved in double quick time, but capacity building regarding the dirt road - which is really critical to the future of the country - takes more time. Soldiers and civilians would hash it out at the PRT. Back in Ottawa, where the delegated authority for communications lay, they had their own divisions of labour and lack of coordination, and sometimes departmental territorialism would outright compromise what we were trying to do in the field. The bureaucracy of war surprised me.

Scott Taylor on the domestic media's lack of initiative: 
I have large respect for unilateral reporters but there is a huge factor of danger in Afghanistan, especially when you have tribal leaders, because who they are and what they do is very complicated. We have diasporas here in Canada, like in Toronto, where we can go and ask questions to understand these complexities, but the reporters here don't even go to embassies, yet alone the diasporas, who are certainly still plugged in.

\section{Conclusions}

The intent of this chapter was to present the views of government and military officials who had direct contact with the media during the Afghanistan War. Rarely have officials who work with war journalists been asked to provide observations gleaned through their unique experiences; a gap that this chapter seeks to fill through 13 interviews with government and military officials whose expertise and experience range from diplomacy and development to military combat and strategic planning.

Canada's mission in Afghanistan was the largest and most complicated whole-ofgovernment initiative in Canada's history. Yet most members of the Canadian public were and are unaware of the scope of the mission — primarily due to an absence of comprehensive media coverage of it. Some of this was due to the complicated nature, long-term investment, and perceived banality of diplomatic and development projects. Some of it was due to the early framing of the CFMEP - initiated in 2006 - as a military conduit, prior to the Manley report's 2008 refocus on the "whole of government" approach. Some of it was due to editorial decisions that were made in Toronto-based offices, far from the effects of the war. And some of it was due to the perceived news appetite of the Canadian consumer, correct or not. 
A key theme of comments by military and government officials in this chapter concerned which issues received media attention, or did not. Coverage of military matters clearly outweighed coverage of civilian efforts, even after government directives shifted emphasis to the 3D's: diplomacy, development, and defence. While cultural differences are largely acknowledged between military and media worlds, it was surprising to find such a schism between military and civilian ambitions: both part of the overall mission, both important, but one starkly overshadowing the other.

A second theme was displeasure with the increasing media emphasis on covering soldier injuries, fatalities and ramp ceremonies, still part of the military focus, but unwanted. During the course of my interviews, I began to suspect that the initially encouraged focus on soldiers and military movements may have contributed if not led to this subsequent focus on soldier fatalities and ramp ceremonies, which certainly displeased most of the military respondents. While some officials - both military and civilian - believed that media attention to soldier fatalities and covering the ramp ceremonies was respectful to the memory and sacrifices made by CF personnel, most disagreed with the degree to which it occurred and resented the apparent home-desk insistence on this coverage, leading to use of the disparaging term, "death watch." These two themes support my thesis argument of a discernible structural influence on media coverage that reflected the accord reached between the two disparate cultures, the military and media: a focus on military matters, initially desired but subsequently resented, to the detriment of attention to diplomatic and humanitarian efforts in Afghanistan. 
Another theme, voiced by several government officials, was frustration with political meddling and delays from above, particularly by the communications staff at the PMO. The commonality of shared experiences seems to support the claim there was an attempt by select Ottawa personnel to control the message on the other side of the planet. There there was no such criticism from military officials, perhaps because the very structure of the military is predicated on decisions made at the top and uniformly passed down.

The effects of reporters living and working in close proximity to CF soldiers was another theme. One of the unintended effects was that it allowed soldiers and military personnel to gain a better knowledge of the way that journalism and journalists work, however, the real concern for several respondents was a potential loss of objectivity by reporters. These concerns point to an awareness that it is human nature to report favourably on those closest to you, particularly if they are responsible for protecting your life. Others felt that journalism professionalism would safeguard against this and, in fact, several noted that embedded journalists could be critical of military behavior on occasion.

One final but omnipresent theme involved the notion of context as it pertained to the Afghanistan mission. Differences in the definition of context reflected differences in cultural values and ideologies. From a military perspective, context often meant sharing and understanding reasons for, or providing background on, battlefield decisions and objectives. Context from a civilian perspective meant giving equal value to the different components of the "whole of government" approach, such as diplomacy and 
development. Context from a journalist perspective meant examining the wider effects of the war on the lives and future prospects of the people of Afghanistan.

\author{
These findings and themes, in conjunction with findings and themes from media \\ interviews in chapter 4 , and discourse analysis of media coverage in chapter 6 , will be \\ further analyzed and discussed in chapter 7.
}

\title{
NOTES
}

${ }^{50}$ Two of whom requested anonymity.

${ }^{51}$ The KPRT is a small base located in downtown Kandahar City.

${ }^{52}$ Captain Harmes is still a reservist.

${ }^{53}$ Defined as consultation, usually a meeting of tribal elders, local religious leaders, administrators, etc.

${ }^{54}$ See (Galloway 2009) for more details.

${ }^{55}$ For additional details, see (UNDP 2015).

${ }^{56}$ Camp Mirage was the codename for a former CF forward logistics facility located in the desert outside of Dubai, United Arab Emirates. The facility was established in December 2001 and, while not officially acknowledged by the CF, many considered it an "open secret." The base was reportedly closed in November 2010.

${ }^{57}$ The envoy remarked this occurred during the 2008 to 2009 period of the mission.

${ }^{58}$ However, several government respondents still cited restrictions emanating from PMO officials as major constraints to answering media queries in a timely manner.

${ }^{59}$ Reference: The Savage War: The Untold Battles of Afghanistan, 2011.

60 "The Van Doos" is an anglicized pronunciation of the French word for 22 or vingt-deux. The Royal $22^{\text {nd }}$ Regiment is a CF regiment, mostly francophone, located in Quebec City. It comprises three regular force battalions, two primary reserve battalions, and a band.

${ }^{61}$ Please reference DAOD 2008-2: "Media Relations and Public Announcements: 4.7 - When dealing with a media request for an interview or information concerning what they do, CF members and DND employees (3) shall discuss only their own job within their personal areas of experience or expertise; 4.8. - In addition, CF members and DND employees speaking in their official capacity, including designated subject matters experts and PAOs, shall not (4) speculate about events, incidents, issues or future policy decisions, (5) offer personal opinion on government, DND or CAF policy...." (1998). 


\section{CHAPTER SIX: MEDIA COVERAGE ANALYSIS}

This chapter seeks to review media coverage provided by embedded and dis-embedded journalists vis-à-vis military units during the Afghanistan War in order to examine any notable difference in news reports and emphases as demonstrated by coverage, theme, and tone. This chapter is an important component of my original contribution to the field for two reasons. First, analysis of actual media coverage can serve as a "reality check" on the observations, hopes and opinions of the three groups - journalists, government and military officials - previously interviewed. Second, it serves as a baseline body of data for present and future use given that a 10-year analysis of media coverage of the Afghanistan mission does not currently exist. The data gathered and presented in this chapter support my core argument that the negotiated structure of CFMEP embed policy led to an overwhelming media focus on the military to the detriment of diplomatic and humanitarian efforts by the Canadian government, which will be further discussed at the end of this chapter as well as in chapter 7.

Of note: as addressed in chapters 3 and 5, the CFMEP in Afghanistan - unlike the prior American and British systems in Iraq - allowed reporters to dis-embed and re-embed at their own discretion. While unilateral reporters could operate within the Canadian context, very few did so and none within the confines of the four prominent Canadian media outlets examined in this chapter. ${ }^{62}$ Analysis for the following 10 -year synopsis of Afghanistan coverage was carried out in conjunction with three different periods of $\mathrm{CF}$ involvement in Afghanistan. Period I extended from the official beginning of the war in 
October 2001 through to July 2002, when CF troops primarily assisted a U.S.-led task force hunting al-Qaeda terrorists. Period II extended from February 2003 through to the end of 2005, when Canadian troops were primarily stationed in Kabul as part of Operation Athena. Period III began in February 2006, when the CF was primarily stationed in Kandahar province as part of Operation Archer, up to December 2011 when the mission officially ended.

\subsection{Methodology}

I will use CDA to perform content analysis of media coverage of Canada's participation in the Afghanistan War from 2001 through to 2011. While the preceding chapters looked at the perspectives and attitudes toward embedded reporting of those most closely involved with its design, implementation, and practice, this chapter will examine its impact on media coverage by Canadian journalists. I will use CDA to bridge the "gap" between what van Dijk $(2008,87)$ calls the micro and macro approaches to discourse. Language use, discourse, verbal interaction, and communication belong to what he calls the micro level of the social order. Power, dominance, and inequality between social groups typically belong to a macro level of analysis. I will examine both, scrutinizing the former with concrete examples throughout this chapter, and relating it to the latter toward the close of this chapter.

Information gathering will be conducted in two stages. Prior to discourse analysis of media coverage from 2001 to 2011, I will use a method of data collection called 
constructed week sampling (hereafter noted as CWS) during this 10-year period. This is a type of stratified random sampling (SRS) technique used in media studies in which the final sample represents all seven days of the week (Jones and Carter 1959; Stempel III 1952) to account for cyclic variation of news content (Riffe, Aust and Lacy 1993). For example, constructing one week from a population of one month would involve selecting one Sunday from all four Sundays that month, one Monday from all four Mondays, etc., until each day of the week is represented in the final sample.

This form of qualitative content analysis will ascertain the broad content of each text (written and verbal) over time, thus providing a database of passages that specifically address the Afghanistan War and can subsequently be given a more detailed analysis. An understanding of the texts on a broad level is necessary in order to place a more specified or precise analysis into context and, furthermore, can help to avoid viewing the selected passages in isolation but, rather, as part of a possible trend, convergence, and/or dominance of media coverage by one media entity more than another.

This technique will be modified for the three time periods I will be examining, the reasons for which were described in greater detail in chapter 3. Period one extends from October 2001 through to June 2003, a total of 21 months. I will construct a sample of three weeks of media coverage from 7 October 2001 through to 7 June 2003. For example, I will select one Sunday from the second week of October $2001,{ }^{63}$ one Monday from the third week of November 2001, one Tuesday from the fourth week in December 2001, and so on. Period two extends from July 2003 through to February 2006, a total of 32 months. I will 
construct a sample of four and a half weeks of media coverage from 6 July 2003 through to 1 February 2006, repeating the earlier process: selecting one Sunday from the second week of July 2003, ${ }^{64}$ and so on. Period 3 extends from March 2006 through to December 2011 , a total of 70 months. I will construct a sample of 10 weeks of media coverage from 5 March 2006 through to 24 December 2011, selecting one Sunday from the second week of March $2006^{65}$, and so on.

Table 1 illustrates my sampling construction of $17 \frac{1}{2}$ weeks of media coverage from October 2001 through to December 2011, a 10-year period in total.

TABLE 1

Constructed Week Sampling, Oct. 2001 - Dec. 2011

\begin{tabular}{|c|c|c|c|c|c|c|c|}
\hline$\underline{\text { Week }}$ & $\underline{\text { Sunday }}$ & $\underline{\text { Monday }}$ & $\underline{\text { Tuesday }}$ & $\underline{\text { Wednesday }}$ & Thursday & Friday & Saturday \\
\hline \multicolumn{8}{|l|}{$\begin{array}{l}\text { Period } \\
\text { I }\end{array}$} \\
\hline 1 & 7 Oct. 2001 & 12 Nov. & 18 Dec. & 30 Jan. 2002 & 7 Feb. & 15 Mar. & 27 Apr. \\
\hline 2 & 26 May & 3 June & 16 July & 21 Aug. & 5 Sept. & 11 Oct. & 16 Nov. \\
\hline 3 & 22 Dec. & 27 Jan. 2003 & 4 Feb. & 12 Mar. & 24 Apr. & 30 May & 7 June \\
\hline \multicolumn{8}{|l|}{ Period } \\
\hline \multicolumn{8}{|l|}{ II } \\
\hline 4 & 6 July & 11 Aug. & 23 Sept. & 29 Oct. & 6 Nov. & 19 Dec. & 24 Jan. 2004 \\
\hline 5 & 29 Feb. & 1 Mar. & 6 Apr. & 12 May & 24 June & 30 July & 7 Aug. \\
\hline 6 & 5 Sept. & 11 Oct. & 23 Nov. & 29 Dec. & 6 Jan. 2005 & 18 Feb. & 26 Mar. \\
\hline 7 & 24 Apr. & 2 May & 7 June & 13 July & 25 Aug. & 30 Sept. & 1 Oct. \\
\hline 8 & 6 Nov. & 12 Dec. & 24 Jan. 2006 & $61 \mathrm{Feb}$. & & & \\
\hline \multicolumn{8}{|l|}{ Period } \\
\hline \multicolumn{8}{|l|}{ III } \\
\hline 9 & 5 Mar. & 10 April & 23 May & 28 June & 6 July & 18 Aug. & 23 Sept. \\
\hline 10 & 29 Oct. & 6 Nov. & 12 Dec. & 24 Jan. 2007 & $1 \mathrm{Feb}$. & 9 Mar. & 21 Apr. \\
\hline 11 & 20 May & 25 June & 3 July & 8 Aug. & 13 Sept. & 26 Oct. & 3 Nov. \\
\hline 12 & 9 Dec. & 21 Jan. 2008 & $826 \mathrm{Feb}$ & 5 Mar. & 17 Apr. & 30 May & 7 June \\
\hline
\end{tabular}




\begin{tabular}{|c|c|c|c|c|c|c|}
\hline 6 July & 11 Aug. & 23 Sept. & 29 Oct. & 6 Nov. & 19 Dec. & 24 Jan. 2009 \\
\hline $1 \mathrm{Feb}$ & 9 Mar. & 14 Apr. & 20 May & 4 June & 10 July & 15 Aug. \\
\hline 20 Sept. & 26 Oct. & 3 Nov. & 9 Dec. & 14 Jan. 2010 & 26 Feb. & 6 Mar. \\
\hline 4 Apr. & 10 May & 22 June & 28 July & 5 Aug. & 10 Sept. & 16 Oct. \\
\hline 21 Nov. & 27 Dec. & 4 Jan. 201 & $116 \mathrm{Feb}$ & 24 Mar. & 29 Apr. & 7 May \\
\hline 5 June & 11 July & 23 Aug. & 28 Sept. & 6 Oct. & 18 Nov. & 24 Dec. \\
\hline
\end{tabular}

Note: For periods 1, 2 and 3, $n=17.5$ weeks

The second stage, a more meticulous discourse analysis, "traces its roots back to linguistics" and allows for detailed analysis of the 'semantics' and 'syntax' of the texts (Johnston 1995, 220) vis-à-vis the research focus: quantifiable influence of embedded status. The units of measurement will be theme, a central idea or convergence on a subject, such as the hunt for Osama bin Laden; presentation, if the journalist is reporting from an embedded or dis-embedded vantage point; and tone, such as an observable choice of personalized, neutral, or sensationalistic language to report events, for example, the media's often somber reporting on the "ramp ceremonies" of returning soldiers killed in combat.

For print media, I will focus on five separate types of news items: one, front-page news articles (reporting fact); two, other news articles (found on subsequent pages, including features and news briefs/bullets); three, editorials (opinions expressed by in-house editors, including columnists); four, letters to the editor (voices of readers); and five, opinion pieces (essays or analyses written by intellectuals, "experts," political or community leaders, etc.). There is also a miscellaneous category that includes book and film reviews. For broadcast media, I will focus on five types of broadcasts: one, lead news stories 
(mentioned at the top of the news broadcast); two, other reports (occurring later during news broadcast) or dialogue with reporter; three, special segment, report, or feature during newscast; four, news brief or bullet read by host; and five, commentary by viewers or special guests.

I will use discourse analysis to examine all coverage of the Afghanistan War (keyword=Afghanistan) by four representatives of English and French-language print and television media. These are the Globe and Mail, which has a policy orientation, and La Presse, which has more of quotidian orientation; both daily newspapers have the largest circulations in Canada in their respective languages, and wield significant influence in English- and French-language populations. I will also examine coverage by CBC-TV and Télévision de Radio-Canada ( $S R C$-TV), both prominent members of the electronic media and both of which broadcast in all Canadian provinces. ${ }^{66}$ Following consultation with library Research Data Management personnel at Carleton University, the following sources were determined to be the most thorough. Globe news stories were accessed through the Canadian Newsstand Complete electronic database at Carleton University. CBC-TV broadcast transcripts were accessed through the CBCA Complete electronic database at Carleton University. La Presse and SRC-TV news stories were accessed through the Eureka.cc electronic database at Carleton University. However, there is currently a two-year gap from 1 October 2001 to 1 October 2003 for $S R C$-TV broadcast transcripts at Carleton. Thus, I contacted $\mathrm{CBC} / S R C$ directly and, with the assistance of Denis Allaire, Expert Consultant with Media Support in French Services Productions, 
Montréal, I was able to fill the previous gap, although the data presents in a much more 'raw' format and many of the accents are incorrect (but in the original format I received).

As part of my analysis, I will select pertinent passages from the media coverage that are most relevant to the research question of embedding's effects and arrange them in a private matrix. I will examine the semantics and syntax of extracted passages as part of, and not disconnected from, the texts as wholes. I will then analyze and extrapolate the data to demonstrate if and how embedding reporting serves to frame wartime issues during each of the three time periods examined.

\subsection{Findings}

Below are the findings for time periods one, two, and three, followed by a brief summary of each.

\subsubsection{Period One: October 2001 - June 2003}

This first time period of 21 months (see Table 2), a CWS of three weeks, and using a keyword search of "Afghanistan," yielded 95 media-coverage results or "hits." For the purposes of comparison with periods two and three, this is a rate of 4.52 hits per month. Period one received the highest amount of media attention for all three periods (versus 1.47 for period two and 3.07 for period three). As seen in Chart 1, the Globe and Mail dominated coverage by the other three media outlets (which were comparable to one 
another) during this period. Collectively speaking, coverage by the two English-language outlets was greater than coverage by the two French-language outlets (56 versus 39 hits). The greatest amount of coverage for both English and francophone media was during the workweek, excluding the weekend, although the reasons for this are unclear.

TABLE 2

Period one: October 2001 through to June 2003

Constructed Weeks

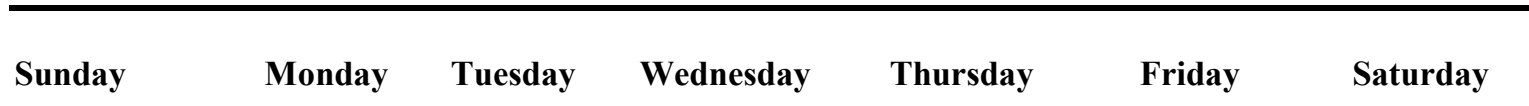

2001

7 Oct $12 \mathrm{Nov} \quad 18 \mathrm{Dec}$

2002

\begin{tabular}{|c|c|c|c|c|c|c|}
\hline & & & $30 \mathrm{Jan}$ & $7 \mathrm{Feb}$ & $15 \mathrm{Mar}$ & 27 April \\
\hline 26 May & 3 June & 16 July & 21 Aug & $5 \mathrm{Sept}$ & $11 \mathrm{Oct}$ & 16 Nov \\
\hline
\end{tabular}

2003

27 Jan $\quad 4$ Feb $\quad 12$ Mar $\quad 24$ April $\quad 30$ May 7 June

Note: Period one comprises 21 months, constructed $n=3$ weeks 


\section{Chart 1 \\ Period 1: October 1 - June 2003 \\ Media coverage, compared (hits)}

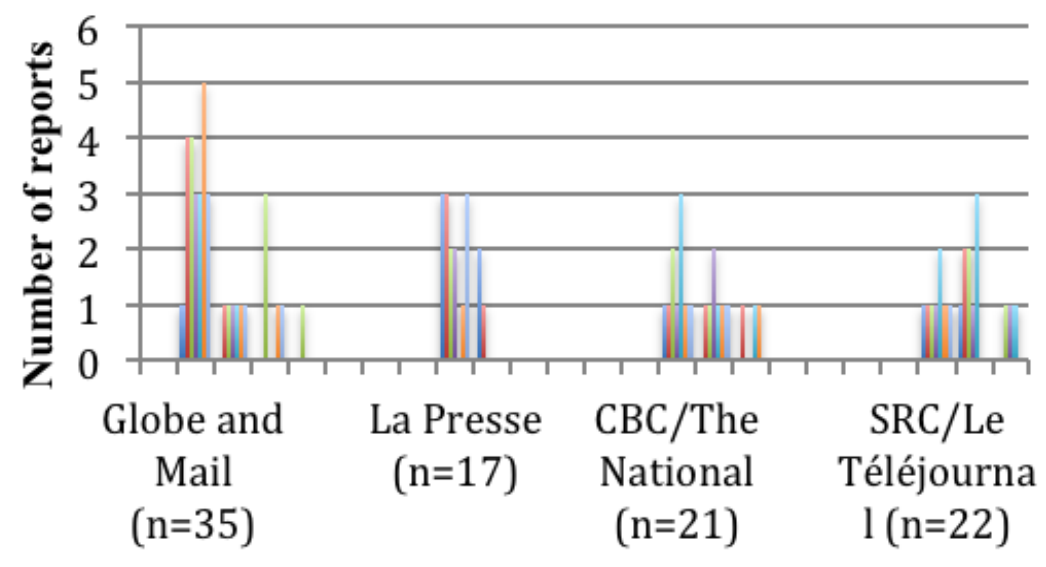

- Sunday

- Monday

- Tuesday

Wednesday

Selected English and French media

- Thursday

- Friday

Saturday

\section{Globe and Mail}

Content Overview. There were a total of 35 media hits during the CWS of three weeks, a rate of 11.67 per week. These were further categorized as 22 news articles, of which four were front-page news items discussing Afghanistan, none of the four appearing past 30 January 2002. One addressed the Taliban's retreat, one focussed on Bin Laden's "legend," one addressed a possible peacekeeping plan, and one pertained to Prime Minister Jean Chrétien's unawareness that Canadian troops were handing over Afghan detainees to U.S. Special Forces ${ }^{67}$ Of two feature articles, one on 27 April 2002 addressed the "friendly fire" deaths of four Canadian troops at the hands of a U.S. fighter pilot and the other discussed a past Christmas in Afghanistan. There were two column pieces, the first addressing the Geneva 
Convention rights of Afghan detainees and the second more generally pondering the nature of evil and the tendency to "other" members of foreign cultures.

There were five opinion pieces and one analysis: the analysis paid early attention to the tribal complexities of Afghan society and tinder-box potential of supporting one ethnic group over others; of the opinion pieces, one supported a cautious response to $9 / 11$ (written by a Toronto Star editor emeritus), one was a reflection by "peace analysts" that Afghanistan would not have become a haven for al Qaeda if prior "humanitarian intervention" had protected the Afghan population, one called for close scrutiny of the failure of American security and intelligence vis-à-vis 9/11, one addressed the impact of media convergence on editorial and media coverage of events such as the Afghanistan War, and another questioned the legitimacy of UK Prime Minister Tony Blair's use of 9/11 to support for an American war against Iraq. Finally, there were two news briefs/bullets, and one review of the movie, "Charlie Wilson's War," a fictionalized account of U.S. Congressman Wilson's efforts to expel the Soviet Army from Afghanistan in 1989.

Discourse Analysis. The themes or central ideas of early coverage were initially varied. Following Canada's official launch of Operation Apollo in October 2001, the front-page coverage revolved around the manhunt for and the elusive nature of Osama bin Laden and deposed Taliban leader Mullah Mohammed Omar, characterized by phrasing such as "disgraced or on the run," "slipped out," "cave hideouts," (a fascination with caves that was repeated in other coverage), and "greatest of secrecy." Another key front-page theme 
was the confusion and disagreement surrounding western troops, including Canadians, being deployed to Afghanistan: key phrasing included "sharp differences," "sympathies are unclear," "controversial," and "deep misgivings." In January 2002, secondary articles began to focus on the issue of Afghan detainees being handed over to U.S. Special Forces, a theme that would grow in importance in the months and years to follow.

In February 2002, Globe and Mail bylines originating from Afghanistan began to appear, and the accompanying tone became more critical of the effects of the war on the day-today lives of Afghans:

Residents here complained that the international community has done little to improve the lives of ordinary Afghans, and say there was more stability and less crime under the Taliban, which seized power in Afghanistan in 1996.

"We are increasing our hate of the U.S. There is no progress in our lives, just more crime," said one man who stopped to read the bulletin at the Lashkar Gah mosque. "During the Taliban, of course, things were better. There were no thieves," he said. (MacKinnon, 27 April 2002, A13)

Also in April, coverage and commentary became focused on the "friendly fire" deaths of four Canadian troops and eight injured at the hands of a U.S. fighter pilot, and the tone became critical - "What we will likely never know" - as well as deeply sympathetic to the troops and their families, juxtaposed against the detached lives of those ordering the troops to war:

It is 2:25 a.m. in Afghanistan. As the recovery continues in Kandahar, the news hits back home. Deputy Prime Minister John Manley is at a swanky dinner party at the Ottawa home of U.S. Ambassador Paul Cellucci. He is delivering a toast and extolling the commitment the two countries have made since the terrible events of Sept. 11 when a butler taps Cellucci on the shoulder and tells him he has an urgent call. (Anderssen, Mahoney, and MacKinnon, 27 April 2002, F4) ${ }^{68}$ 
Remaining CWS coverage for this time period was thematically disparate: addressing the political future of Afghan interim leader Hamid Karzai in a fairly negative tone - "The backroom deals that produced Mr. Karzai's endorsement suggest that many of the most important decisions are being made in private beforehand" (Reuter, 3 June 2002, A7) - as well as the seizure of weapons along the Pakistani border, the extension of German troop participation in the U.S.-led campaign, and the death of two Afghan United Nations (UN) employees.

\section{La Presse}

Content Overview. There were a total of 17 media hits during the CWS of three weeks, a rate of 5.67 per week. These were further categorized as 14 news articles, of which eight were front-page news items, although the majority of the latter only peripherally mentioned Canada in Afghanistan. Furthermore, nine articles used reports from Agence France-Presse (AFP), an international news agency headquartered in Paris. There were two column pieces - the first a reprint from the New York Times addressing the high financial cost of reporting on the Afghan mission, the second primarily addressed the impending war with Iraq albeit with a brief mention of American soldiers in Afghanistan - and one letter that primarily addressed the G-20 meeting in Ottawa.

Discourse Analysis. A theme of detachment can be found during this period. Major events or developments - such as the Northern Alliance moving toward Kabul, the American flag being raised over Kabul, and the manhunt for Osama bin Laden - were all addressed 
through the prism of AFP coverage. There were no personalized reports, other than a piece on the Taliban's imminent return of British reporter Yvonne Ridley, who had illegally crossed into Afghanistan from Pakistan (AFP, 7 October 2001, A7). The tone of general coverage was perfunctory, almost "helicopter reporting," in the sense that events were generally covered from a distance, both in terms of the La Presse resources and geographically. However, several pieces used a more analytical lens.

Following Canada's official launch of Operation Apollo in October 2001, front-page coverage included a predominantly analytical piece on Pakistani religious extremists that wished to install a Taliban-styled fundamentalist regime in their own country; a countervoice was provided by an Islamabad university professor who called these individuals “dangereux fanatiques" and "fascists violents," comparing them to the "Ku Klux Klan des États-Unis" (Paquin, 7 October 2001, A1). This was the sole La Presse byline from the region for the entire CWS period, albeit from Pakistan. On the same day, another article dissected the rationale behind Asia's resistance to the Pentagon's post-9/11 priorities: “...ils refusent d'endosser une opération des États-Unis, unilatéraliste sous couvert d"'alliances" et de "coalitions," qui vise à étendre les frontières du "Nouvel Ordre mondial" inauguré il y a 10 ans par la "guerre" du Golfe. Ce que la China Daily de Pékim nomme "la volonté d'hégémonie" (Khan, 7 October 2001, A8). Rarely does one find a word such as "hegemony" in English media coverage.

In early 2002, two similar front-page articles appeared by La Presse reporters stationed in New York City and Washington. The first covered President Bush's State of the Union 
address that focused on the Afghanistan War as well as U.S. economic issues (30 January 2002); the second covered Prime Minister Jean Chrétien's visit to the While House. It focused on three major issues: bilateral trade, Afghanistan, and border security - three key issues also addressed in chapter 3 . The article made a point of mentioning a sense of camaraderie between the two leaders, as witnessed by Canadian media: "C'est à ce moment d'ailleurs qu'un rapide échange entre le président et le premier ministre à mené à un éclat de rire général sur la pelouse du jardin des Rosiers, attenante au bureau Ovale, où étaient assemblés les médias, canadiens surtout” (Vallières, 15 March 2002). In summary, while media coverage during this period appears sparse, the depth of analysis was on occasion comparatively deep. Notably absent, however, was significant coverage or analysis of Canada's role in the war, particularly by reporters in the region.

Finally, the one letter during this period was written by a Cégep student, decrying the silence of the media vis-à-vis arrests and protests of the International Monetary Fund, World Bank, and G-20 meeting, claiming that: "La mondialisation constitue un phénomène tout aussi dangereux qu'avant la guerre [en Afghanistan]" (12 November 2001).

CBC-TV

Content Overview. There were a total of 21 media hits during this CWS of three weeks, a rate of seven per week. These were further categorized as two lead stories, two features and one special segment, nine standard reports, and seven news briefs. Both of the lead 
stories progressed into the features: one addressing the unexpected seizure of Kabul by Northern Alliance rebels and related desertion of the capital by the Taliban; the other examined the post-9/11 surge of support and recruitment levels for all four branches of the U.S. military. The special segment was an in-depth interview with exiled Prince Mostapha Zaher, grandson of Mohammed Zahir Shah, the last King of Afghanistan.

Coverage by the remaining reports and news briefs can be divided into three general categories: Canadian soldiers; conflict-related events and living conditions in Afghanistan; and domestic/international political developments. There were two reports from Afghanistan during this period - Kabul and Kandahar - although the reporters did not appear to be embedded with the CF. ${ }^{69}$ For the first time, the arrest by U.S. forces in Afghanistan of 15-year-old Canadian citizen Omar Khadr was reported; initially, one of the major concerns was that this arrest would help to support the belief by some in the U.S. that "Canada [was] a safe haven for terrorists" (Roumeliotis, 5 September 2002).

Discourse Analysis. Initial coverage seemed to have a theme of watchfulness, coupled with a sceptical tone of what path future events might follow. When Northern Alliance troops quickly routed the Taliban and moved into Kabul, coverage noted "frantic diplomatic efforts at the United Nations" to prevent an upsetting of tribal balances as well as concerns about potential violence against perceived enemies. The associated feature focused on whether or not bombing should cease during the Muslim holy month of Ramadan, while noting earlier fighting by the Taliban, Arab nations against Egypt, Christians and Muslims in Lebanon, adding that Muhammed himself fought during this 
traditional time of prayer and fasting. The reporter cited a University of Toronto professor who labelled this "a propaganda issue," adding that "Ramadan will inevitably be a rallying cry for Muslim opponents of the war" (Stewart, 11 November 2001).

The other lead and feature focused on the psychological effects that $9 / 11$ had had on the U.S. public's attitude toward its military. "Young Americans are lining up to serve and the public seems content to give the world's most powerful military permission to do whatever it deems necessary," led host Mansbridge. Young recruits were quoted saying that 9/11 had "changed my forever," and proudly declaring that "[w]e're the first ones out, first ones to take control and we're the best," while visibly supported by the "dizzying pride of the parents." Mansbridge's introductory comment that this was "comforting for some, a serious concern for others," was later reiterated by U.S. Rear Admiral Eugene Carroll, a commander during the Vietnam War: "Heaven help us when the American public are not skeptical about military power," he said. "We are a confrontational nation today because we trust and over rely on our military. Until we look to the future and realize that we must move into a cooperative relationship in the world order, we are on the wrong path" (Arsenault, 5 September 2002).

Echoing coverage by the Globe, CBC-TV marked the end of 10 days of national mourning for the "friendly fire" deaths of four members of the Princess Patricia's Canadian Light Infantry and their memorial service in Edmonton, mentioning each of the four by name (27 April 2002). "This arena holds about 18,000 people and many believe it will be full for the memorial with people from all over Edmonton, Alberta and beyond," including the 
Prime Minister and Governor General. As noted earlier, on 21 May 2002, the Chrétien government announced it would be bringing home CF troops that July and that they would not be replaced.

Attention to $\mathrm{CF}$ activities continued vis-à-vis reports on training at Edmonton Garrison prior to deployment to Afghanistan (30 January 2002), searching for al-Qaeda fighters in Afghan mountain caves under the auspices of Operation Harpoon (15 March 2002), and the possibility of a Kabul explosion being targeted at nearby "Canadian peacekeepers" (Stewart, 30 May 2003). Of interest is that, still, by the end of this period, media reports were referring to "Canadian peacekeepers" even though Operations Apollo (October 2001 - October 2003) and Harpoon clearly included less-than-peacekeeping duties such as hunting al-Qaeda terrorists in nearby mountains.

Télévision de Radio-Canada (SRC)

Content Overview. There were a total of 22 media hits during this CWS of three weeks, a rate of 7.33 per week (marginally higher than $\mathrm{CBC}$ coverage). These were further categorized as four lead stories, two features, seven standard reports, and nine news briefs. All four lead stories revolved around military activities in Afghanistan: initial bombings by U.S. and British forces; the survival of, and subsequent report by a local (Montreal) reporter on, a Taliban ambush of Alliance forces; the search for bin Laden in Afghan caves; and the handing over of captured fighters by CF soldiers to U.S. troops. The two features also addressed troop activities, from different perspectives: the first was an in- 
depth treatment of $\mathrm{CF}$ soldiers departing Afghanistan after a six-month campaign; the second addressed the biggest initiative ever of embedding reporters with U.S. combat units, primarily focusing on Iraq but mentioning Afghanistan as a learning ground for both the media and the military.

Coverage by the remaining reports and news briefs was disparate: the majority addressed various aspects of CF troops - movements, the secretive nature of Canada's Special Operations Forces, new uniforms - as well as the evolution of their image from guardians of the peace to combatants, while the remainder recounted a rush on gas masks following 9/11, bombings and military fatalities in Afghanistan, and one story on the effects of 20 years of conflict on an Afghan family.

Discourse Analysis. Initial coverage during roughly the first year explored a general theme of the war's progression and Canada's involvement in it, and was less dispassionate than $\mathrm{CBC}$ coverage. This may have reflected the initial support of Gilles Duceppe and the Bloc Québécois for the mission in 2001 and 2002. Coverage depicted aspects that ranged from Canada's reaction to 9/11 - "Jean Chrétien ne precise pas comment ... mais les Forces canadiennes vont participer [à] l'opèration [sic] militaire" (Cormier, 7 October 2001) - to a substantial report on Canada's initiation of troop withdrawal after a six-month commitment to war, not peace-keeping:

S'il est un groupe de Canadiens pour qui cette année semble avoir changé quelque chose, ce sont les membres des Forces armées. Nous étions habitués les voir en gardiens de la paix.... Cette fois, on les a envoyés en mission de combat. Ce qui n'a pas changé cedependant, ce sont les problèmes chroniques des Force armées canadiennes, commencer par un manque d'effectifs et de moyens et qui font se 
demander si les militaires pourront accomplir longtemps tout ce que le Canada leur demande [sic]. (Chartrand, 5 September 2002)

Retired Major-General Lewis MacKenzie was more direct: "We are not a peacekeeping nation. It [has] been in successive governments' interests to convince the Canadian taxpayers we were a peacekeeping nation because it is cheaper. You don't have to maintain well-equipped, mobile, lethal fighting machines to do peacekeeping." Subsequent commentary noted that Canada did not need to send a battalion for the sake of greater numbers, but did so to lend legitimacy to U.S. action. “À veut dire qu'ils sont pas tous seuls, à veut dire qu'un autre pays respecté participe à leur action [sic].” Addressed later in the coverage, but likely first on Canadians" minds, was the "friendly fire" or "tir fratricide" of four Canadian soldiers by a U.S. pilot on 17 April 2002 (Chartrand, 5 September 2002).

Also during this first year, lead coverage noted the capture, and handing over, of Afghan militants by Canadian to American troops, bitingly questioning Minister of Defense Art Eggleton's knowledge of the matter and sharing of that information with the Prime Minister. "Avec sa dernière version, le ministre affirme d'être tenu au courant chaque jour des opérations militaires en Afghanistan," said reporter Geneviève Asselin in her closing remarks." Mais du même coup, il révéle qu'il n'a pas rendu le meme service à son patron" [sic] (30 January 2002).

After roughly one year, $S R C$ coverage sharply dropped - likely due to attention being transferred to the new war in Iraq. While the second feature during this period 
predominantly addressed the role that embedding with U.S. troops would play in Iraq, it possessed implications for Afghanistan and future conflicts. “Jamais encore on n'avait vu un si grand nombre de journalistes intégrés d'un tel degré dans la structure militaire. C'est une révolution dans les relations entre la Presse and les Forces Armées américaines," said reporter Luc Chartrand. A subsequent voice-over noted that "[1]a grande question, toujours en suspens, c'est la liberté des médias. Une liste de 50 rëgles precise ce qu'il est permis et ce qui n'est pas permis de diffuser" [sic]. Conversely, U.S. Lieutenant-Colonel Rick Long was later quoted as saying "I don't see this as part of a propaganda war. There is no agenda on the message. You report the facts. And let people decide for themselves" (12 March 2003).

There were six reports from Afghanistan (and Pakistan) during this period - northern Afghanistan, Kandahar, and Kabul - filed by two regionally placed $S R C$ reporters and three roving special correspondents. None of the reporters appeared to be embedded with the CF. The tone of reportage appeared eager at the beginning of the war, "Les Etats-Unis préparaient la riposte depuis le 11 septembre: c'est fait" (Cormier, 7 October 2001), then becoming more sympathetic to the war's effects on Afghans: “... les réfugiés qui fuient les bombardements se préparent d'affronter l'hiver ... l'insécurité, la précarité absolue, s'ajoute une autre misère ... par les Talibans et par les soldats de l'Alliance" (Murray, 12 November 2001), and "Pour les Afghans qui vivent dans la pauvreté ... la nourriture est un luxe" (Murray, 18 December 2001).

\section{Summary: Period One}


Media coverage during this first period was almost text-book in nature, particularly for the Globe, meaning that after 9/11, interest and coverage was initially high when the war was perceived as a just pursuit and punishment of evil terrorists, a matter of honour and might, and an opportunity for Canada - in the view of most politicians and economists - to stand shoulder to shoulder with its American ally on the side of right. The tone was primarily sympathetic, even patriotic. Within several months, however, the tone became more critical, and questions were raised about the role that CF troops had been, and would be, playing in Afghanistan, particularly as questions about Afghan detainees arose. Then, on 27 April 2002, four Canadian troops were killed and eight injured in a "friendly fire" incident at the hands of a U.S. fighter pilot during night training. Given that this was a time before advanced smart phones and social media such as Facebook and Twitter, most Canadians learned about the incident from the front page of their newspaper and morning newscasts. Public reaction was likened to a 'sudden mass shock,' and the Chrétien government announced in May that it would be bringing home CF troops that July and that they would not be replaced.

Although three of the four media outlets - the Globe, CBC, and $S R C$ - carried reports from Afghanistan (and Pakistan) during this period, the embedding program was still in development and media ties with CF troops were in flux due to historical estrangement addressed in chapter 3. Any arrangements made during 2001 and 2002 were done so on a case-by-case basis, with DND using the American model as a blueprint, and later “Canadianizing” it during 2003. The reports' discourse generally used a matter-of-fact 
tone that held in check any emotional bonds with CF troops - at least until the April 2002 so-called "friendly fire" deaths of four Canadian soldiers at the hand of a U.S. pilot at Tarnak Farm - however, when coverage addressed day-to-day challenges faced by ordinary Afghans, it often used a tone of marked sympathy.

\subsubsection{Period Two: July 2003 - February 2006}

This second time period of 32 months (see Table 3), a CWS of four and a half weeks, and using a keyword search of "Afghanistan," yielded 47 media-coverage results or "hits." For the purposes of comparison with the two other periods, this is a rate of 1.47 hits per month, garnering the least amount of media attention for all three periods. This may have been due to two reasons: one, $\mathrm{CF}$ troops were primarily engaged in less-dramatic, peacesupport activities in Kabul, and two, the invasion of Iraq began in March 2003, drawing away significant media resources and attention. As seen in Chart 2, the Globe once again had more coverage than the other three media outlets during this period. Collectively

speaking, coverage by the two English-language outlets was greater than coverage by the two French-language outlets (29 versus 18 hits). Coverage by both English and francophone media was concentrated on the weekend and at the beginning of the week, although the reasons for this are unclear. 
TABLE 3

Period two: July 2003 through to February 2006

Constructed Weeks

\begin{tabular}{|c|c|c|c|c|c|c|}
\hline Sunday & Monday & Tuesday & Wednesday & Thursday & Friday & Saturday \\
\hline \multicolumn{7}{|l|}{2003} \\
\hline 6 July & 11 Aug & $23 \mathrm{Sept}$ & 29 Oct & $6 \mathrm{Nov}$ & 19 Dec & \\
\hline \multicolumn{7}{|l|}{2004} \\
\hline & & & & & & 24 Jan \\
\hline $29 \mathrm{Feb}$ & $1 \mathrm{Mar}$ & 6 April & 12 May & 24 June & 30 July & 7 Aug \\
\hline $5 \mathrm{Sept}$ & 11 Oct & $23 \mathrm{Nov}$ & 29 Dec & & & \\
\hline \multicolumn{7}{|l|}{2005} \\
\hline & & & & 6 Jan & $18 \mathrm{Feb}$ & $26 \mathrm{Mar}$ \\
\hline 24 April & 2 May & 7 June & 13 July & 25 Aug & $30 \mathrm{Sept}$ & $1 \mathrm{Oct}$ \\
\hline $6 \mathrm{Nov}$ & $12 \mathrm{Dec}$ & & & & & \\
\hline \multicolumn{7}{|l|}{2006} \\
\hline & & 24 Jan & $1 \mathrm{Feb}$ & & & \\
\hline
\end{tabular}




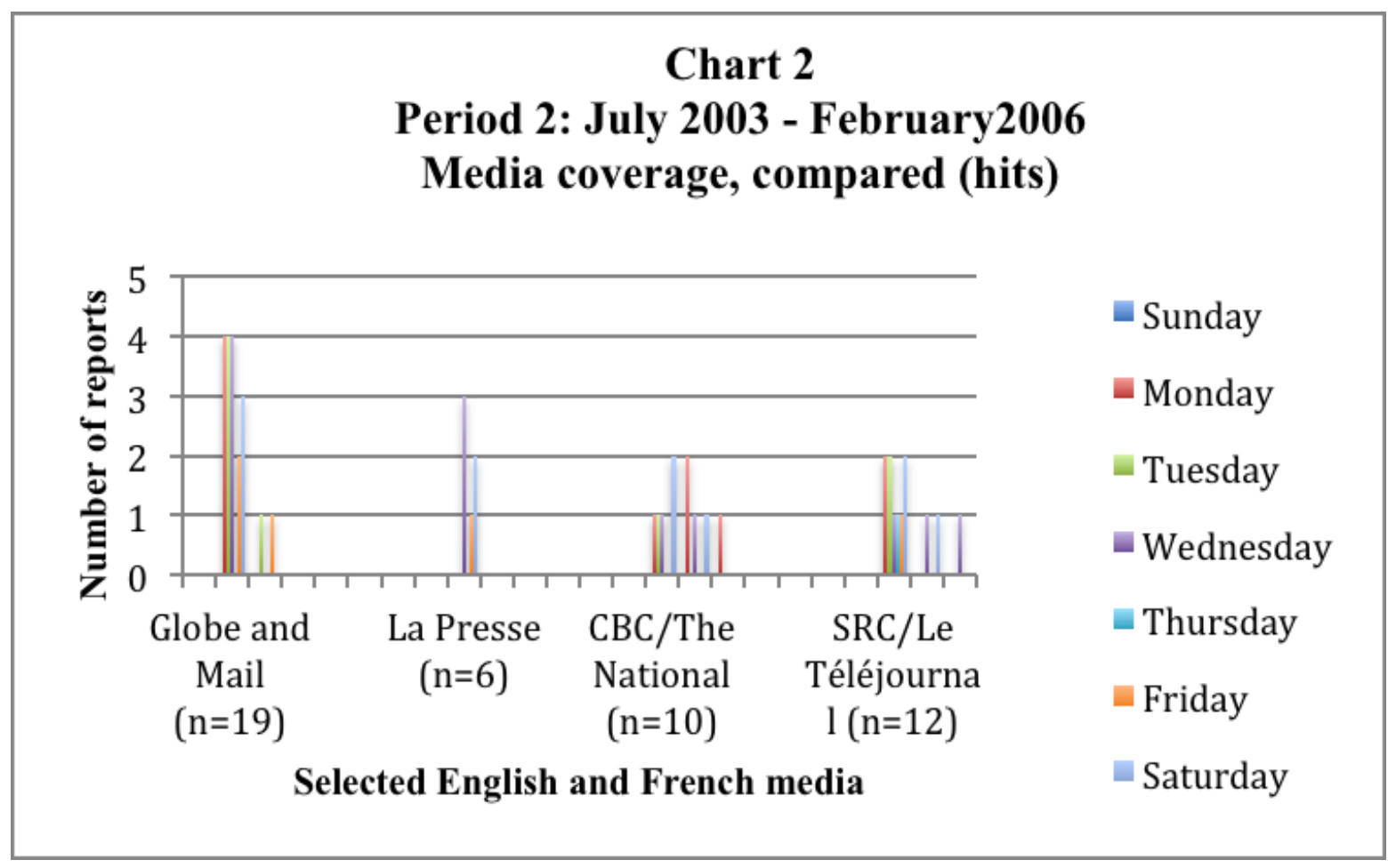

Globe and Mail

Content Overview. There were a total of 19 media hits during the CWS of 4.5 weeks, a rate of 4.22 per week. These were further categorized as 17 news articles, none of which were front-page news items. The majority of the articles, 10, were cursory in nature, thematically focussing on characteristics of war related to other non-Canadian troop injuries and casualties as well as kidnappings, American political and military developments, Spain's national security, and the fighting's impact on international markets. Four articles paid slightly more in-depth attention to a Senate committee report on national security and defence and its findings of inadequacy, Canadian troops finding an arms cache near their base in Kabul, Afghan election complications, and the explosion 
of a bomb near a Canadian convoy. Two of the three larger articles focused on CF troops, while a third revolved around a struggling domestic film industry in Afghanistan.

There was one column written during this period, addressing the Democratic Party presidential nomination of U.S. Senator from Massachusetts John Kerry and its relevance to the Afghanistan War. There was also one letter to the editor, vociferously opposed to Canada's involvement in the war and its toll on Canadian soldiers.

Discourse Analysis. For the most part, the discourse used during this second period employed a cursory and matter-of-fact tone that simply chronicled events both within and outside of Afghanistan that were related to the war, often using Canadian Press and Associated Press reports. The theme behind more in-depth coverage largely revolved around Canadian troops, although there were three outliers to this central idea: the Senate report on national security, voter-fraud concerns during the Afghan election, and an exploration of Afghan filmmaking. Of these three, the noticeable lack of cynicism regarding President Hamid Karzai's political record, candidacy, and familial drug ties was striking, however, this may have been due to the Globe's use of a stringer:

Mr. Karzai needs at least 60 per cent of the vote to have a strong mandate to push through his reform agenda, which includes disarming private militias, fighting the opium trade and establishing the rule of law. He has been hampered for the past three years by coalition agreements he has made with military commanders who are heavily involved in the drug trade. (Ghafour, 11 October 2004, A9)

The Canadian Forces (CF) were a clear theme of the four remaining articles (and the one letter to the editor) and the tone was consistently respectful. The briefest article addressed 
an arms cache that was discovered by Canadian combat engineers, mentioning the hometown (Quebec City) of the Sergeant quoted in the piece. Another article covered the withdrawal of Canadian troops from Camp Julien, a military camp just outside of Kabul:

By all accounts the most recent mission, led by the famed Vandoos, was a success. No soldiers were killed. In the first rotation, which began last August, three died, including two killed by an anti-tank mine planted by terrorists last October.

And Kabul is in better shape than when the Taliban were overthrown in November of 2001, Col. Ellis said. "On security side, the use of foot patrols into local villages has led to stability because we have a strong presence and there was a decrease in criminal activity," he said. "On civilian-military side, we were building schools and wells, delivering humanitarian supplies and rebuilding an orphanage." (Ghafour, 7 August 2004, A5)

An accompanying article to the Julien departure noted the discrepancy between Canada's international commitments and the troops it had available. The fourth article, recounting an improvised explosive device (IED) exploding within metres of a Canadian convoy, highlighted the growing risks to Canadian soldiers serving in Afghanistan, just weeks before hundreds rotated into Kandahar airfield as Operation Athena was transitioning into Operation Archer. Coming just nine days after senior Foreign Affairs official Glyn Berry was killed in a suicide bombing outside Kabul, the IED explosion rattled incoming Canadian troops:

The soldiers have been discussing the risks they face among themselves, said Corporal Brian Gibson, 22. "We talk about it all the time, we talk about stuff," he said. "That's why we train, though. It's more or less getting our families ready for something like that. I tell them what I do, that I'm safe, and I trust everyone I work with. And that's all you can really tell them." (Van Tandt, 24 January 2006) 


\section{La Presse}

Content Overview. There were a total of six media hits during the CWS of 4.5 weeks, a rate of 1.33 per week. These were further categorized as five news articles, one of which was on the front page, and one news brief/bullet. Three of the six were sourced by AFP. Of the five news articles, four merely mentioned the war in Afghanistan within a greater focus on the March 2003 invasion of Iraq, Guantanamo prisoners, and beauty salons in Kabul. Only one article directly addressed Afghanistan, although the theme revolved around infighting between President Karzai and his key ministers prior to the scheduled 9 October election. Ironically, the only media coverage that directly addressed the war was the news brief - sourced by AFP - in which UN Secretary General Kofi Annan warned that the future of Afghanistan depended on a reversal of deteriorating security conditions.

Discourse Analysis. Thematically, Afghanistan seems to have been 'shelved' behind the invasion of Iraq during this period. As noted above, the country was simply mentioned in passing within four articles. Only the news brief had a tone of urgency, noting that: "La dégradation de l'état de la sécurité au cours des derniers mois a, pour l'essentiel, réduit les activités des organisations humanitaires, prises pour cible par les rebelles, dans le nord du pays" (19 December 2003). The article addressing pre-election infighting among Karzai and his ministers was sourced by AFP, and quoted the chief editor of the Kabul Weekly saying that the positioning was less about ministerial duties and more about "le programme de désarmement, la répartition et le contrôle de l'aide international" (AFP, 7 August 2004). 
CBC-TV

Content Overview. There were a total of 10 media hits during the CWS of 4.5 weeks, a rate of 2.22 per week. These were further categorized as four lead stories, one special segment, two regular reports, and three news briefs. The majority of the coverage addressed the movements of CF troops between Canada and Afghanistan, their activities, casualties and fatalities, the latter occurring during a car-bomb attack near Kandahar that killed Canadian diplomat Glyn Berry on 15 January 2006. (The CBC's David Common appeared to be stationed in Kabul, however, his contribution in this case was primarily background.) One lead story - mentioning Afghanistan in passing - optimistically projected that the unfolding Abu Ghraib prison scandal might change the treatment of prisoners in detention centres.

Also during this period, $\mathrm{CBC}$ invested significant time and money on a special program tracing the path allegedly chosen by a Kuwaiti-born Canadian from an Ontario high school to working for the al-Qaeda network and, ultimately, to U.S. custody.

Discourse Analysis. Similar to the three other media outlets examined, the CBC significantly reduced its coverage of the Afghanistan War during this period. Its main theme was attention to and concern for the activities, well-being, and fatalities of CF troops, often with a respectful tone that relayed the troops' belief in their mission to help Afghans achieve a better life without indulging in adulation. 
The engineers perhaps are the unsung heroes of this mission because usually what happens with the peacekeeping force is that they come in and they take over some premises in the host country and the thing gradually grows up ad hoc, using local water, local electricity. In this case, they took an area of ground out in the outskirts of Kabul near an old royal place and built from scratch a completely self-contained base for 2,000 soldiers with lots of facilities including a hospital, and a gym, all in tents.

...the international control and security in this country really gets very weak once you get outside the capital. And a lot of the soldiers here wish that there had been more of them and that the politicians had made the mission a much bigger one than it was. (Brown, 7 August 2004)

The one stand-out programming note from this period was an in-depth investigation that detailed the journey of Kuwaiti-born Canadian Mohammed Mansour Jabarah from a Catholic high school in St. Catherine's, Ontario to arrest and imprisonment by U.S. officials. The special report by Terence McKenna, tracing the evolution of a 12-year-old immigrant into an al-Qaeda operative - from Catholic schooling to a Kuwaiti mosque to al-Qaeda training camps in Pakistan to Eastern Asian terrorist cells, and beyond explored the theme of religious indoctrination. Quoting journalist and author Maria Resa:

It's not just religious teaching. It's indoctrination. Yes, it's a cy-war. Yes, it is brainwashing. It's inculcating them with a view of the world that is so virulently full of hatred for the satanic people, the United States, the Western world, anyone who is not Muslim. It takes the Muslim faith and twists it on itself and presents a whole new world order and in that world order, they're still the shadows of the men they were, the kids they were, but they have a whole new purpose that they believe in wholeheartedly, enough to kill themselves for.

The tone throughout was hard-nosed: critical of al-Qaeda methods - "Osama was especially interested in him because he had a Canadian passport," the Jabarah family "parents whose children go and join these extremist and terrorist groups ... have to take partial responsibility for the part taken by those children," as well as arresting officials "[i]f the Americans are wise, if the Canadians are wise, they will give him a lesser 
sentence. It is important to give lesser sentences to terrorists who cooperate" (McKenna, 11 October 2004).

Télévision de Radio-Canada ( $S R C)$

Content Overview. There were a total of 12 media hits during the CWS of 4.5 weeks, a rate of 2.67 per week. As Chart 2 shows, while $S R C$ significantly reduced its coverage of the Afghanistan War during this period, as did the three other media outlets examined, the amount was unusually high enough to surpass that of both CBC-TV as well as La Presse. This was likely due to the stationing of the Quebec City-based Van Doos regiment (3rd Battalion) in Kabul from February to August 2004. News coverage was further categorized as one lead story, one feature, three standard reports, and seven news briefs. The lead story covered the return of $143 \mathrm{CF}$ troops from their mission outside of Kabul; five of the reports and bullets also addressed the deployment of and injuries sustained by CF troops. The feature report focused on media coverage of the war in Iraq, but also investigated how Al-Jazeera's alternative reportage contributed to the development of the embedding program. Remaining coverage addressed Karzai's election win, U.S. soldiers mistakenly firing upon a convoy of Canadian diplomats, the release of three kidnapped UN employees, and events in countries bordering on Afghanistan.

Discourse Analysis. The main theme was attention to the movements and well-being of CF troops, often with a mournful tone for those who had died during service, including continued referencing of the so-called "friendly fire" incident on 27 April 2002, albeit 
choosing to avoid that phrase: "En Afghanistan, en 2002, un avion de chasse américain avait visé et tué quatre soldats canadiens" (Langlois, 1 February 2006). Conversely, an absence of injury or death was deemed a success, according to reporter Patrick Brown: “...je pense qu'on peut juger la mission des derniers six mois une réussite. Il y a eu, par exemple, aucun mort ou blessé parmi les troupes canadiennes" (7 August 2004). This was also the sole report during the CWS by a journalist who was stationed in Afghanistan Kabul to be exact - although Brown did not appear to be embedded with CF troops. Nonetheless, he appeared to be privy to the thoughts of CF forces: “...les soldats rentrent de bon cœur avec le sentiment qu'ils avaient vraiment aidé à maintenir et peut-être à promouvoir la sécurité dans ce pays.”

The tone of the feature report on media coverage of the war in Iraq was highly critical, using a choice of content and commentary that dethroned the "images qui étaient très, très bien contrôlées par le Pentagone" during the Gulf War, according to researcher Claude Beauregard. While primarily directed toward media coverage of Iraq, it provided a deeper analysis of behind-the-scenes military/media developments that preceded and likely contributed to the U.S. embedding program. As noted in chapter 1, Al-Jazeera's alternative reportage was a significant factor:

Les Américaines ont toujours, toujours contrôlé les communications en période de guerre, et là, voilà qu'en 2001, en Afghanistan, ils perdent cet avantage stratégique, justement parce qu'il y a un nouveau réseau, un réseau arabe, AlJazira, qui, finalement, diffuse des images, diffuse des points de vue qui ne représentent pas nécessairement ceux des Américains." Et pour changer cette chose-là, on a donc, pendant la dernière guerre en 2003, on a donc intégré les journalistes aux unîtes américaines.

Beauregard's comments also depicted the military as an efficient student of history: 
...chez les militaires, on parle souvent de la cinquième dimension de la guerre, c'est-à-dire les quatre dimensions classiques : la guerre qui se fait sur la terre, sur la mer, dans les airs, dans l'espace, et on parle de plus en plus de cette dimension de la guerre de l'information [qui inclut] les mots, le vocabulaire qui est utilisé, et, bien entendu, les images. (Poirier, 12 May 2004)

\section{Summary: Period Two}

Period two had the lowest rate of media coverage of Afghanistan for all three periods, doubtless due to three developments: one, a very public recall of CF troops from Afghanistan beginning in July 2002 following the earlier April "friendly fire" deaths of four Canadian soldiers; two, a new conflict in Iraq beginning with a 2003 invasion led by the U.S. based largely on the assertion that Saddam Hussein possessed weapons of mass destruction (WMDs); and three, a relatively quiet deployment of CF troops to Kabul from February 2003 to the end of 2005.

Thematically speaking, Afghanistan seemed to have become the secondary war, after Iraq. While much of the coverage was cursory in nature, three of the four media outlets ( $L a$ Presse coverage was negligible) utilized content both written and visual that continued to pay attention to and show concern for the activities, well-being, and casualties of $\mathrm{CF}$ troops. The tone of these three outlets was respectful of CF troops; the two English outlets in particular lauded the troops' humanitarian efforts and belief in their mission to help Afghans improve their lives. In contrast, $S R C$ coverage became notably more critical of both the developing Iraq War as well as military efforts to control media coverage. Globe and $\mathrm{CBC}$ journalists produced several reports from Afghanistan during this period, 
appearing to work closely, and likely housed, with CF troops in the Kabul area. As noted above, the tone was respectful of the CF troop activities without becoming fawning; at the same time, coverage addressed the discrepancy between Canada's international commitments and the relatively few troops it had available to meet these commitments.

\subsubsection{Period Three: March 2006 - December 2011}

This third time period of 70 months (see Table 4), a CWS of 10 weeks, and using a keyword search of "Afghanistan," yielded 215 media-coverage results or "hits." For the purposes of comparison with the two other periods, this is a rate of 3.07 hits per month. By the beginning of this period, $\mathrm{CF}$ troops had transitioned from Operation Athena to Operation Archer, from the relative safety of Kabul to the turbulent Kandahar region, becoming engaged in the largest full-scale combat offensive for Canadian troops since the Korean War (Windsor, Charters and Wilson 2008). Also, the CFMEP was formally established in 2006. Once again, as seen in Chart 3, the Globe and Mail dominated coverage by the other three media outlets during this period. Collectively speaking, coverage by the two English-language outlets was greater than coverage by the two French-language outlets (150 versus 64 hits). Collective coverage by English and francophone media was roughly distributed throughout the week, highest on Tuesday and lowest on Sunday. 
TABLE 4

Period three: March 2006 through to December 2011

Constructed Weeks

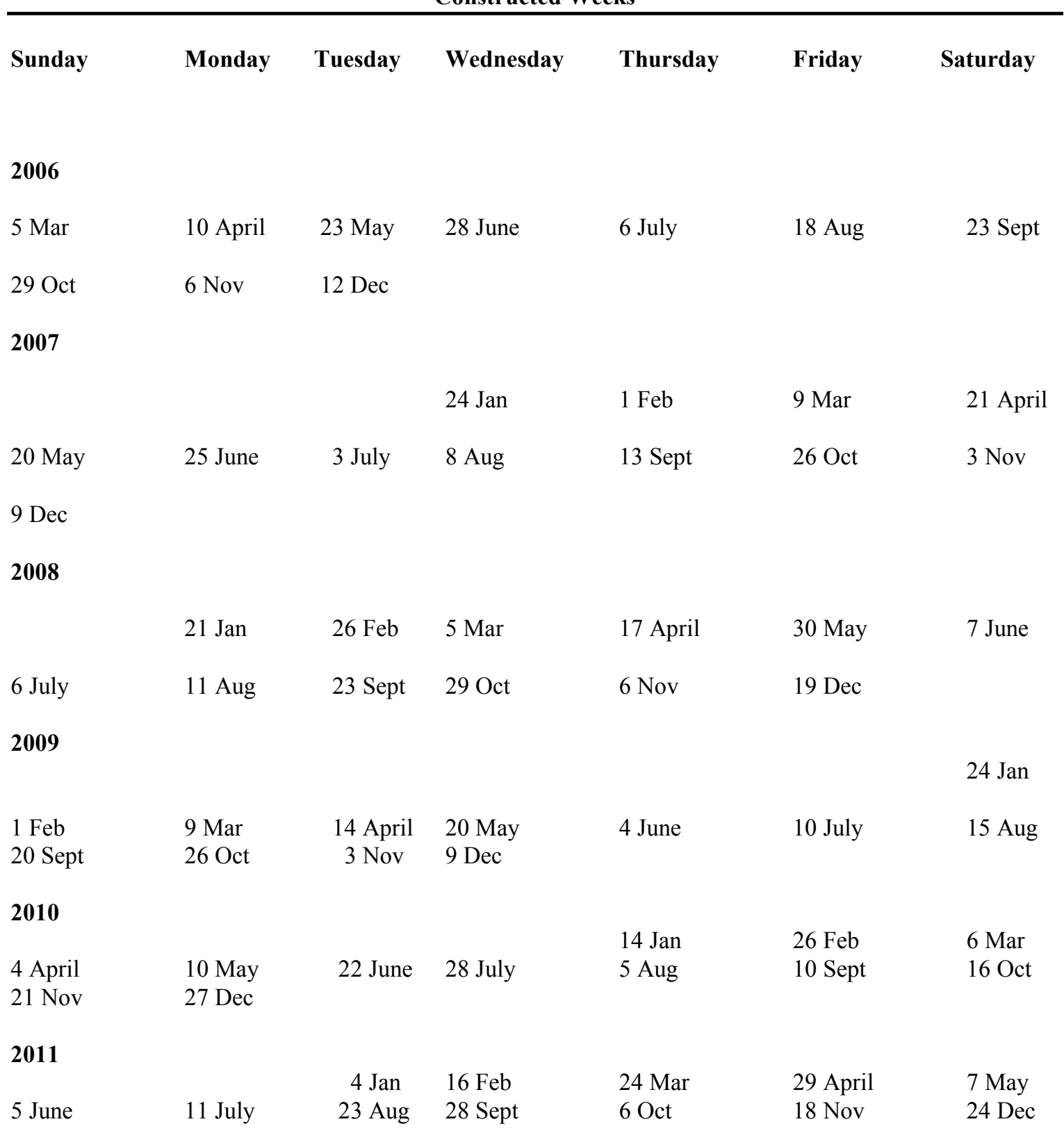

Note: Period one comprises 70 months, constructed $n=10$ weeks 


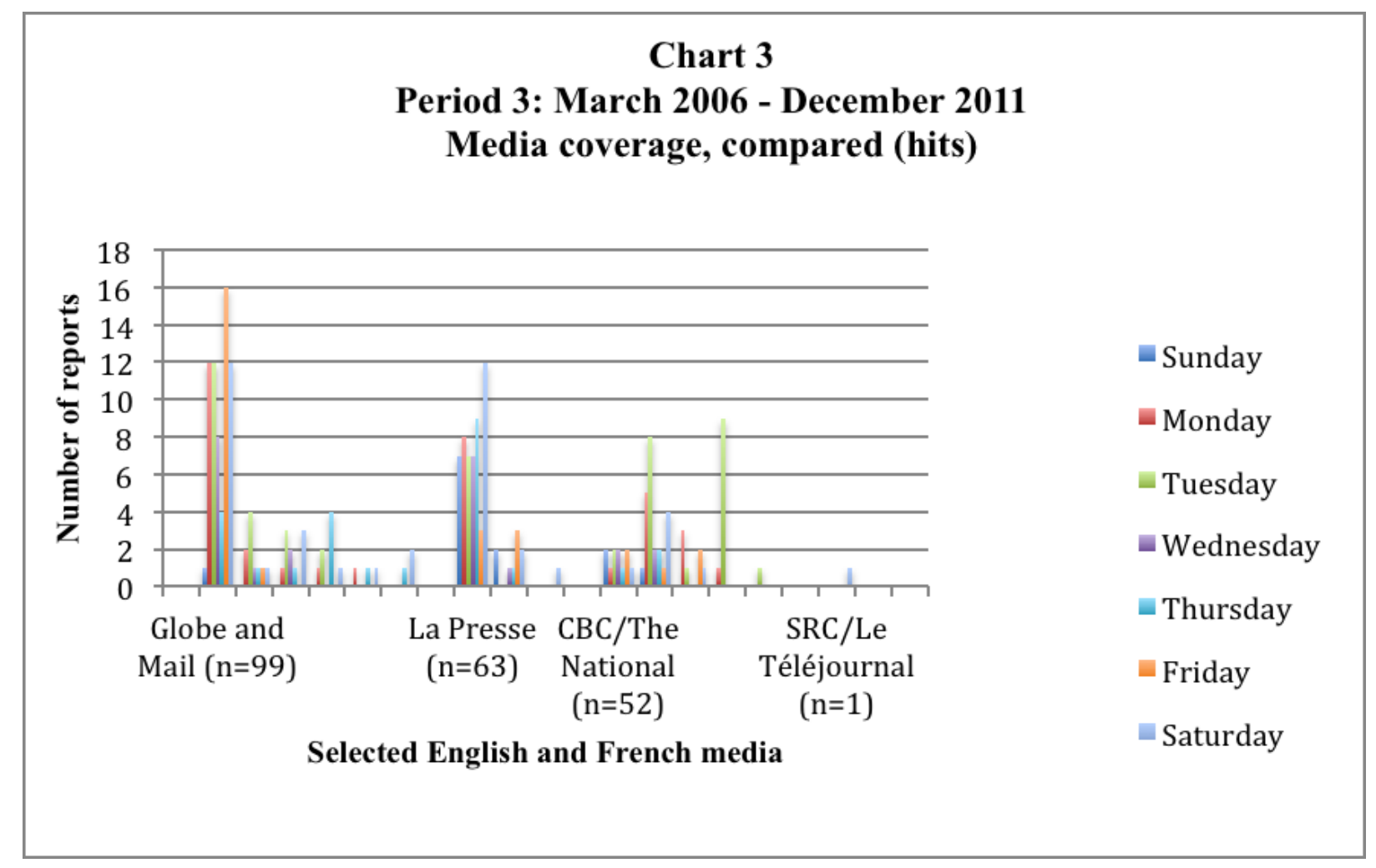

Globe and Mail

Content Overview. There were a total of 99 media hits during the CWS of 10 weeks, a rate of 9.9 per week. These were further categorized as 63 news articles, 10 of which were front-page news items. The majority of the articles addressed domestic political decisions behind the war and the issue detainees, challenges faced by the Canadian military in Afghanistan, such as limited equipment and the role of the Taliban, warlords, and U.S. forces, as well as the nature of the Afghan environment, including police corruption, graft, women's lack of rights, and President's Karzai's political performance, particularly leading up to and following the November 2009 elections. Of the 10 front-page articles: four focused on the deaths of Canadian soldiers, two on the deaths of Afghan civilians - 
and in all cases, U.S. soldiers and mercenaries were negatively portrayed; two addressed President Karzai; and two were international and/or political in nature. All three feature articles addressed the complex nature of the conditions surrounding the deployment of Canada's troops to Afghanistan, the holding of democratic elections in a country fractured by decades of warfare, and the soldiers' gritty work to improve the lives of Afghan villagers.

There were six opinion pieces written during this period, primarily addressing, once again, the Canadian military's lack of needed equipment, one supporting the regulation of the Afghan poppy industry instead of destroying it at the expense of Afghan farmers' livelihoods, and one commentary on the ongoing destructive nature of Afghan tribalism. There were four editorials, one of which highlighted the need to remember the detainee issue, which seemed to have largely faded from daily news coverage, as well as five columns, one of which again addressed the lack of resources facing the Canadian military serving in Afghanistan, one primarily underscoring the societal damage caused by Taliban rule, and another calling for harder questions to be asked about the entire purpose of committing Canadian troops to Afghanistan. There were 13 letters to the editor, a majority of which questioned the purpose, cost, nature, and extent of the war; one rejected the idea, earlier raised, of negotiating with the Taliban to any degree, and another was neutral in nature, only opining that Afghans would surely choose a better life if they were able. Finally, there were three news briefs/bullets, and two reviews of the same book, one by retired Major-General Lewis MacKenzie: Christie Blatchford's Fifteen Days: Stories of Bravery, Friendship, Life and Death from Inside the New Canadian Army. 
Discourse Analysis. The overriding theme of front-page news coverage during this third period concerned military operations, more specifically, the wellbeing and safety of Canadian soldiers, followed by Afghan casualties and deaths, and political machinations both domestic and international. As the CF began providing security and helping with reconstruction as part of a Canadian Provincial Reconstruction Team (PRT) in Kandahar province from 2005 onward, so too did Globe media coverage shift - at least in terms of geography. However, an ongoing criticism by the Canadian government and military was that journalists too often highlighted military casualties, such as "ramp ceremonies," instead of rebuilding efforts in the Afghan countryside.

Two front-page articles - by dis-embedded reporters Geoffrey York and Jessica Leeder exemplified a general tone of concern for Canadian forces, sympathy for Afghan civilians, but disdain for coalition and U.S. attacks. The former was presented along with a poignant photograph of a three-year-old Afghan boy, lying with arms spread out in the intensivecare ward of a Kandahar hospital:

With puffy face and red eyes, 12-year-old Mahmood was still fighting back tears as he told his story yesterday. He had gotten the news in a phone call at dawn. His entire family - mother, father, three sisters, three brothers - had been killed by a coalition bombing attack on his village near Kandahar.

The civilian casualties and mounting violence will make it harder for Canada's soldiers to continue the campaign to win support from ordinary Afghans.

There were strong hints that the assault was a special-forces operation, which would normally be kept secret. (York, 23 May 2006, A1)

A second article on civilian deaths repeats this tone and theme: 
Taliban insurgents in a remote village northeast of Kandahar provoked an attack by coalition troops that devastated a wedding party on Monday and resulted in dozens of civilian deaths ...

Although Canadian troops are responsible for Kandahar province, the Canadian Forces is adamant about its lack of involvement in the attack....

...Rahmatullah Raoufi, the Governor of Kandahar, identified U.S. forces as the troops involved in the attack.

Between 2006 and 2007, there was a three-fold increase in civilian deaths from aerial attacks, according to a report released in September by the New York-based group Human Rights Watch. The deaths are largely due to unplanned air strikes called in by U.S. forces, said the report, which put the number of civilian deaths due to air strikes at more than 300 for 2007. (Leeder, 6 Nov 2008, A1)

As noted in chapter 3, increasing suicide attacks and IED bombings during the latter half of the Canadian mission in Afghanistan contributed to safety concerns for journalists and soldiers. In turn, a greater journalistic focus on military casualties heightened public awareness of the "warrior" versus "peacekeeper" nature of the mission that, along with a stronger questioning of its purpose, also became themes reflected in letters to the editor.

Not so surprisingly for a military unit, "some soldiers said they wished they had used their weapons for more than deterrence, and voiced frustration at not having fought since having landed in Kandahar two weeks ago. 'That's what we're here for.... And if it doesn't happen, we'll find it a little boring. We haven't come here just for the camping. We need some action"” (Dobrota, 8 Aug 2007, A13). Sometimes the action came from very unexpected quarters: "It is believed that the [mercenaries] guarding the convoy saw the Taliban, heard the shots and ... fired into the fray. In the confusion that ensued, MCpl. Roberts was fatally wounded. He is the $89^{\text {th }}$ member of the Canadian Forces killed in Afghanistan...." (Galloway and O’Neill, 11Aug 2008, A1). Always the numbers were tallied higher: "In a region where insurgent strikes were once infrequent, roadside bomb 
kills Trooper Marc Diab ... the $112^{\text {th }}$ Canadian solider to die in Afghanistan. He is the fourth soldier to die in the week since Prime Minister Stephen Harper acknowledged on U.S. national television that he believes Canada is "never going to defeat the insurgency"” (McArthur and Galloway, 9 March 2009, A1).

The tone of the 13 letters to the editor during this period largely reflected the critical tenor of media coverage: one was by former NDP leader Jack Layton, emphasizing that Canada's "engagement" was in fact "war," and noting that his party members were not "instinctive anti-Americans" due to their demand for a debate of related issues (23 May 2006); one observed Canada's rejection of the Kyoto Protocol versus its commitment to Afghanistan, both costly and global contributions (23 May 2006); one hoped that "the Afghan commitment is not as great a disaster as Dieppe was" (23 September 2006); one called for a departure of Canadian troops by February 2008 (21 April 2007); one writer absolutely rejected any negotiations with the Taliban (13 September 2007); yet another called for Canadian soldiers to come home despite the actions of Canadian politicians (27 December 2010).

Remaining articles likewise addressed military operations and casualties, while three features - the first two written by dis-embedded reporter Graeme Smith - thematically 'mined deeper' into justifications for the Canadian mission: exploring the complexities facing CF troops deployed to Afghanistan; the price and prospects of democratic elections in a country fractured by decades of warfare; and CF soldiers' gritty efforts to improve Afghan village life. 
Graeme Smith led his feature on the challenges facing Canadian troops in Kandahar with a brief explanation of the conundrum that the opium trade - the country produces 90 percent of the world's opium, and it is also the largest domestic 'industry' - presents to western troops:

The Taliban originally banned poppy growing after they took power in 1997, mounting one of the most successful anti-drug campaigns in modern history. But the new Taliban insurgency has forged powerful alliances with Afghanistan's drug mafia. Opium money now funds the insurgency, and poor farmers' anger toward foreign armies destroying their main source of income has given the Taliban a fresh batch of recruits. (10 April 2006, A8) $)^{70}$

Another article by Smith - part of an overall stellar sequence of writings on Afghanistan addressed the tribal hostilities that underlay much of Afghan life, and government corruption capable of igniting an always-present spark:

The official story of Operation Medusa has been repeated many times ... its biggest offensive to date. The Taliban entrenched themselves in a swath of terrain, terrorizing local villagers; Canadian soldiers led a massive assault, killing more than 1,000 Taliban and routing others....

But interviews with tribal elders, farmers and senior officials in the city of Kandahar suggest a version of events that is more complicated, and less reassuring. Many of the fighters killed - perhaps half of them, by one estimate were not Taliban stalwarts, but local farmers who reportedly revolted against corrupt policing and tribal persecution. (23 September 2006, A15)

As the promised withdrawal of 2011 approached, one embedded reporter delved deep into the daily lives and challenges of Canadian soldiers working to implement Canadian Brigadier-General Jonathan Vance's "Key Village Approach" in an effort to stabilize parts of the countryside:

...85 percent of Canada's 2,800 troops are scattered through villages, in groups of a few dozen or less, trying to make a lasting difference. With the lives of 140 
Canadian soldiers lost, hundreds more wounded and billions of dollars already spent, it's here, at these platoon houses, that Canada will stake its legacy.

It's these stories that soldiers don't feel are told to the broader Canadian public. "I think what they're missing is the progress, however slow and painful," says Cpt. Steve Suke, 26. Pte. Klyer Wilson, 22, shakes his head. "They just see the dead soldiers coming back."

The article closed with some sobering facts: "The number of Canadian soldiers who have died in the Afghan conflict (along with four Canadian civilians): 140. The expected total cost of the Afghan mission to Canada, by government estimate in late 2009: \$11.3 billion" (Wingrove, 6 March 2010, F1)

While the majority of articles were written by Canadian reporters residing in the same camp as, if not embedded with, Canadian Forces, and their accompanying tone of writing was sympathetic to Canadian soldiers as well as Afghan civilians, seldom did the language they used to report events become overtly personalized, as was wont with many American journalists embedded with U.S. soldiers. While the sympathetic and frequently admiring tone used would rule out claims of "neutrality," it would be incorrect to claim evidence of more than professional admiration. In the following story, for example, while clearly the reporter was riding in the helicopter with the troops, the use of personalized pronouns and the glorification of combat were avoided, and instead the story led with the impact that wars can have on families left behind:

Major Jonathan Knaul was at the controls of the first helicopter in Canadian military history to lift Canadian troops into a combat zone. "This is cool," he said to himself as the Chinook carrying 30 soldiers landed in dusty farmland deep inside Taliban territory on Saturday.

But Major Knaul was also thinking about his 85-year-old mother in Toronto. Marie Knaul lived through the bombing of London during the Second World War. Her husband was a survivor of Auschwitz. Today she has a son who flies helicopters in a war zone. (Galloway, 9 March 2009, A11) 
Toward the latter part of period three, the pitch of media coverage - front-pages news, regular articles, and feature pieces - became increasingly more despondent prior to and following the August 2009 Afghan presidential election, then shifting to one more critical of the cost of the mission both in terms of soldiers' lives and tax dollars, and lamenting the challenges of change in a country scarred by decades of war, drug-trade corruption, political graft, the absence of equality for women and girls, and the ever-present Taliban.

Prior to the August election, the New-York based Human Rights Watch accused President Karzai of "selling out Afghan women by ratifying a Shia law, which has drawn wide condemnation over its harsh provisions on women, before [the] election" (Burch, 15 August 2009, A15). An interview with Ronald Gould, Canada's former Assistant Chief Electoral Officer, highlighted Gould's opinion that "holding a vote in Afghanistan is a waste of time," and a "dead loss" (McArthur, 26 Oct 2009, A7). A front-page article about Karzai's winning presidential bid was titled "A tarnished leader, an uncertain future," and continued within to label Karzai "an incompetent tribal politician who has failed to suppress the insurgency and turned a blind-eye to corruption (Verma, 3 Nov 2009, A1). Finally, as Canadian combat forces withdrew from Afghanistan, a closer look at the hundreds of billions of dollars spent on rebuilding Afghanistan noted that the electrical system in Kandahar - the country's second-largest city - was nevertheless on the verge of collapse: "unless they have their own generators, live in the prison or stay at the main hospital, city residents have electricity for just six hours a day, every other day" (Sachs, 11 July 2011, A9). 
Of the 15 commentary pieces - six opinion pieces, four editorials, and five columns - the main issues of concern were a Canadian military that was being asked to do too much with too little in Afghanistan, understanding Afghan domestic challenges such as the opium industry and tribalism, and Afghan detainees. For example, one column observed that "four countries are doing the heavy lifting in Afghanistan's dangerous south: the U.S., Britain, Canada and the Netherlands. Feelings are bitter.... In an alliance that prides itself on burden-sharing and collective action, the parcelling out of danger has been grossly unfair. Canada has suffered 71 deaths, roughly three times the number of much bigger Germany" (Gee, 26 October 2007). Retired Major-General Lewis MacKenzie demanded the provision of medium-lift helicopters for Canadian forces fighting "in a NATO operational theatre" (11 August 2008). One column on the poppy industry called for its regulation, which in light of Smith's coverage of an entrenched drug mafia and government corruption seems highly unlikely (Polanyi, 23 September 2006); another column on Afghan tribalism essentially reiterated previous commentary on its destructive influence on current conditions and prospects for peace. Surprisingly, given that the first public allegations of detainee abuse began in early February 2007, only one editorial in this period's CWS (6 March 2010), as well as one article (Chase, 10 September 2010, A6) addressed the issue. That said, both were critical of the government, the former noting that "the government has little credibility on Afghan detainees," the latter using remarks by Richard Colvin, a diplomat who was posted in Afghanistan for Canada, to counter prior testimony by a Canadian Forces general with a simple comment that "the [Afghan National Directorate of Security] tortures people - that's what they do." 


\section{La Presse}

Content Overview. There were a total of 63 media hits during this CWS of 10 weeks, a rate of 6.3 per week. These were further categorized as 52 news articles, two of which were on the front pages, nine news briefs, and two documentary reviews. The two articles that merited front-page placement addressed, one, mental-health issues among Canadian soldiers (2006) and, two, a convoy of soldiers and La Presse reporters that came under insurgent fire near Zhari (2007), a district in the southern province of Kandahar. There were three major categories, listed in order of prominence determined by number: events, developments, and personalities specific to the war (20); Canadian Forces (19); and domestic policies and measures related to the war (11). To a much lesser degree, public opinion, humanitarian issues, and Pakistan comprised additional categories of news coverage.

Consistent with the previous two periods, La Presse used AFP as a source for several stories, albeit less often than before; instead, La Presse Canadienne (PC) was used more often, sometimes in conjunction with AFP, and occasionally The Associated Press (AP) was used. In addition, at least two articles were written by journalists with bylines from the Kandahar area; one was clearly embedded with CF troops, while one reported from a refugee camp near Kandahar, no doubt using a driver to temporarily dis-embed for her report, as described elsewhere in an interview. ${ }^{71}$ 
Discourse Analysis. The overriding theme of the two front-page news stories during this third period concerned military operations, more specifically, the mental-health status of Canadian soldiers, and an insurgent attack on a CF convoy near Kandahar. Just like the Globe, La Presse shifted its coverage in conjunction with CF troops providing security and helping with reconstruction as part of a Canadian Provincial Reconstruction Team (PRT) in Kandahar province from roughly 2005 onward.

The first front-page article explored in significant detail the hidden psychological wounds suffered, and increasing at an alarming rate -400 percent during the previous five years by returning Canadian soldiers. "Ces statistiques indiquent à quel point les militaires canadiens paient d'un lourd tribute leur participation à des missions beaucoup plus dangereuses que par le passé comme l'Afghanistan, ou plus horribles comme le Rwanda et la Bosnie dans les années 90" (Duchesne, 28 June 2006, A1). Citing Pamela Price, a spokesperson for Veterans Affairs, Duchesne reported that: "Plus que jamais, les membres des Forces canadiennes sont déployés sur des missions plus longues et plus dangereuses. Et on leur demande de retourner en mission avec moins de temps pour récupérer.” Of particular concern was post-traumatic stress disorder (PTSD), followed by depression. Sadly, 10 years later, the same problems exist among veterans of Canada's participation in international conflicts.

The second front-page (and embed) article concerned an insurgent attack on a CF convoy, and was followed up in greater detail by a secondary story inside. The tone of the first article was perfunctory, briefly reporting the facts; the second was much more excitatory, 
likely related to a probable lack of bombings in the usual life of a reporter, and admiration for the calm reaction of those in charge: “Avec ses 35 années d'expérience dans l'armée, l'adjudant-maitre Richard Thibodeau a semblé être le premier à réaliser ce qui se passait. 'OK,' a-t-il simplement laissé tomber, pendant que le major sommait toutes les troupes à terre de regagner les véhicules" (Meunier, 13 September 2007, A1, A5). Given that the casualty count of the ambush comprised four wounded police officers, it is doubtful that the event would have warranted such media attention if not for the presence of several $\mathrm{La}$ Presse reporters in the convoy.

The remaining story by a Kandahar-based reporter, dis-embedding for her visit to a nearby refugee encampment full of nomads no longer receiving provisions due to their classification as "Internally Displaced Persons" rather than "Battle-Affected Displaced Persons, adopted a highly sympathetic tone to recount the residents' "histoire de survie, d'indifférence et d'impuissance" (Ouimet, 3 November 2007). A powerful and eloquent description of the group's plight, 5,000 former nomads called the "Kouchis de Kandahar" who had lost their livestock due to drought, and subsequently denied food privileges by the Governor of Kandahar province due to a mere classification decision ... was placed deep within the newspaper on page A29.

General coverage of the Afghanistan war often revolved around a theme of select personalities and their actions and/or comments: Karzai, then-Minister of Foreign Affairs Peter MacKay, Harper, newly elected U.S. President Barack Obama, special refugee to Canada Masoda Younasy, granddaughter of former Afghan king Mohammed Zahir Shah, 
and the assassination of Osama bin Laden. A handful of stories addressed NATO operations and bombings, civilian casualties, security threats to a Canada-funded polio program, and the strategic/historical importance of Kandahar.

Coverage pertaining to Canadian troops often listed the death of soldiers, accompanied by the total count up to that point. There was an ongoing tone of concern for the war's mental-health toll on the troops: mentioned earlier in the Duchesne article (28 June 2006, A1); again as two CF soldiers were on trial for beating a Cyprus resident, where they had been sent by the Canadian army to "décompressent avant de retourner à la maison" (Duchesne, 5 March 2008, A9); an expansion by the CF of the definition of suicide in order to "permettrait de brosser un portrait plus juste de la santé mentale des soldats et de la pression qu'ils subissent" (PC, 10 July 2009, A5); and the fact that Canadian soldiers were taking fewer sick days despite their amplified participation in Afghan combat activities (PC, 9 December 2009, A10). The downsizing of the Afghan mission as 2011 waned, as well as the work and dangers facing the 950 troops left to train Afghan forces until 2014, rounded out La Presse attention to CF issues.

Finally, issues related to domestic politics concerning the war were fairly prominent, including a House of Commons debate "de la nature de l'opération qui, pour d'aucuns, n'a plus rien à voir avec les ancienne missions de paix" (Duchesne, 10 April 2006, A3); several articles related to differences between then-Liberal leader Stéphane Dion and Harper, the former accusing the latter of "partisannerie déplacée" (PC, 3 July 2007, A12), having "induit en erreur" Parliament concerning the true nature of the Afghan intervention 
(PC, 13 September 2007, A12); eventual Liberal support for the Conservative's minority government motion to extend the mission in Afghanistan "contre le Bloc québécois et le NPD” (Toupin, 26 February 2008, A13); and the NDP's demand for information concerning the cost of the mission. The continuing plight of Omar Khadr and the detainee issue received limited coverage.

\section{CBC-TV}

Content Overview. There were a total of 52 media hits during the CWS of 10 weeks, a rate of 5.2 per week. These were further categorized as four lead stories, three feature reports, 23 regular reports, 21 news briefs, and one commentary. The majority of the coverage addressed the activities of and conditions facing CF troops, and fatalities incurred by them. Events occurring in Afghanistan, from opium-trade activity to bombings to civilian deaths to donkeys joining the troops in Kandahar made up the next general category, followed by domestic politics, and lastly the status of Canadian military equipment. The federal election in October 2008 seemed to pose somewhat of a dividing line in Canada/Afghanistan-specific coverage. There were 28 news items in the 32 months (a ratio of 0.875 ) leading up to the election, much of the domestic coverage having to do with political activities regarding an extension as well as recommendations of the impending Manley Report. However, following the election, and up to December 2011, there were nine news items during 38 months (a ratio of 0.237 ), and the major recurring category was comprised of CF deaths/ramp ceremonies. 
All three features revolved around the ramifications and future of the mission: one, the effects of stress on families of serving soldiers; two, the questionability of westerners 'micro-managing' Afghan efforts versus valuing and utilizing local talents and traditions; and three, the viability of the Kandahar mission and its objectives. There was one commentary during this period, by Rex Murphy, supporting an extension of the mission (23 May 2006) but lambasting Parliament for having neglected to adequately explain to the Canadian public a rationale for it.

Discourse Analysis. Similar to Globe treatment of the mission, the overriding theme during this period concerned the activities and welfare of CF troops, more specifically, their military operations and deaths in Afghanistan, their training/living conditions in and departure from Canada, and domestic political machinations that would have an impact on their current and future safety. The dominant tone of coverage was concern and respect for the troops, both in Afghanistan and Canada. "One by one, the solemn procession: four caskets, four fallen soldiers, four families overcome. They were killed Monday, in a small village far from home, by a man on a bicycle, pretending to be friendly. ... Thirty-six Canadian soldiers have now returned from Afghanistan this way." (Saltzman, 23 September 2006). On the same day, Afghan President Karzai’s visit to Canada was referenced thus: “This is Karzai's key message. The Canadian mission in Afghanistan is dangerous, costly, and worth it. He specifically mentioned those four soldiers brought home today" (Cudmore, 23 September 2006). Given subsequent reports that "the Afghan government of President Hamid Karzai is widely viewed as corrupt and is losing support 
nationwide as security deteriorates" (Stewart, 6 November 2006), the tone was becoming at best skeptical if not disdainful of the cost of CF troop involvement.

As noted in chapter 3 , increasing suicide attacks and especially IED bombings during the latter part of Period III contributed to safety concerns for both journalists and soldiers. This likely explains why there were only eight reports with a byline from Afghanistan during this CWS of 70 weeks; seven from Kandahar and one from Kabul. Furthermore, after CBC reporter Mellissa Fung was kidnapped on 12 October 2008 by criminal elements outside of Kabul and held for 28 days, only three reports were subsequently filed during the roughly three remaining years from Afghanistan (two from Kandahar, one from Kabul). The tone of coverage was predominantly matter-of-fact. For example, one story covered Governor General Michaëlle Jean's visit to Afghanistan: “Jean ... had one last meal with the troops. She says she's coming away from this trip feeling that Canadians need to have a better understanding of the mission and the difference that the soldiers are making here" (Kelley, 9 March 2007) The last Afghanistan-based story in this CWS reported on a Taliban claim of bringing down a Canadian chopper, saying that "Canada's Chinooks are aging. They all date back to the 1960s" (MacIntosh, 5 August 2010).

This latter concern was echoed by a subsequent report featuring Lieutenant-General Andrew Leslie's comments to a Senate committee. Host Mark Kelley led off: “...the Army's top soldier didn't mince words today on what he thinks the mission in Afghanistan is doing to this country's military. ...Leslie used words like 'crisis' and 'strained.' He said the military is short on experienced officers and equipment, and the 
solution?" The question was answered by reporter Rosemary Barton: "The Army now says after the mission in Afghanistan is over in 2011, it will need at least a year without another mission in order to regroup" (9 March 2009).

Seemingly instead of "boots-on-the-ground" Afghanistan coverage, $\mathrm{CBC}$ ran a series of "Road Stories" that visited Canadian Forces Bases (CFBs) like Trenton and Petawawa. In Trenton, reporters Tom Murphy spoke with soldiers and their family members: "I don't want to be looking at an empty pillow," said wife Melinda Anthony. "I'm too young to be a widow." Her husband added: “Am I apprehensive? Yes, I am because it's the unknown." Murphy then noted: "One of the few knowns? It will be a dangerous mission. There are mounting Canadian casualties, a reality that sinks in when a soldier fills out the next-ofkin forms" (12 December 2006). The same visit produced a report by host Peter Mansbridge riding along with troops on a C-130 Hercules air-drop and defensivemaneuvers training run. Future coverage of Petawawa was also promised: "Nearly 900 of its soldiers are in Afghanistan right now. More are getting ready to go. But our focus will be on their families. How are they coping? How are they being supported? We'll have several reports on that, including a story on a special program for their children" (Mansbridge, 12 December 2006).

Similar to Globe coverage, a greater journalistic focus on military casualties increased public awareness of a change in CF status from "peacekeeper" to "warrior" and the dangers that accompanied that transformation. 
"We've become accustomed to Canadian troops as peacekeepers abroad. But that is not their only role in Afghanistan," commented CBC political correspondent Keith Boag. "They are actively engaging an enemy, and they are taking more casualties. Back home, this change is now sinking in.” Professor of international relations Andy Knight seconded his words: "What's happening in Afghanistan right now is not peacekeeping for sure. Canadians haven't been aware of that because there has not been a debate about or a discussion about our mission in Afghanistan." (10 April 2006)

On 22 January 2008, just prior to a possible federal election, a highly anticipated report, often referred to as the Manley Report, by “The Independent Panel on Canada's Future Role in Afghanistan" - appointed by Harper in October 2007 to evaluate options - was released. The day before its release, a CBC feature analyzed the Kandahar mission and its future prospects, its choice of content depicting an urgent and crucial crossroads.

According to former U.N. ambassador Robert Fowler: “... are we there to put little girls in school, or are we there to prevent the Government of Mr. Karzai ... becoming a failed state, or are we there to stop the Taliban from taking over Afghanistan, or are we there to defeat al-Qaeda? And frankly, it seems to me that the purposes change from time to time." Canada's role was portrayed as vital, citing former Canadian ambassador to the U.N. Paul Heinbecker: "While we can't perhaps be decisive in winning this battle, there's a risk we could be decisive in losing it. If we were to walk out and leave NATO in a position where it couldn't replace us ... we'd risk ... contributing to the defeat of the mission and to the unraveling, ultimately, of NATO” (Stewart, 21 January 2008).

Roughly a month later, the mission was extended when the Liberals accepted the Conservative's proposed budget, thereby avoiding a federal election: "So they'll let it 
pass, and they'll support the Government on the Afghanistan mission extension" (Boag, 26 February 2008).

Télévision de Radio-Canada (SRC)

Content Overview. There was a precipitous drop in coverage by the $S R C$ during this time period, as Chart 3 shows: only one lead story during the CWS of 10 weeks, a rate of 0.1 per week. Coverage addressed President Karzai’s visit to Quebec to encourage support for the war.

Discourse Analysis. The tone of the report was largely matter-of-fact, noting that Karzai's intent was to "plaide sa cause au Québec," meet with NDP leader Jack Layton, who was highly opposed to a military solution in Afghanistan, and "aussi l'occasion de vanter les mérites de la mission canadienne auprès des Québécois, plus réticents qu'ailleurs au pays" (LaMontagne, 23 September 2006). Indeed, perhaps the averseness felt by the Quebecois to the war might explain the paucity of media coverage given to it during this time period.

\section{Summary: Period Three}

Media coverage by three of the four outlets ( $S R C$ coverage was negligible) closely tracked the operations, wellbeing, and casualties of CF troops as they began providing security and helping with reconstruction efforts as part of a Canadian Provincial Reconstruction Team (PRT) in Kandahar province from 2005 onward. A significant focus of coverage by 
the Globe and the $\mathrm{CBC}$ were military casualties, which heightened public awareness of the "warrior" rather than "peacekeeper" nature of the Afghan mission that, along with a tougher questioning of its purpose, also became topics reflected in Globe letters to the editor. Another theme of coverage was the "strained" nature of a Canadian military that was being asked to do too much with too little in Afghanistan, reflected in commentary by "experts" as well as members of the public. La Presse paid substantial attention to mentalhealth issues among Canadian soldiers serving in combat and - as did the $\mathrm{CBC}$ - when reporting on the death of $\mathrm{CF}$ troops, would include a total count up to that point. Coverage seemed reach a turning point in 2008: initially focussing on the release of the Manley Report in January 2008, an extension of the Afghan mission in February 2008, and then petering out following the federal election in October 2008, which ushered in a minority Conservative government. A brief return to the theme of military exhaustion was captured in testimony to the Senate defense committee in March 2009. Subsequently, until the end of the mission in December 2011, sporadic coverage ranged from a tone of despondency, such as the Globe's reporting on the August 2009 Afghan presidential election, to watchfulness, such as La Presse's reporting on the dangers still faced by CF troops remaining until 2014 to train Afghan forces, to concern for the toll the war was taking, such as the CBC's reporting on the mission's effects on CF troops and families.

Embedded reporting continued by the Globe, La Presse, and CBC. During this period recall that the CFMEP was formally established in 2006 - there were a mere handful of reports filed by dis-embedded reporters. All clearly adopted a different theme and tone than those used in embedded reports: the themes going beyond military manoeuvres to 
explore the impact of coalition activities, and delving into the complexities of a battleground steeped in historical tribal hostilities, modern drug trafficking, and the inconsistencies of religious convictions; the tone expressing sympathy for the Afghan population racked by a war not of its making. Four reports were by Globe reporters: two by Smith addressed the operations of the Afghan drug mafia and its impact on the Canadian mission, as well as the intricacies of tribal hostilities that often ended with local farmers bearing the brunt of warfare; one by York included a hospital visit to speak with civilians after coalition bombing of their village near Kandahar; and one by Leeder that covered the aftermath of coalition bombing of a wedding party. One report was by a $L a$ Presse reporter: Ouimet visited an encampment full of Afghan refugees who were classified as ineligible for assistance.

However, increasing suicide attacks and IED bombings - such as the one that killed Calgary Herald reporter Michelle Lang in Kandahar on 30 December 2009 - heightened safety concerns for journalists and soldiers and led to stricter safety protocols. The Globe's Graeme Smith, one of the more prolific embedded/dis-embedded/unilateral reporters, also had to leave Afghanistan in 2009 following his report on government ties to the opium trade, which led to death threats (Smith 2013). La Presse maintained very few journalists in the Kandahar area, relying predominantly on reports by PC, AFP, and AP. One La Presse reporter was clearly embedded with CF troops, reporting admiringly on their calm reaction to a convoy attack; another reported from a refugee camp near Kandahar, likely dis-embedding for that report and then rejoining CF troops, unlike the American system where dis-embedding is disallowed. The majority of $\mathrm{CBC}$ coverage 
occurred during the first half of the mission, seven from Kandahar and one from Kabul, however, after CBC reporter Mellissa Fung was kidnapped on 12 October 2008, only three reports were subsequently filed during the roughly three remaining years (two from Kandahar, one from Kabul).

\section{Conclusions}

The first large-scale program of embedding reporters with U.S. soldiers occurred in 2003 at the beginning of the Iraq War. The program was subsequently replicated by Canada in Afghanistan, even though that war had begun earlier, in 2001. There have been several concerns raised in conjunction with the embedding program, most prominently, the ability of journalists to retain their reporting objectivity while housed with soldiers actively responsible for ensuring journalists' safety. This study is the first to investigate this issue within a Canadian context through examination of 10 years of Canadian media coverage of the Afghanistan War. Findings from this chapter indicate that it was more the structural influence of embedding policy that had a discernible impact on media coverage rather than a dismissal of objectivity by journalists, leading to a marked focus on military rather than diplomatic or humanitarian efforts during the mission.

This chapter examined media coverage by four outlets: the Globe and Mail, La Presse, CBC-TV, and Télévision de Radio-Canada (SRC-TV). The Globe and Mail dominated coverage by the other three media outlets during all three periods examined; similarly, coverage by the two English-language outlets dominated coverage by the two French- 
language outlets during all three time periods. The Globe and Mail appeared to embed more reporters with $\mathrm{CF}$ forces than the other three media outlets during all three periods, followed by CBC; similarly, embedded reporting was used by the two English outlets more than the two francophone outlets during all three time periods.

As noted earlier, I used as a baseline for investigation what van Dijk $(2008,87)$ calls the micro and macro approaches to discourse: micro referring to language use, discourse, verbal interaction, and communication; macro referring to power, dominance, and inequality between social groups. Regarding the former, my findings indicate that embedded reporting - while often employing a tone admiring and respectful of the Canadian soldiers - particularly after the so-called "friendly fire" deaths of four Canadian soldiers at the hand of a U.S. pilot at Tarnak Farm in April 2002 - rarely reached the personalized and politicized tone of reporting found by earlier studies of American and British reporters embedded with soldiers (for example, Pfau et al. 2004, 2005; Lewis, et al., 2004; Lewis \& Brookes, 2004; Fahmy 2007). While interviews with military personnel sometimes provided positive relational cues, the predominant discourse in Canadian reporting used a matter-of-fact tone that seemed to preclude emotional commentary. The one exception was La Presse coverage of an insurgent attack on a CF convoy - including several reporters - in which four police officers were wounded. This outlier of personalization seemed random, given that La Presse generally had very little media coverage of the war, and when it did, often used the services of AFP, PC, and occasionally, AP rather than its own reporters, embedded or otherwise. While a focus on combat missions, casualties, and fatalities certainly existed, there were also 
representations of the war's effects on Afghan civilians, quite possibly a benefit of the Canadian reporters' ability to dis-embed to pursue these stories.

In fact, war coverage was markedly clear of personal pronouns cited as evidence of “interpersonal relationships” (Reyes 2011, 35). Although Reyes' work examines the intricacies of political discourse in both English and Spanish contexts, elements of his study can be applied to embedded media representation of conflict. Textual structures found in embedded reporting, for example - "I," "we," and "us" - include both the reporter and the viewer in the unfolding events. "I" does this when the writer refers to his/her own persona, displaying a subjective remark or evaluation about an issue (Fox and Park, 2006); in other words, pronouns and verb conjugations in first-person singular serve to personalize the discourse. Similarly, "we" makes the writer and the audience part of the story, making the audience an active participant in the event. In contrast, traditional reporting generally uses third-person language - "he," "she," "they," and "them" - which underscores the distance between the viewer and the event (Gerbner, 1994).

My findings show a clear difference in coverage between embedded and dis-embedded reports. While the number of stories by embedded reporters is much greater than that by dis-embedded reporters - owing to the facts that the CFMEP was formally initiated only in 2006 , and that few reporters appeared to take advantage of their ability to dis-embed from the CFMEP - the five dis-embedded reports found and addressed in my analysis demonstrate a stark difference in theme and tone from embedded reports. 
In reference to what van Dijk $(2008,87)$ calls a macro approach to discourse, or power relations, conflicts did exist between embedded reporters and the military related to differences of goals of and views on operations security (OPSEC). As noted in chapter 4, several reporters felt the use of OPSEC was sometimes abused. Conversely, as noted in chapter 5 , military and government officials largely felt that OPSEC is a logical component of war strategy and its use was measured. Although the media initially presented themes of coverage and use of discourse very favourable to the Canadian and American governments' position on the war after 9/11, within months coverage became much more critical of the reasons for and cost of participating, particularly after the deaths of four CF soldiers in April 2002. An ongoing criticism by the Canadian government and military of journalists was that they too often highlighted military casualties through coverage of "ramp ceremonies," rather than the rebuilding efforts CF troops were pursuing in the Afghan countryside. While media reports on Canada-sponsored aid in Afghanistan did eventually appear, coverage remained sparse and it was unclear if this was due to a change in what Johnson and Fahmy called "management techniques rather than outright censorship" $(2010,522)$ by military personnel, or simply a reflection of the pursuit of a human-interest story. Although the Canadian policy of allowing embedded reporters to dis-embed to pursue stories allowed much greater latitude in their reporting, few did, and later security and safety concerns drew them closer to the troops as the mission wound down. If an observable imbalance in power relations were said to exist, one might say it was reflected by the tone of cynicism that Canadian media occasionally used toward U.S. military operations that seemed to occur with impunity, and a subtle 
resentment of the inequity of the war's weight carried by CF soldiers and their aging equipment.

This chapter, a 10-year overview of Afghanistan media coverage by four chosen media outlets - two in English- and two in French-language - in conjunction with the two preceding chapters of interviews with embedded, dis-embedded, and unilateral journalists, as well as military and political personnel, have helped support my core argument regarding the structural impact that embedded reporting has had on war reporting.

I found a clear difference in coverage between embedded and dis-embedded reports in this chapter; albeit few in number, dis-embedded reports exhibited a stark difference in theme and tone from embedded reports. This would support earlier comments in chapters 4 and 5 that few reporters took advantage of dis-embedding - predominantly those more experienced - and those that did focused on non-military subject matter. However, while media coverage of military efforts was clearly greater than diplomatic or humanitarian efforts during the mission, it was not fawning, which would indicate that journalists and/or their editors back in Canada maintained a degree of objectivity not always demonstrated by U.S. media coverage. Taken jointly, the lack of direction supporting and personal effort to dis-embed as well as the co-existing lack of sycophantic coverage would indicate that structural influences of the embedding policy had more of a discernible impact on media coverage than a dismissal of objectivity by journalists. 
The next chapter will review and analyze findings from my case study to discuss how the

Canadian media, and military and government personnel - representing two very different, and sometimes opposing, perspectives on conflict reporting - worked or did not work together, and what impact that relationship had on the Canadian media's use of discursive practices to portray the Afghanistan War. I will investigate the interplay of power relations between the media discourse of sharing information and the military/government discourse of controlling/withholding information and how that might have differed and unfolded in a Canadian context.

\section{NOTES}

${ }^{62}$ That said, in the interest of providing context, I included interviews with unilateral journalists in chapter four and will incorporate analysis of their comments in my final discussion chapter.

${ }^{63}$ There is no Sunday in the first week of October 2001, only in the second week, which is where I began my data collection.

${ }^{64}$ Again, there is no Sunday in the first week of July 2003; thus, I began my data collection for this period in the second week.

${ }^{65}$ As before, the first Sunday in March 2006 occurs during the second week.

${ }^{66}$ The name "Radio-Canada" refers to all television, radio, and internet operations in the French language. Furthermore, the network is normally coded as $S R C$ (for Société Radio-Canada).

${ }^{67}$ Yet another front-page article mentioned Afghanistan, but it was in mere passing as the main topic concerned protesters at the annual World Economic Forum in New York City.

${ }^{68}$ On 21 May 2002, the Chrétien government announced it would be bringing home CF troops that July and that they would not be replaced.

${ }^{69}$ The apparent lack of embedded reporting by the CBC during this period may be related to its earlier policy rejection of embedding its reporters into the Iraq War under the auspices of the Pentagon's embedded program. It is unclear when and why exactly CBC policy was changed to allow embedded reporters in Afghanistan with the Canadian Forces Media Embedding Program (CFMEP).

${ }^{70}$ Smith continued to write about drug corruption in Afghanistan, to the detriment of his own safety. As recounted in his book:

... about 50 to 70 percent of the insurgents' weapons arrived by road, with help from corrupt figures in the Afghan government itself.

My article about drug corruption appeared in early 2009, using the phrase 'toxic triangle' to summarize the three-way relationship between [sic] the traffickers, insurgents and government figures. Within days of publication it became clear that I should stay away from the country for a while. A U.S. military intelligence analyst sent a message saying that Afghanistan "isn't healthy for you to come back to for at least a good, long while .... I don't want to to be attending a funeral" (2013, 258-259).

${ }^{71}$ See Picard 2008. 


\section{CHAPTER SEVEN: DISCUSSION AND ANALYSIS}

More than half of this battle is taking place in the battlefield of the media. We are in a media battle in a race for the hearts and minds of Muslims.

- al Qaeda in Iraq leader Abu Musab al-Zarqawi, quoted by U.S. Secretary

Defense Donald Rumsfeld in 2006 (Corman and Schiefelbein 2008, 72)

The military and the media have long been involved in a complicated relationship, at times adversarial and other times symbiotic. Embedded reporting - when journalists are attached to military units involved in armed conflicts - became formalized by the U.S. in 2003 during the Iraq War and, since then, has become an almost de facto component of the military/media relationship for numerous countries. This relationship is constructed differently for each country. I have examined the development, practice, and impact of embedded reporting in a Canadian context - specifically, during the Afghanistan War. I used two methodologies: semi-structured elite interviews, and content analysis. First, I interviewed 29 individuals from three groups: journalists who had first-hand experience of reporting from Afghanistan, and military and government officials who had in-theatre contact with the media during the war. Second, I used content analysis to examine Canadian war reporting during a 10-year period. My objective was to examine pertinent views on, and the effects of, embedded reporting within a Canadian context, which has not to date been addressed in such a comprehensive manner. My hope is that this body of work will help shed light on a relationship and media practice that has engendered much criticism but little analysis on the Canadian home front. 


\subsection{A brief review}

Prior to the formalization of an embedded-reporting program in 2003 during the Iraq War, a war reporter's presence and access during conflicts was often situation-specific in nature, depending on arrangements struck between: one, individual reporters and military personnel (the U.S. military badly wanted Ernie Pyle to report on their Pacific-theatre manoeuvres); two, media organizations and government/military officials (six war correspondents were embedded with the British army during WWI, and eventually knighted for services rendered); and three, specific individuals, such as U.S. General David Petraeus and former Washington Post reporter Thomas E. Ricks in Iraq (McKelvey 2009). Communication has become increasingly recognized and coveted as a powerful tool and commodity, and those who best manage the conduits of communication are the unsung lords of war.

Geopolitical authorities that generate wars strive hard to frame disputes through texts both verbal and written - that legitimize their chosen policies, often through repetition and reciprocity, such as policy, public speeches, and media outreach. As van Dijk (1998) explains, legitimization is a crucial social function of ideology that often manifests as a "complex, ongoing discourse practice involving a set of interrelated discourses" (255). Circumstances leading to Canadian troop involvement in Afghanistan for roughly 10 years were predominantly related to Canada's perpetual state of living next door to an elephant ${ }^{72}-$ an involvement that, in retrospect, many perceive as ill advised. ${ }^{73}$ Canada's mission in Afghanistan contained the CF's first formal partnership with the media, 
embodied by the CFMEP. This has provided an opportunity to examine what impact embedded reporting may have had through its very structure - more specifically, if and how the framing and indexing of issues occurred - on media coverage for Canadians.

Following is a discussion of several themes that combine the results of chapters 4 (media interviews), 5 (government and military interviews), and 6 (media coverage analysis).

\subsection{Embedded reporting: It's complicated}

Language is an important means by which discourse exists, discourse defined as "socially constitutive as well as socially shaped" (Fairclough and Wodak 1997, 258). Language in the service of discourse not only reflects events that take place in the world, as noted in chapter 2, but also interprets those events, formulates understandings of them, and constitutes their sociopolitical reality. Language is a tool used to create meanings, and there is inherent power in the ability to create meanings. The process of 'meaning making' is also innately political as it draws upon power relations that fluctuate in accordance with presenting, maneuvering, arguing, negotiating, and relaying the meanings at hand. That said, while power defined as control is often invisible - what van Dijk $(2009,77)$ refers to as the "incompleteness" of discourse meaning - discourse analysis is designed to investigate the linguistic manifestations of it. In sum, language is much more than a transparent medium of human interaction that uses meanings we might presume to be a stable and neutral reflection of events. Journalists, military officials, 
government officials all create and disperse stories about events in order to support their standpoint, whether or not they realize they are part of a larger discursive discussion.

The journalists I interviewed - those best situated to comment on the practice of embedding - were aware of several of its oft-cited, potentially negative attributes: tunnel vision, a form of Stockholm syndrome, message control. However, journalists do not comprise a homogenous group, and their views regarding the effects of embedding on their reporting reflected this. A minority of the journalists I spoke with were wholly accepting of a restricted scope of embedded reporting, primarily covering military matters and Canadian soldiers, and firmly believed this perspective was most relevant for the Canadian public. A greater number of respondents felt that embedded reporting was an important tool in the reporter's handbag of many tools that could be buttressed by alternate forms of reporting. This latter acceptance was partly professional, using available resources to meet the perceived needs of an audience, and predominantly practical, given the dangers of reporting from a war zone: embedding was simply safer. Those reporters who were most suspicious and/or wary of embedded reporting appeared to be more independent by nature: often operating as unilateral reporters - understanding, accepting, and preparing for its dangers - and their comments placed them within a critical school of thought that questioned authority much more readily than accepted it.

\subsubsection{Objectivity}

Critics of embedding have charged that because journalists were stationed day after day 
with soldiers, on whom they depended for food, shelter, transportation, and fundamental safety, these journalists would experience a version of "Stockholm syndrome," a bonding that can develop between victims and their captor(s) during a lengthy hostage situation, sometimes to the point where the victim will defend their captor (see Brandenburg 2007; Lindner 2009). While some perceive this characterization as extreme, other research has shown that the drive to belong to any larger, encompassing group can promote enculturation, a person's acceptance of a given organization's culture and values. As commitment to any organization - religious, academic, work-related, or social - grows, people internalize attitudes and adopt behaviours that tie them to the group. While enculturation occurs in all organizations, military-culture researcher Soeters (2000) notes that its effects are especially magnified in combat conditions, when "there is a strong need for a so-called collective mind" (475). Furthermore, even normal relationships can become accelerated during intense or hot conditions (Hensley 1996) - when uncertainty levels are high and circumstances dangerous - which is typical in combat. These conditions can lead to accelerated enculturation (Pfau et al. 2005, 471) and accelerated bonding, what behavioural scientist Hensley calls swift trust—both of which may have an impact on objective reporting.

These concerns were raised in one form or another by most of the journalists I interviewed for chapter 5. Conversely, as Geoffrey York - currently the Globe's Africa correspondent, and who had visited Afghanistan five times, including one month embedded - said, an independent-minded reporter can always find ways to remain independent, regardless of the pressures or sympathies. Nor does a month on a military 
base force a reporter to become a pro-military cheerleader. "Why would a journalist suddenly forget everything he or she learned about journalism within a few days of arriving at a military base?" he asked. "We have our standards, our experience, our training and our pride, and we don't throw those away easily" (Sheppard 2006).

My media-coverage analysis indicates that embedded reporting - while often employing a tone admiring and respectful of the Canadian soldiers - particularly after the so-called "friendly fire" deaths of four Canadian soldiers at the hand of a U.S. pilot at Tarnak Farm in April 2002 - rarely reached the personalized and politicized tone of reporting found by earlier studies of American and British reporters embedded with soldiers (for example, Pfau et al. 2004, 2005; Lewis, et al., 2004; Lewis \& Brookes, 2004; Fahmy 2007). Instead, Canadian war coverage was markedly clear of textual structures such as personal pronouns that have been cited as evidence of "interpersonal relationships" (Reyes 2011, 35) - "I," "we," and "us" - which include both the reporter and the viewer in the unfolding events. "I" does this when the writer refers to his/her own persona, displaying a subjective remark or evaluation about an issue (Fox and Park, 2006), while "we" makes the writer and the audience part of the story, making the audience an active participant in the event.

The one exception that I encountered to the above was a La Presse article from September 2007 about a convoy ambush in which four police officers were wounded. While the textual structuring was not personalized to the point of using personal pronouns, the article was written from a first-person perspective, and also mentioned 
other reporters' names who were present and even quoted one of them. Although this article was clearly concentrated on the individual in combat (and their observers) rather than employing a wider scope, it was also a blip in my analysis of media coverage and I do not believe it was typical of overall Canadian coverage of the war.

Several journalists in chapter 4, as well as military and government officials in chapter 5, commented that short rotations, personal agendas, and lack of experience and training could make a significant difference in the ability of some embedded reporters in the CFMEP to maintain a professional journalistic appropriateness. Former Canadian military officer David Harmes, now a professor of public relations, was assigned to work with a number of embedded and unilateral journalists in Afghanistan during 2003 to 2004. "Embedding is less of a problem than inexperience," he said. "Seasoned 'journos' who are embedded seem to find ways to overcome some of the inherent problems. Inexperienced journos seem to be unaware of them" (pers. comm., 21 November 2010). Lieutenant Colonel Christian Lemay held a similar view: "Strong reporters comfortable with their status and long term presence with the troops never commented on the risk to be perceived too close to the troops or having the feeling of losing their objectivity," he said (pers. comm., 6 February 2016).

As noted in chapter 4, journalists were critical of those reporters who abandoned their impartiality and became caught up in the exhilaration of battle. This speaks to a different level of professionalism among more seasoned journalists or perhaps a deeper understanding of a reporter's role and responsibility. In summary, comments indicated a 
number of junior or unmotivated reporters were less inclined to dis-embed, to seek nonmilitary stories outside of the wire, to deeply probe or even question the stories provided to them by military sources, and more inclined to adopt the values and perspective of their military hosts. I contend that it was the work produced by this cadre of embedded reporters that was most susceptible to the structural confines of the CFMEP policy, and resulted in such a greater focus on military rather than diplomatic or humanitarian efforts.

\subsubsection{Leaving the wire a.k.a. Experiencing Afghanistan}

The prevailing opinion among interviewees was that embedded reporting works best if it is balanced by additional reporting, such as dis-embedded or unilateral reporting. That a combination of the two or three would facilitate the creation of a more complete "space" that allows for language - a tool used to create meanings of, and stories that relay, events - to variably reflect different versions of the same reality. In lay terms, perspective or context. As noted in chapter 2, the constitutive dimension of language goes far beyond the mere telling of pre-existing and neutral phenomena, particularly where contentious issues such as warfare are concerned. Language expresses thought, sentiment, and direction, creates a public space, and then places items for assimilation into that space. It facilitates relations among individuals and subsequently establishes shared meanings. Thus, "relations of power and property themselves are not possible without language; they are essentially realized in language" (Taylor 1985, 271). Ultimately, if this space is

limited, so too will the resulting texts - written or oral or visual - be limited by whatever framing structures exist. 
Framing is a form of packaging. Politicians frame their platforms to have a particular impact on a desired audience, advertisers frame their messaging to reach certain markets, and for journalists, framing in service of informing utilizes what Gitlin calls "persistent patterns of cognition, interpretation, and presentation, of selection, emphasis, and exclusion, by which symbol-handlers routinely organize discourse, whether verbal or visual" $(1980,7)$. The news frame serves as a "central organizing idea for making sense of relevant events, suggesting what is at issue" (Gamson and Modigliani 1989, 3) in order to facilitate the audience's awareness and interpretation of, and response to, news stories. While framing vis-a-vis public-opinion formation has gained a negative connotation, it must be said that framing can also benefit the public, particularly when contestation fosters informed acceptance or rejection of competing frames, ultimately leading to common ground or at least informed opinion. However, the latter scenario pre-supposes a certain degree of informed awareness, which is often not the case for international issues.

As noted in chapter 2, when attributions of responsibility for distant and remote issues such as terrorism are associated with ideological conflicts and poorly understood disputes in distant locales, these attributions tend to be highly responsive to framing (Iyengar 2007). I would similarly argue that attributions of responsibility for warfare and associated ideological issues in distant and remote locales are highly responsive to framing for much the same reasons: western unfamiliarity with issues and events occurring on the other side of the world enables the news media to play a large role in the mediation of those views. 
Afghanistan can be a formidable country for those ill-suited to operate as an independent reporter, let alone during a hostile environment that is war. While it is understandable that the majority of reporters chose to report from within a safer environment - compared to reporting from outside the wire where risk was ill-defined and possibly life-threatening that choice fundamentally predisposed the substance of their reporting. The construction of news-media frames is an interactive process in which journalists actively attempt to find a narrative 'fit' between incoming information and pre-existing media frames that are familiar to their audience(s). When the scope of incoming information is limited - as it naturally was for reporters who remained 'inside the wire,' that limited information as well as its sources will have an important influence on the information-construction process. As a result, the CFMEP by its very design and structural boundaries had the strongest framing impact on reporters who did not go outside the wire.

In summary, the structural information environment that the CFMEP provided to embedded journalists - despite the well-meaning intentions of some PAOs I interviewed - was by its very nature designed to impart what it knew best: the military perspective. When reporters did not choose to dis-embed, a unique Canadian policy that allowed them to pursue stories away from the base, or were not allowed to dis-embed by their home offices due to later security and safety concerns as the mission wound down, that information environment became all-encompassing.

\subsubsection{Censorship or security?}


Operations security (OPSEC) was the most discordant issue associated with the CFMEP, and the greatest source of power clashes between embedded reporters and the military. While reporters and officials agreed on the need for OPSEC, given that all parties were operating in a war zone and reporters wished to avoid endangering the troops, that agreement dissolved in the face of stricter-than-expected definitions of, and justifications for, restrictions on information. The primary accusation was that military personnel sometimes misused OPSEC; the secondary contention, as noted by Hobson $(2011,6)$, was the occasional "fuzzy definition of operations security."

While OPSEC was formerly laid out in military doctrine and was part of the embed agreement that all journalists wishing to embed were required to sign, a number of reporters interviewed for chapter 4 strongly felt that OPSEC could be misused at the intheatre level. As veteran $\mathrm{CBC}$ reporter Brian Stewart said: "My feeling was that rules were briefly read once before going to Afghanistan and then Ottawa-led access took precedence,” he said. “... OPSEC could be pulled down like a curtain” (pers. comm, 8 December 2015). Stewart's ire led to a pointed critique (2010).

Conversely, as noted in chapter 5 , the majority of military and government personnel felt that OPSEC is a necessary component of war strategy and its use in Afghanistan was reasonable. "[The policies] may not have allowed [reporters] to be as free as they liked, but I think that the embed policies were far less restrictive than some of their own editors' 
policies about were they could go, and when they could leave," aid General Jonathan Vance, chief of defence staff (pers. comm, 18 March 2016).

These two opposing views represent a low-level clash of two worldviews or ideologies: the military's hegemonic worldview of structure, order and restriction of information - in this case, defined as sensitive - contested by journalistic opposition to the legitimacy of that position and further characterization of it as unwarranted in many cases. The clatter of these two belief systems is made all the louder by their closer-than-normal proximity to one another within the CFMEP; a relationship agreed upon and created by DND and parent media organizations but enacted by individuals at ground level.

The bottom line is that, in war zones such as Afghanistan, embedded reporters were housed on the base for their own safety and access, and had to adhere to rules that had been prearranged by military and media chiefs, and signed by each embed; thus, the CF held the upper hand merely through providing the space within which journalists moved and by supplying the majority of mission information, or access to mission information, to the embeds. This would, of course, be irksome for individuals who had cut their journalism teeth on, and firmly believed in, questioning authority.

\subsubsection{Death Watch}

During the initial reporting from Afghanistan (and Pakistan) following 9/11, and prior to any semblance of an embed program beginning in 2003, Canadian media reports were 
predominantly matter-of-fact in tone - until the April 2002 so-called "friendly fire" deaths of four Canadian soldiers at the hand of a U.S. pilot at Tarnak Farm, in the south near Kandahar. A month later, in May 2002, the Chrétien government announced it would be bringing home CF troops that July and that they would not be replaced. Yet roughly a year later, during the summer of 2003, the mission was re-instated in Kabul, albeit considered a safer location. Then, in 2006, the mission once again moved south to become fully based in Kandahar, and the CFMEP was formally established. Soon, media attention to Canadian soldiers became a strong and consistent theme, but it was also likely rooted in the memory of the four killed in 2002; both developments undoubtedly contributed to a later media focus on "ramp ceremonies," disparagingly called a "death watch" by members of the military and government.

For example, media coverage by three of the four outlets I analyzed ( $S R C$ coverage was negligible) closely tracked the operations, wellbeing, and casualties of CF troops as they provided security and helped with reconstruction efforts in the move to Kandahar province beginning in 2005. An early and significant focus of coverage by the Globe and $\mathrm{CBC}$ were military casualties. Another theme of coverage - reflected in commentary by "experts" as well as members of the public - was the "strained" nature of a Canadian military that was being asked to do too much with too little in Afghanistan. La Presse paid substantial attention to mental-health issues among Canadian soldiers serving in combat. Each time there were CF fatalities, La Presse and the $\mathrm{CBC}$ would include a total count of fatalities up to that point in time. 
While the CFMEP was clearly designed to house and share information with embedded journalists, the media's growing focus on military fatalities was vexing for the military, and seemingly unexpected. The Canadian government and the military would have preferred that journalists pay greater attention to the rebuilding efforts CF troops were pursuing in the Afghan countryside. In fact, this was one of the key recommendations given in the Manley report, released in January 2008 (38): “The Government should provide the public with franker and more frequent reporting on events in Afghanistan, offering more assessments of Canada's role and giving greater emphasis to the diplomatic and reconstruction efforts as well as those of the military."

However, the recommendation that received the greatest media attention was that the Canadian military should gradually shift focus from combat to training Afghan nationalsecurity forces. In February 2008, the mission was extended until 2011, also reported in the media. While several media reports on certain Canada-sponsored projects in Afghanistan did eventually appear, it was intermittent. Media coverage of testimony given to the Senate defense committee in March 2009 once again raised the issue of military exhaustion. Subsequent media coverage through to the end of the mission in December 2011 ranged from a tone of despondency over corruption in the country, to concern for the safety of CF troops remaining until 2014 to train Afghan forces, to worry about the toll the war was taking on CF troops and families. In short, while the CFMEP encouraged media attention on the troops and the overall mission, the specifics of the representation of the mission that was being relayed to the Canadian public did not necessarily coincide with what military and government officials believed they should be. 
This micro-focus on the morbidity and mortality caused by the war was due to three major reasons: one, journalists' genuine respect and concern for the troops; two, directives from media home offices to report on soldier fatalities for the Canadian public; and three, security and safety concerns for the reporters that drew them closer to the troops as the mission wound down. The worries were valid: in October 2008, CBC reporter Mellissa Fung was kidnapped near Kabul; then in December 2009, an IED bombing killed Calgary Herald reporter Michelle Lang in Kandahar. "Post-Fung, the relationship of the media and the military changed in a very devastating way," said the CBC's David Common. "It was not the cause, but a contributing factor. Some journalists spent all their time on the base, so soldiers knew we were not taking risks, but then they started to perceive us as 'vultures' waiting around for someone to die" (pers. comm., 11 December 2015).

I contend that the origins of the controversial media attention to ramp ceremonies, especially during the latter part of the Afghanistan mission, can be traced back to the deaths of the four soldiers killed near Tarnak Farm in 2002. Not only did their deaths affect Canadian sentimentalities, but also beget further media coverage of, and public attention to, the subsequent trial and legal arguments and decisions. Those sentimentalities were awakened once more when CF soldiers were sent into combat, clearly not peacekeeping, in the Kandahar region in 2006 - at the same time that the CFMEP program was formally launched and designed to create interest in the Canadian military. This convergence of events was not lost upon a media industry designed to 
create profit: military missions and Canadian soldiers were ready-made issues for consumption by the Canadian public.

However, the fighting was fierce and casualty numbers cumulatively grew. The CF did not have a policy like the U.S. of barring reporters from covering ramp ceremonies. In addition, fear among and for reporters was keeping them closer to the base, wary of venturing outside the wire. I would also suggest that toward the end of the mission, media-parent organizations more often circumvented military wishes regarding coverage of ramp ceremonies because one, reporters were available on-site, and two, the belief that the Canadian public continued to be highly interested in their soldiers, including their demise. In sum, a number of events and circumstances - not just one, not just reporter horridness - led to the bleakly named death watch.

\subsection{Dis-embedding}

One of the key features of the CFMEP was the flexibility for embedded reporters to leave the base, called dis-embedding, in order to seek sources and stories outside of the wire. As noted in chapter 3 , this ability to disengage from and re-engage with the program to cover non-CF issues greatly differentiated the Canadian program from its American counterpart. That said, this novel feature of the Canadian embed program ${ }^{74}$ was due less to ideological differences between DND and DoD as it was to a lack of CF readiness for an influx of reporters as well as limited deployment space on transport such as Light Armored Vehicles (Price 2009, 56-59). 
Nonetheless, the ability to dis-embed had the effect of encouraging greater independence among embedded reporters to find their own drivers and "fixers," and appeared to help provide a wider range of resulting media coverage. However, while the majority of journalists who agreed to be interviewed for my research possessed a range of experience that included embedded, dis-embedded, and unilateral reporting, it appears that only a minority of the overall number of embedded reporters in the program from its inception until the end of the mission in 2011 took advantage of the opportunity to dis-embed.

A representation of their stories can be found in chapter 6: five reports by dis-embedded reporters during Period Three. All of the stories adopted a different theme - examining the human impact of coalition bombings, and delving into the complexities of a battleground that encompassed historical tribal hostilities, modern drug trafficking, and government corruption - although the tone primarily invoked empathy for the Afghan population, a tone not often found in typical embed stories.

While a clear majority of reporters who responded in chapter 4 supported the ability to dis-embed, few seemed to do so. One who did was former Globe reporter Graeme Smith, writing in The Dogs Are Eating Them Now. "I spent time with military forces from several countries, and was impressed by their hospitality, but the Canadian military stood above the rest because of its uniquely open system of embedding," he wrote (Smith 2013, 289). Conversely, only one reporter was opposed to its practice: Postmedia's Mathew Fisher believed the ability allowed some journalists to use the Kandahar airport as a hotel. 
"I agree with the American approach of, when you are embedded, then you are embedded," he said (pers. comm., 5 February 2016).

Dis-embedding or reporting as a unilateral was risky. Finding sources outside of the wire, travelling, and reporting on stories not facilitated by the CF were more difficult and dangerous to achieve. Those reporters who did so were admired by their peers. They were also admired by military and government officials. For instance, Lieutenant Colonel Christian Lemay personally encouraged and facilitated embedded reporters' venturing beyond the wire "on their own or with fixers to get the smell and feel of the street," he said (pers. comm., 6 February 2016). The main reasons for why few reporters did not venture beyond the Kandahar Airfield (KAH) camp were: one, lack of experience, likely related to fear of the unknown; two, ease of working with the ready-made menu of military-heavy information provided by PAOs; three, perception of military-related stories as more exciting than Afghan or development stories; four, editorial direction by home offices; and five, growing levels of danger and decreasing security as the mission became protracted. While points two, three and four speak to structural issues underlying the embed policy that was put into place, all of these reasons converged, at different time points during the decade-long mission, with a result of abundant media coverage of military versus civilian stories, which will be addressed next. 


\subsection{Military versus civilian media coverage}

The strongest theme running throughout media coverage for the 10 years analyzed in this study was support and respect for Canadian soldiers. This theme existed independently from the steady supply of CF-related information that was provided to embedded reporters. While certainly the constancy of military updates and opportunities to accompany the troops had a positive impact on reporters' perceptions, support for Canadian soldiers rarely wavered whereas support for the mission was less than absolute. Nonetheless, the CFMEP was highly successful in its intent to remake the image of the CF following the disastrous 1993 "Somalia Affair," the subsequent disbanding of the Canadian Airborne Regiment, inaction during the 1994 Rwandan genocide, and 1995 reports of violent hazing and sexual assaults by CF members, all addressed in chapter 3 . The CFMEP was much less efficacious, however, regarding media coverage of civilian efforts in the areas of development and diplomacy.

In 2008, the Manley report clearly attempted to increase public awareness of efforts being

made by development and diplomatic personnel in Afghanistan: "The Government should provide the public with franker and more frequent reporting on events in Afghanistan, offering more assessments of Canada's role and giving greater emphasis to the diplomatic and reconstruction efforts as well as those of the military" (38). Rules regarding Ottawabased communication were loosened and personnel were dispatched to Afghanistan to assist. For example, former Global Affairs official Katherine Heath-Eves was posted to Afghanistan from 2009 to 2010 , first at $\mathrm{KAH}$ and then with the $\mathrm{KPRT},{ }^{75}$ one of 25 
provincial teams throughout Afghanistan designed to "facilitate delivery of reconstruction and development aid from a variety of international donors or contractors" (Cox 2007) to Afghans for local projects. "The embedded program ... is the best way to bring in journalists to gain exposure to the mission, to showcase what they want to showcase, and to do it all safely," she said (pers. comm., 8 January 2016).

Although media coverage of Canada-sponsored aid in Afghanistan did eventually appear, the one La Presse article captured by my analysis primarily addressed security threats to a Canada-funded polio program. One additional Globe article addressed then-BrigadierGeneral Jonathan Vance's “Key Village Approach” to stabilizing parts of the countryside, profiling the Haji Baba and Nakhonay villages, and another La Presse article addressed the plight of nomads in a refugee encampment outside of Kandahar who were no longer receiving provisions due to their classification as "Internally Displaced Persons" rather than "Battle-Affected Displaced Persons." In other words, development-related issues were still largely ignored.

Despite Manley Report efforts, civilian efforts in Afghanistan remained largely "unsaid" in media coverage. As noted by Dedaić and Nelson (2003), when a particular framework of understanding is discursively declared, then other, possible understandings remain unsaid. For example, in relation to the mayhem and death caused on $9 / 11$ : “...it was rarely said, either by ordinary Americans on television or by their political leaders, that what had happened was primarily a criminal act [against New York or icons of capitalism.] The words of criminality were subsumed by those of war" (xiv). Similarly, 
the framework for understanding Canada's mission in Afghanistan had earlier been discursively established as military in focus, and neither a government report nor intheatre insertion of personnel were able to dramatically effect a change.

At a fundamental level, again, likely triggered by the much-earlier April 2002 "friendly fire" deaths of four Canadian troops at the hands of a U.S. fighter pilot during night training, the Afghanistan mission had become framed as soldier-oriented in the public's perception. As Goffman (1974) argued, only certain aspects of society fit within the "frames" that individuals use to define their society; in this case, a war perceived as an extension of Canadian society. These frames direct our expectations of how society works. In contrast, what falls outside of the frame is delegitimized or excluded from the cultural basis of understanding, in this case, diplomatic and development efforts.

Another reason for the lack of media coverage of civilian issues has to do with power structures. The CFMEP was designed by the military, run by the military, and housed on a military base. As noted in chapter 2, power is about relations of difference, and particularly about the effects of differences in social structures (Wodak and Meyer 2009, 10). The CFMEP was designed to facilitate the military working with embedded reporters, both bodies needed each other to create their respective products, but the CFMEP always had the alpha role at the in-theatre level. On a different level, the power relationship between the military and the media-parent organizations was more equal. Thus, media coverage of ramp ceremonies - when reporters were directed by home offices to do so - continued despite military disapproval, and media coverage of 
development and diplomatic issues was extremely limited for the same reason - editorial perception of the Canadian public's interest.

An unexpected finding in my research was the profound disappointment that a number of government officials felt, as well as some military officials, regarding the lack of attention that the media - and by extension, the Canadian public - paid to civilian efforts in Afghanistan. As noted in chapter 5, while cultural differences between military and media worlds are largely expected, it was surprising to find such a schism between military and civilian ambitions: both were part of the overall mission, both were considered imperative to the mission's success, but the former clearly overshadowed the latter. To add salt to wound, many civilians were left floundering professionally upon their return to Canada, their experience and expertise minimized if not discounted, becoming "The forgotten members of the mission in Afghanistan" (Potter 2011).

To sum it up, as voiced in chapter 5 by Colonel Roch Lacroix, deputy commander of Canadian and NATO Forces in Kandahar Province during 2009, now retired. "I think that the reporters' mandate was to report on the military operations ongoing in Afghanistan," he said. "I don't think they ever met the mandate that was written for them of reporting on the collective efforts of our 3Ds mission in Afghanistan: diplomacy, development and defense “(pers. comm., 29 January 2016). Although counter-measures were developed post-Manley, embedding served to facilitate the near-shunning of diplomacy and development projects in lieu of defence coverage. 


\subsection{Message control from the motherland}

While the military was in charge in situ, interviews with journalists, as well as military and government officials, indicated marked attempts from afar to control the media message emanating from Afghanistan: these attempts originated in the upper levels of government in Ottawa, and head media offices in Toronto. Criticisms concerning PMO interference was evenly divided among interviewed journalists and government officials, while the majority of criticism aimed at media head-office interference came from military and government officials, slightly more military than government officials.

\subsubsection{Nixonian ventures}

As noted in chapters 4 and 5, a number of journalists and government officials voiced frustration with political delays and meddling that seemingly originated from within the communications staff at the PMO. The commonality of shared experiences and comments - some of which are revisited below - would support the perception of attempts by upperechelon Ottawa personnel to control the Afghanistan message that was reaching the Canadian public.

As noted in chapter 4, veteran $\mathrm{CBC}$ reporter Brian Stewart said there was a lack of transparency. "Very frequently officers and others would relay the terrible feeling that war was being run out of the PMO and not the Defence department," he said. "Requests

for interviews with CF personnel always had to go through the PMO for approval ...."76 
The CBC's David Common agreed: "We knew of instances of the PMO and PCO trying to coordinate the message, not the [Afghanistan] Task Force ${ }^{77}$ simply because of the coordination of the message." Both Canadian Press journalist Murray Brewster and CBC senior correspondent Susan Ormiston noted that as the war dragged on, control attempts seemed to increase: Brewster called it "political control and managing of the messaging," while Ormiston recalled an unwillingness to even "acknowledge negative news." The only military official to comment on political interference was Colonel Pat Stogran, commanding officer of the first Canadian soldiers in Afghanistan from 2001 to 2002, now retired, who said the political pressure from above was "because the Harper government was so preoccupied with controlling the message."

Of the government officials interviewed for chapter 5, none was closer to the PMO nor perhaps as distressed by its attempts at control as David Mulroney, former deputy minister in charge of the Afghanistan Task Force, and secretary to the Independent Panel on Canada's Future Role in Afghanistan, which produced the Manley Report. He explained that "civilians were under strict orders not to talk to reporters without permission that was rarely granted [and] if there was any mistake, the retribution was severe and vindictive and that meant people became very, very reluctant to communicate because they were so afraid of reprisals." He clearly identified that control as emanating from the PMO communications team.

Former public diplomacy officer Adam Sweet, and former DFAIT officers Emma Welford and Katherine Heath-Eves echoed Mulroney's remarks. "There was also a 
fundamental failure with the government trying to control messages from above," said Sweet. Welford agreed: "There was a very restrictive approvals process to speaking on the record to reporters, coming from the PCO." Heath-Eves concurred. "The control by the PMO was so tight that it made my job very difficult in working with reporters," she said.

I contend that indexing theory can be used to only indirectly explain attempts by the Harper government to control the message seeping down to reporters in Afghanistan. According to indexing theory - first introduced by Bennett (1990) - the U.S. media tend to harmonize their reporting to the views of the political elite and other official sources. This approach, which argues that national news framing tends to correlate with and is limited to the range of debate among the political elite - has been shown to apply to the American media, particularly regarding foreign-issues coverage such as conflicts. A comparative investigation of elite press coverage of 9/11 in the U.S., Italy, France, and Pakistan (Archetti 2008), found that it cannot be applied outside the American context. However, Canada has more in common with the U.S. than the countries Archetti examined. While the Harper government - largely through its majority Parliamentary status and squelching of debate by other political elites, with the notable exception of former NDP leader Jack Layton - attempted to harmonize elite and media framing of the Afghanistan mission on the domestic front, and this can be the subject of a future study, ultimately they failed to have this impact on the embedded media. 
As noted in chapter 2, the media bias within indexing is based on two assumptions. One is an affinity toward those perceived to hold power; "a tendency to slant news favorably toward the side regarded as most powerful, popular, and unified" (Entman 2007, 167). The second is the belief that authority figures, government experts, and elite informants can serve as sources that will provide a complete picture, thereby forestalling additional investigation by a reporter. As disclosed in chapter 6, the embedded media did not demonstrate a bias toward the Harper government - in fact, several military and government respondents suggested that growing antagonism between the media and the Harper government may have contributed to the negative tenor of media coverage; that as the country became politically opposed to PM Harper, criticism of the mission increased. Furthermore, contrary to the Afghanistan-based media receiving a complete picture through PMO channels, the latter were instead predominantly obstructionist rather than informative.

That this attempt at obstructionism and control existed vis-à-vis the Afghanistan message should not surprise those who read Justice Charles Vaillancourt's 2016 ruling and comments regarding the PMO following Senator Mike Duffy's trial for inappropriate domicile and expense claims. "The political, covert, relentless, unfolding of events is mind-boggling and shocking. The precision and planning of the exercise would make any military commander proud. However, in the context of a democratic society, the plotting as revealed in the emails can only be described as unacceptable" (Allan 2016). 
In summary, indexing theory cannot be applied to the Harper government's messaging attempts regarding Afghanistan because, unlike the Bush administration's success in having the American media channel its reasons for invading Iraq ((Bennett, Lawrence, and Livingston 2007, 13-45), the Canadian government failed to fully engage the Canadian media. Instead, the Harper government appeared to target its message-control efforts through bureaucratic channels and, when that proved ineffective, through retaliatory methods. The major casualty of this failed strategy was the incomplete telling of the reasons for and the effects of a Canadian presence in Afghanistan, particularly civilian efforts.

\subsubsection{Editorial command}

Military and government officials were very critical of what they perceived to be Toronto-centric editorial control of embedded reporters and, as a result, the message from Afghanistan. Two key issues of contention were coverage of civilian activities and soldier fatalities.

As addressed in chapter 4, despite the 2008 Manley Report recommendations that allowed government officials to have freer contact with reporters in order to share information about diplomacy and development efforts taking place in Afghanistan on behalf of Canadians, this change in policy did not materialize as change in coverage. A number of officials felt this was a clear result of directives from media home offices. "Canadian reporters seemed to have restraints put upon them by their senior managers 
about what they could and could not do, what they could and could not report on, and what kinds of stories the Canadian public was interested in," said the senior civilian envoy in chapter 5, "saying 'our editors are telling us to be available for ramp ceremonies. ${ }^{\prime 78}$

Sweet and Heath-Eves both agreed: “... reporters coming into KAF wouldn't be allowed to come out with the KPRT without approval from their head office, due to insurance concerns," said Sweet. Unofficially, he added, "they had to be close by in order to quickly cover a ramp ceremony if there were casualties." Heath-Eves recalled that a number of reporters wouldn't take the risk to come out to the KPRT from KAF to cover civilian-side stories claimed their editors said they could not travel. CBC's Ormiston confirmed that "there was a fear of missing the story about casualties, I think that covering casualties had too much importance."

Lieutenant Colonel Lemay was relatively nonplussed by home-office direction. "Like any news story written at home or by deployed reporters, these are always edited by their national desk," he said. "They will give directions and angles to be covered." CDS Vance, on the other hand, was highly disappointed. He felt that reporting of the mission was overly focused on soldier deaths, Afghan victims, and a lack of progress. "[OPSEC policies] may not have allowed them to be as free as they liked, but I think that the embed policies were far less restrictive than some of their own editors' policies about were they could go, and when they could leave," he said. Lacroix was likewise sorely disappointed 
that the media narrative focused on death and military manoeuvres rather than the help being given to Afghans. "I think the editors failed us back in Canada," he said.

From a market perspective, help didn't sell very well. News as a commodity has to be sold to as many people as possible to turn a profit: thus it becomes essential to find the words, images, and stories to attract an audience that will be satisfied enough to tune in regularly. Following 9/11, Canadian media organizations initially pursued a form of solidarity with Canada's allies. During that initial and often emotional coverage, the dichotomous approach of Us/Westerners versus the Other/Taliban/al Qaeda was employed, but this dramatically decreased as the war progressed and ties of solidarity were questioned, particularly after four Canadian soldiers were killed in 2002. Concurrently, news editors realized that the Canadian public had developed strong affection for the Canadian soldier serving his/her country abroad (less, apparently, for those returning to Canada and suffering from PTSD). The heterogeneity of a complex war became distilled into the more homogenous image of Canadian soldiers. "War coverage is particularly suited for that purpose, as the political process of creating images reduces the heterogeneity of illustrated subjects into homogeneity by fitting them under specific themes, thereby eliminating any subtleties and even silencing some subjects" (Martin 2006, 238). Coverage of the CF soldier serving in battle morphed into coverage of the CF soldier who had died in battle, because this is what Canadian news editors had decided the Canadian public wanted to witness. 


\section{Conclusions}

As noted earlier, while embedded reporting has received a significant amount of attention (Aday, Lingston and Hebert 2005; Beane, Jr. 2009; Cortell, Eisinger, and Althaus 2009; Fahmy and Johnson 2005; Katovsky and Carlson 2003; Lehman 2004; Paul and Kim 2004; Pfau et al. 2004, 2005; US Army War College 2004; to name a few), and criticism (Lewis et al. 2004; Schechter 2003), most of that attention has focused on its use in Iraq (Carruthers 2011; Schechter 2006; Knightley 2004; Fox and Byungho Park, 2006). Very little research has addressed its use in Afghanistan (Edy and Meirick 2007; Rall 2010; Haigh 2014; Weisman 2015), much less so within the Canadian sphere of military/media relations (Price 2010; Hobson 2011; Bergen 2010), and some is palpably biased against the news media with little merit or academic substantiation (Maloney 2005; 2009; 2011).

My research has helped fill this space for communications scholars and others interested in this topic by identifying several key themes through interviews with 29 individuals journalists with first-hand experience of reporting from Afghanistan, and military and government officials with in-theatre contact with the media during the war - as well as content analysis of Canadian war reporting during a 10-year period. The key themes, as noted above, include: one, continued debate regarding the impact of embedded reporting on objectivity; two, the role of operations security within an embedded environment; three, an intense focus on soldier fatalities in media coverage; four, political and media head-office influence on reporting; and five, the unique ability that Canadian embedded reporters had to dis-embed/re-embed and what impact that had on their reporting. 
Woven throughout these key themes are the threads that collectively demonstrate how the structural formalization of an embed policy by two disparate cultures - the military and the media - influenced the content and emphases of ensuing media coverage. First, the program was developed largely within the operational confines of the military, an environment that exacted compliance by participant journalists concerning a number of objectives, particularly security and safety. These cultural and physical boundaries facilitated a focus on Canadian soldiers, both in life and in death. The former was welcomed by the military and enabled by media organizations, the latter was not welcomed by the military but still enabled by media organizations. Second, the unique component of Canada's embed program that allowed journalists to dis-embed and reembed upon request and arrangement was rarely taken advantage of by embedded reporters during the Afghanistan mission. On those few occasions when it did occur, the expanded topics and depth of insight dis-embedding provided served to better inform the Canadian public about the multidimensional effects of the war rather than its often glorified means. In sum, it was the very structure and enclosure of the embed program within the folds of the military, as well as the inability and/or unwillingness of many participants to take advantage of the Canadian option of dis-embedding, that effectively ceded the vantage point of the majority of news coverage to the military rather than diplomatic and humanitarian efforts.

Apropos upper-level interference, while this study was not designed to investigate warreporting direction by political bodies such as the PCO and head offices of media 
organizations, I suggest that the architecture of those practices and behaviours needs to be further unpacked and addressed. Such an examination would have future policy implications regarding war journalism as well as international cooperation among Canadian entities serving abroad.

Another theme I found and briefly addressed in chapter 5 concerned the ideological nature of contextualization as it pertained to the Afghanistan mission. As van Dijk (2001) notes, the typical approach to ideology is to study its effects on discourse forms and meanings, and how discursive structures may in turn contribute to the formation and transformation of ideologies. However, ideologies are also at play when language users engage in an ongoing construction of context as subjective, as well as group-sensitive, interpretations of certain situations, in this case, war events and the resulting stories. In other words, personal and group ideologies may influence the ways social attitudes are expressed in discourse structures. For example, van Dijk wrote that when whites speak about blacks, the meanings and style of utterances may be influenced by racist or antiracist ideologies; that ideologies may influence the ways social attitudes are expressed in discourse structures. This same ideology may also influence the way whites construct themselves and blacks as participants in a conversation, how they define any interaction, and what knowledge, beliefs or goals are activated during these conversations. I found in my interviews that contextualization did indeed reflect particular ideologies. From a military perspective, it often meant sharing and understanding reasons for, or providing background on, battlefield decisions and objectives. From a civilian perspective, it meant giving equal value to the different components - such as diplomacy and development - of 
the "whole of government" approach. From a journalist's perspective, it meant examining the wider effects of the war on the lives and future prospects of the people of Afghanistan. I suggest that a promising direction of future research could involve examination of the structure and strategies of the formation of, and changes in, context models that influence varied discourse understanding.

Finally, embedded reporting means a number of distinctive things to different individuals and groups, but one of the highlights of my research was the opportunity to examine three disparate worlds, generally accustomed to functioning independently from one another, yet here operating within the unusual and challenging environment of foreign conflict. The military is clearly familiar with conflict, but less so with the media, and even less with the very differently structured culture of the media. Certain journalists are familiar with the demands of foreign and war reporting, but fewer and fewer as that genre of reporting is shrinking, and clearly there exist a discernible skill set and attitude that accompany the genre that is also disappearing. Lastly, civilians rarely serve in war zones and, even if they have requested the posting, may not always understand the ramifications of working in that environment, particularly when their endeavors are undermined by political machinations from afar. Exploring the nuances of language use and effects on reporting within this context has been fascinating, but there are many more issues that can be investigated, not the least of which is how PTSD can affect soldiers, journalists, and government officials alike who have served in war zones. 


\section{Notes}

${ }^{72}$ Words spoken by Pierre Elliott Trudeau to the (U.S.) National Press Club in Washington on 25 March 1969: "Living next to [the U.S.] is in some ways like sleeping with an elephant. No matter how friendly or even tempered is the beast ... one is affected by every twitch and grunt." (Trudeau 1969)

${ }^{73}$ For example, David Halton, former foreign affairs correspondent for the CBC, said "the Afghanistan War tells us a story about a colossal failure, the folly of trying to change a culture and country in just a few years" (pers. comm., 18 December 2015).

${ }^{74}$ A feature which Postmedia reporter Matthew Fisher said the U.S. military greatly disliked.

${ }^{75}$ The KPRT is located in downtown Kandahar City.

${ }^{76}$ Stewart was referring to the Canadian government's decision to ban the media from covering the return of bodies of soldiers killed in the line of duty. Many in the media perceived this decision as a duplication of the Bush administration's ban, of images of the arrival of flag-draped coffins containing the remains of soldiers killed in Iraq, due to concern that such photographs would lower public support for the military campaign.

${ }^{77}$ The Afghanistan Task Force was responsible for inter-agency/department coordination and cooperation on Canadian diplomatic, deployment, and aid mission to Afghanistan. The task force was located within the Privy Council Office (PCO), and headed by former Foreign and Defence Policy Advisor and Associate Deputy Minister of Foreign Affairs David Mulroney. The task force was responsible for coordination between the principal departments of Foreign Affairs and International Trade (now Global Affairs), National Defence, and the Canadian International Development Agency in addition to other departments and agencies with some form of involvement, including the Royal Canadian Mounted Police and Correctional Service Canada.

${ }^{78}$ The envoy remarked this occurred during the 2008 to 2009 period of the mission. 


\section{CONCLUSION}

Journalists, artists, and editors are mediators who must not only give as much, and as accurate, information as possible, but who have to sell it on the market. What they choose to report, whatever level they are working at, is what will feed their readers' memories. Thus, these mediators are capitalist makers of national memory (Martin 2006, 106).

The goal of this dissertation was to investigate Canadian military/media relations throughout a period of roughly 10 years during Canada's mission in Afghanistan. In doing so, I examined how official procedures governing media coverage - particularly embedding policy - gave shape to the war reporting that was received by Canadians. I have argued that the structural influences of an embed policy that was negotiated by two disparate cultures and accompanying ideologies - a military that is by nature disciplined, rule-oriented and often secretive, and a news media that often seems undisciplined, is both public service and business, and seeks to uncover secrets - changed both how war coverage was produced, as well as the content of what was produced.

This was owing to two primary developments. First, the program was largely housed within the physical confines of the military base in Kandahar, an environment that provided select information to participant journalists with a view to both security and safety. In terms of security, the military's first order of business was to fight a war, and OPSEC always took precedence over the sharing of information with embedded reporters. In terms of safety, reporters who stayed on the base or only left in the company of soldiers defined for themselves how they would produce news for Canadians. As one reporter told 
me, staying embedded did not mean those journalists were covering the Afghan War, it meant they were covering the Canadian military in the Afghan war.

Second, even though the CFMEP evolved to grant embedded reporters the unique ability to dis-embed and re-embed, allowing a greater latitude in story subjects and sources, that opportunity was rarely taken advantage of by individual journalists. This was due to a variety of reasons, most predominantly safety issues, media-parent directives, and a difficult physical and linguistic terrain "outside of the wire" that would seem imposing to many. The few examples of media coverage that did go beyond within-wire stories, focusing on the multidimensional effects of the war rather than its often glorified means, offered just a glimpse of what could be reported.

The net result of these two developments for war reporting was a discernible framing of media coverage on military issues - battles, pursuits, soldier morbidity and mortality - at the expense of civilian, historical, humanitarian, diplomatic, and human-interest issues.

While news reporters have been sporadically attached to military units during times of conflict as far back as the Franco-Prussian War of 1870, the U.S. implemented the first official and large-scale embedded program in 2003 during the Iraq War. The CFMEP was officially implemented in 2006 during the Afghanistan War. Although considerable research has been carried out on the U.S. and British embed programs and the impact they have had on media coverage of conflicts, there has been extremely little academic research on Canada's embed program, ${ }^{79}$ nor its impact on media coverage of the 
Afghanistan War. None has addressed the issue with the breadth - time span and depth of analysis - of this study.

\subsection{Approach}

I carried out my investigation using two methods. First, I conducted semi-structured elite interviews with three groups of individuals having direct involvement with embedded reporting during the Afghanistan mission: journalists with first-hand experience reporting from Afghanistan; and two groups of officials - military and government - who played key roles in the development and/or implementation of the CFMEP and who also had intheatre media contact while in Afghanistan. I chose to draw from three independent yet linked perspectives in order to avoid a one-dimensional approach to my examination of embedded reporting. My questions were designed to probe, on a macro level, awareness of the discursive role that each group may have played in the representation of their environments. On more of a micro level, I gathered a wide spectrum of insight into how embedded policies and practices have developed, opinions on how the program operated and what it delivered, how participants worked together, what the outcomes were, and suggestions for change.

Second, I used CDA to carry out a content analysis of media coverage of Canada's participation in the Afghanistan War during a 10-year period, from 2001 through to 2011, by four representatives of English- and French-language print and television media. These were the Globe and Mail, which has a policy orientation, and La Presse, which has more 
of quotidian orientation; both daily newspapers have the largest circulations in Canada in their respective languages, and wield significant influence in English- and Frenchlanguage populations. I also examined coverage by CBC-TV and Télévision de RadioCanada (SRC-TV), both prominent members of the electronic media and both of which broadcast in all Canadian provinces. ${ }^{80}$

The triangulated approach described above - interviews with journalists, and officials, in conjunction with analysis of media coverage - unfolds in three separate but related chapters. These data constitute my study's practical significance for communication professionals in this field. These data also comprise the corpus of my research and construe a major portion of my original contribution to the literature. As the first such scholarly contribution of its kind in Canada, the issues this study has detected help to clarify and position the relationship between the Canadian Forces and journalists reporting on the Afghanistan War within the larger context of western military/media relations. Following the discussion of my findings, I will address their implications, offer recommendations, and suggest future research directions.

\subsection{Key findings}

Following is a listing of central issues raised by my research on the impact of embedded reporting during Canada's Afghanistan mission. First, this study shows that, similar to other research on embedded reporting, the matter of objectivity is a point of concern and dissention. Most journalists believed that journalistic experience was a safeguard against 
bias; that embedding with the CFMEP did not equate with getting a lobotomy, and that years of training on the job and depth of professionalism would not suddenly be forgotten due to a few weeks of housing in close quarters with soldiers. A minority of journalists agreed with American journalist, essayist and novelist Nora Ephron who once said: "I’ve never believed in objective journalism and no one who is a journalist in his or her right mind does because all writing is about selecting what you want to use. And as soon as you choose what to select, you're not being objective...." (Terkel 1975). Most military and government officials felt that embedded journalists were fair, and that the professionalism and experience of journalists had predominantly supported objectivity in reporting. However, I encountered both covert and overt rumblings in all three groups concerning a lack of professionalism as well as limited war-reporting experience among a number of embedded reporters in the CFMEP, who stayed for too short a time to become sufficiently aware of complex issues, were disinclined to go beyond information provided "inside the wire" or to leave the base for alternative stories, and became enthralled by their environment to the point of getting "all Rambo'ed up" (Welford 2016).

Second, the greater latitude allowed by dis-embedding from/re-embedding into the CFMEP - unique compared to other countries' embed programs - enabled reporters to go beyond military-sourced stories located "outside of the wire" and then return. Although the origins of CFMEP dis-embedding were primarily practical in nature, the end result for some reporters was a greater journalistic sense of independence, more control over topics, and pride in the ability to give the Canadian public different viewpoints on Afghanistan. While dis-embedding did not guarantee a greater degree of objectivity, it certainly 
facilitated the search for and coverage of alternate stories for the Canadian public. In other words, it provided an opportunity for a greater degree of balance in coverage. Unfortunately, few embedded reporters took advantage of this capability, for reasons of inexperience, fear, exigencies of their home desks, sloth, or disinterest. Even fewer journalists chose to report as independents or unilaterals, a decidedly more dangerous and complicated endeavour in a country like Afghanistan, and one that almost demanded a curriculum vitae that included some hard-core war-reporting experience. As one former PAO observed, "I found that the more junior a journalist was, the more likely they were embedded, whereas the more senior, the greater chance of reporting as a unilateral" (Harmes, cited in Wasilow 2011).

Third, findings support my concerns regarding framing. By their very composition, embed programs - including the CFMEP - will facilitate the dominance of military framing of media coverage. In the specific case of the CFMEP, reporters were housed on base, the CF generously provided all means of living and working benefits, PAOs conducted military briefings and/or answered reporters' queries (sometimes they did not answer questions which, as one reporter noted, is not the same as lying), and when possible some journalists would accompany soldiers on various missions or junkets. It was a mutually beneficial arrangement, for the large part, and the public face of a tacit understanding between DND and Canadian news media organizations. As one key reporter told me: "The military has a role, the media have a role, and yes I think there was an understanding on all sides," he said. "The PA officers were pleasant, good at their jobs, and there was always this understanding that they were going to push good-news 
stories and downplay the fact that security was deteriorating. By mid-2007, it was too dangerous to have a news bureau in Kandahar, so most major Canadian reporters were staying in two little canvas tents on a sunbaked airfield and they weren't going anywhere. We knew that it was going to be a long war, that the war would top the news every day, and we couldn't afford to alienate the Canadian military because we had to stay embedded for years. Similarly, the Canadian military couldn't afford to alienate the most influential media outlets" (former Globe staff correspondent, 31 December 2015). It is important to note that the majority of boots-on-the-ground reporters who spoke with me clearly understood the limitations of embedded reporting but were also highly supportive of dis-embedded and unilateral reporting as counter-framing measures as defined by Entman $(1991,2003) .{ }^{81}$ As noted in the preceding paragraph, only a minority of reporters took advantage of the counter-framing capabilities afforded by dis-embedding. In sum, the very infrastructure and location of the CFMEP, and the inability and/or unwillingness of many journalists to dis-embed, effectively ceded the vantage point of the majority of news coverage to the military.

An unexpected finding was a lack of indexing as defined by Bennett (1990; Bennett et al. 2007), which contends that the media have a bias toward power and consistently present the agenda of the political elite. While the traditional application of this theory occurs at a domestic level, I had originally thought - and sought to investigate if - it extended to embedded media. Perhaps unsurprisingly, my research showed that indexing attempts by Ottawa-based political elites had more of an impact on Canadian government officials based in Afghanistan than it did on the Canadian embedded media. Although he was 
commenting on government/media relations, reporter Geoffrey York's comments also apply to attempts by the PCO to control all non-media messages emanating from Afghanistan: "The government does try to manipulate the story — just as governments everywhere in the world will always try to spin the story to their own advantage," he said. "Businesses and citizen groups also try to manipulate the story.... Everyone tries to control the message" (Sheppard 2006). Several government officials in Afghanistan described their attempts at "work arounds" when faced with PCO directives they considered impractical or eleventh-hour, responses that were less about alternative agendas and more about resistance to autocratic oversight.

A second unexpected finding was very high discontent among government officials with, one, CFMEP-design effects, and two, embedded media coverage. More specifically, numerous Canadian government officials serving in Afghanistan were notably dismayed by the lack of Canadian media attention to, and coverage of, diplomatic and development efforts in Afghanistan, despite the Manley Report (2008) clearly emphasizing a need for expanded attention to the "3Ds:" defence, diplomacy, and development. On one hand, respondents realized that the CFMEP was a military-based and -sponsored program, therefore, defence issues would and did take promotional prominence. (Several respondents also noted the more enthralling nature of military exploits compared to development projects.) On the other hand, despite military efforts to help facilitate greater post-Manley media attention to the remaining 2Ds - and I personally witnessed this at a joint military/civilian presentation given at Carleton University in $2010^{82}-$ little changed from the media's general focus on military topics and more specifically CF soldiers. It is 
unclear if this was due to individual journalist preferences, or directives from media home desks. Truth be told, the military also had difficulties in drawing reporters to their own development-type efforts in Deh-e-Bagh, an example of their "model village" approach situated south of Kandahar. Ostensibly the draw of development projects was simply much lower on the radar for many of the embedded journalists in Afghanistan.

A third unexpected finding was more personal in nature. Prior to beginning my research, I had a more skeptical view of embedded reporting. As my research progressed, I came to not only understand its merits - particularly in a country as challenging as Afghanistan, and especially for a woman - but also came to value the uniqueness of the Canadian embed program that allowed for reporters to dis-embed to pursue a wider range of stories.

\subsection{Implications and recommendations}

The relevance of the Vietnam War to military/media relations is still a cause for debate some continue to blame the media for "losing" that war, while others say the media simply followed the lead of capitol-based sources who became alarmed by the war's costs and casualties (Mueller 1973, 42-61). Vietnam was nonetheless a significant wake-up call regarding the media's influence during times of conflict, leading to a number of military/media policy adjustments in the decades that followed. The development of embedded reporting has similarities to the development of foreign-language policies during the Britain from the 1940s onward (Footitt and Tobia, 2013). Both are stories of the growing realization on the part of political and military authorities that the support, 
cooperation, and goodwill of media - like language - are needed if the West is to conduct its military operations successfully, and both led to a gradual integration of media - like language - capacities within the principal activities of war. The process by which this has occurred vis-à-vis embedding has been contentious, and certainly bumpy, but one could argue that the clock cannot be turned back. Therefore, practical measures are required to ensure that both cultures - military and media - understand one another's perspectives and boundaries.

There is a discernible need for a post-Afghanistan meeting of minds - by senior journalists and/or media chiefs, as well as senior military and government officials - to discuss what did and did not work in Afghanistan, what could be done differently, and suggest options for future joint efforts. Attentive deliberations are difficult within an intheatre setting, fatigue is a reality, and emotions can run high. This dialogue could be similar to the Pentagon's recent consultations with news organizations, which Pentagon lawyer Jennifer O'Connor has said "helped us improve the [Law of War guidelines] manual and communicate more clearly the department's support for the protection of journalists under the law of war" (Burns 2016). The same approach could be applied to the CFMEP, with the objective of free and open debate. While another military engagement such as Afghanistan is unlikely, it is always prudent to think ahead and plan accordingly.

Furthermore, as I have noted previously, I find it curious that media organizations do not appear to be as disciplined as military organizations when it comes to analyzing 
communications practices such as war reporting. As Knightley $(2004,484)$ has observed: "Wars are studied, lessons are learnt, systems are devised, tested and polished" (Knightley 2004, 484). Conversely, war reporters do not seem to have a tradition, manual, or guidebook for passing on their valuable experiences, nor systematic and consistent training other than event-specific "boot camps." Moreover, according to those interviewed during this study, there are no formalized debriefing sessions or post-combat support systems for reporters, both in terms of sharing, analyzing, and learning from their experiences, let alone for dealing with any form of post-traumatic stress syndrome (PTSD) than can affect journalists and soldiers alike. Media organizations need to do better by their members.

\subsection{Limitations and future research directions}

This study covered a period of 10 years. While this range of media analysis is considerably larger than other studies of Canadian war reporting, it is nonetheless limited to the Afghanistan War, during which embedded reporting became an established program. However, a more comprehensive and systematic examination of war reporting including those instances of less-formalized embedded reporting by Canadian journalists that occurred prior to Afghanistan, such as during Kosovo (Bergen 2005) and WWII could go back 50 to 100 years, similar to what Knightley (2004) did in his seminal work and Bourrie (2012) did for Canada-related war reporting. This would allow for a more complete examination of the effects of embedding reporting, before it became formally known as embedded reporting, on war journalism. 
Similarly, one of the few comparative studies of the coverage of the Iraq War (Dimitrova, Kaid, Williams and Trammell 2005) found significant differences in war framing between U.S. and international news websites: foreign sites were more likely to include the responsibility frame, where the "emphasis is on the party/person responsible for the event" (32), while American sites were more likely to focus on military conflict. A future area of research could investigate how the domestic Canadian media's war coverage compares to that of other countries' war coverage through both framing and indexing lenses.

The passage of time, administrative delays, and perceptions of risk had a limiting effect on the number of individuals interviewed for this project. One can always interview more people, tap into into different demographics, or approach groups with contrasting or even conflicting opinions in order to expand the horizon of one's research, but at some point, all researchers must draw that proverbial line in the sand.

Originally, before the scope of available materials had become apparent, I had wanted to analyze differences between works produced by Canadian embedded and unilateral reporters; however, unilateral productions are scarce within the Canadian context. One of the notable exceptions to this is Scott Taylor's excellent documentary, Afghanistan: Outside the Wire, which I examined elsewhere (Wasilow 2012). 
One more important direction for future research is one that I could not accomplish for reasons of accessibility to CF soldiers: exploration if embedded reporting has become a psychological form of "indexing" from the ground up. In other words, instead of the media following a bias perceived in the upper echelons of power and tracing official or elite views 'downward' in a discernible pattern, has embedding facilitated a process by which frontline journalists follow a personal bias based on an emotional bond of camaraderie with their peers, subsequently tracing soldiers' views of the war 'upward,' even adopting those views as their own for public consumption?

\subsection{Final words}

With respect to war journalism, I argue that the formalization of embedded reporting has been one of, if not the, most consequential developments in recent history of military/media relations. It has essentially fused together two previously separate cultures. Furthermore, I contend that embedded reporting is here to stay, likely not in the exact form we saw during the Afghanistan War, but it will likely continue in some semblance, tied to army and naval combat. This is due to several reasons. For the media, first and foremost, war sells; it generates revenue through engaging public interest. Second, embedding provides greater security for journalists; war reporting is dangerous, and reporting on Afghanistan was particularly perilous. Third, despite misgivings about issues of independence, the Canadian version of embedded reporting during Afghanistan that allowed for dis-embedding and re-embedding - despite American disdain - proved both novel and popular in Canadian journalistic circles. For the military, embedded reporting 
allows for a typically detached institution to connect with the public at an emotional level. Embedding allows for the humanity of the soldiers to become front and centre in the public eye, followed by entry-level citizen awareness of and connection to strategic operations, objectives, and both wins and losses. Finally, while I contend that the formalized practice of embedded reporting that was introduced by the U.S. in Iraq in 2003 was engineered to facilitate the creation of a particular discourse representation of language practice via creation of a controlled context that affected what was said, written and interpreted, I also assert that the Canadian military's version is "kinder and softer" due to its incorporation of dis-embedding practices, which is perhaps why the U.S. military objects to it so strenuously. This is not to claim that the Canadian military is unaware of the beneficial effects of embedded reporting to its image - particularly subsequent to a history that includes the "Somalia Affair," 83 - but the propaganda machinations and outcomes do not seem to this writer to be as manipulative as some might claim.

In conclusion, I offer this dissertation as a useful contribution to the literature on Canadian embedded reporting in Afghanistan specifically, and to military/media relations more generally. Although my research was designed to examine the architecture and effects of embedding, an unexpected benefit and personal pleasure was connecting with those individuals whose rich and insightful experiences in Afghanistan allowed an academic to enter and experience their worlds however briefly and vicariously. I strongly believe in transdisciplinary research that links and investigates the complexities of human 
nature with overarching ideologies, and I hope that this work - bridging journalism

practice and communication theory - plays a contributing role in that type of inquiry.

\section{NOTES}

${ }^{79}$ An unpublished MA thesis called "Inside the Wire: A Study of Canadian Embedded Journalism in Afghanistan" (Price 2009), and the more recent Adapting in the Dust: Lessons Learned from Canada's War in Afghanistan (Saideman 2016).

${ }^{80}$ The name "Radio-Canada" refers to all television, radio, and internet operations in the French language. Furthermore, the network is normally coded as $S R C$ (for Société Radio-Canada).

${ }^{81}$ As were some military officials such as Lieutenant Colonel Lemay.

82 "Canada's Evolving Mission in Afghanistan," a presentation by Colonel Roch Lacroix, Former Deputy Commander, Task Force Kandahar, and Tara Denham, Chief of Staff to the Representative of Canada in Kandahar, 4 February 2010, Dunton Tower, Carleton University.

${ }^{83}$ As noted in chapter three, the "Somalia Affair" was a military scandal about two Canadian soldiers who, while participating in humanitarian efforts in Somalia, beat a Somali teenager to death. There were subsequent charges of an attempted cover-up. The affair led to the disbanding of Canada's elite Canadian Airborne Regiment, damaged the morale of the Canadian Forces, and besmirched the formerly excellent domestic and international reputation of Canadian soldiers. 


\section{REFERENCES}

Aday, Sean, Steven Lingston, and Maeve Hebert. 2005. "Embedding the Truth: A CrossCultural Analysis of Objectivity and Television Coverage of the Iraq War." The Harvard International Journal of Press/Politics 10(1):3-21.

Aikins, Matthieu. 2016. "The Bidding War: How a Young Afghan Military Contractor Became Spectacularly Rich.” 7 March. Accessed 13 March 2016 from http://www.newyorker.com/magazine/2016/03/07/the-man-who-made-millionsoff-the-afghan-war

Alexievich, Svetlana. 1992. Zinky Boys: Soviet Voices from the Afghanistan War. Translated by Julia and Robin Whitby. New York: W.W. Norton and Co.

Allan, Susan. 2016. "Read the Judge's Decision in the Duffy Trial.” macleans.ca, 21 April 2016. Accessed 14 July 2016 at: http://www.macleans.ca/politics/ottawa/read-the-judges-decision-in-the-duffy$\underline{\text { trial} /}$

Althaus, Scott L. 2003. When News Norms Collide, Follow the Lead: New Evidence for Press Independence. Political Communication 20(4):381-414.

Archetti, Cristina. 2008. "Unamerican Views: Why US-Developed Models of Press-State Relations Do Not Apply to the Rest of the World. Westminster Papers in Communication and Culture 5(3):4-26.

Arlen, Michael J. 1969. Living-Room War. New York: Viking Press.

Ayres Jr., B. Drummond. 1974. "Westmoreland Faces Decision On Entering Carolina Politics; Favors Censorship.” New York Times, 13 January. Accessed 5 June 2012 at

http://select.nytimes.com/gst/abstract.html?res=F10B15FF395A1B778DDDAA09 94D9405B848BF1D3

Balzer, Timothy. 2010. The Information Front: The Canadian Army and News Management during the Second World War. Vancouver: UBC Press.

Bamford, James. 2005. "The Man Who Sold the War." rollingstone.com, 30 November. Accessed 14 June 2012 at http://www.rollingstone.com/music/pictures/rollingstones-biggest-scoops-exposes-and-controversies-2-aa-624/the-man-who-soldthe-war-by-james-bamford-3323040

Barkho, Leon. 2010. News from the BBC, CNN, and Al-Jazeera: How the Three Broadcasters Cover the Middle East. Cresskill, NJ: Hampton Press. 
Barstow, David. 2007. Behind TV Analysts, Pentagon's Hidden Hand. New York Times, 20 April. Accessed 30 June 2011 at http://www.nytimes.com/2008/04/20/us/20generals.html?_r=1

Battaglia, Philip F. 2005. "A Guide for Small Unit Commanders on the Media Embed Program." Infantry Magazine 94.3(May-June):15.

Baudrillard, Jean. 1995. The Gulf War Did Not Take Place. Translated by Paul Patton. Bloomington: Indiana University Press.

Beane, Jr, Thomas C. 2009. Military and the Media - What's Next After Embedding? Carlisle Barracks, PA: Army War College. Accessed 31 October 2011 at http://www.dtic.mil/cgibin/GetTRDoc?AD $=$ ADA500793\&Location $=\mathrm{U} 2 \&$ doc $=$ GetTRDoc.pdf

Bearden, Milton. 2001. "Afghanistan, Graveyard of Empires." Council on Foreign Relations, November/December 2011 issue. Accessed 4 February 2015 at http://www.foreignaffairs.com/articles/57411/milton-bearden/afghanistangraveyard-of-empires

Beniger, James R., and Jodi A. Gusek. 1995. "The cognitive revolution in public opinion and communication research." In Public opinion and the communication of consent, eds. Theodore L. Glasser and Charles T. Salmon. New York: Guilford Press.

Bennett, W. Lance. 1990. Toward a Theory of Press-State Relations in the United States. Journal of Communication 40(2):103-125

Bennett, W. Lance. 2003. "Operation Perfect Storm: The Press and the Iraq War." Reportedly published in Political Communication Report, Fall. Accessed 11 November 2014 at http://www.warmwell.com/2sept27press.html

Bennett, W. Lance. 2004. "Gatekeeping and Press-Government Relations: A Multi-Gated Model of News Construction." In Handbook of Political Communication Research, ed. Lynda Lee Kaid. Mahwah, NJ: Lawrence Erlbaum.

Bennett, W. Lance. 2012. News: The Politics of Illusion, 9th edition. Boston: Longman.

Bennett, W. Lance and David L. Paletz, eds. 1994. Taken by Storm: The Media, Public Opinion, and US Foreign Policy in the Gulf War. Chicago: University of Chicago Press.

Bennett, W. Lance, Regina G. Lawrence, and Steve Livingston. 2006. "None Dare Call It Torture: Indexing and the Limits of Press Independence in the Abu Ghraib Scandal." Journal of Communication 56(3):467-485. 
Bennett, W. Lance, Regina G. Lawrence, and Steven Livingston. 2007. When the Press Fails: Political Power and the News Media from Iraq to Katrina. Chicago: University of Chicago Press.

Bergen, Robert W. 2005. "Balkan Rats and Balkan Bats: The art of managing Canada's news media during the Kosovo air war." Unpublished Doctoral Thesis, Centre for Military and Strategic Studies, University of Calgary.

Bergen, Bob. 2010. Censorship; the Canadian News Media and Afghanistan: A Historical Comparison with Case Studies. Calgary: University of Calgary, Centre for Military and Strategic Studies.

Berkowitz, Leonard. 1965. "Some Aspects of Observed Aggression. Journal of Personality and Social Psychology 2(3):359-369.

Blatchford, Christie. 2007. Fifteen Days: Stories of Bravery, Friendship, Life and Death from Inside the New Canadian Army. Toronto: Doubleday Canada.

Bourdieu, Pierre. 1991. Language and Symbolic Power. Ed. John B. Thompson, trans. by Gino Raymond and Matthew Adamson. Cambridge, MA: Harvard University Press.

Bourrie, Mark. 2012. Fighting Words: Canada's Best War Reporting. Toronto: Dundurn Press.

Boykoff, Maxwell T. 2008. "Media and Scientific Communication: A Case of Climate Change.” In Communicating Environmental Geoscience, eds. David Gordon Earl Liverman, Christopher P. G Pereira, and Brain Marker. Geological Society, Special Publications 305:11-18. London: The Geological Society of London. Accessed 10 November 2014 at http://sciencepolicy.colorado.edu/admin/publication_files/2008.39.pdf

Braestrup, Peter, ed. 1984. Vietnam as History: Ten Years after the Paris Peace Accords. Washington, D.C.: University Press of America.

Brandenburg, Heinz. 2007. "Security at the Source: Embedding Journalists as a Superior Strategy to Military Censorship.” Journalism Studies 8(6):948-963.

Brewer, Susan A. 2009. Why America Fights: Patriotism and War Propaganda from the Philippines to Iraq. New York: Oxford University Press.

Breznican, Anthony. 2002. "Bill Maher Tapes Last Talk Show." Associated Press, 28 June. Accessed 26 January 2015 at http://www.apnewsarchive.com/2002/BillMaher-Tapes-Last-Talk-Show/id-9b94cb3a3f03e1ab4c7dbd4a2aae66a7 
British Nationality (Falklands Islands) Act. 1983. Parliament of the United Kingdom. Chapter 6. Accessed 5 December 2013 at http://www.legislation.gov.uk/ukpga/1983/6

Brockus, Susan. 2009. 'Coming to You 'Live:' Exclusive Witnessing and the Battlefield Reporter." Journal of Communication Inquiry 33(1):27-42.

Brothers, Caroline. 1997. War and Photography: A Cultural History. New York: Routledge.

Burns, Robert. 2016. "Pentagon Revises Manual to Clarify Protections of Journalism." The Monitor, 22 July. Accessed 26 July 20162012 at http://www.themonitor.com/news/elections/pentagon-revises-manual-to-clarifyprotections-of-journalism/article 583ef0ea-8863-5887-a14f-9a4e573a0254.html

Bush, George W. 2004. State of the Union Address. Washington, D.C.: White House. Accessed 26 July 2011 at http://www.presidency.ucsb.edu/ws/index.php?pid=29646\#axzz1TE5xrXVD

Bush, Laura. 2001. "Radio Address by Mrs. Bush.” Washington, D.C.: White House. Accessed 26 July 2011 at http://georgewbushwhitehouse.archives.gov/news/releases/2001/11/20011117.html

Bush, George W. 2006. "National Pearl Harbor Remembrance Day, 2006.” Accessed 25 May 2012 on The White House: President George W. Bush website at http://georgewbush-whitehouse.archives.gov/news/releases/2006/12/20061201$\underline{6 . h t m l}$

Calame, Byron. 2005. "The Miller Mess: Lingering Issues Among the Answers." New York Times, 23 October. Accessed 1 June 2012 at http://www.nytimes.com/2005/10/23/opinion/23publiceditor.html?pagewanted=al $\underline{1}$

Cappella, Joseph N. and Kathleen Hall Jamieson. 1997. Spiral of Cynicism: The Press and the Public Good. New York: Oxford University Press.

Cappella, Joseph N. and Kathleen Hall Jamieson. 2007. "Cognitive Bases for Framing Effects." In The Political Communication Reader, eds. Ralph Negrine and James Stanyer, 181-186. New York: Routledge.

Carragee, Kevin M. and Wim Roefs. 2004. "The Neglect of Power in Recent Framing Research.” Journal of Communication 54:214-33. 
Carruthers, Susan L. 2011. The Media at War, $2^{\text {nd }}$ edition. Houndmills, Basingstoke, Hampshire: Palgrave MacMillan.

CBC. 2003. "Canadian Soldiers Heading Back to Afghanistan." 12 February. Accessed on 17 April 2014 at http://www.cbc.ca/news/canada/canadian-soldiers-headingback-to-afghanistan-1.392857

CBS 60 Minutes. 2004. "Abuse of Iraqi POWs by GIs Probed.” Correspondent Rebecca Leung. Accessed 5 December 2013 at http://www.cbsnews.com/news/abuse-ofiraqi-pows-by-gis-probed/

Chadwick, Alex. 2004. Interview: Tony Perry Discusses His Experiences as an Embedded Reporter in Fallujah" (17 June) National Public Radio, Day to Day. Accessed 22 July 2016 at Academic OneFile: https://proxy.library.carleton.ca/login?url=http://go.galegroup.com/ps/i.do?id=GA

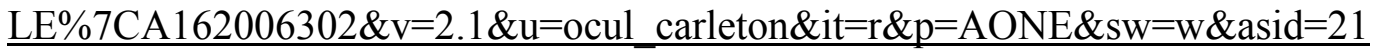
e8caa3cded4d2120135fb137e53ba3

Charlie Rose Show. 2004. "A Discussion about the Implications of the Abu Ghraib Photographs." charlierose.com, 3 May. Accessed 14 June 2012 at http://www.charlierose.com/view/interview/1454

Chase, Steven. 2015. "More Jihadist Attacks Likely, Kenney Says, Defending Anti-Terror Bill." theglobeandmail.com, 19 February. Accessed 15 July 2016 at http://www.theglobeandmail.com/news/politics/more-jihadist-attacks-likelykenney-says-defending-anti-terror-bill/article23070749/

Chong, Dennis. 1996. "Creating Common Frames of Reference on Political Issues." In Political Persuasion and Attitude Change, ed. D.C. Mutz, P.M. Sniderman, R.A. Brody, 195-224. Ann Arbor: University Michigan Press.

Chong, Dennis. 2000. Rational Lives: Norms and Values in Politics and Society. Chicago: University Chicago Press.

Chong, Dennis and James N. Druckman. 2007. "Framing Theory." Annual Review of Political Science 10:103-26.

Chossudovsky, Michel. 2014. “'The War is Worth Waging:' Afghanistan's Vast Reserves of Minerals and Natural Gas: The War on Afghanistan is a Profit Driven 'Resource War.'” Montreal: Global Research: Centre for Research on Globalization (February 21). Accessed on 12 March 2014 at http://www.globalresearch.ca/the-war-is-worth-waging-afghanistan-s-vastreserves-of-minerals-and-natural-gas/19769 
Chouliaraki, Lilie and Norman Fairclough. 1999. Discourse in Late Modernity: Rethinking Critical Discourse Analysis. Edinburgh : Edinburgh University Press.

CIA World Fact Book. 2014. "South Asia: Afghanistan. People and Society." Accessed on 12 March 2014 at https://www.cia.gov/library/publications/the-worldfactbook/geos/af.html

CNN. 2001. "Bush: 'There's No Rules."' CNN.com, 17 September. Accessed 12 June at http://articles.cnn.com/2001-09-17/us/gen.bush.transcript_1_strong-symbol-safehavens-military-police? s=PM:US

Cohen, Bernard Cecil. 1963. The Press and Foreign Policy. Princeton, NJ: Princeton University Press.

Common, David. 2006. "2 Canadians Hurt in Kandahar Rocket Attack." 30 June. Accessed 24 March 2016 at http://army.ca/forums/index.php?topic=46582.5;wap2

Cook, Timothy. 1994. "Domesticating a Crisis: Washington Newsbeats and the Network News on the Iraq Invasion of Kuwait." In Taken by Storm: The Media, Public Opinion, and U.S. Foreign Policy in the Gulf War, eds. W. Lance Bennett and David L. Paletz. Chicago: University of Chicago Press.

Cooley, Alexander. 2012. Great Games, Local Rules: The New Great Power Contest in Central Asia. New York: Oxford University Press.

Corman, Steven R. and Jill S. Schiefelbein. 2008. "Communication and Media Strategy in the Islamist War of Ideas." In Weapons of Mass Persuasion: Strategic Communication to Combat Violent Extremism, ed. Steven R. Corman, Angela Trethewey and H.L. Goodall, Jr. New York: Peter Lang Publishing.

Cortell, Andrew P., Robert M. Eisinger, and Scott L. Althaus. 2009. "Why embed? Explaining the Bush Administration's Decision to Embed Reporters in the 2003 Invasion of Iraq." American Behavioral Scientist 52(5):657-677.

Couldry, Nick and John Downey. 2004. "War or Peace?: Legitimation, Dissent, and Rhetorical Closure in Press Coverage of the Iraq War Build-Up." In Reporting War: Journalism in Wartime, ed. Stuart Allen and Barbie Zelizer. New York: Routledge.

Cox, Jim. 2007. Afghanistan: The Canadian Military Mission. 7 November, PRB 07-19E. Ottawa: Parliament of Canada. Accessed 13 February at http://www.lop.parl.gc.ca/content/lop/researchpublications/prb0719-e.htm

Creel, George. 1972. How We Advertised America. New York: Arno Press. 
Croteau, David and William Hoynes. 2000. Media/Society: Industries, Images, and Audiences, $2^{\text {nd }}$ edition. Thousand Oaks, CA: Pine Forge Press.

Dadge, David. 2006. The War in Iraq and Why the Media Failed Us. Westport, CT: Praeger.

Dedaić, Mirjana N. and Daniel N. Nelson. 2003. At War with Words. New York: Mouton de Gruyter.

Defence Administrative Order and Directive (DAOD) 2008-2. 1998. Media Relations and Public Announcements. Ottawa: Government of Canada. Accessed 1 July 2016 at http://www.forces.gc.ca/en/about-policies-standards-defence-admin-ordersdirectives-2000/2008-2.page

Department of National Defence (DND). 1997. "Media Relations." Dispatches 4(3):1-24 (March). Kingston: The Army Lessons Learned Centre.

Dillman Carpentier, Francesca R., David R. Roskos-Ewoldsen and Beverly B. RoskosEwoldsen. 2008. "A Test of the Network Models of Political Priming." Media Psychology 11(2):186-206.

Dillow, Gordon. 2003. "Grunts and Pogues: The Embedded Life," Columbia Journalism Review May:32-33.

Dimitrova, Daniela V. and Jesper Strömbäck. 2005. MISSION ACCOMPLISHED? Framing of the Iraq War in the Elite Newspapers in Sweden and the United States. Gazette: The International Journal for Communication Studies 7(5):399-417.

Dimitrova, Daniela V., Lynda Lee Kaid, Andrew Paul Williams and Kaye D. Trammell. 2005. "War on the Web: The Immediate News Framing of Gulf War II." The Harvard International Journal of Press/Politics 10(1):22-44.

Dodds, Klaus. 2005. "Contesting War: British Media Reporting and the 1982 South Atlantic War." In War and the Media: Reportage and Propaganda, 1900-2003, eds. Mark Connelly and David Welch. New York: I.B. Tauris.

Dorman, William A. 2006. "A Debate Delayed is a Debate Denied: US News Media before the 2003 War with Iraq." In Leading to the 2003 Iraq War: The Global Media Debate, eds. Alexander G. Nikolaev and Ernest A. Hakanen. London: Palgrave MacMillan.

Dorn, Walter and Mike Varey. 2009. "The Rise and Demise of the "Three Block War." Canadian Military Journal 10(1):38-45. Accessed 17 April 2014 at http://www.journal.forces.gc.ca/vol10/no1/doc/07-dornvarey-eng.pdf 
Dowd, Maureen. 2005. "Woman of Mass Destruction." New York Times, 22 October. Accessed 15 December 2014 at http://query.nytimes.com/gst/fullpage.html?res=9A02E3D8133FF931A15753C1 $\underline{\mathrm{A} 9639 \mathrm{C} 8 \mathrm{~B} 63}$

Downie Jr., Leonard. 2004. Iraq: New Abuse Details. Discussion Transcript. The Washington Post, May 21. Accessed 17 November 2014 at http://www.washingtonpost.com/wp-dyn/articles/A44952-2004May21.html

Doyle Driedger, Sharon, Brenda Branswell, Jane O’Hara, Stephanie Nolen, John Geddes and Shanda Deziel. "Rape in the Military. Maclean's, 25 May. Accessed 17 April 2014 at http://www.thecanadianencyclopedia.ca/en/article/rape-in-the-military/

Driedger, S. Michelle. 2008. "Creating Shared Realities through Communication: Exploring the Agenda-Building Role of the Media and its Sources in the E. coli Contamination a Canadian Public Drinking Water Supply." The Journal of Risk Research, Vol. 11(1-2):23-40.

Dunmire, Patricia L. 2007. “'Emerging Threats' and 'Coming Dangers.”' In Discourse, War and Terrorism, ed. Adam Hodges and Chad Nilep. Philadelphia: John Benjamins Publishing Company.

Edwards, Matthew. 2003. "The New Great Game and the New Great Gamers: Disciples of Kipling and Mackinder." Central Asian Survey 22(1): 83-102.

Edy, Jill A. and Patrick C. Meirick. 2007. "Wanted, Dead or Alive: Media Frames, Frame Adoption, and Support for the War in Afghanistan." Journal of Communication 57(1): 119-141.

Elegant, Robert. 1981. "How to Lose A War: The Press and Viet Nam." Encounter LVII(2, August):73-90. Accessed 4 June 2012 at http://www.wellesley.edu/Polisci/wj/Vietnam/Readings/elegant.htm

Entman, Robert M. 1991. "Framing U.S. coverage of international news: Contrasts in narratives of the KAL and Iran air incidents." Journal of Communication 41(4):627.

Entman, Robert M. 1993. "Framing: Toward Clarification of a Fractured Paradigm." Journal of Communication 43(4):6-27.

Entman, Robert M. 2003. "Cascading Activation: Contesting the White House's Frame after 9/11." Political Communication 20(4):415-432.

Entman, Robert M. 2004. Projections of Power: Framing News, Public Opinion, and US Foreign Policy. Chicago: University Chicago Press. 
Entman, Robert M. 2007. "Framing Bias: Media in the Distribution of Power." Journal of Communication 57:163-173.

Entman, Robert M. 2010. "Media framing biases and political power: Explaining slant in news of Campaign 2008." Journalism 11(4):389-408.

Entman, Robert M. and Benjamin I. Page. 1994. "The News Before the Storm.” In Taken by Storm: The Media, Public Opinion, and US Foreign Policy in the Gulf War, ed. W. Lance Bennett and David L. Paletz, Chicago: University of Chicago Press.

Fahmy, Shahira. 2004. "Picturing Afghan Women: A Content Analysis of AP Wire Photographs During the Taliban Regime and After the Fall of the Taliban Regime." Gazette 66(2):91-112.

Fahmy, Shahira and Thomas J Johnson. 2005. "How We Performed:" Embedded Journalists' Attitudes and Perceptions towards Covering the Iraq war. Journalism and Mass Communication Quarterly 82(2):301-317.

Fahmy, Shahira \& Thomas J. Johnson. 2007. Embedded Versus Unilateral Perspective on Iraq War. Newspaper Research Journal 28:98-114.

Fairclough, Norman L. 1992. Discourse and Social Change. Cambridge: Polity.

Fairclough, Norman L. 2002. "Critical and Descriptive Goals in Discourse Analysis.” In Critical Discourse Analysis: Critical Concepts in Linguistics, ed. Michael Toolan. New York: Routledge.

Fairclough, Norman L. 2003. Analyzing Discourse: Textual Analysis for Social Research. London: Routledge.

Fairclough, Norman L. and Ruth Wodak. 1997. "Critical Discourse Analysis." In Discourse Studies: A Multidisciplinary Introduction, Vol. 2. Discourse as Social Interaction, ed. Teun van Dijk. London: Sage.

Fialka, John J. 1992. Hotel Warriors: Covering the Gulf War. Washington, DC: Woodrow Wilson Center Press.

Fisher, Matthew. 2011. "Matthew Fisher: A Year in Afghanistan.” 11 January, The Agenda with Steve Paikin. Accessed 13 February at https://www.youtube.com/watch?v=uyJNBpuxhoU

Fisher, Matthew. 2011. "Where Have All the Embeds Gone?” 11 April. Accessed 25 March 2016 at http://o.canada.com/news/canadian-media-largely-missing-fromafghanistan-these-days 
Fisk, Robert. 1991. "Out of the Pool. Mother Jones 16(3, May/June):56-9. Accessed 11 June 2012 at http://books.google.ca/books?id=IecDAAAAMBAJ\&q=fisk\#v=snippet\&q=fisk\& $\underline{\mathrm{f}=\text { false }}$

Footitt, Hilary and Simona Tobia. 2013. WarTalk: Foreign Languages and the British War Effort in Europe, 1940-47. Basingstoke, HampshirePalgrave Macmillan.

Fox, Julia R. and Byungho Park. 2006. "The "I" of Embedded Reporting: An Analysis of CNN Coverage of the "Shock and Awe" Campaign." Journal of Broadcasting and Electronic Media (March):36-51.

Foucault, Michel. 1972. The Archaeology of Knowledge. London: Routledge.

Frum, David. 2003. The Right Man: The Surprise Presidency of George W. Bush. New York: Random House.

Galloway, Gloria. 2009. “Top Soldier Lambastes Local Afghans.” 28 September. Accessed 22 April 2016 at http://www.theglobeandmail.com/news/world/topsoldier-lambastes-local-afghans/article1202827/

Gans, Herbert. 2005. Deciding What's News: A Study of CBS Evening News, NBC Nightly News, Newsweek, and Time. Evanston, IL: Northwestern University Press.

Gee, James Paul. 2011. How to Do Discourse Analysis: A Toolkit. New York: Routledge.

Gee, James Paul and Michael Handford. 2012. "Introduction." In The Routledge Handbook of Discourse Analysis, ed. James Paul Gee and Michael Handford. New York: Routledge.

Geertz, Clifford. 1973. The Interpretation of Cultures; Selected Essays. New York: Basic Books.

Gerbner, George. 1994. "Instant History, Image History: Lessons from the Persian Gulf War." In Images in Language, Media and Mind, ed. Roy F. Fox (123-140). Urbana, IL: National Council of Teachers of English.

Gershkoff, Amy and Shane Kushner. 2005. "Shaping Public Opinion: The 9/11-Iraq Connection in the Bush Administration's Rhetoric." Perspective on Politics 3:525537.

Gibbs, Philip. 1923. Adventures in Journalism. New York: Harper \& Brothers. 
Gilboa, Eytan. 2005. "The CNN Effect: The Search for a Communication Theory of International Relations." Political Communication 22(1):27-44.

Girardet, Edward. 2012. Killing the Cranes: A Reporter's Journey through Three Decades of War in Afghanistan. White River Junction, VT: Chelsea Green Publishing.

Gitlin, Todd. 1980. The Whole World Is Watching: Mass Media In The Making and Unmaking Of The New Left. Berkeley: University of California Press.

Globe and Mail, editorial. 2014. "What Canada Did - and Did Not - Achieve in Afghanistan," 14 March. Accessed 4 February 2015 at http://www.theglobeandmail.com/globe-debate/editorials/now-that-our-war-inafghanistan-is-over/article17501889/

Goffman, Erving. 1974. Frame Analysis: An Essay on the Organization of Experience. Cambridge, MA: Harvard University Press.

Goldenberg, Eddie. 2006. The Way it Works: Inside Ottawa. Toronto: McClelland \& Stewart.

Government of Canada. 2001. "37th Parliament, 1st Session, Edited Hansard, Number 094. Monday, October 15." Accessed 15 December 2014 at http://www.parl.gc.ca/HousePublications/Publication.aspx?Pub=Hansard\&Mee=9 $\underline{4 \& \text { Language }=\mathrm{E} \& \mathrm{Parl}=37 \& \mathrm{Ses}=1}$

Granatstein, Jack L. and Dean F. Oliver. 2011. The Oxford Companion to Canadian Military History. Don Mills, ON: Oxford University Press.

Greenway, H.D.S. 1999. “This Warring Century.” Columbia Journalism Review September/October:49-53.

Groshek, Jacob. 2008. "Coverage of the Pre-Iraq War Debate as a Case Study of Frame Indexing." Media, War \& Conflict 1(3):315-338.

Hadaway, Benjamin W. 2006. "Lampreys Under a Shark: Embedded News Reporters and the Military in the 21st Century." Master's Thesis, Carleton University, School of Journalism and Communication, Ottawa.

Haigh, Michel M. 2014. "Afghanistan War Coverage More Negative Over Time." Newspaper Research Journal 35(3):38-51.

Hallin, Daniel C. 1986. The "Uncensored War:" The Media and Vietnam. New York: Oxford University Press. 
Hamilton, John Maxwell. 2009. Journalism's Roving Eye: A History of American Foreign Reporting. Baton Rouge: Louisiana State University Press.

Hamilton, John, Regina Lawrence, and Raluca Cozma. 2010. "The Paradox of Respectability: The Limits of Indexing and Harrison Salisbury's Coverage of the Vietnam War." The International Journal of Press/Politics 15(1):77-103.

Harris, Robert. 1983. Gotcha! The Media, the Government, and Falklands Crisis. London: Faber.

Hastie, Reid and Bernadette Park. 1986. "The Relationship between Memory and Judgment Depends on Whether the Task is Memory-Based or On-Line." Psychological Review 93:258-268.

Hebdige, Dick. 1993. "Training Some Thoughts On the Future.” In Mapping the Futures: Local Cultures, Global Change, ed. Jon Bird, Barry Curtis, Tim Putnam, George Robertson, and Lisa Tickner. London: Routledge.

Herman, Edward S. and Noam Chomsky.1988. Manufacturing Consent: The Political Economy of the Mass Media. New York: Pantheon Books.

Hersh, Seymour M. 2004. "Torture at Abu Ghraib." newyorker.com, 10 May. Accessed 14 June 2012 at http://www.newyorker.com/archive/2004/05/10/040510fa fact

Hess, Stephen. 1983. The Golden Triangle: The Press at the White House, State, and Defense." The Brookings Review 1(Summer):14-19.

Hetherington, Tim and Sebastian Junger, directors. 2010. Restrepo: Afghan Outpost [Documentary]. United States: National Geographic Entertainment.

Hensley, Wayne E. 1996. "A Theory of the Valenced Other: The Intersection of the Looking-Glass Self and Social Penetration. Social Behavior and Personality: An International Journal 24:293-308.

Hess, Stephen and Marvin Kalb, eds. 2003. The Media and the War on Terrorism. Washington, DC: Brookings Institution Press.

Hillier, Rick. 2009. A Soldier First: Bullets, Bureaucrats and the Politics of War. Toronto: HarperCollins.

Hobson, Sharon. 2006. "General Rick Hillier - Canadian Forces Chief of the Defence Staff," 9 August:1-3. Interview. Jane’s Defence Weekly. Accessed 9 April 2014 at https://janes-ihscom.proxy.library.carleton.ca/CustomPages/Janes/DisplayPage.aspx?DocType $=\mathrm{N}$ ews\&ItemId $=+++1154413$ 
Hobson, Sharon. 2007. The Information Gap: Why the Canadian Public Doesn't Know More about Its Military. Calgary: Canadian Defence \& Foreign Affairs Institute. Accessed on 9 April 2014 at http://www.cdfai.org/PDF/The\%20Information\%20Gap.pdf

Hobson, Sharon. 2011. “Operations Security and the Public's Need to Know.” March. Calgary: Canadian Defence \& Foreign Affairs Institute.

Holonen, Doug. 2003. “Q\&A: The Pentagon Experiment; Spokeswoman Clarke Deconstructs Embed Process." TelevisionWeek 22(20):18-20.

Horn, Colonel Bernd. 2010. No Lack of Courage: Operation Medusa, Afghanistan. Toronto: Dundurn Press.

House of Commons, Great Britain. 1982. Falklands Campaign: A Digest of Debates in the House of Commons, 2 April to [15] June 1982. Parliament. London: HMSO.

Humphries, Arthur A. 1983. "Two Routes to the Wrong Destination: Public Affairs in the South Atlantic War.” Naval War College Review XXXVI (3)May-June:56-71.

Inskeep, Steve. 2010. "Reporter's Notebook: Embedded with Marines in Marjah," (interview with reporter Soraya Sarhaddi Nelson, 4 March). National Public Radio, Morning Edition. Accessed 13 April 2015 at http://www.npr.org/templates/story/story.php?storyId=124303324\&utm_source $=$ n pr_newsletter\&utm medium $=$ email\&utm content $=20160722 \& u t m \_$campaign $=n p$ $\underline{\mathrm{r} \text { email a friend\&utm term }=\text { storyshare }}$

Ivens, Martin. 2010. "More Guile Needed in the Afghan Game.” Sunday Times, 24 January. Accessed 2 April 2014 at http://www.thesundaytimes.co.uk/sto/news/Features/Focus/article195765.ece

Ives, Stephen, director. 2003. Reporting America at War. [Documentary]. Alexandria, VA: PBS Home Video. Accessed 29 January 2015 at https:/www.youtube.com/watch?v=DVY4H9P6nKU

Iyengar, Shanto and Donald R. Kinder. 1987. News that Matters: Television and American Opinion. Chicago: University of Chicago Press.

Iyengar, Shanto. 1991. Is Anyone Responsible? How Television Frames Political Issues. Chicago:University of Chicago Press.

Iyengar, Shanto. 2007. "Effects of Framing on Attributions of Responsibility for Crime and Terrorism." In The Political Communication Reader, eds. R. Negrine and J. Stanyer, 187-194. New York: Routledge. 
Jacobs, Andrew. 2003. "My Week at Embed Boot Camp." The New York Times Magazine (2 March):34.

Jacoby, W.G. 2000. "Issue Framing and Public Opinion on Government Spending." American Journal of Political Science 44(4):750-67.

James, Patrick. 2012. Canada and Conflict. Don Mills, ON: Oxford University Press.

Janzen, Jay (Major). 2004. “Op Athena Roto O-Embedded Media.” Canadian Army Journal (Fall/Winter, 7.3/7.4):43-51. Accessed 2 April 2014 at: http://publications.gc.ca/collections/Collection/D12-11-7-3-4E.pdf

Johnson, Thomas J. and Shahira Fahmy. 2010. "When 'Good' Conflicts Go Bad: Testing a Frame-Building Model on Embeds' Attitudes toward Government News Management in the Iraq War." The International Communication Gazette 72(6):521-544.

Johnston, Hank. 1995. “A Methodology for Frame Analysis: From Discourse to Cognitive Schema." In Social Movements and Culture, eds. Hank Johnston and Bert Klandermans. Abingdon: Routledge.

Jones, Robert L., and Roy E. Carter, Jr. 1959. "Some Procedures for Estimating 'News Hole' in Content Analysis.” Public Opinion Quarterly 23:399-403.

Joseph, John Earl. 2006. Language and Politics. Edinburgh: Edinburgh University Press.

Junger, Sebastian. 2010. War. New York: Twelve.

Kahneman, Daniel and Amos Tversky. 1984. "Choices, Values, and Frames." American Psychologist 39:341-350.

Kahneman, Daniel. 2011. Thinking, Fast and Slow. New York: Farrar, Straus and Giroux.

Katovsky, Bill and Timothy Carlson. 2003. Embedded: The Media at War in Iraq. Guilford, CT: Lyons Press.

Kaylan, Melik. 2008. "Welcome Back To the Great Game.” The Wall Street Journal, 13 August. Accessed 2 April 2014 at http://online.wsj.com/news/articles/SB121858681748935101?mg=reno64wsj\&url=http $\% 3 \mathrm{~A} \% 2 \mathrm{~F} \% 2$ Fonline.wsj.com $\% 2$ Farticle $\% 2 F S B 1218586817489351$ $\underline{01 . h t m l}$

Kellner, Douglas. 2008. "War Correspondents, the Military, and Propaganda: Some Critical Reflections.” International Journal of Communication 2:297-330. 
Kertzer, Joshua D. 2008. "ISAF in Afghanistan, or Learning to Love CounterInsurgency." 1 September, Policy Options. Accessed 3 April 2016 at http://policyoptions.irpp.org/magazines/canadas-working-poor/isaf-inafghanistan-or-learning-to-love-counter-insurgency/

King, Gary, Robert O. Keohane, and Sidney Verba. 2004. "The Importance of Research Design.” In Rethinking Social Inquiry: Diverse Tools, Shared Standards, ed. Henry E. Brady and David Collier. Lanham, MD: Rowman \& Littlefield Publishers.

Klapper, Joseph T. 1960. The Effects of Mass Communication. New York: Free Press.

Klass, Rosanne, ed. 1987. Afghanistan: The Great Game Revisited. New York: Freedom House.

Knightley, Phillip. 2004. The First Casualty: The War Correspondent as Hero and MythMaker from the Crimea to Iraq. Baltimore, MD: Johns Hopkins University Press.

Lang, Gladis E. and Kurt Lang. 1981. "Watergate: An Exploration of the Agenda Building Process.” In Mass Communication Review Yearbook, Volume 2, eds. G. Cleveland Wilhoit and Harold de Bock. Beverly Hills: Sage.

Lazuka, Anna. 2006. "Communicative Intention in George W. Bush's Presidential Speeches and Statements from 11 September 2001 to 11 September 2003." Discourse and Society 17(3):299-330.

Lears, T.J. Jackson. 1985. "The Concept of Cultural Hegemony: Problems and Possibilities." The American Historical Review 90(3): 567-593.

Lehman, Patrick Robert. 2004. Embedded Media and the Operational Commander. Newport, RI: Naval War College. Accessed 13 October 2011 at http://www.dtic.mil/cgi$\underline{\text { bin/GetTRDoc? } \text { Location }=\mathrm{U} 2 \& \text { doc }=\text { GetTRDoc.pdf\&AD }=\mathrm{ADA} 422789}$

Lemay, Christian. 2013. Personal communication with the Chief Public Affairs Officer, Canadian Joint Operations Command, Ottawa, Ontario, 6 February.

Lennox, Patrick. 2009. At Home and Abroad: The Canada-US Relationship and Canada's Place in the World. Vancouver: UBC Press.

Lewis, Justin and Rod Brookes. 2004. "How British Television News Represented the Case for the War in Iraq." In Reporting War: Journalism in Wartime, ed. Stuart Allen and Barbie Zelizer. New York: Routledge. 
Lewis, Justin, and Roderick Brookes. 2004. "Reporting the War on British Television." In Tell Me lies: Propaganda and Media Distortion in the Attack on Iraq, ed. David Miller (132-143). London: Pluto Press.

Lewis, Justin, Terry Threadgold, Rod Brookes, Nick Mosdell, Kirsten Brander, Sadie Clifford, Ehab Bessaiso, and Zahera Harb. 2004. Too Close for Comfort? The Role of Embedded Reporting during the 2003 Iraq War: Summary Report. School of Journalism Media and Cultural Studies, Cardiff University. London: Harlequin.

Lichty, Lawrence W. 1973. "The War We Watched on Television: A Study in Progress." American Film Institute Report 4(Winter):29-37.

Lichty, Lawrence W. 1984. "Comments on the Influence of Television on Public Opinion.” In Vietnam as History: Ten Years after the Paris Peace Accords, ed. Peter Braestrup. Washington, D.C.: University Press of America.

Livingston, Steven and W. Lance Bennett. 2003. "Gatekeeping, Indexing, and Live-Event News: Is Technology Altering the Construction of News?" Political Communication 20:363-380.

MacArthur, John. R. 2004. Second Front: Censorship and Propaganda in the 1991 Gulf War, $2^{\text {nd }}$ edition. Berkeley: University of California Press.

Maclean's. 1996. "Somalia Affair: Chronology." 15 April. Accessed 21 April 2014 at http://www.thecanadianencyclopedia.ca/en/article/somalia-affair-chronology/

Malek, Abbas and Lisa Leidig. 1991. "US Press Coverage of the Gulf War." Media Development (October). Accessed 11 June 2012 through World Association for Christian Communication at http://waccglobal.org/en/resources/mediadevelopment.html

Maloney, Sean M. 2005. Enduring the Freedom: A Rogue Historian in Afghanistan. Washington, DC: Potomac Books.

Maloney, Sean M. 2009. Confronting the Chaos: A Rogue Military Historian Returns to Afghanistan. Annapolis: Naval Institute Press.

Maloney, Sean M. 2011. Fighting for Afghanistan: A Rogue Historian at War. Annapolis: Navel Institute Press.

Manley, John. 2008. Independent Panel on Canada's Future Role in Afghanistan. Ottawa: Government of Canada. FR5-20/1-2008, January. Accessed 4 April 2014 at http://www.afghanistan.gc.ca/canadaafghanistan/assets/pdfs/Afghan_Report_web_e.pdf 
Marsden, Peter. 1998. The Taliban: War, Religion and the New Order in Afghanistan. New York: Zed Books.

Martin, Michèle. 2006. Images at War: Illustrated Periodicals and Constructed Nations. Toronto: University of Toronto Press.

Mascaro, Lisa. 2011. "Patriot Act Provisions Extended Just In Time.” latimes.com, 27 May. Accessed 12 June 2012 at http://articles.latimes.com/2011/may/27/nation/lana-patriot-act-20110527

Massing, Michael. 2004. Now They Tell Us: The American Press and Iraq. New York: New York Review of Books.

Mattelart, Armand. 1994. Mapping World Communication: War, progress, culture. Minneapolis: University of Minnesota Press.

McCombs, Maxwell E. 1976. "Elaborating the Agenda Setting Influence of Mass Communication." In Bulletin of the Institute for Communication Research, Number 7. Keio University: Tokyo.

McCombs, Maxwell E. and Donald L. Shaw, D. 1972. "The Agenda-Setting Function of Mass Media." Public Opinion Quarterly (36):176-187.

McCombs, Maxwell, Juan Pablo Llamas, Esteban Lopez-Escobar, and Federico Rey. 1997. "Candidate Images In Spanish Elections: Second-Level Agenda-Setting Effects.” Journalism \& Mass Communication Quarterly 74(4):703-717.

McCombs, Maxwell, Donald L. Shaw, and David Weaver. 1997. Communication and Democracy: Exploring the Intellectual Frontiers In Agenda-Setting Theory. Mahwah, NJ: Lawrence Erlbaum Associates.

McKelvey, Tara. 2009. “Too Close for Comfort?” Columbia Journalism Review, September/ October. Accessed 4 June 2016 at http://www.cjr.org/cover story/too close for comfort.php

McKew, Maxine. 2003. “TV Networks Prepare for War.” LATELINE, abc.net.au, 14 February. Australian Broadcasting Corporation. Accessed 30 January 2015 at http://www.abc.net.au/lateline/stories/s785071.htm

McQuail, Denis. 1994. Mass Communication Theory: An Introduction, 3rd edition. Thousand Oaks, CA: Sage.

Menon, Rajan. 2003. "The New Great Game in Central Asia." Survival: Global Politics and Strategy 45(2):187-204. 
Mercer, Derrik, Geoff Mungham, and Kevin Williams. 1987. The Fog of War: The Media on the Battlefield. London: Heinemann.

Mermin, Jonathan. 1999. Debating War and Peace: Media Coverage of U.S. Intervention in the Post-Vietnam Era. Princeton, N.J.: Princeton University Press.

Miles, Donna. 2006. "Pearl Harbor Parallels 9-11." Military.com, 7 December. Accessed 25 May 2012 at http://www.military.com/NewsContent/0,13319,120133,00.html

Miller, David, ed. 2004. Tell Me Lies: Propaganda and Media Distortion in the Attack on Iraq. London: Pluto Press.

Moeller, Susan D. 2006. “The Power Joe Rosenthal Knew.” The Washington Post, 26 August. Accessed 29 January 2015 at http://www.washingtonpost.com/wpdyn/content/article/2006/08/25/AR2006082500939.html

Mordan, Jon. 1999. "Press Pools, Prior Restraint and the Persian Gulf War." Air \& Space Power Journal, Chronicles Online Journal. Accessed 28 October 2011 at http://www.airpower.au.af.mil/airchronicles/cc/mordan.html

Morrison, David E. and Howard Tumber. 1988. Journalists at War: The Dynamics of News Reporting during the Falklands Conflict. Thousand Oaks, CA: Sage Publications.

Moskos, Charles C. 2000. The Media and the Military in Peace and Humanitarian Operations. Chicago: Robert R. McCormick Tribune Foundation.

Mueller, John. 1973. War, Presidents and Public Opinion. New York: John Wiley.

NATO. 2006. "The Afghanistan Compact." The London Conference on Afghanistan (31 January - 1 February 2006). Accessed on 17 April 2014 at http://www.nato.int/isaf/docu/epub/pdf/afghanistan compact.pdf

NATO Training Mission-Afghanistan (NTM-A). 2009. “Operation Attention.” National Defence and the Canadian Armed Forces. Accessed 31 March 2014 at http://www.forces.gc.ca/en/operations-abroad-current/op-attention.page

NBC. 2001. "NBC Nightly News," 7 October. YouTube.com. Accessed 12 June 2012 at http://www.youtube.com/watch?v=Q-St8s9RKEU

New York Times. 2001. “A Nation Challenged.” nytimes.com, 11 September 2001 - 31 December 2001. Accessed 12 June 2012 at http://www.nytimes.com/pages/national/dayofterror/

Nixon, Richard M. 1978. The Memoirs of Richard Nixon. London: Sidgwick \& Jackson. 
Ochs, Elinor. 1979. “Transcription as Theory.” In Developmental Pragmatics, eds. Elinor and Bambi B. Schieffelin. New York: Academic Press.

Overholser, Geneva. 2003. "Cowed Press Ignores World at Public's Peril." Sacramento Bee, 12 January. At WSpeak, 16 January. Citation accessed 3 June 2012 at http://wspeak.blogspot.ca/2003_01_12_archive.html

Pan, Zhongdang and Gerald M. Kosicki. 1993. "Framing Analysis: An Approach to News Discourse.” Political Communication 10(1):55-75.

Patterson, Thomas E. 1998. "Political Roles of the Journalist." In The Politics of News: The News of Politics, eds. Doris A. Graber, Denis McQuail, and Pippa Norris. Washington, DC: Congressional Quarterly Press.

Paul, Christopher and James J. Kim. 2004. Reporters on the Battlefield: The Embedded Press System in Historical Context. Santa Monica, CA: RAND National Security Research Division.

Pfau, Michael, Michel Haigh, Mitchell Gettle, Michael Donnelly, Gregory Scott, Dana Warr, and Elaine Wittenberg. 2004. "Embedding Journalists in Military Combat Units: Impact on Newspaper Story Frames and Tone." Journalism and Mass Communication Quarterly 81(1):74-88.

Pfau, Michael, Michel M. Haigh, Lindsay Logsdon, Christopher Perrine, James P. Baldwin, Rick E. Breitenfeldt, Joel Cesar, Dawn Dearden, Greg Kuntz, Edgar Montalvo, Dwaine Roberts, and Richard Romero. 2005. "Embedded Reporting during the Invasion and Occupation of Iraq: How the Embedding of Journalists Affects Television News Reports." Journal of Broadcasting \& Electronic Media 49:468-487.

Phillips, Karin. 2008. Afghanistan: Canadian Diplomatic Engagement. Ottawa: Parliament of Canada. PRB 07-38E, 4 February. Accessed 28 March 2014 at http://www.parl.gc.ca/Content/LOP/ResearchPublications/prb0738-e.htm

Picard, Sandra. 2008. “Au Front avec Michèle Ouimet.” Fédération Professionnelle des Journalistes du Québec 32(7, juillet-aout). Accessed 22 June 2015 at http://www.fpjq.org/au-front-avec-michele-ouimet/

Pigott, Peter. 2007. Canada in Afghanistan. Toronto: Dundurn Press.

Ponsonby, Arthur. 1936. Falsehood in Wartime: Containing An Assortment Of Lies Circulated Throughout The Nations During The Great War. London: Allen. Accessed 21 November 2013 at http://gutenberg.net.au/ebooks10/1000011.txt 
Porpora, Douglas V., Alexander Nikolaev, and Julia Hagemann. 2010. "Abuse, Torture, Frames, and the Washington Post." Journal of Communication 60:254-270.

Potter, Andrew. 2011. "The Forgotten Members of the Mission in Afghanistan." Macleans.ca, 18 July. Accessed 7 April 2015 at http://www.macleans.ca/general/our-best-and-brightest-now-forgotten/

Potter, Mitch. 2002. "Kandahar, Inside and Out." Toronto Star, 10 February. Accessed 23 April 2014 at http://www.pakdef.org/forum/topic/846-kandahar-inside-and-out/

Powell, Colin. 2012. It Worked For Me: In Life and Leadership. New York: Harper Collins.

Price, Dominique L. 2009. "Inside the Wire: A Study of Canadian Embedded Journalism in Afghanistan.” Unpublished MA Thesis, Carleton University, Ottawa.

Price, Vincent and David Tewksbury. 1997. "News Values and Public Opinion: A Theoretical Account of Media Priming and Framing." In Progress in Communication Sciences: Advances in Persuasion, ed. George A. Barett and Franklin J. Boster (Volume 13. Greenwich, CT: Ablex.

Price, Vincent, David Tewksbury, and Elizabeth Powers. 1997. "Switching Trains of Thought: The Impact of News Frames On Readers' Cognitive Responses.” Communication Research 24:481-506.

Puzic, Sonja. 2014. 'CCanada Will Never Be Intimidated,' Harper Says after Shootings in Ottawa." ctvnews.ca, 22 October. Accessed 15 July 2016 at http://www.ctvnews.ca/canada/canada-will-never-be-intimidated-harper-saysafter-shootings-in-ottawa-1.2065443

Ranney, Austin. 1983. Channels of Power: The Impact of Television on American Politics. New York: Basic Books.

Rashid, Ahmed. 2002. Taliban: Islam, Oil and the New Great Game in Central Asia. New York: I.B. Tauris.

Reese, Stephen D. 1991. "Setting the Media's Agenda: A Power Balance Perspective." In Communication Yearbook 14, ed. James Anderson. Beverly Hills: Sage.

Reese, Stephen D. and Seth C. Lewis. 2009. "Framing the War on Terror: The Internalization of Policy in the US Press.” Journalism 10(6):777-797.

Reyes, Antonio. 2011. Voice in Political Discourse. New York: Continuum International Publishing Group. 
Riechers, Maggie. 2003. "Direct from the Front." HUMANITIES 24(6, November/December). Accessed 28 January 2015 at http://www.neh.gov/humanities/2003/novemberdecember/feature/direct-the-front

Reston, James. 1972. "The End of the Tunnel.” newyorktimes.com, 26 October. Accessed 15 June 2012 at http://select.nytimes.com/gst/abstract.html?res=F10617FD385E127A93C5AB178 BD95F468785F9

Riker, W.H. 1996. The Strategy of Rhetoric: Campaigning for the American Constitution. New Haven, CT: Yale University Press.

Rall, Ted. 2010. "The Embed Cocoon.” Editor and Publisher (1 November). Accessed 24 January 2017 at http://www.editorandpublisher.com/feature/the-embed-cocoon/

Romano, Allison. 2003. "Embeds Return, Laden With Stories." Broadcasting \& Cable 133(16, 21 April):3.

Roskos-Ewoldsen, David R., Beverly Roskos-Ewoldsen, and Francesca Dillman Carpentier. 2002. Media Priming: An Updated Synthesis. In Media Effects in Theory and Research, $3^{\text {rd }}$ edition, ed. Jennings B. Bryant \& Mary Beth Oliver. New York: Routledge.

Roth, Mitchel P. 2010. The Encyclopedia of War Journalism $1807-2010,2^{\text {nd }}$ edition. Amenia, NY: Grey House Publishing.

Rubin, Elizabeth. 2009. “Up Front: Embed with an Embed.” Vogue 199.12 (1 December): 102,108,110,114.

Rush Limbaugh Show. 2004. "It's Not About Us; This is War!" rushlimbaugh.com, 4 May. Accessed 14 June 2012 at http://www.rushlimbaugh.com/daily/2004/05/04/it_s_not_about_us_this_is_war

Said, Edward W. 1978. Orientalism. New York: Pantheon Books.

Scheufele, Dietram A. 1999. "Framing as a Theory of Media Effects. Journal of Communication 49(1):103-122.

Scheufele, Dietram A. and David Tewksbury. 2007. "Framing, Agenda Setting, and Priming: The Evolution of Three Media Effects Models." Journal of Communication 57:9-20.

Schilke, Tim. 2005. Growing Up Red: Outing Red America from the Inside. Lincoln, NE: iUniverse. 
Schechter, Danny. 2003. Embedded - Weapons of Mass Deception: How the Media Failed to Cover the War on Iraq. Amherst, NY: Prometheus Books.

Schechter, Danny. 2006. When News Lies: Media Complicity and the Iraq War. New York: Select Books.

Schoenfeld, Michael W. 1992. Military and the Media: Resolving the Conflict. Newport, RI: Naval War College. Accessed 14 October 2011 at http://www.dtic.mil/cgibin/GetTRDoc?AD=ADA253110\&Location=U2\&doc=GetTRDoc.pdf

Schudson, Michael. 2003. The Sociology of News. New York: Norton.

Seib, Philip. 1997. Headline Diplomacy: How News Coverage Affects Foreign Policy. Westport, CT: Praeger.

Shah, Dhavan V., Nojin Kwak, Mike Schmierbach, and Jessica Zubric. 2004. The Interplay of News Frames on Cognitive Complexity. Human Communication Research 30(1):102-120.

Sharkey, Jacqueline. 1991. Under Fire: U.S. Military Restrictions on the Media from Grenada to the Persian Gulf. Washington, DC: Center for Public Integrity.

Shaw, Eugene F. 1979. "Agenda Setting and Mass Communication Theory." International Communication Gazette 25(May):96-105.

Shaw, Donald L. and Maxwell E. McCombs. 1989. "Dealing With Illicit Drugs: The Power - and Limits - of Mass Media Agenda Setting. In Communication Campaigns about Drugs: Government, Media, and the Public, ed. Pamela J. Shoemaker. Hillsdale, NJ: L. Erlbaum Associates.

Sheppard, Jim. 2006. "Globe Columnist, Reporters on 'Embedded' Journalists." theglobeandmail.com, 8 June. Accessed 21 November 2010 at http://www.theglobeandmail.com/news/opinions/ globe-columnist-reporters-on-embedded-journalists/article829027/singlepage/

Shoemaker, Pamela J., ed. 1989. Communication Campaigns about Drugs: Government, Media, and the Public. Hillsdale, NJ: L. Erlbaum Associates.

Shoemaker, Pamela J. and Stephen D. Reese. 1996. Mediating the Message: Theories of Influences On Mass Media Content, 2nd edition. White Plains, NY:Longman.

Singh, Jaswant. 2010. "China and India: the Great Game's New Players." The Guardian, 25 September. Accessed 2 April 2014 at http://www.theguardian.com/commentisfree/2010/sep/25/china-india-great-game 
Sjolander, Claire Turenne. 2009. "A Funny Thing Happened on the Road to Kandahar: The Competing Faces of Canadian Internationalism?" Canadian Foreign Policy 15(2):78-98.

Smith, Graeme. 2013. The Dogs Are Eating Them Now: Our War in Afghanistan. Toronto: Alfred A. Knopf Canada.

Sniderman, Paul M and Sean M. Theriault. 2004. "The Structure of Political Argument and the Logic of Issue Framing. In Studies in Public Opinion, ed. W.E. Saris and P.M. Sniderman, 133-65. Princeton, NJ: Princeton University Press.

Soeters, Joseph. 2000. "Culture in Uniformed Organizations." In Handbook of organizational culture and climate, ed. Neal Ashkanasy, Celeste Wilderom, and Mark Peterson. Thousand Oaks, CA: Sage.

Sproule, J. Michael. 1997. Propaganda and Democracy. Cambridge: Cambridge University Press.

Stabile C.A. and D. Kumar. 2005. "Unveiling Imperialism: Media, Gender and the War on Afghanistan.” Media, Culture \& Society 27(5):765-782.

Stamper, Kory. 2014. "Slang for the Ages." International New York Times, The Opinion Pages, Oct 3. Accessed 4 October 2014 at http://www.nytimes.com/2014/10/04/opinion/slang-for-theages.html?emc $=$ edit th_20141004\&nl=todaysheadlines\&nlid $=16517235 \& \_r=0$

Stein, Janice Gross and Eugene Lang. 2007. The Unexpected War: Canada in Kandahar. Toronto: Viking Canada.

Stephenson, Scott. 2005. “The Embeds’ War.” Infantry Magazine 85.3(May-June):96.

Stewart, Brian. 2010. "What Our Military Isn't Telling Us.” 17 March. Accessed 9 December 2015 at http://www.cbc.ca/news/canada/what-our-military-isn-t-telling$\underline{\text { us- } 1.900290}$

Sulzberger, Cyrus Leo. 1970. "Foreign Affairs: Danger of the Private Eye." New York Times, 29 April. Accessed 4 June 2012 at http://select.nytimes.com/gst/abstract.html?res=FB091EFF385A157493CBAB178 FD85F448785F9

Sun. 1982. "Stick It Up Your Junta." Headline, 20 April. Accessed 8 June 2012 at http://sunheadlines.blogspot.ca/2008/12/classics-stick-it-up-your-junta.html

Sun. 1982. "Gotcha: Our Lads Sink Gunboat and Hole Cruiser." Headline, 8 May. Accessed 8 June 2012 at https://lh5.googleusercontent.com/- 
$\underline{\text { 1H4NKsx5uMk/TYdgKtYXTLI/AAAAAAAAAHw/o53psz2GCwA/s1600/sun+f }}$ alklands.jpg

Sylvester, Judith and Suzanne Huffman. 2004. Reporting from the Front: The Media and the Military. Lanham, MD: Rowman \& Littlefield.

Tankard, James, Laura Hendrickson, Jackie Silberman, Kriss Bliss, and Salma Ghanem. 1991. "Media Frames: Approaches to Conceptualization and Measurement." Paper presented at the annual meeting of the Association for Education in Journalism and Mass Communication (AEJMC), August 7-10, Boston.

Taylor, Charles. 1985. Human Agency and Language: Philosophical Papers 1. Cambridge: University of Illinois press.

Taylor, John. 1991. War Photography: Realism in the British Press. New York: Routledge.

Taylor, Philip. 1995. "War and the Media: Sandhurst Keynote." Lecture presented at a conference on media-military relations at the Royal Military Academy at Sandhurst. Accessed 7 June 2012 at http://icswww.leeds.ac.uk/papers/vp01.cfm?outfit=pmt\&folder=25\&paper $=47$

Taylor, Scott, journalist. 2010. Afghanistan: Outside the wire [Documentary]. Canada: Cable Public Affairs Channel.

Terkel, Studs. 1975. "Nora Ephron Talks with Studs Terkel (1975/07/28)." The Studs Terkel Radio Archive (00:32:18), The wfmt Radio Network: Chicago History Museum. Accessed 17 July 2016 at http://studsterkel.wfmt.com/categories/feminism

Thayer, Carlyle A. 1992. "Vietnam: A Critical Analysis." In Defence and the Media in Time of Limited War, ed. Peter Young. Portland, OR: Frank Cass.

The Green Book. 2010. "MOD Working Arrangements with the Media." Version 7 , Ministry of Defence. Accessed 9 June 2012 at http://www.mod.uk/defenceinternet/aboutdefence/corporatepublications/doctrineo perationsanddiplomacypublications/thegreenbook/

Thomson, Alex. 1992. Smokescreen: The Media, the Censors, the Gulf. Tunbridge Wells, Kent: Laburnham and Spellmount.

Thussu, Daya Kishan \& Freedman, Des, eds. 2003. War and the Media: Reporting Conflict 24/7. Thousand Oaks, CA: Sage. 
Toolan, Michael. 2002. Critical Discourse Analysis: Critical Concepts in Linguistics. New York: Routledge.

Trudeau, Pierre Elliott. "Address." Speech given at the annual meeting of the National Press Club, Washington, 25 March 1969. Accessed 16 September 2015 at http://www.cbc.ca/player/Digital+Archives/Politics/Prime+Ministers/Pierre+Trud $\underline{\text { eau/ID/1801879425/ }}$

Tuchman, Gaye.1978. Making News: A Study in the Construction of Reality. New York: Free Press.

Tumber, Howard and Jerry Palmer. 2004. Media at War: The Iraq Crisis. Thousand Oaks, CA: Sage Publications.

Tversky, Amos and Daniel Kahneman. 1973. Availability: A Heuristic for Judging Frequency and Probability. Cognitive Psychology (5):207-232.

Ullman, Harlan and James Wade, Jr. 1996. "Shock and Awe: Achieving Rapid Dominance." Institute for National Strategic Studies. Washington, DC: National Defence University. Accessed 14 June 2012 at http://www.dodccrp.org/files/Ullman_Shock.pdf

Umberson, Debra and Kristin Henderson. 1992. "The Social Construction of Death in the Gulf War.” OMEGA - Journal of Death and Dying 25(1):1-15.

United Nations Assistance Mission in Afghanistan (UNAMA). 2010. "Harmful Traditional Practices and Implementation of the Law on Elimination of Violence against Women in Afghanistan.” Kabul, Afghanistan. Accessed on 5 August 2011 at http://unama.unmissions.org/Portals/UNAMA/Publication/HTP\%20REPORT_E NG.pdf

United National Development Programme. 2015. “Afghanistan.” Accessed 23 April 2016 at http://hdr.undp.org/en/countries/profiles/AFG

United States Army War College. 2004. Perspectives on Embedded Media. Selected Papers. Carlisle Barracks, PA: U.S. Army War College. Accessed 24 October 2011 at http://www.au.af.mil/au/awc/awcgate/armyusawc/embedded media papers.pdf

United States Department of Defense (DoD). 1993. Statement of DoD Principles for News Media Coverage of DoD Operations. (Number 5122.5, 2 December). Accessed 29 November 2013 at http://community.marines.mil/news/publications/Documents/MCO\%205720.67.p df 
U.S. DoD. 1996a. ASD PA Kenneth Bacon news briefing. 7 May. Accessed 29 November 2013 at http://www.defense.gov/transcripts/transcript.aspx?transcriptid=515

U.S. DoD. 1996b. Captain Michael Doubleday news briefing. 9 May. Accessed 29 November 2013 at http://www.defense.gov/transcripts/transcript.aspx?transcriptid=516

U.S. DoD. 2001. ASD PA Meeting with Media Pool Bureau Chiefs, 30 September. Access 30 June 2011 at http://www.defenselink.mil/transcripts/transcript.aspx?transcriptid=1945

United States Department of the Army (DA). 1997. Field Manual FM 46-1: public affairs operations, Washington, DC: Headquarters, Department of the Army. Accessed 29 November 2013 at http://armypubs.army.mil/doctrine/DR_pubs/dr_a/pdf/fm46_1.pdf

USA PATRIOT Act. 2001. "Uniting and Strengthening America by Providing Appropriate Tools Required to Intercept and Obstruct Terrorism Act of 2001," Public Law Pub.L. 107-56. Washington, DC: US Congress. Accessed 12 June 2012 at http://www.sec.gov/about/offices/ocie/aml/patriotact2001.pdf

Valpy, Michael. 2009. “Canada's Military: Invisible No More.” The Globe and Mail, 20 November. Accessed 23 November 2015 at http://www.theglobeandmail.com/news/politics/canadas-military-invisible-no$\underline{\text { more/article } 4215847 / \text { ?page }=\text { all }}$

Van Dijk, Teun A. 1993a. Elite Discourse and Racism. Newbury Park, CA: Sage Publications.

Van Dijk, Teun A. 1993b. "Principles of Critical Discourse Analysis." Discourse \& Society 4(2):249-283.

Van Dijk, Teun A. 1998. Ideology: A Multidisciplinary Approach. London: Sage.

Van Dijk, Teun A. 2001. "Discourse, Ideology and Context." Folia Linguistica 35(1-2, January):11-40. Accessed 15 June 2016 at http://www.discourses.org/OldArticles/Discourse, $\% 20$ ideology $\% 20$ and $\% 20$ conte xt.pdf

Van Dijk, Teun A. 2005. "War Rhetoric of a Little Ally: Political implicatures and Aznar's legitimatization of the war in Iraq." Journal of Language and Politics 4(1):65-91. 
Van Dijk, Teun A. 2008. Discourse and Power. New York: Palgrave Macmillan.

Van Dijk, Teun A. 2009. "Critical Discourse Studies: A Sociocognitive Approach.” In Methods of Critical Discourse Analysis, $2^{\text {nd }}$ edition, ed. Ruth Wodak and Michael Meyer. Thousand Oaks, CA: SAGE Publications.

Von Clausewitz, Carl Philipp Gottfried. 2006. On War. Gutenberg.org, 25 February. Produced by Charles Keller and David Widger. Accessed 15 June 2012 at http://www.gutenberg.org/files/1946/1946-h/1946-h.htm

Walberg, Eric. 2011. Postmodern Imperialism: Geopolitics and the Great Games. Atlanta, GA: Clarity Press.

Walsh, K.C. 2003. Talking About Politics: Informal Groups and Social Identity in American Life. Chicago: The University of Chicago Press.

Ware, John. 2014. “The Taliban Resurgence in Afghanistan: 2002-2006.” BBC. Accessed on 25 April 2014 at http://www.bbc.co.uk/history/events/the taliban_resurgence_in_afghanistan

Washington Post. 2003. "A Policy of Evasion and Deception."' eMediaMillWorks, 5 February. Accessed 29 May 2012 at http://www.washingtonpost.com/wpsrv/nation/transcripts/powelltext 020503.html

Wasilow, Sherry. 2011. "Hidden Ties that Bind: The Psychological Bonds of Embedding Have Changed the Very Nature of War Reporting." Stream: Culture/Politics/Technology 4(1). Accessed 2 December 2012 at http://journals.sfu.ca/cpt/index.php/stream/article/view/65

Wasilow, Sherry. 2012. "How Media Framing of Afghan Women's Rights Devalued Them." Paper presented at the Women in War and at War conference sponsored by the Department of Law and Criminology, Aberystwyth University. Aberystwyth, Wales, 11-12 May.

Weisman, Jon. 2015. "TV Vet Embeds in Battle to Tell Story of U.S. Troops." Variety 328(2):53-55.

Welsh, Jennifer. 2004. At Home in the World: Canada's Global Vision for the 21st Century. Toronto: HarperCollins Publishers.

Western, Jon W. 2005. Selling Intervention and War: The Presidency, the Media, and the American Public. Baltimore: Johns Hopkins University Press.

Westmoreland, William C. 1976. A Soldier Reports. Garden City: Doubleday. 
Westmoreland, William C. 1979. "Vietnam in Perspective." Military Review 59(i):34-43.

Wildermuth, Ron. 1990. "Annex Foxtrot." Pentagon Rules on Media Access to the Persian Gulf War, hearing before the Committee on Governmental Affairs, United States Senate, One Hundred Second Congress, first session, 20 February 1991. Washington, DC: Government Printing Office (microfiche).

Wilson, Joseph C. 2003. "What I Didn't Find in Africa." newyorktimes.com, 6 July. Accessed 24 June 2012 at http://www.nytimes.com/2003/07/06/opinion/what-ididn-t-find-in-africa.html?pagewanted $=$ all \&src $=$ pm

Wodak, Ruth, ed. 1989. Language, Power, and Ideology: Studies in Political Discourse. Philadelphia: J. Benjamins Publishing Company.

Wodak, Ruth. 1995. "Critical Linguistics and Critical Discourse Analysis." In Handbook of Pragmatics, ed. Jef Verschueren and Jan Ola Östman. Amsterdam: John Benjamins Publishing Company.

Wodak, Ruth. 2009. The Discourse of Politics in Action: Politics as Usual. New York: Palgrave Macmillan.

Wodak, Ruth and Michael Meyer, eds. 2009. Methods of Critical Discourse Analysis, $2^{\text {nd }}$ edition. Thousand Oaks, CA: SAGE Publications.

Wodak, Ruth. 2012. "Re/Inventing Nationalism and National Identities: Recontextualising Traditional Themes in Global Politics - A discourse-historical perspective." Lecture presented at Carleton University, sponsored by the School of Linguistics and Language Studies, and the Faculty of Arts and Social Sciences, 30 October.

World Bank. 2011. “Afghanistan Country Overview 2011.” Washington, DC: The World Bank Group. Accessed on 6 August 2011 at http://www.worldbank.org.af/WBSITE/EXTERNAL/COUNTRIES/SOUTHASIA EXT/AFGHANISTANEXTN/0,,contentMDK:20154015 menuPK:305990 page PK:1497618 piPK:217854 theSitePK:305985,00.html

York, Geoffrey. 2006. "Dispatches From an Embedded Life." 3 June. Accessed 13 March 2016 from http://www.theglobeandmail.com/incoming/dispatches-from-anembedded-life/article709783/

Zaller, John and Dennis Chiu. 2000. "Government's Little Helper: US Press Coverage of Foreign Policy Crises, 1946-1999.” In Decisionmaking in a Glass House: Mass Media, Public Opinion, and American and European Foreign Policy in the 21st Century, ed. Brigitte Nacos, Robert Y. Shapiro, and Pierangelo Isernia, eds. 2000. Lanham, Md.: Rowman \& Littlefield Publishers. 
Zimmerman, Rebecca. 2014. "Stuck Between a Rock and the 'Zero Option.'” US News and World Report, 11 March. Accessed 12 March 2014 at http://www.usnews.com/opinion/blogs/world-report/2014/03/11/the-zero-optionin-afghanistan-is-a-major-test-for-obama 


\section{APPENDIX A: Interviewee List, Media}

In alphabetical order $(\mathrm{n}=16)$ :

- Matthieu Aikins, freelance

- Christie Blatchford, formerly with Globe and Mail, now the National Post

- Murray Brewster, Canadian Press

- Patrick Brown, formerly with the CBC \& SRC

- David Common, CBC

- Michel Cormier, SRC

- Matthew Fisher, National Post

- Edward Girardet, freelance

- David Halton, formerly with the CBC

- Naheed Mustafa, freelance

- Susan Ormiston, CBC TV

- Brian Stewart, formerly with the CBC

- Stephen Thorne, Canadian Press

- Paul Watson, formerly with the Toronto Star

- current reporter who wishes to remain anonymous, Globe and Mail

- former reporter who wishes to remain anonymous, Globe and Mail 


\section{APPENDIX B: Interviewee List, Military and Government Officials}

In alphabetical order $(\mathrm{n}=13)$ :

Military

- Captain David Harmes, former public affairs officer

- Colonel Roch Lacroix, former Deputy Commander, Task Force Kandahar (Norman

Paterson speaker, 2010)

- Lieutenant Colonel Christian Lemay, former chief public affairs officer with Canadian Joint Operations Command, Ottawa

- Lieutenant-Colonel Pat Stogran, 3 PPCLI in Kandahar, Afghanistan

- Scott Taylor, former infantry soldier, 3 PPCLI, now editor/publisher of Esprit de Corps magazine

- General Jonathan H. Vance, Chief of the Defense Staff

Government

- Renee Filiatrault, former DFAIT public diplomacy officer

- Katherine Heath-Eves, formerly with DFAIT (before it became Global Affairs)

- David Mulroney, former deputy minister in charge of the Afghanistan Task Force, and secretary to the Independent Panel on Canada's Future Role in Afghanistan

- Adam Sweet, former public diplomany officer

- Emma Wellford, former head of public diplomacy and communications, DFAIT

- former senior Canadian civilian envoy with DFAIT (before it became Global Affairs) who wishes to remain anonymous

- former senior public diplomacy officer with DFAIT (before it became Global Affairs)

who wishes to remain anonymous 


\section{APPENDIX C: Carleton Ethics Approval (Media)}

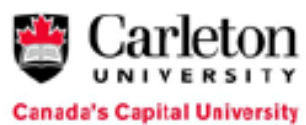

Ethics Clearance Form - New Clearance

\author{
Carleton University \\ Research Ethics Office \\ Research Ethics Board \\ 511 Tory, 1125 Colonel By Drive \\ Ottawa, ON K1S 5B6 Canada \\ Tel: 613-520-2517, ethics@ carleton.ca
}

This is to certify that the Carleton University Research Ethics Board has examined the application for ethical clearance. The REB found the research project to meet appropriate ethical standards as outlined in the Tri-Council Policy Statement: Ethical Conduct for Research Involving Human, 2nd edition, and the Carleton University Policies and Procedures for the Ethical Conduct of Research.

Date of Clearance: November 10, 2015

Researcher: Christopher T. Dornan (Primary Investigator) Sherry Wasilow (Student Research: PhD) Department: Faculty of Public Affairs IJournalism and Communications (School of) University: Carleton University Research Supervisor (if applicable): Prof. Christopher T. Dornan Project Number: 103585

Project Title: Contemporary Canadian Military/Media Relations: Embedded Reporting during the Afghanistan War (media)

Funder (if applicable): N/A

Clearance Expires: August 31, 2016

\section{All researchers are governed by the following conditions:}

Annual Status Report: You are required to submit an Annual Status Report to either renew clearance or close the file. Failure to submit the Annual Status Report will result in the immediate suspension of the project. Funded projects will have accounts suspended until the report is submitted and approved.

Changes to the project: Any changes to the project must be submitted to the Carleton University Research Ethics Board for approval. All changes must be approved prior to the continuance of the research.

Adverse events: Should a participant suffer adversely from their participation in the project you are required to report the matter to the Carleton University Research Ethics Board. You must submit a written record of the event and indicate what steps you have taken to resolve the situation.

Suspension or termination of clearance: Failure to conduct the research in accordance with the principles of the Tri-Council Policy Statement: Ethical Conduct for Research Involving Humans, 2nd edition and the Carleton University Policies and Procedures for the Ethical Conduct of Research may result in the suspension or termination of the research project.

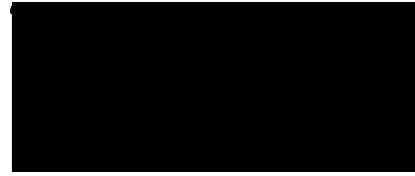

Louise Heslop

Chair, Carleton University Research Ethics Board

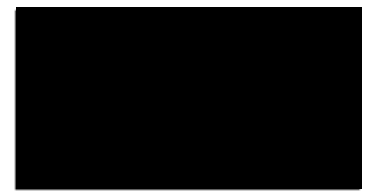

Andy Adler

Vice-Chair, Carleton University Research Ethics Board 


\section{APPENDIX D: Introduction/Invitation Letter (English and French)}

\section{Carleton}

Canada's Capital University

Communication

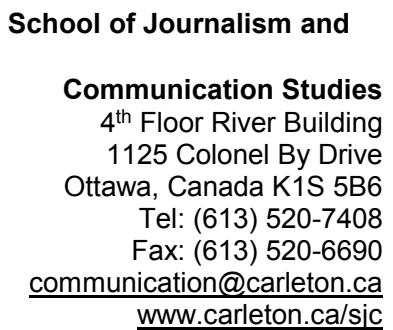

DATE 2015, 2016

www.carleton.ca/sjc

Dear ???:

Greetings. My name is Sherry Wasilow. I am a Ph.D. student in the School of Journalism and Communication at Carleton University in Ottawa.

I wish to request an interview for my dissertation research undertaking. My project seeks to understand the nature and impact of embedded, dis-embedded, or unilateral reporting in a Canadian context, using the Afghanistan War as a case study.

My research will include interviews with professionals like you who are familiar with the practice of embedded, dis-embedded, or unilateral journalism from a particular vantage point or knowledge base. These interviews will provide me with a wide spectrum of insight into how embedded policies and practices have developed, perceptions regarding how the program operates and delivers, how participants perform and work together, what the outcomes are, and possible suggestions for change.

I am the sole researcher in this study; however, the project is under the supervision of Dr. Christopher Dornan, an associate professor and Graduate Advisor in the School of Journalism and Communication at Carleton University in Ottawa.

Through media analysis, related research, personal contacts, and review of media and military documents and directories, you have been identified as a knowledgeable candidate with potentially valuable information related to media and/or military performance during the Afghanistan War. Your views and experience would greatly benefit my study. Your participation in this project will involve an interview where you are asked to share information about yourself, your embedded, dis-embedded, or unilateral experience and/or related observations, and suggestions for the future. If in person, by telephone, or via Skype, the interview will take approximately 60 minutes; my primary chronicling will be note-taking, secondary will be audiorecording. Please note that Skype is subject to the U.S. Patriot Act, therefore, our conversation will not be confidential. I may contact you again later in the spring of 2016 to arrange a follow up interview.

You are being asked to participate in this study in your professional capacity as a (capacity). Any comments made by you during the interview may be included verbatim in the dissertation or 
other products of the research and will be attributed to you unless you request that your name be kept confidential. You may decline to answer any question asked of you during the interview. If at any point during or up to 30 days after the interview you decide that you no longer wish to participate in the study, you may withdraw any or all comments. At that point, you may decide if I can use the information you already provided.

The notes, digital recordings, and transcripts of the interviews will be kept by me in a locked cabinet on a portable hard drive at my home office. It is possible that this data will be used in future research, presentations and/or reports. Full transcripts may be shared with my supervisor and/or dissertation examining committee. You may also request a copy of the final report which might provide you with helpful information on the development and nature of embedded reporting in Canada.

The final dissertation will be made accessible to the public through the Carleton University Library and the Reader's Digest Resource Centre (located in the River Building at Carleton). If you would like to be notified when the results are available, you will be given the option of receiving that information via email. This project was reviewed and received ethics clearance by the Carleton University Research Ethics Committee. If you have any concerns or questions about your involvement in the study, you may direct questions or comments to the ethics committee chair:

Dr. Louise Heslop, CUREB-A Chair

Carleton University Research Ethics Committee

Research Ethics Office

511 Tory

Carleton University

1125 Colonel By Drive

Ottawa, ON, Canada

K1S 5B6

Tel: 613.520 .2517

Email: ethics@carleton.ca

I realize that this request is an imposition on your time, but your experience and reflections would be a valuable contribution to my research and to our understanding of the pragmatics and outcomes of embedding journalists in the combat theatre. If you are willing to participate in my research, please contact me by email at SherryWasilow@cmail.carleton.ca or swasilow.carleton@gmail.com so that we might schedule an interview as well as a date and time convenient to you.

With respect and gratitude,

Sherry Wasilow, M.A.

School of Journalism and Communication

Communication Studies

Email: SherryWasilow@cmail.carleton.ca, swasilow.carleton@gmail.com 


\section{Carleton \\ Canada's Capital University}

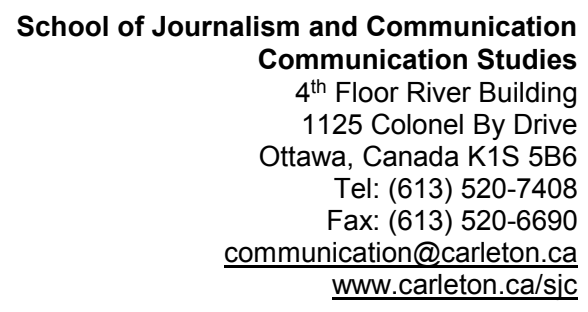

DAT 2015, 2016

Salutations. Mon nom est Sherry Wasilow. Je suis une candidate au doctorat à l'école de journalisme et de communication à l'université Carleton à Ottawa.

Je vous contacte pour demander une entrevue pour ma thèse de recherche. Mon projet vise à comprendre la nature et l'impact d' être intégré, pas-intégré, ou déclaré unilatérale dans un contexte de journalisme canadien, en utilisant la guerre en Afghanistan comme une étude de cas.

Ma recherche comprendra des entrevues avec des professionnels comme vous qui sont familiers avec la pratique du journalisme intégré, pas-intégré, ou unilatéral à partir d'un point de vue particulier ou base de connaissances. Ces entretiens me fournir un large éventail de comprendre comment les politiques et pratiques se sont développées, les perceptions concernant la façon dont le programme fonctionne et délivre, comment les participants exécutent et travaillent ensemble, quels sont les résultats, et les suggestions pour changement.

Je suis la seule chercheuse dans cette étude; toutefois, le projet est sous la supervision du Dr, Christopher Dornan, professeur agrégé et responsable des études supérieures à l'école de journalisme et de communication à l'université Carleton à Ottawa.

Grâce à l'analyse des médias, la recherche liée, les contacts personnels, et l'examen des médias et des documents militaires et des répertoires, vous avez été identifié comme un candidat compétent avec des renseignements potentiellement utiles liées aux médias et / ou la performance militaire pendant la guerre en Afghanistan. Vos points de vue et l'expérience bénéficieraient grandement mon étude. Votre participation à ce projet comprendra une interview où vous êtes invité à partager des informations sur vous votre, ou de l'expérience intégré, dis-intégré our unilatérale et / ou observations connexes, et des suggestions pour l'avenir. Je voudrais vous envoyer mes questions par courriel, et vous demander de répondre en nature - par courriel. Je peux vous contacter plus tard au printemps 2016 pour organiser une entrevue de suivi.

Vous êtes invité à participer à cette étude en votre qualité professionnelle en tant que journaliste. Tous les commentaires que vous avez faites être inclus textuellement dans la dissertation ou d'autres produits de la recherche et seront attribués à vous, sauf si vous demandez que votre nom soit gardé confidentiel. Vous pouvez refuser de répondre à toute question posée. Si à tout moment pendant ou jusqu'à 30 jours après avoir répondu, vous décidez que vous ne souhaitez plus participer à l'étude, vous pouvez retirer tout ou commentaires. À ce moment, vous pouvez décider si je peux utiliser les informations vous avez déjà fournies. 
Les courriels seront conservés par moi dans une armoire verrouillée ou sur un disque dur portable à mon bureau à domicile. Il est possible que ces données seront utilisées dans de futures recherches, des présentations et / ou des rapports. Transcriptions complètes peuvent être partagées avec mon superviseur et / ou une dissertation comité d'examen. Vous pouvez aussi demander une copie du rapport final qui pourrait vous fournir des informations utiles sur le développement et la nature des rapports intégré au Canada.

La dissertation finale sera rendue accessible au public par la bibliothèque universitaire de Carleton et aussi le centre de ressources Reader's Digest (situé dans le bâtiment de la Rivière à l'université Carleton). Si vous souhaitez être informé lorsque les résultats sont disponibles, vous aurez la possibilité de recevoir cette information par courrier électronique. Ce projet a été examiné et a reçu l'autorisation de l'éthique par le Comité d'éthique de la recherche de l'université Carleton. Si vous avez des questions ou des préoccupations au sujet de votre participation à l'étude, vous pouvez adresser vos questions ou commentaires à la présidence du comité d'éthique:

\author{
Dr. Louise Heslop, CUREB-A Chair \\ Carleton University Research Ethics Committee \\ Research Ethics Office \\ 511 Tory \\ Carleton University \\ 1125 Colonel By Drive \\ Ottawa, ON, Canada \\ K1S 5B6
}

Tel: 613.520.2517

Email: ethics@carleton.ca

Je me rends compte que cette demande est une imposition sur votre temps, mais votre expérience et réflexions serait une contribution précieuse à mes recherches et à notre compréhension de la pragmatique et les résultats de l'intégration de journalistes dans le théâtre de combat. Si vous êtes prêt à participer à mes recherches, s'il vous plaît contactez-moi par e-mail à

SherryWasilow@cmail.carleton.ca ou swasilow.carleton@gmail.com afin que nous puissions planifier une entrevue ainsi qu'une date et l'heure qui vous convient.

Avec respect et gratitude,

Sherry Wasilow, M.A.

School of Journalism and Communication

Communication Studies

Email: SherryWasilow@cmail.carleton.ca, swasilow.carleton@gmail.com 


\section{APPENDIX E: Letter of Consent (English and French) \\ Carleton \\ Canada's Capital University}

School of Journalism and Communication Communication Studies $4^{\text {th }}$ Floor River Building 1125 Colonel By Drive Ottawa, Canada K1S 5B6 Tel: (613) 520-7408 Fax: (613) 520-6690 communication@carleton.ca www.carleton.ca/sjc

Date 2015, 2016

\section{LETTER OF CONSENT}

Researcher:

Sherry Wasilow, M.A.

School of Journalism and Communication

Communication Studies

Email: SherryWasilow@cmail.carleton.ca, swasilow.carleton@gmail.com

Supervisor:

Christopher Dornan, Ph.D.

Supervisor

Associate Professor, Graduate Supervisor - Journalism

School of Journalism and Communication

Telephone: $613.520 .2600 \times 7460$

Email: chris_dornan@carleton.ca

Title of project: Contemporary Canadian military/media relations: Embedded reporting during the Afghanistan War

Information on the project:

Sherry Wasilow, the primary researcher, is conducting in-depth interviews with members of the media, military, and government who are familiar with the practice of embedded, dis-embedded, or unilateral journalism from their particular vantage points or knowledge base. These interviews will provide insight into how embedded reporting may or may not have had an impact on Canadian war reporting. The research is supervised by Dr. Chris Dornan, Associate Professor and Graduate Supervisor, Journalism in the School of Journalism and Communication at Carleton University in Ottawa.

\section{INFORMED CONSENT}

This consent form, a copy of which has been given to you, is only part of the process of informed consent. If you want more details about something mentioned here, or information not included 
here, you should feel free to ask. Please take the time to read this carefully and to understand any accompanying information.

Purpose of the study:

This project seeks to understand the nature and impact of embedded reporting in a Canadian context, using the Afghanistan War as a case study. You have been identified as a person knowledgeable about the practice and/or use of embedded, dis-embedded or unilateral journalism in this context. As such, I invite you to share information about your experiences, observations, evaluations, and suggestions for the future.

What will you be asked to do?

This part of the research will involve a semi-structured, open-ended interview led by the researcher. If conducted in person, by telephone, or on Skype, the interview will last approximately one hour. Please note that Skype is subject to the U.S. Patriot Act, therefore, our conversation will not be confidential. The researcher will primarily take detailed notes, but in order to ensure accuracy, the interview will also be recorded and later transcribed if needed. You may ask that the interview not be recorded, and instead the researcher will simply take detailed notes. Your participation in this interview is voluntary and you may withdraw any or all of your comments from the study at any time during or up to 30 days after the interview by contacting the researcher at SherryWasilow@cmail.carleton.ca or swasilow.carleton@gmail.com. If you wish to participate in the interview via written correspondence, I would ask that you respond within two weeks, but you may still withdraw any or all comments from the study up to 30 days after submitting your responses by contacting the researcher at SherryWasilow@cmail.carleton.ca or swasilow.carleton@gmail.com. You will be given the choice of the following:

Do you wish for this interview to be

a) on the record (you may be quoted and your name given),

b) on the record but no attribution (quoted but no name),

c) off the record (background only), or

d) some combination of the above (please specify)?

What type of personal information will be collected/reported?

You will be asked to provide your name, title/job description, organization, and city/province in which your organization resides, as well as certain demographical information for contextual information. In the final research report or any research product developed from the data, some of your specific responses or comments may be included verbatim and will be attributed to you. We are including these identification markers as you are being asked to participate in your professional capacity. While the confidentiality level you request will be respected, you should be aware that if you allow attribution of your comments to you or, if because of the uniqueness of your experiences, unattributed comments may be determined by others to be from you, and any of these comments are critical of your employer or former employers, this may place you at risk concerning your employment. If at any point during or up to 30 days after the interview you decide that you no longer wish to participate in the study, you may withdraw any or all comments.

The final dissertation will be made accessible to the public through the Carleton University Library and the Reader's Digest Resource Centre (located in the River Building at Carleton). If you would like to be notified when the results are available, please let me know and I will ensure that you receive that information via email. This project was reviewed and received ethics clearance by the Carleton University Research Ethics Committee. If you have any concerns or 
questions about your involvement in the study, you may direct questions or comments to the ethics committee chair:

Dr. Louise Heslop, CUREB-A Chair

Carleton University Research Ethics Committee

Research Ethics Office

511 Tory

Carleton University

1125 Colonel By Drive

Ottawa, ON, Canada

K1S 5B6

Tel: 613.520.2517

Email: ethics@carleton.ca

Signatures (written consent):

Your signature on this form indicates that you:

1) understand to your satisfaction the information provided to you about your participation in this research project, and

2) agree to participate as a research subject.

Participant's name: (please print)

Participant's signature:

Date:

Do you wish for this interview to be (please circle your preference):

1) on the record (you may be quoted and your name given),

2) on the record but no attribution (quoted but no name),

3) off the record (background only), or

4) some combination of the above (please specify here)? 


\section{Carleton \\ Canada's Capital University}

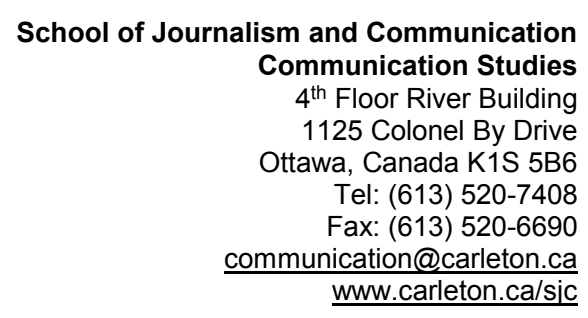

Dat 2015, 2016

\section{LETTRE D'ACCORD}

Chercheuse:

Sherry Wasilow, M.A.

School of Journalism and Communication

Communication Studies

Email: SherryWasilow@cmail.carleton.ca, swasilow.carleton@gmail.com

Superviseur:

Christopher Dornan, Ph.D.

Associate Professor, Graduate Supervisor - Journalism

School of Journalism and Communication

Telephone: $613.520 .2600 \times 7460$

Courriel: chris_dornan@carleton.ca

Titre du projet: relations militaires / médias canadiens contemporains: le journalisme integré au cours de la guerre en Afghanistan

Information sur le projet:

Sherry Wasilow, la chercheuse principale, mène des entrevues en profondeur avec les membres des médias, de l'armée et du gouvernement qui sont familiers avec la pratique du journalism integré, dis- integré, ou unilatéral de leurs points de vue particulières ou base de connaissances. Ces entretiens permettront de mieux comprendre la façon dont les rapports intégré peut ou peut ne pas avoir eu un impact sur le reportage de guerre du Canada. La recherche est supervisée par le Dr. Chris Dornan, professeur agrégé et superviseur d'études supérieures, journalisme à l'école de journalisme et de communication à l'université Carleton à Ottawa.

\section{CONSENTEMENT INFORMÉ}

Ce formulaire de consentement, dont une copie a été donnée à vous, ne constitue qu'une partie du processus de consentement éclairé. Si vous voulez plus de détails sur quelque chose mentionné ici, ou information pas inclus ici, vous devriez vous sentir libre d'en demander. S'il vous plaît prendre le temps de lire attentivement et de comprendre tout renseignement y afférent.

But de l'étude: 
Ce projet vise à comprendre la nature et l'impact du reportage intégré dans un contexte canadien, en utilisant la guerre en Afghanistan comme une étude de cas. Vous avez été identifié comme une personne bien informée sur la pratique et / ou l'utilisation du journalism integré, dis-integré, ou unilatéral dans ce contexte. En tant que tel, je vous invite à partager des informations sur vos expériences, observations, des evaluations, et des suggestions pour l'avenir.

Que ferez-vous être demandé de faire?

Si vous pouvez participer à l'entrevue par correspondance écrite, je voudrais vous demander de répondre dans les deux semaines, mais vous pouvez toujours retirer tout ou partie des observations de l'étude jusqu'à 30 jours après le dépôt de vos réponses en contactant la chercheuse à SherryWasilow@cmail.carleton.ca ou swasilow.carleton@gmail.com. Votre participation à cette entrevue est volontaire et vous pouvez retirer tout ou partie de vos commentaires de l'étude à tout moment pendant ou jusqu'à 30 jours après l'entrevue en contactant la chercheuse à SherryWasilow@cmail.carleton.ca ou swasilow.carleton@gmail.com. Vous avez le choix de ce qui suit:

Avez-vous le souhaitez pour cette interview soit

a) sur le dossier (vous pouvez être cité et votre nom donné),

b) sur le dossier, mais pas d'attribution (cité, mais pas de nom),

c) off the record (fond seulement), ou

d) une combinaison de ce qui précède (s'il vous plaît préciser)?

Quel type d'information personnelle sera collectée / rapporté?

Vous serez invité à fournir votre nom, votre titre / description de l'emploi, de l'organisation, et la ville / province dans laquelle votre organisation réside, ainsi que certaines informations démographiques pour les informations contextuelles. Dans le rapport final de la recherche ou de tout produit de recherche développé à partir des données, certains de vos réponses ou des observations spécifiques peuvent être inclus verbatim et sera attribué à vous. Nous incluons ces marqueurs d'identification parce que vous êtes invité à participer à votre capacité professionnelle. Alors que le niveau de confidentialité que vous demandez sera respectée, vous devez être conscient que si vous autorisez l'attribution de vos commentaires à vous ou, si à cause de l'unicité de vos expériences, commentaires non attribuées peuvent être déterminées par les autres d'être auprès de vous, et l'un des ces commentaires sont critique de votre employeur ou d'anciens employeurs, cela peut vous exposer à des risques concernant votre emploi. Si à tout moment pendant ou jusqu'à 30 jours après l'entrevue, vous décidez que vous ne souhaitez plus participer à l'étude, vous pouvez retirer tout ou commentaires.

La dissertation finale sera rendue accessible au public par la bibliothèque universitaire de Carleton et le centre de ressources Reader's Digest (situé dans le bâtiment de la Rivière à l'université Carleton). Si vous souhaitez être informé lorsque les résultats sont disponibles, s'il vous plaît laissez-moi savoir et je ferai en sorte que vous recevez cette information par courriel. Ce projet a été examiné et a reçu l'autorisation de l'éthique par le Comité d'éthique de la recherche de l'université Carleton. Si vous avez des questions ou des préoccupations au sujet de votre participation à l'étude, vous pouvez adresser vos questions ou commentaires à la présidence du comité d'éthique:

Dr. Louise Heslop, CUREB-A Chair

Carleton University Research Ethics Committee

Research Ethics Office

511 Tory

Carleton University 
1125 Colonel By Drive

Ottawa, ON, Canada

K1S 5B6

Tel: 613.520.2517

Email: ethics@carleton.ca

Signatures (du consentement écrit):

Votre signature sur ce formulaire indique que vous:

1) comprendre à votre satisfaction les informations fournies au sujet de votre participation à ce projet de recherche, et

2) accepter de participer en tant que sujet de recherche.

Nom du participant: (s'il vous plaît

imprime)

Signature du participant:

Date: 


\section{APPENDIX F: Questionnaire, Media (English and French)}

Questionnaire for Reporters

Please answer each of the following questions with as much detail as possible. We can go through them in person, via telephone or Skype, or you can respond via email.

\section{General}

1. Name

2. Media organization

3. Age

4. Gender

5. Education

6. How would you describe your political ideology?

7. How many years of media experience have you had (reporting, editorial, etc.)?

8. What experience(s) with conflict- or foreign-news reporting have you had? (Embedded, dis-embedded, or unilateral experience will be addressed below.)

9. Do you wish for this interview to be

a) on the record (you may be quoted and your name given),

b) on the record but no attribution (quoted but no name),

c) off the record (background only), or

d) some combination of the above (please specify)?

II. Embedded, dis-embedded, or unilateral experience

1. Can you list your deployment(s) with the Canadian Forces (CF) Media Embedding Program (CFMEP) and/or assignment(s) as a unilateral reporter?

2. Did you engage in any preparations prior to deployment or assignment?

a) If so, boot camp, research, courses, language prep, fitness, etc?

3. Did you plan beforehand to tell certain stories?

a) What stories were you best able to tell?

4. Did you find certain stories challenging to tell?

a) If so, why?

5. Can you describe any personal challenges in reporting your stories?

6. If embedded, did you feel a sense of losing sight of the bigger picture ... that micro-coverage supplanted addressing a broader picture?

7. If dis-embedded, did you feel constricted in the stories you could address because of your ties to the CFMEP?

a) How easily were you able to dis-embed and re-embed?

b) Who determined the freedom of your movements "outside of the wire?"

8. How would you assess your own embedded/dis-embedded performance?

9. If reporting as a unilateral, did you feel a greater sense of freedom to address stories?

10. How important was the use of a fixer in your work? 
11. Would you have changed anything about your embedded, dis-embedded, or unilateral experience?

a) If so, what?

12. Do you perceive the CFMEP favourably in comparison to other countries' embed programs?

13. Do you think the CFMEP should be continued?

14. Do you think the CFMEP could be changed/improved?

a) If so, how?

III. Military experience

1. Was your embedded, dis-embedded, or unilateral experience what you had anticipated?

2. What are the pros and cons to embedding with the CF?

3. What are the pros and cons to reporting as a unilateral?

4. Did CFMEP policies make certain stories more difficult than others to tell?

5. Did you face personal difficulties in reporting challenges due to operations security (OPSEC) or censorship?

a) If so, please describe.

6. Did you ever censor your own stories for reasons of OPSEC or otherwise?

7. Did you have difficulties in approaching/having soldiers speak on the record?

8. Were your experiences with military Public Affairs (PA) personnel positive?

a) If not, please describe the nature of those disagreements.

9. Do you think that PA personnel provided thorough information to reporters?

10. Did you find that CFMEP policy rules matched practice in-theatre?

11. To your knowledge, how did the CF military treat embedded, dis-embedded and unilateral reporters compared to how the US military treated reporters?

IV. Media coverage

1. Do you think Canadian coverage of the Afghanistan mission was top quality?

a) Why?

2. Did you notice a difference between print and television coverage?

3. Did you notice a difference between English and French coverage?

4. Did you notice a difference in coverage over the duration of the Afghan mission?

5. Do you think your media organization's coverage compared favourably to coverage by other organizations in Canada or the U.S.?

6. Do you think any reporter stood out as part of the Afghanistan mission?

a) If so, who and why?

\section{Editorial experience}

1. Was your media organization supportive of your reports and suggestions?

2. Did your editors suggest/show major interest in a particular type of story?

a) If so, what kind? 
3. Did certain of your stories receive a better placement vis-à-vis page or lineup? a) If so, which ones?

4. Could embedded, dis-embedded, or unilateral reporting best criticize CF action?

5. Any advice for future embedded, dis-embedded, or unilateral reporters? 
Questionnaire pour les journalistes

S'il vous plaît répondre à chacune des questions suivantes avec autant de détails que possible.

\section{Général}

10. Nom

11. Organisation de médias

12. Age

13. Sexe

14. Éducation

15. Comment décririez-vous votre idéologie politique?

16. Combien d'années d'expérience de média avez-vous eu (reporting, éditoriale, etc.)?

17. Quelle est l'expérience (s) avec des reportage nouvelles de conflict ou de l'étranger avez-vous eu? (Integré, dis-integré, ou unilatérale seront addressées ci-dessous.)

18. Voulez-vous que cette interview soit

e) sur le dossier (vous pouvez être cité et votre nom donnée),

f) sur le dossier, mais pas d'attribution (cité, mais pas de nom),

g) off the record (fond seulement), ou

h) une combinaison de ce qui précède (s'il vous plaît préciser)?

II. Expérience integré, dis-integré, ou unilatérale

15. Pouvez-vous énumérer votre déploiement (s) avec la Programme d'intégration des medias aux forces armées Canadiennes (PIMFC) et / ou d'assignation (s) comme un journaliste unilatérale?

16. Avez-vous engager dans des préparatifs précédant le déploiement?

b) Si oui, le camp d'entraînement, de la recherche, des cours, préparation linguistique, fitness, etc?

17. Avez-vous planifié à l'avance pour dire certaines histoires?

b) Quelles histoires étaient vous mieux capable en dire?

18. Avez-vous trouvé certaines histoires difficiles à raconter?

b) Si oui, pourquoi?

19. Pouvez-vous décrire les défis personnels à reporter vos histoires?

20. Si integré, avez-vous éprouvé un sentiment de perdre de vue le tableau d'ensemble ... que les micro-couverture supplanté adressant une vue plus grande?

21. Si dis-intégré, avez-vous sentir avoir une capacité limitée de conter des histoires à cause de vos liens avec le PEMFC?

c) Trouvez-vous facile la capacité d'intégrer, dis-intégrer et d'intégrer de nouveau?

d) Qui en a fixé la liberté de vos mouvements "en dehors du fil?"

22. Comment évaluez-vous votre propre performance intégré ou dis-intégré? 
23. Si vous étiez un journaliste unilatérale, avez-vous ressenti un sentiment de liberté pour partir des histoires?

24. Quelle était l'importance de l'utilisation d'un "fixer" dans votre travail?

25. Auriez-vous changé quelque chose au sujet de votre expérience integré, disintegré, ou unilatérale?
a) Si oui, quoi?

26. Avez-vous percevez le PEMFC favorablement par rapport aux programmes similares d'autres pays?

27. Pensez-vous que la PEMFC doit être poursuivi?

28. Pensez-vous que la PEMFC pourrait être modifié / amélioré?
a) ISi oui, comment?

III. L'expérience militaire

12. Est-ce que votre experience integrés, dis- integrés, ou unilatérale ce que vous aviez prévu?

13. Quels sont les avantages et les désavantages de l'intégration avec les FC?

14. Quels sont les avantages et les désavantages de rapporter comme unilatérale?

15. Est-ce que les politiques FC ont fait certaines des histoires plus difficiles que d'autres à raconter?

16. Avez-vous trouvé des difficultés personnelles à a raconteur des nouvelles pour raison de la sécurité des opérations (OPSEC) ou la censure?

b) Si oui, s'il vous plaît décrire.

17. Avez-vous jamais censurer vos propres histoires pour des raisons de OPSEC ou autrement?

18. Avez-vous eu des difficultés à approcher / ayant soldats parler sur le dossier?

19. Étaient vos expériences avec des affaires publiques militaires (AP) personnel positives?

a) Si non, s'il vous plaît décrire la nature de ces désaccords.

20. Pensez-vous que le personnel PA fourni de l'informations suffisamment aux journalistes?

21. Avez-vous trouvé que les règles de la politique PEMFC ètaient pratique dans le théâtre?

22. À votre connaissance, pouvez-vous comparer le traitement militaire des FC a propose les journalistes intégrés, dis-intégrés et unilatérales avec le traitement militaire de l'armée américaine (de ces journalistes)?

IV. Couverture médiatique

7. Pensez-vous que la couverture canadienne de la mission en Afghanistan était de qualité supérieure?

a) Pourquoi?

8. Avez-vous remarqué une différence entre la couverture de presse et la couverture de la télévision?

9. Avez-vous remarqué une différence entre la couverture française et anglais? 
10. Avez-vous remarqué une différence de la couverture pendant la durée de la mission en Afghanistan?

11. Pensez-vous que la couverture de votre organisation médiatique se compare favorablement à la couverture par d'autres organisations au Canada ou aux ÉtatsUnis?

12. Pensez-vous qu'il y avait de travail superbe d'un journaliste dans le cadre de la mission en Afghanistan?

b) Si oui, qui et pourquoi?

V. Expérience éditoriale

6. Était votre organisation favorable à vos rapports et vos suggestions?

7. Est-ce que vos éditeurs suggèrent / montrent un intérêt majeur dans un rapoprt particulier?

a) Si oui, quel genre?

8. Avaient reçus certaine de vos histoires un meilleur placement vis-à-vis de page ou lineup?

a) Si oui, lesquels?

9. Quels journalists - intégré, dis- intégré, ou unilatérale - pouvaient mieux critiquer l'action CF?

10. Avez vous des conseils pour journalistes de l'avenir intégrés, dis-intégrés ou unilatérales? 


\section{APPENDIX G: Carleton Ethics Approval (Military and Government)}

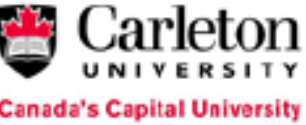

Ethics Clearance Form - New Clearance
Carleton University

Research Ethics Office

Research Ethics Board

511 Tory, 1125 Colonel By Drive

Ottawa, ON K1S 5B6 Canada

Tel: 613-520-2517, ethics@ carleton.ca

This is to certify that the Carleton University Research Ethics Board has examined the application for ethical clearance. The REB found the research project to meet appropriate ethical standards as outlined in the Tri-Council Policy Statement: Ethical Conduct for Research Involving Human, 2nd edition, and the Carleton University Policies and Procedures for the Ethical Conduct of Research.

Date of Clearance: October 28, 2015

Researcher: Christopher T. Dornan (Primary Investigator)

Department: Faculty of Public Affairs।Journalism and Communications (School of)

University: Carleton University

Research Supervisor (if applicable): Prof. Christopher T. Doman

Project Number: 103586

Project Title: Contemporary Canadian Military/Media relations: Embedded reporting during the

Afghanistan War (Mil/Gov)

Funder (if applicable): N/A

Clearance Expires: October 01, 2016

All researchers are governed by the following conditions:

Annual Status Report: You are required to submit an Annual Status Report to either renew clearance or close the file. Failure to submit the Annual Status Report will result in the immediate suspension of the project. Funded projects will have accounts suspended until the report is submitted and approved.

Changes to the project: Any changes to the project must be submitted to the Carleton University Research Ethics Board for approval. All changes must be approved prior to the continuance of the research.

Adverse events: Should a participant suffer adversely from their participation in the project you are required to report the matter to the Carleton University Research Ethics Board. You must submit a written record of the event and indicate what steps you have taken to resolve the situation.

Suspension or termination of clearance: Failure to conduct the research in accordance with the principles of the Tri-Council Policy Statement: Ethical Conduct for Research Involving Humans, 2nd edition and the Carleton University Policies and Procedures for the Ethical Conduct of Research may result in the suspension or termination of the research project.

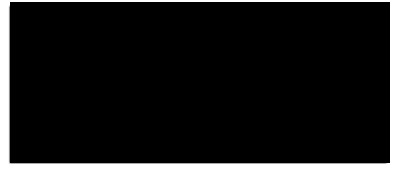

Louise Heslop

Chair, Carleton University Research Ethics Board

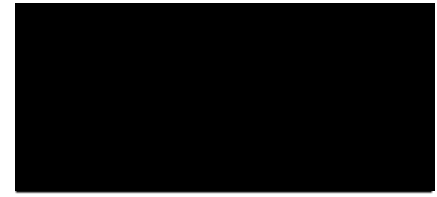

Andy Adler

Vice-Chair, Carleton University Research Ethics Board 


\section{APPENDIX H: Questionnaire, Military and Government}

Questionnaire for Military/Government Personnel

Please answer each of the following questions with as much detail as possible. We can go through them in person, via telephone or Skype, or you can respond via email.

\section{General}

19. Name

20. Title/organization

21. Age

22. Gender

23. Education

24. How many years of experience have you had in working with the media (e.g. Public Affairs, Communications, Media Relations, personal interview(s), etc.)?

25. Have you had experience(s) working with domestic or foreign-news reporters?

26. Do you wish for this interview to be
a) on the record (you may be quoted and your name given),
b) on the record but no attribution (quoted but no name),
c) off the record (background only), or
d) some combination of the above (please specify)?

II. Canadian Forces (CF) Media Embedding Program (CFMEP)

1. Are you familiar with the Canadian Forces (CF) Media Embedding Program (CFMEP)?

a) If so, what do you believe was the intent of the CFMEP?

b) In your opinion, what are the advantages as well as disadvantages of the CFMEP for the CF?

c) In your opinion, what are the advantages as well as disadvantages of the CFMEP for the media?

d) To your knowledge, who decides which and how many reporters are embedded with whom and for how long?

2. Are you familiar with CFMEP operations?

a) Do you recall if/when embedded or dis-embedded reporters did not observe CFMEP policies?

b) In your opinion, were CFMEP policies fair to the media?

c) To your knowledge, have significant changes been made to the CFMEP since its initiation at the beginning of the Afghanistan mission?

d) Did you find that CFMEP policy rules matched practice "on the ground?"

e) Do you perceive the structure and flexibility of the CFMEP favourably in comparison to other countries' embed programs?

3. Do you think the CFMEP should be continued?

4. Do you think the CFMEP could be changed/improved? 

a) If so, how?

III. Media experience

1. Were your experiences with embedded or dis-embedded reporters what you had anticipated?

2. Did you have any experience(s) with unilateral reporters (e.g. unaffiliated with the military, neither embedded nor dis-embedded)?

3. Did you feel that embedded reporters effectively relayed stories?

4. Did you feel that dis-embedded and unilateral reporters effectively relayed a bigger picture of the war (e.g. Canadian reconstruction efforts, the war's effects)?

5. Did you witness disagreements/conflicts between Canadian authorities and embedded, dis-embedded, or unilateral reporters?

a) If so, what was the source of these disagreements?

6. Did you believe that censorship in the name of operations security (OPSEC) was/is warranted?

7. Would you have changed anything about the way that embedded, dis-embedded, or unilateral reporters were treated?

a) If so, what?

8. Could you easily speak on the record to reporters?

9. Did you think that PA personnel provided thorough information to reporters?

10. To your knowledge, how did the CF military treat embedded, dis-embedded, and unilateral reporters compared to how the US military treated reporters?

IV. Media coverage

13. Do you think Canadian coverage of the Afghanistan mission was top quality?

a) Why?

14. Did you notice a difference between print and television coverage?

15. Did you notice a difference between English and French coverage?

16. Did you notice a difference in coverage over the duration of the Afghan mission?

17. Do you think any reporter stood out as part of the Afghanistan mission?

c) If so, who and why?

V. Federal oversight

11. Was military/government administration supportive of your work with reporters?

12. Did senior personnel want certain stories covered more than others?

13. Do you believe certain media stories received more attention than warranted?

a) If so, which ones?

14. Do you believe certain stories should have received more attention than they did?

15. Did senior personnel have a preference for working with embedded, disembedded, or unilateral reporters?

16. Were unilateral reporters were more prone to criticize military action? 
17. Any advice for future military/government personnel who may work with embedded, dis-embedded, or unilateral reporters? 


\section{APPENDIX I: Social Science Research Review Board Approval}

Email dated 20 January 2016:

The research submission titled, " Contemporary Canadian military/media relations: Embedded reporting during the Afghanistan War" has been approved by the DGMPRA Social Science Research Review Board, in accordance with DAOD 5062-0 and 5062-1. The SSRRB approval \# is 1509/15F. 


\section{APPENDIX J}

CANADIAN EXPEDITIONARY

FORCE COMMAND

101 Colonel By Drive

Ottawa, Ontario K1A 0K2

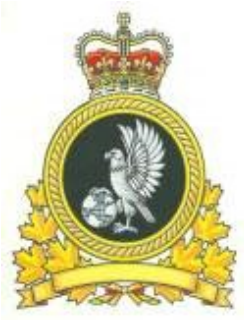

COMMANDEMENT DE LA FORCE

EXPÉDITIONNAIRE DU CANADA

101, promenade Colonel By

Ottawa (Ontario) K1A 0K2

\section{Canadian Forces Media Embedding Program \\ Guidelines, Ground Rules and Documentation \\ for \\ Land-based Operations}




\section{Table of Contents}

PART 1: GENERAL INSTRUCTIONS .......................................................................... 457

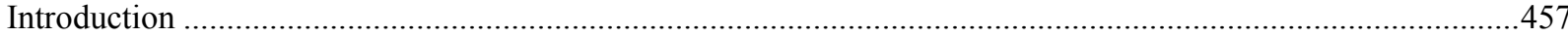

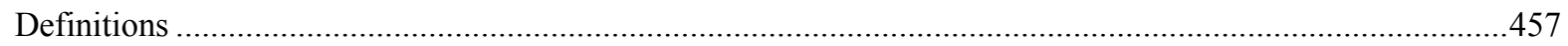

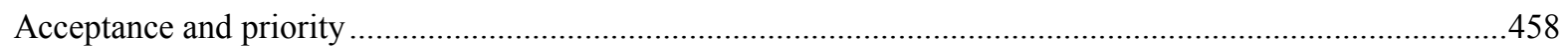

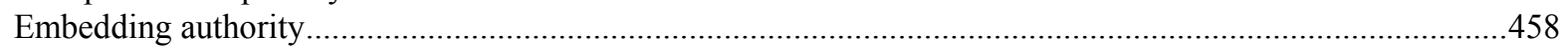

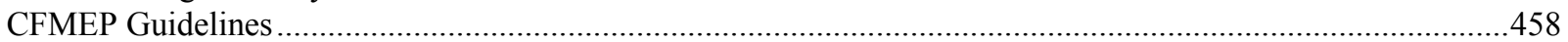

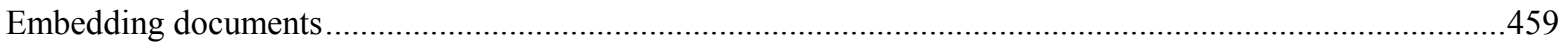

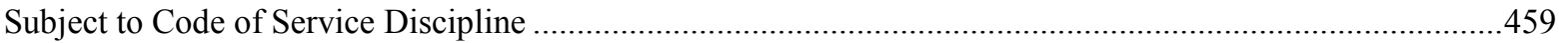

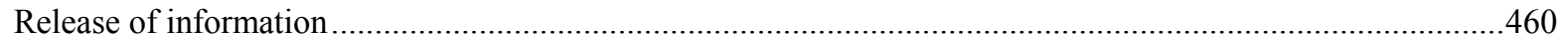

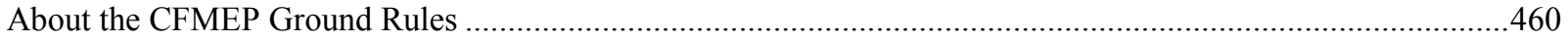

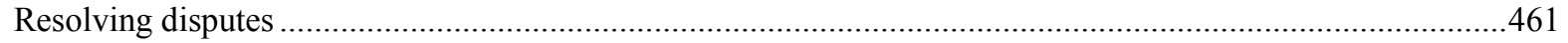

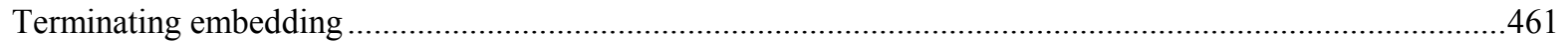

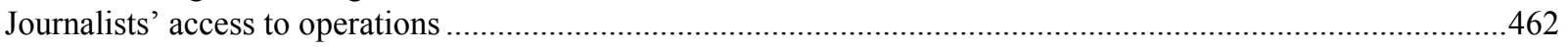

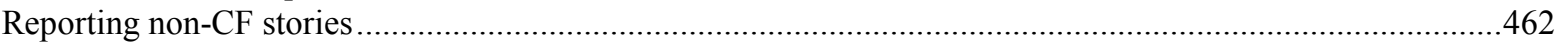

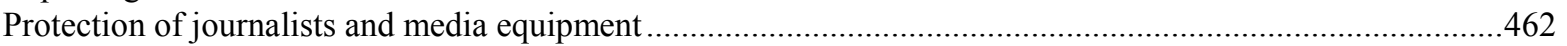

Hazards to embedded journalists: Injury, death and kidnapping ..................................................................462

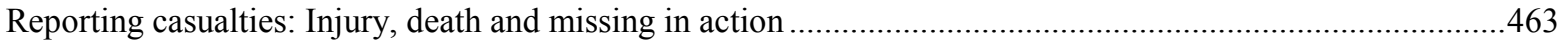

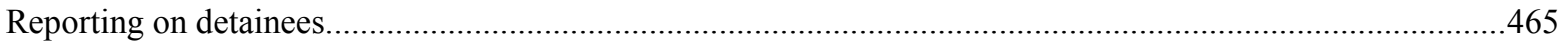

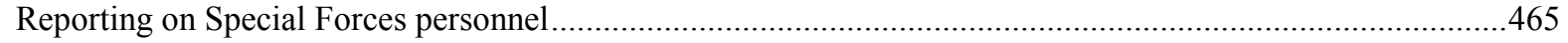

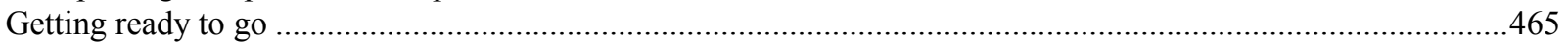

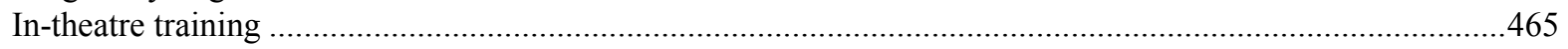

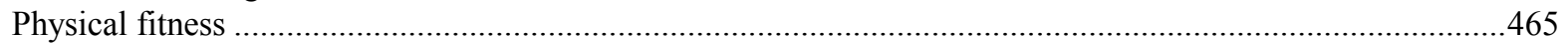

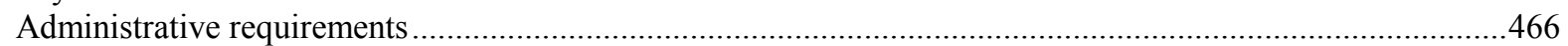

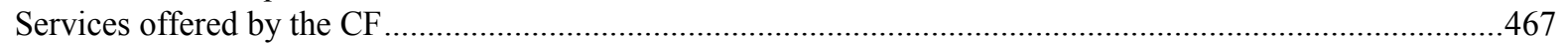

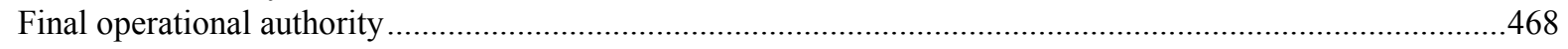

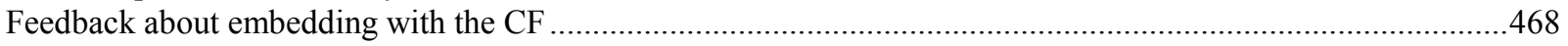

PART 2: GROUND RULES AND DOCUMENTATION .................................................... 469

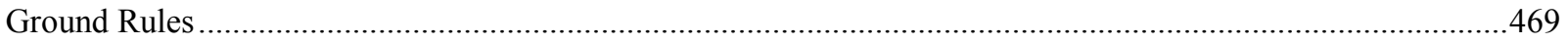

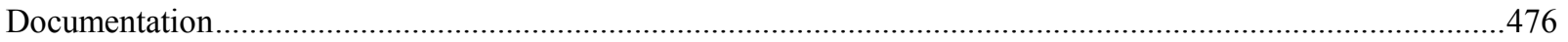

PART 3: PREPARATION ASSISTANCE AND FREQUENTLY ASKED QUESTIONS 485

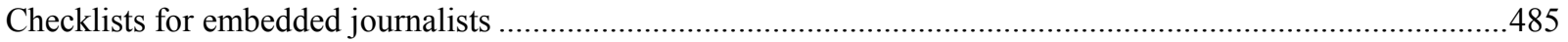

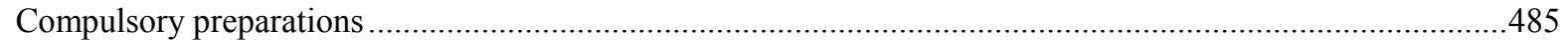

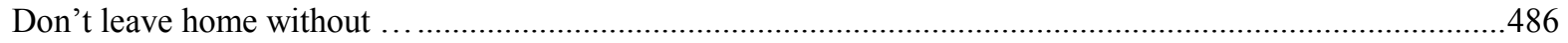

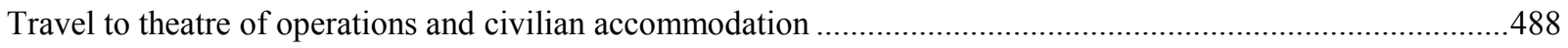

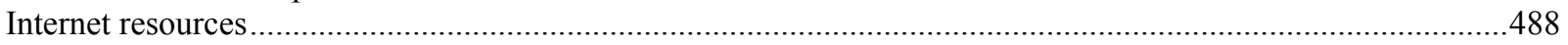

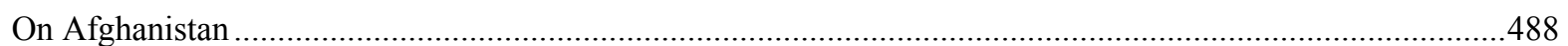

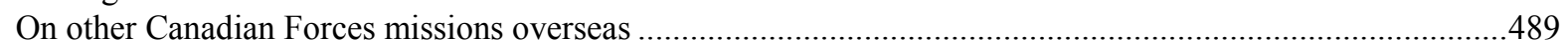

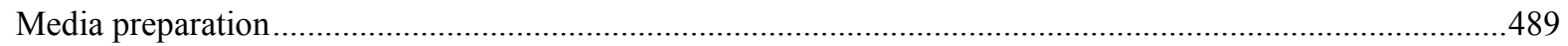

Journalists' frequently asked questions................................................................................489

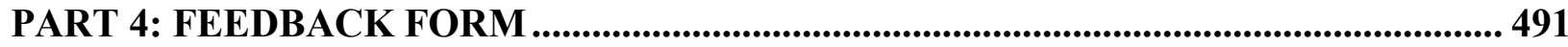




\section{CANADIAN EXPEDITIONARY}

FORCE COMMAND

101 Colonel By Drive

Ottawa, Ontario K1A 0K2

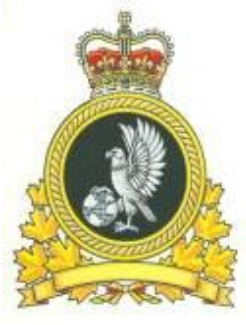

COMMANDEMENT DE LA FORCE

EXPÉDITIONNAIRE DU CANADA

101, promenade Colonel By

Ottawa (Ontario) K1A 0K2

1. Part 1: General Instructions

- $\quad$ Introduction

1. The objective of the Canadian Forces Media Embedding Program (CFMEP) is to inform Canadians about the role, mandate and activities of the Canadian Forces (CF) on deployed operations.

2. The aim of this document is to provide the necessary guidelines to journalists who intend to embed with CF task forces conducting land or air operations outside North America.

\section{Definitions}

3. The following definitions apply throughout this package of documents:

a. Accreditation: The formal acknowledgement by a media organization that it employs or has a contract with a journalist, intends to publish or broadcast the journalist's material, and assumes the responsibilities laid out in this document.

b. Embedding: The formal attachment of a journalist to the $\mathrm{CF}$ for an extended period.

c. Journalist: A person who is employed by or under contract to a media organization, and is seeking to embed with the CF to report on its activities. A journalist may be (but is not limited to) a reporter, a photographer, an equipment operator, a producer or a technician.

d. Media organization: A business that employs journalists to produce news reports and features for broadcast and/or publication through media outlets (e.g., newspapers, radio stations, television stations, websites).

e. CEFCOM: Canadian Forces Expeditionary Force Command, the operationallevel command of the $\mathrm{CF}$ responsible for the planning and conduct of all $\mathrm{CF}$ operations outside North America except for those conducted by Canadian Special Operations Forces Command (CANSOFCOM).

f. Task Force Senior Public Affairs Officer: The senior member of the Public Affairs staff of a deployed task force, usually a major.

g. Government of Canada institutions: Departments, agencies and other organizations of the Canadian federal government, such as the Department of Foreign Affairs and International Trade (DFAIT), the Canadian International Development Agency (CIDA), the Royal Canadian Mounted Police (RCMP), or and Correctional Services Canada (CSC).

h. Casualty: A person who has died, or who is injured, sick or missing, as a result of a specific incident. 


\section{Acceptance and priority}

4. To be accepted for the CFMEP, journalists must be accredited and in possession of documents identifying them as journalists.

5. Applications to the CFMEP are accepted in the following order:

Priority 1: Journalists representing national Canadian media organizations, at the rate of one radio or print journalist $\boldsymbol{o r}$ one two-person television team from each major media organization.

Priority 2: Journalists representing regional Canadian media organizations.

Priority 3: Journalists representing international media organizations.

\section{Embedding authority}

6. The Chief of the Defence Staff delegates the authority to embed journalists with deployed CF task forces to the Commander CEFCOM. The Public Affairs section at CEFCOM Headquarters (CEFCOM PA) manages and coordinates embedding opportunities, handling the relationship between journalists and their media organizations and the Task Force Commander, who hosts embedded journalists in theatre.

- $\quad$ CFMEP Guidelines

7. Here are the general guidelines for the conduct of the CFMEP on land-based operations overseas:

a. Journalists are embedded for a fixed period of time agreed to in advance before joining an overseas task force.

b. As a general rule, a task force deployed overseas will accept only one international (i.e., non-Canadian) embed request at a time.

c. Although most task forces can usually accommodate journalists, at any given time a Task Force Commander may decide that the current operational situation requires a reduction in the number of journalists embedded with his/her task force.

d. Embedding with a deployed CF task force is based on the understanding that journalists will primarily cover $\mathrm{CF}$ and Government of Canada activities, and will accompany troops into the field whenever a viable opportunity is made available.

e. Handovers that require out-going and in-coming journalists from the same media organization to be in theatre at the same time are granted on an exceptional basis only, and requests must be submitted to CEFCOM PA well in advance to determine feasibility.

f. Journalists who wish to extend their embedding period must submit a request to CEFCOM PA at least 10 days before the scheduled departure date. This request may be submitted through either their media organization or the Senior Public Affairs Officer of the deployed task force. CEFCOM PA is the authority that grants or denies extensions. Journalists and media organizations must not consider themselves entitled to extensions.

g. Embedded television crews may operate in a media pool or independently. When operating independently, each television crew will comprise only two people: one 
reporter and one videographer. This limit is strictly enforced to permit all the major Canadian television networks to have teams in a particular theatre of operations at the same time.

\section{General conduct while deployed}

a. Journalists and their media organizations must respect the privacy of CF personnel, in particular their right to relax away from cameras and questions.

b. An embedded journalist is his or her media organization's primary news source and point of contact in a theatre of operations. A media organization with a journalist embedded with a deployed CF task force should request interviews with task force members through their embedded journalist, not the Media Liaison Office in Ottawa. Journalists should, therefore, deploy with reliable communications equipment, such as a satellite telephone, so they can maintain direct two-way communication with their employer at all times.

c. Media organizations should be mindful of the phenomenon of "journalists interviewing journalists." Although a journalist embedded with a deployed CF task force will learn a great deal about that particular mission, a few weeks in theatre does not make anyone a subject-matter expert. Embedded journalists should interview the Task Force Commander, designated spokespersons or appropriate CF subject-matter experts to ensure that CF operations are reported accurately and without speculation.

d. Embedding with a deployed CF task force does not give a journalist access to the forces of other nations operating in the same theatre of operations. Before interviewing foreign military personnel, even if they are based at the same camp, an embedded journalist must ask the Task Force Senior PAO to obtain permission from the potential interviewee's chain of command.

\section{Embedding documents}

9. Before embedding, journalists and their sponsoring media organizations must complete and sign the documents found in Part 2: Ground Rules and Documentation. By submitting the embedding documents with their signature, journalists and media organizations certify that:

a. they have read all the rules and guidelines contained therein, and

b. they understand that failure to comply with the Ground Rules and the embedding guidelines could result in the termination of their embedding agreement and their immediate removal from a theatre of operations.

\section{Subject to Code of Service Discipline}

10. As long as they are embedded with a deployed CF task force, journalists are subject to the Code of Service Discipline (Part III of the National Defence Act). This arrangement is one of the terms set out in the document entitled "Engagement with the Minister of National Defence" (page 23), which journalists must sign indicating acceptance before embedding. Consequently, embedded journalists can be charged for violations of the Code of Service Discipline. 


\section{Release of information}

11. Embedded journalists will be frequently reminded of the need for operations security (OPSEC) and technical accuracy. The Task Force Commander retains the right to review and require changes in media products containing potentially sensitive information, but only to the extent necessary to ensure that OPSEC is neither violated nor breached. A subject matter expert may revise technical information, but changes will be factual and not editorial. Content will not otherwise be restricted. Media products and equipment will not be confiscated or impounded.

12. The goal of OPSEC is to prevent adversaries from obtaining information that is essential to our missions. This objective allows for the safeguarding of some information that has an operational impact on our mission, while permitting Canadians to know as much as possible about their soldiers, sailors, airmen and airwomen, and the civilian members of the deployed "whole of government" team.

13. For journalists, the consequences of failure to obey direction regarding the release of information concerning force protection can include termination of their embedding and removal from the deployed task force.

14. Should personal information be disclosed to journalists inadvertently during a media briefing or other encounter with task force personnel, and journalists are told that releasing that information would result in a violation of the Privacy Act, the Crown may choose to take legal action against a journalist who then includes that personal information in a media product, thus exposing the Crown to liability.

15. When a deployed PAO or a military spokesperson presents a formal briefing, conditions may be applied to the information provided. These conditions are stated in advance, using the following release caveats:

a. Attributable: Journalists are free to quote the spokesperson fully, using the information with direct attribution — identifying the source by name — or indirect attribution, in which the name of the source is not given and he/she is identified institutionally; e.g., as "a DND official" or "a CF spokesperson."

b. Not for attribution: The information may be used, but without attribution to a named source.

c. Background: The information is provided only to help journalists understand the situation; the briefer will state whether the information may be published. If published, the information may not be attributed in any way.

d. Not for use: The information may not be published and is provided only to help journalists understand the situation.

Note: CF members and Defence civilians do not speak "off the record."

- $\quad$ About the CFMEP Ground Rules

16. To be accepted for the CFMEP, journalists and their media organizations must formally agree to obey the Ground Rules; consequently, journalists should read them thoroughly and ensure that they understand them. 
17. The CFMEP Ground Rules are set out in Part 2: Ground Rules and Documentation. Journalists are encouraged to carry a copy of the Ground Rules with them at all times while they are embedded.

18. The CFMEP Ground Rules were developed by CEFCOM PA in consultation with deployed task force commanders and their Public Affairs staff, and the Assistant Deputy Minister (Public Affairs) at National Defence Headquarters. The aim of the Ground Rules is to safeguard sensitive information (that is, both classified national security information and designated personal information) as required by Canadian legislation and Canadian Forces orders. The Ground Rules acknowledge the right of journalists to unclassified and undesignated information and are not intended to prevent the release of information that could be construed as derogatory, embarrassing, negative or uncomplimentary.

19. Release of information, imagery or video gathered while embedded with the CF must comply with the CFMEP Ground Rules at all times, both during embedding and after departure from the CFMEP.

\section{Resolving disputes}

20. Disputes about the CFMEP Ground Rules or General Instructions and their application should be resolved at the lowest level as soon as possible. Disputes that cannot be resolved locally are forwarded through the chain of command to CEFCOM PA (representing Commander CEFCOM) for resolution in consultation with the affected media organization and, if necessary, the Assistant Deputy Minister (Public Affairs).

21. Unit and sub-unit commanders (i.e., leaders subordinate to the Task Force Commander) may temporarily restrict a journalist's access to operations until a dispute is resolved. In such cases, it must not be assumed that the dispute will lead to termination of the journalist's embedding.

\section{Terminating embedding}

22. An embedding agreement can be terminated at any time by Commander CEFCOM, the embedded journalist, or the journalist's media organization. When Commander CEFCOM takes the initiative to terminate, the action will be based on a recommendation by the Task Force Commander. CEFCOM PA will make every effort to resolve the situation with an embedded journalist's media organization before terminating embed status. If a journalist or media organization demonstrates a history of terminating embed status either voluntarily or involuntarily, CEFCOM PA may refuse further embedding requests from that journalist or media organization.

23. Commander CEFCOM reserves the right to deny, postpone or cancel any request to embed, and accepts no liability for expenses incurred by journalists or media organizations in preparation for an embedding that does not proceed on schedule, including (but not limited to) the cost of airline tickets, immunization, and travel documentation such as passports and visas.

24. Clear violations of the Embedding Ground Rules will result in termination of the journalist's embedding and his/her removal from the theatre of operations. 
- $\quad$ Journalists' access to operations

25. Journalists will be given access to operational missions, including mission preparations and debriefings, whenever feasible. Feasibility is determined by the Task Force Commander or a designated deputy.

26. Journalists' access to patients in CF medical facilities is governed by the instructions of attending physicians as well as all applicable regulations, standard operating procedures, and operations orders. If the Commanding Officer of the facility and Task Force Commander authorize embedded journalists to visit a medical facility, a Public Affairs Officer or medical personnel must escort the journalists at all times. Visits by journalists must not interfere with medical treatment.

\section{Reporting non-CF stories}

27. Journalists apply to the CFMEP on the understanding that their primary objective is to cover CF and Government of Canada activities.

28. Embedded journalists who decide to leave the task force to report a non-CF story must convey their intentions to both their media organization and to the Senior PAO of the deployed task force, who then informs CEFCOM PA. This measure ensures that the CF maintains general awareness of their whereabouts for security purposes.

29. Embedded journalists must comply with the CFMEP Ground Rules even when they have left the task force to report a non-CF story.

\section{Protection of journalists and media equipment}

30. Embedded journalists are entitled to protection of their person and their equipment to the limit allowed by the Rules of Engagement governing the deployed task force. Journalists must acknowledge and accept that the deployed task force cannot guarantee their personal safety or the safety of media equipment in theatre.

31. Journalists who leave the protection of a deployed task force to meet "fixers" and report non-CF stories do so at their own risk. The CF is not responsible for rendering any assistance to journalists in these situations.

\section{Hazards to embedded journalists: Injury, death and kidnapping}

32. Embedded journalists and the media organizations they represent are each responsible for ensuring that they have adequate indemnity and insurance coverage. Any journalist who is injured while embedded receives emergency medical care to the extent available to the deployed task force and in accordance with CF regulations.

Note: A journalist who has been contaminated with a radiological, biological or chemical agent may not be repatriated until the situation is resolved.

33. The employing media organization is responsible for repatriating a journalist who is killed or injured while embedded, and for providing injured journalists with any medical care they require beyond that offered by the deployed task force. (Media organizations with freelance journalists under contract must pay particular attention to these obligations.) 
34. Here is the procedure the CF will follow should an embedded journalist be killed or injured:

a. The unit with which the journalist was embedded immediately reports the incident and the journalist's condition to the chain of command, which then informs CEFCOM PA.

b. CEFCOM PA contacts the affected media organization, which is responsible for notifying the journalist's next of kin.

c. When the journalist's next of kin have been notified, the media organization informs CEFCOM PA, which — if required - coordinates the release of information in accordance with the procedure for notifying the next of kin of military casualties.

Note: If the media organization decides to announce the injury or death of a journalist before DND formally releases information about the incident, the news report must not contain any information about the incident or CF members involved.

35. Although the media organization is primarily responsible for obtaining medical care and repatriating an injured journalist, military airlift may be made available to evacuate or repatriate journalists injured or killed while embedded. Decisions about use of military airlift are made on a case-by-case basis, and the sole criterion is availability.

36. Embedded journalists greatly increase their risk of being kidnapped or taken hostage if they leave the task force. Journalists who choose to work in an operational area without a military escort must accept that they do so at their own risk, and that the CF is not responsible for their safety. Should a journalist be seized while under CF escort, the Head of Mission at the Embassy of Canada in the theatre of operations would take the lead in co-operating with the local authorities to obtain the journalist's safe release, and in all related communications and notifications.

\section{Reporting casualties: Injury, death and missing in action}

37. Following an incident involving the death and/or critical or serious injury of a CF member, media organizations represented by embedded journalists are placed under embargo to protect OPSEC and allow time for the CF to notify the casualties' next of kin. Such an embargo applies to any release of the subject information, including to local journalists and fixers.

Note: The embed status of any embedded journalist or media organization found to have released information provided by the $\mathrm{CF}$ under embargo will be immediately terminated.

38. The decision to lift an embargo will be made by Commander CEFCOM in consultation with the Task Force Commander. As much information as possible is made available as quickly as possible, within the constraints imposed by OPSEC and the requirement for time to notify next of kin.

39. While under embargo, media organizations are permitted to echo reports that are already in the public domain. These reports, however, will lack CF or Canadian confirmation of events and should clearly state that the embedded journalists under embargo did not generate the content of these reports. 
40. When a member of a deployed task force is killed, embedded journalists are invited to a media opportunity with the Task Force Commander. Shortly after this media opportunity, a news release is issued from NDHQ to Canadian national media.

41. When a critical incident involves mass casualties, the Task Force Commander may decide to identify the unit or group involved, and indicate the scale of the incident - for example, how many people have been killed and injured - before all the next of kin have been informed. This is done to counter enemy propaganda and to minimize the anxiety of families whose loved ones are not involved.

42. When a member of a deployed task force is wounded and the injuries are deemed by the medical staff to be either critical or serious (following the scale set out in The Canadian Press Stylebook), embedded journalists receive the details of the incident as quickly as possible within the constraints of OPSEC and following notification of the next of kin.

43. When medical staff assess the condition of an injured CF member as fair or good, embedded journalists may not be briefed. The Task Force Commander's decision in such a case is influenced by OPSEC considerations, the impact of operations, and the frequency of like occurrences.

44. Here is the medical condition assessment scale set out in The Canadian Press Stylebook and used in media briefings:

a. Critical: Death may be imminent. The pulse, breathing and other vital signs are abnormal and unstable and there are major complications.

b. Serious: The patient is acutely ill and the chance of recovery is uncertain. The pulse, breathing and other vital signs may be abnormal or unstable.

c. $\quad$ Fair: The pulse, breathing and other vital signs are near normal and the patient is conscious, but he or she is uncomfortable or may have minor complications. The outlook for recovery is favourable.

d. Good: The pulse, breathing and other vital signs are normal and stable. The patient is comfortable and conscious, and the outlook for recovery is good.

45. OPSEC, patient welfare, patient privacy, and family considerations are the concerns that govern coverage of sick and wounded CF members. Permission to interview or photograph patients, including those undergoing surgery, is granted under the following strict conditions:

a. with the informed consent of the patient, witnessed by the embedded journalist's escort;

Note: "Informed consent" means the patient understands that the journalist is taking pictures and asking questions for news reports, and his/her image and quotes may appear in a wide variety of news media. The attending physician must confirm that the patient is medically capable of giving informed consent. In all such cases, disclosure of information will conform to paragraphs $3 \mathrm{~b}, 7$ and 8 of the Privacy Act.

b. with the consent of both the attending physician and Task Force Commander; and

c. as a general rule, injured CF members will not be interviewed within 24 hours of the incident in which they were hurt. 
46. Media visits to medical facilities must be conducted in accordance with applicable regulations, standard operating procedures, operations orders and instructions by attending physicians. If the Task Force Commander authorizes embedded journalists to visit a medical facility for which s/he is responsible, CF or medical personnel must escort the embedded journalists at all times. Visits must not interfere with medical treatment.

47. When a member of the deployed task force - including Canadian civilians, embedded journalists and personnel from allied nations as well as CF members - is missing in action, information about the circumstances may be placed under embargo or otherwise withheld in anticipation of a rescue mission or to keep it from an adversary in case the missing person is trying to evade capture. Media organizations may echo reports that have already been released, but they must not report on any aspect of CF or Government of Canada response to the incident, or any other action taken in relation to the incident.

Note: Journalists and their media organizations should be aware that an adversary can derive significant value from news reports about individuals who are missing. If the person has been taken prisoner, news reports about him/her could provide personal information that an interrogator would find useful.

\section{Reporting on detainees}

48. Only the Chief of the Defence Staff may authorize media access to detainees, and strictly on a case-by-case basis.

\section{Reporting on Special Forces personnel}

49. Embedded journalists shall not report on or capture any kind of imagery of personnel or operations of Canadian Special Operations Forces Command (CANSOFCOM).

- $\quad$ Getting ready to go

\section{In-theatre training}

50. Upon arrival and before leaving a theatre of operations, journalists may be required to attend security and safety briefings. The Task Force Commander is responsible for the content of these briefings.

\section{Physical fitness}

51. Journalists considering embedding should be physically fit and prepared to withstand the conditions of the theatre of operations.

52. Before completing and submitting the embedding documents, journalists are required to consult a physician to ensure that they are fit to travel, able to withstand the climate of the area of operations, and strong enough to cope with the physical demands of living with and accompanying task force members on operations.

53. Before embedding, journalists must ensure that they complete all appropriate immunization procedures, including malaria chemoprophylaxis if required, and obtain all vaccination certificates required by Health Canada for travellers returning from a theatre of 
operations. Embedding journalists must bring their own medication, including allergy kits, and advise CEFCOM PA and the deployed Public Affairs staff of any special medical requirements.

\section{Administrative requirements}

54. Media registration and multinational operations. When a CF task force is deployed outside Canada, it is part of a multinational operation conducted by a military coalition, such as NATO, or an international organization, such as the U.N. In rare cases, a CF task force joins an ad hoc coalition force led by one of the combatant commands of the United States. A journalist embedded with a CF task force deployed overseas is, therefore, also integrated into a multinational mission, and must obtain permission to embed from the media liaison office of the combined headquarters that is directing it.

55. As part of their initial contact with CEFCOM PA, all journalists seeking to embed with a deployed CF task force will be given detailed instructions for requesting permission to embed from the relevant international mission. This permission is mandatory; journalists lacking the travel order, press pass or other credentials issued by the mission headquarters will not be allowed to embed with the CF task force that is part of that mission.

56. CEFCOM embedding documents. Before embedding, journalists must provide CEFCOM PA with the following documentation, completed according to the instructions, by fax to $613-945-2323$.

a. The following documents, located at pages 20 to 27 in Part 2: Ground Rules and Documentation (journalists must bring the original signed copies of these documents with them):

i. $\quad$ Media Embedding and Ground Rules Agreement

ii. Indemnity Agreement and Liability Waiver

iii. Engagement with the Minister of National Defence

iv. Personal Information Sheet for Embedding Journalists

v. Authority to Release Medical Information

b. a cover letter from the media organization supporting the embedding request;

c. materials for preparation of media identification before arrival in the theatre of operations:

i. a photocopy of a valid passport spread open at the signature page,

ii. a photocopy of a valid visa for the country being visited (if required), and

iii. a passport-style photo in digital format (200-300 Kb; send by e-mail);

d. a biography; and

e. $\quad$ story ideas to pursue while embedded.

57. All journalists applying to embed receive acknowledgement of their documentation from CEFCOM PA, which also provides confirmation of acceptance and follow-up to ensure the safe arrival of each embedding journalist. 
58. Personal travel documents: Passports, visas and insurance. Journalists must obtain their own passports, visas, and any additional life, medical and air medevac insurance they or their media organization consider appropriate. Journalists (or their media organizations) are responsible for the cost of any medical care they obtain from civilian facilities.

59. Equipment, luggage and travel arrangements. Media organizations are responsible for ensuring that their journalists arrive in a theatre of operations with appropriate personal protective equipment, including:

a. For everyone:

i. Kevlar helmet, and

ii. Level-IV body armour with ceramic plates.

b. For some missions, as required:

i. ballistic eyewear,

ii. long-sleeved shirt of natural material (e.g., cotton, linen, wool), and

iii. fire-retardant gloves.

60. Journalists must pack their personal equipment, clothing, boots, sleeping bag and hygiene items in an appropriate bag or rucksack, remembering that they will have to carry all their own gear. They should also bring insect repellent, sunscreen, a water bottle, a flashlight, eating utensils, and a plastic plate and cup. All clothing and equipment must be subdued in colour and appearance.

61. Journalists must bring their own communications equipment to a theatre of operations; a satellite cellular telephone with a good footprint, such as the Iridium and Thuraya systems, is recommended. If a journalist's equipment fails, the Task Force Commander may authorize the use of military communications equipment for filing or transmitting media products, depending on operational tempo and availability of CF equipment. No communications equipment used by journalists is specifically prohibited, although the Task Force Commander may impose temporary restrictions for security or operational reasons. Unless specifically authorized by the Task Force Commander or a designated representative, journalists must ask permission to use electronic devices in operational environments.

62. Journalists must travel to and from a theatre of operations by commercial means and stay in hotels and other commercial accommodations at their own expense. Journalists embedded with a deployed task force are not allowed to use their own vehicles.

63. The deployed task force provides journalists with transport only while covering task force operations, events and activities. Journalists who choose to leave the task force are responsible for their own transportation both to the main gate of the camp and outside the camp.

\section{Services offered by the CF}

64. Embedded journalists receive rations, workspace and basic accommodations from the CF, and may use the sports facilities, messes, retail outlets and postal services used by the task force members. Once journalists are forward-deployed - i.e., accompanying troops on operations outside the camp - they may find conditions more austere. The basic needs of forward-deployed journalists - security, food and water - are met to the greatest extent possible, but it should be 
understood that they will face limitations with respect to comfort, workspace and facilities for filing or transmitting stories.

\section{Final operational authority}

65. Commander CEFCOM is the final authority, through the chain of command, for support to embedded journalists, and may add instructions and/or rules to those set out in these documents.

- $\quad$ Feedback about embedding with the $\mathrm{CF}$

66. Media organizations and journalists are encouraged to provide feedback on the embedding program to CEFCOM PA. A generic feedback form is included in Part 4 of these instructions, Feedback Form. Please complete it and return it by fax to 613-945-2323. 
CANADIAN EXPEDITIONARY

FORCE COMMAND

101 Colonel By Drive

Ottawa, Ontario K1A 0K2

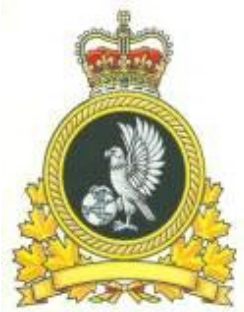

COMMANDEMENT DE LA FORCE

EXPÉDITIONNAIRE DU CANADA

101, promenade Colonel By

Ottawa (Ontario) K1A 0K2

2. Part 2: Ground Rules and Documentation

1. The Chief of the Defence Staff (CDS), through the Commander CEFCOM, is the source of the authority to embed journalists with CF formations, units and task forces. CEFCOM Public Affairs (PA) is responsible for managing and coordinating the embedding program with the journalist and his/her employing media organization. The commanders of deployed task forces are responsible for hosting embedded journalists in their area of responsibility.

2. The embedding journalist and a supervisor from his/her media organization must complete and sign the following documents:

a. Media Embedding and Ground Rules Agreement;

b. Indemnification Agreement and Liability Waiver;

c. Engagement with the Minister of National Defence;

d. Personal Information Sheet for Embedding Journalists; and

e. Authority to Release Medical Information.

3. The Authority to Release Medical Information form was developed for the rare situation in which an embedded journalist who has been injured cannot personally contact his/her next of kin. The journalist's signature on this form gives consent to the release of his/her medical information by a CF medical officer to the journalist's next of kin. Without this prior consent, the Privacy Act bars the disclosure of medical information even to the next of kin.

4. Before leaving for a theatre of operations, journalists must become familiar with the attached Ground Rules. It is also recommended that journalists carry a copy of these rules at all times while embedded with the CF. Journalists wondering how the Ground Rules apply to any particular situation should consult deployed Public Affairs Officers (PAOs) or CEFCOM PA.

5. The media organization employing an embedded journalist is responsible for ensuring that the documentation in this section is completed accurately. Please consult "Administrative Requirements" (beginning at paragraph 53 in Part I: General Instructions) to ensure that all requirements are met before the journalist travels to the theatre of operations.

- $\quad$ Ground Rules

6. The following Ground Rules are intended to encourage open reporting and transparency without breaching operations security (OPSEC) and privacy of individual $\mathrm{CF}$ members. The intent is to restrict the release of certain categories of information that could provide mission details useful to the enemy, thus putting military and civilian lives at risk. 
7. Violation of any of the Ground Rules may result in termination of embedding status and removal of the journalist from the deployed task force.

\section{Administrative Rules}

a. Discipline and dress

i. While they are embedded, journalists are subject to the Code of Service Discipline (National Defence Act) and all Task Force orders and policies (e.g. alcohol, substance abuse, fraternization and de-embedding or "walking out").

ii. Embedded journalists must wear their media passes in a clearly visible location at all times to ensure that their status is made known to CF and allied personnel.

iii. Clothing and equipment used by embedded journalists must be subdued in colour and appearance, and obviously not military.

iv. Embedded journalists will not carry any weapons.

b. Equipment

i. Embedded journalists are responsible for procuring and using protective personal equipment. Such equipment must include a military-grade helmet and body armour.

ii. Embedded journalists must carry and care for any personal and professional gear they take with them, including (but not limited to) protective cases for professional equipment, batteries, cables and converters.

iii. When operating with Canadian troops at night, embedded journalists will not use visible light sources or infra-red devices, including flash or television lights, unless the on-scene commander gives specific prior approval.

c. Movement

i. Embedded journalists will not enter restricted areas without an escort.

ii. When directed to do so, embedded journalists will remain with military escorts at all times and follow their instructions regarding activities and movement.

d. Datelines, interviews, and release caveats

i. All stories will be datelined according to local Ground Rules provided to all journalists upon their arrival in a theatre of operations. When journalists are with a unit outside the main camp, they will use a general geographical description (e.g. "northern area") as a dateline. No specific locations will be used when filing stories without prior approval from the on-scene commander and approval from the Senior PAO of the deployed task force. 
ii. All interviews with task force members are on the record. Security of information is the responsibility of the CF member being interviewed; however, the journalist must inform the CF member when he/she is in an interview situation.

iii. Interviews with $\mathrm{CF}$ members are authorized upon completion of missions; however, release of information must conform to these Ground Rules.

iv. When a briefer applies a restrictive release caveat (i.e., "not for attribution", "background" or "not for use") to the information he/she is providing, journalists must obey that caveat.

Note: For detailed information on release caveats, see paragraph 15 in Part 1, General Instructions.

e. Embargoed information

i. Information on future operations is under embargo until the operation is completed and release authority is received from both the commander in the field (the "battle-space" commander) and the Senior PAO of the deployed task force.

ii. When a critical incident has occurred, embedded journalists are placed under embargo to maintain OPSEC and/or protect $\mathrm{CF}$ members' privacy. Any violation of such an embargo, by either the embedded journalist or his/her media organization in Canada, constitutes grounds for termination of the embedding agreement.

iii. When a critical incident involves casualties, embedded journalists are placed under embargo to allow time for the $\mathrm{CF}$ to notify their primary and secondary next of kin. Journalists who receive any information about such a critical incident shall assume they are automatically under embargo, and will neither call their desks nor file a story until they have received formal permission to do so from a PAO.

iv. Journalists are placed under embargo when they are given information about impending visits by prominent individuals, both military and civilian. The embargo continues until the Task Force Commander lifts it.

v. Information indicating or confirming the location of important military and civilian visitors at the time of a critical incident is subject to embargo until the Task Force Commander authorizes release.

vi. Any other type of information may be subject to embargo by the Task Force Commander for OPSEC reasons or to protect the privacy of individuals. 


\section{f. Reporting casualties}

i. The names and images of fallen soldiers will not be released until the next of kin have given the CF explicit permission to do so.

ii. With respect to specific incidents, DND will not distribute information on, and journalists will not report on, non-fatal casualties (i.e., individuals who are injured, sick or missing).

iii. Journalists will not interview or photograph patients in health care facilities without the informed consent of the patient. This restriction applies to all patients, whatever their nationality. If applicable, the attending physician will confirm whether the patient is medically capable of giving informed consent.

iv. When reporting from outside of a CF camp, journalists will not reveal the identities (i.e., names, faces, nametags, labelled equipment, or any other thing that might serve to identify them) of sick or injured CF members without their prior written consent. If a CF member dies of wounds or illness, next-of-kin reporting rules apply.

Note: For a full explanation of the reasoning behind the rules on reporting casualties, see Part 1, paragraphs 37 to 46.

9. The following information is releasable:

\section{a. People}

i. Arrival of military units in theatre (after the official announcement), with special attention exercised when a unit is being relieved in place:

1) Mode of travel (sea or air),

2) dates of departure, and

3) home station.

ii. Approximate strength of friendly forces (rounded figures).

iii. Type of forces involved (e.g., air defence, infantry, armour), except for Canadian special operations forces and the forces of other nations.

\section{b. Operations}

i. Non-sensitive, unclassified information regarding air and ground operations, past and present.

ii. Size of friendly forces participating in an action or operation, in general terms such as "multi-unit." The specific name and description of forces or units may be released when authorized by the Task Force Commander or his/her designated representative.

iii. Generic origin information on air operations, such as "land-based." 
iv. Date, time, location and results of completed operations.

v. Number of air combat or reconnaissance sorties or missions flown.

\section{c. Equipment}

i. Types of ordnance expended (general terms only).

10. The following information shall not be visually recorded:

a. People

i. $\quad$ The identities (i.e., faces, name tags, labelled equipment, or any other thing that might serve to identify them) of:

1) casualties whose injuries can be visually identified (unless they have given prior written consent), and

2) detainees.

Note: All imagery of detainees will be reviewed by the CF to ensure respect for detainees' rights, and to protect detainees from "public curiosity" in accordance with Article 13 of the Third Geneva Convention. No photograph or other graphic representation of a detained person's recognizable face, nametag or any other feature or item that may serve to identify a detainee may be created.

ii. Unless specifically authorized by the Task Force Commander, the identities (i.e., faces, name tags, labelled equipment, or any other thing that might serve to identify them) of:

1) military and civilian close-protection personnel,

2) snipers,

3) aircrew,

4) members of the intelligence community,

5) Special Forces personnel,

6) counter-IED operators,

7) language and cultural advisors (e.g., interpreters), and

8) dog-handlers while operating.

iii. Unless specifically permitted by the individual, the identities of Canadian civilian police officers.

b. Equipment

i. Damage sustained by CF or allied vehicles and/or air assets as a result of attacks, including (but not limited to) IEDs and suicide bombers, unless specifically authorized by the Task Force Commander. 
ii. Interiors of Type A (front-line) vehicles, such as the RG-31, LAV III and the Coyote. Permission to capture imagery while inside any of these vehicles may be granted to journalists who allow a PAO to screen their imagery for operations security concerns before it is filed for publication.

iii. Classified systems and equipment, and demonstrations of their capabilities, unless specifically authorized by the Task Force Commander.

c. Infrastructure

i. Restricted military areas, facilities and installations, such as the Tactical Operations Centre (TOC).

ii. The flight line at any military airfield and military aircraft operating on or near it, even during ramp ceremonies. Journalists are briefed on the applicable local Ground Rules before each ramp ceremony. Journalists may ask PAOs for special permission to film aircraft on the flight line during a ramp ceremony, but even if permission is granted they will be accompanied at all times by an authorized media escort.

11. The following information shall not be released:

a. People

i. Specific information on troop strength (e.g., parade state).

ii. Unless specifically authorized by the Task Force Commander, information that would reveal the identities of:

1) military and civilian close-protection personnel,

2) snipers,

3) aircrew,

4) members of the intelligence community,

5) Special Forces personnel,

6) counter-IED operators,

7) language and cultural advisors (e.g., interpreters), and

8) dog-handlers while operating.

iii. Unless specifically authorized by the individual concerned, the identities of Canadian civilian police officers.

iv. Information about JTF 2 or Canadian Special Operations Regiment (CSOR) personnel.

Note: Embedded journalists will not interview, photograph, film or report on JTF 2 or CSOR personnel, or operations they conduct or participate in, without prior approval from a representative of 
Canadian Special Operations Forces Command (CANSOFCOM) and the Task Force Commander.

v. Information about friendly special operations forces.

vi. Details of visits by prominent individuals, until the Task Force Commander authorizes release; also, confirmation of the location of important visitors at the time of a significant incident.

vii. Information about detainees.

viii. Information about CF personnel who kill or injure adversaries, including name and military occupation, unless authorized by the Task Force Commander.

b. Operations

Note: Extra precaution in reporting is required at the start of an operation to maximize surprise; therefore, broadcasts by embedded journalists are prohibited until authorized by the unit commander.

i. Rules of Engagement.

ii. Details of current operations (unless otherwise indicated), future operations, postponed and cancelled operations.

iii. During an operation, specific information on friendly force troop movements, tactical deployments, and dispositions that would jeopardize the security of the operation. Information on engagements will not be released until authorized by the on-scene commander.

iv. Information about intelligence-collection activities including targets, methods of attack and results.

v. Information about force-protection measures, including (but not limited to) those at military installations or encampments, except those that are visible or readily apparent.

vi. Information on effectiveness of enemy camouflage, deception, targeting, direct and indirect fire (e.g., rocket attacks, even within the perimeter of a military camp), intelligence collection, security measures and electronic warfare measures.

\section{c. Equipment and aircraft}

i. The type of friendly forces' military vehicles and/or aircraft involved in attacks (including suicide bombings and IED explosions), crashes, and incidents such as mine strikes.

ii. Specific information on the availability of critical equipment and supplies (e.g., artillery, radars, trucks, water);

iii. Information on friendly forces' electronic warfare equipment and procedures. 
iv. The number and type of aircraft flown by any unit smaller than a Wing, except in very general terms (e.g., "large flight," "small flight," "many," "few," "fighters," "fixed wing").

v. The point of origin of any operational flight, other than "landbased" or "carrier-based".

vi. Information on missing or downed aircraft, and task force personnel who are missing or known to be captured, during planning and execution of search and rescue and recovery operations. "Task force personnel" includes Canadian civilians, embedded journalists and personnel from allied nations as well as CF members.

\section{d. Infrastructure and units}

i. Names of tactical infrastructure and specific geographic locations of military units in the area of operations, unless otherwise approved by the Task Force Commander.

ii. Information about security precautions at military installations or encampments, including imagery that shows security arrangements at military sites, especially aerial and satellite imagery that reveals the name and/or specific location of military units and/or installations.

\section{e. Other}

i. Any other information the Task Force Commander orders restricted for operational reasons.

\section{- Documentation}

12. The documents that follow must be completed as directed and submitted by fax or postal mail to CEFCOM PA. 


\section{Media Embedding and Ground Rules Agreement}

$\mathrm{I}$, the following statements are true.

(PRINT NAME), confirm that

1. I am not aware of any physical or health conditions that would adversely affect my participation in strenuous activities. (Initial)

Note: Medical certificate is enclosed.

2. I have read the General Instructions and Ground Rules for Embedding Journalists and agree, with my signature, to abide by them. I understand that any violation of these Instructions and Ground Rules is cause for termination of my embedding with a Canadian Forces deployed Task Force overseas. (Initial)

\begin{tabular}{|ll|}
\hline Signature of Journalist & Date \\
\hline & \\
\hline
\end{tabular}

Printed name, media affiliation, address and telephone number of Journalist

\begin{tabular}{|lll|}
\hline $\begin{array}{l}\text { Signature of Journalist's Supervisor } \\
\text { (Assignment Editor, News Director) }\end{array}$ & \\
\hline
\end{tabular}

Printed name of Journalist's Supervisor

\begin{tabular}{|lll|}
\hline Signature of Witness (CF Member) & & Date \\
\hline
\end{tabular}

Printed name, rank and unit of Witness 


\section{Indemnification Agreement and Liability Waiver}

$\mathrm{I}$, (PRINT NAME), on behalf of myself, my

heirs, my executors and administrators, in consideration of being permitted to embed with and be attached to a deployed Canadian Forces task force from on or about to on or about , 201_, at and the surrounding area.

a. Acknowledge and agree that covering combat and other military operations is inherently hazardous and may result in death, personal injury, whether physical or otherwise, or damage to property, and wishing in any event to participate in covering combat and other military operations, voluntarily consent to participate and assume any risks that may be associated with said participation;

b. Acknowledge, agree and declare that I have been advised of the nature of covering combat and other military operations, that I have been advised of the procedures and safety measures in effect, and that I agree to abide by them;

c. Acknowledge, agree and declare that I have been advised that the Canadian Forces, in pursuing the successful accomplishment of its mission, cannot guarantee my personal safety or the safety of my equipment;

d. Waive all claims of any nature or kind, including but not limited to claims for personal injury or damage to property, against Her Majesty the Queen in Right of Canada, Her officers, servants, agents, employees and members of Her Canadian Forces, in any manner arising from, based upon, occasioned by, attributable to or connected with my participation in covering combat and other military operations while an embedded journalist;

e. Agree that I will not commence or maintain against any person, any action or proceeding that will give rise to a claim against Her Majesty the Queen in Right of Canada, Her officers, servants, agents, employees and members of Her Canadian Forces for contribution or indemnity;

f. Acknowledge, agree and declare that my signing this agreement is a condition to being registered to cover Canadian Forces operations and receiving assistance for that coverage; and

g. Acknowledge having read this liability waiver in its entirety and, understanding that this Waiver is intended to be broad and all-inclusive so as to preclude any claims, I voluntarily indicate my acceptance of this document by my signature. 
DATED at , this day of , 20

\begin{tabular}{|ll|}
\hline Signature of Journalist & Date \\
\hline & \\
\hline
\end{tabular}

Printed name, media affiliation, business address, e-mail address and in-theatre telephone number of Journalist

Signature of Journalist's Supervisor

Date

(Assignment Editor, News Director)

Printed name of Journalist's Supervisor

Signature of Witness (CF Member)

Date

Printed name, rank, unit, e-mail address and telephone number of Witness
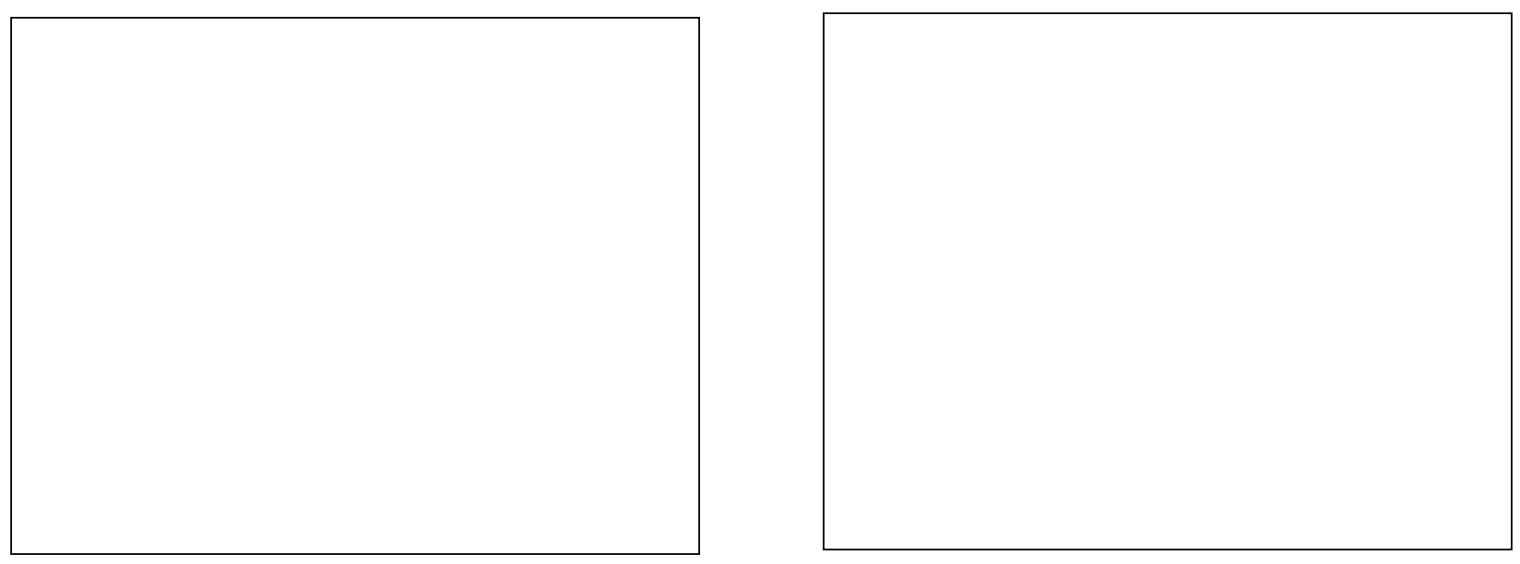


\section{Engagement with the Minister of National Defence}

Pursuant to Section 60(1) (j) of the National Defence Act

\section{TO THE MINISTER OF NATIONAL DEFENCE:}

1. It is hereby acknowledged by the undersigned that an arrangement has been entered into between Her Majesty the Queen in Right of Canada as represented by the Canadian Forces, the Assistant Deputy Minister (Public Affairs) and the Undersigned, for the embedding of the Undersigned into the deployed Canadian task force in

2. Within the context of Canadian deployed operations, the Undersigned hereby agrees to be subject to the Code of Service Discipline, as required under Part III of the National Defence Act, R.S. 1985, c.N-5. Further, the Undersigned hereby agrees to comply with all orders and instructions of the Task Force Commander or his/her designates.

\begin{tabular}{|c|c|}
\hline Signature of Journalist & Date \\
\hline \multicolumn{2}{|c|}{ Printed name, media affiliation, address and telephone number of Journalist } \\
\hline $\begin{array}{l}\text { Signature of Journalist's Supervisor } \\
\text { (Assignment Editor, News Director) }\end{array}$ & Date \\
\hline Printed name of Journalist's Supervisor & \\
\hline
\end{tabular}




\section{Personal Information Sheet for Embedding Journalists}

1. Full name (print):

2. Address:

3. Employer's Name:

4. Employer's Address:

Affix

Photo

Here

5. $\quad \overline{\text { Name(s) of Media organization(s) you will represent (if different from }}$ above):

6. Personal Emergency Notification (whom do you wish to be informed in the event of serious injury):

a. Primary Contact:

i. Name:

ii. Relationship to journalist:

iii. Address:

iv. Phone Numbers (Include area code):

1) Home:

2) Work:

3) Cell:

b. Secondary Contact:

i. Name:

ii. Relationship to journalist:

iii. Address:

iv. Phone Numbers (Include area code):

1) Home:

2) Work:

3) Cell:

7. Your media organization is responsible for emergency notification of your primary and secondary contacts. Who at your media organization should perform this function?

a. Name and Job Title: 
b. Address:

c. $\quad$ Phone Numbers (Include area code):

i. Home:

ii. Work:

iii. Cell:

8. Authority for release of personal information. Do you consent to have personal information released to the persons you have identified in paragraphs 5 and 6 above (circle the appropriate choice):

Yes

No

9. Personal Information:

a. Citizenship:

b. Passport:

i. Number:

ii. Date of expiry:

iii. Place of issue:

c. Date of Birth:

d. Height:

e. Hair colour:

f. Eye colour:

g. Blood type:

h. Cell number in Afghanistan:

i. E-mail in Afghanistan: 
10. I declare that the above statements are, to the best of my knowledge, correct.

Signature of Journalist

Date

Printed name, media affiliation, business address, e-mail and in-theatre telephone number of Journalist

\begin{tabular}{|lll|}
\hline Signature of Witness (CF member) & & Date \\
\hline
\end{tabular}

Printed rank, name, unit, e-mail address and telephone number of Witness 


\section{Authority to Release Medical Information}

In the event that I am unable to make personal contact with my employer (media organization) or next of kin to provide information on my medical condition, I, , give my consent for a medical officer to do so

on my behalf between , 20 _.while I am embedded with the Canadian Forces in

\begin{tabular}{|lll|}
\hline Signature of Journalist & Date \\
\hline
\end{tabular}

Printed name, media affiliation, business address, e-mail and in-theatre telephone number of Journalist

\begin{tabular}{|lll|}
\hline Signature of Witness (CF member) & Date \\
\hline
\end{tabular}

Printed rank, name, unit, e-mail address and telephone number of Witness 


\section{CANADIAN EXPEDITIONARY}

FORCE COMMAND

101 Colonel By Drive

Ottawa, Ontario K1A 0K2
COMMANDEMENT DE LA FORCE

EXPÉDITIONNAIRE DU CANADA

101, promenade Colonel By

Ottawa (Ontario) K1A 0K2

3. Part 3: Preparation Assistance and Frequently Asked Questions

- $\quad$ Checklists for embedded journalists

1. When a journalist agrees to embed with the Canadian Forces overseas, he or she must complete the following preparations:

\begin{tabular}{|c|c|c|}
\hline \multicolumn{3}{|c|}{ Compulsory preparations } \\
\hline & Requirement & $\boldsymbol{C}$ \\
\hline 1. & $\begin{array}{l}\text { Check passport, visa requirements and media identification are } \\
\text { current and valid for the duration of the embedding. }\end{array}$ & \\
\hline 2. & $\begin{array}{l}\text { Send a digital passport-type portrait photograph }(200-300 \mathrm{~Kb}) \text { to } \\
\text { CEFCOM Public Affairs, and hand-carry two passport-size } \\
\text { photographs for in-theatre media accreditation. }\end{array}$ & \\
\hline 3. & $\begin{array}{l}\text { Obtain medical examination and inoculations or other medical } \\
\text { requirements in accordance with Health Canada's standards and } \\
\text { recommendations. Check and/or obtain valid vaccination } \\
\text { certificates. More information is available at } \\
\text { http://www.travelhealth.gc.ca/ }\end{array}$ & \\
\hline 4. & Inform CEFCOM PA of contact telephone numbers. & \\
\hline 5. & $\begin{array}{l}\text { Ensure serviceability of any electronic equipment, such as portable } \\
\text { computer and communications equipment, and pack for field } \\
\text { conditions. Account for support equipment such as batteries, } \\
\text { power converters and cables. }\end{array}$ & \\
\hline 6. & If time allows, complete any necessary dental treatment. & \\
\hline 7. & $\begin{array}{l}\text { If time allows, do personal fitness training and, in particular, } \\
\text { accustom feet to wearing boots. }\end{array}$ & \\
\hline 8. & $\begin{array}{l}\text { Confirm arrangements for training, briefings, personal finance and } \\
\text { travel. }\end{array}$ & \\
\hline 9. & $\begin{array}{l}\text { Confirm that next of kin arrangements have been made and that } \\
\text { your employers (your media organization) understand that they } \\
\text { will be responsible for contacting your next of kin if necessary. }\end{array}$ & \\
\hline 10. & $\begin{array}{l}\text { Purchase or borrow personal protective equipment (PPE). This } \\
\text { includes a Kevlar helmet and body armour. }\end{array}$ & \\
\hline
\end{tabular}




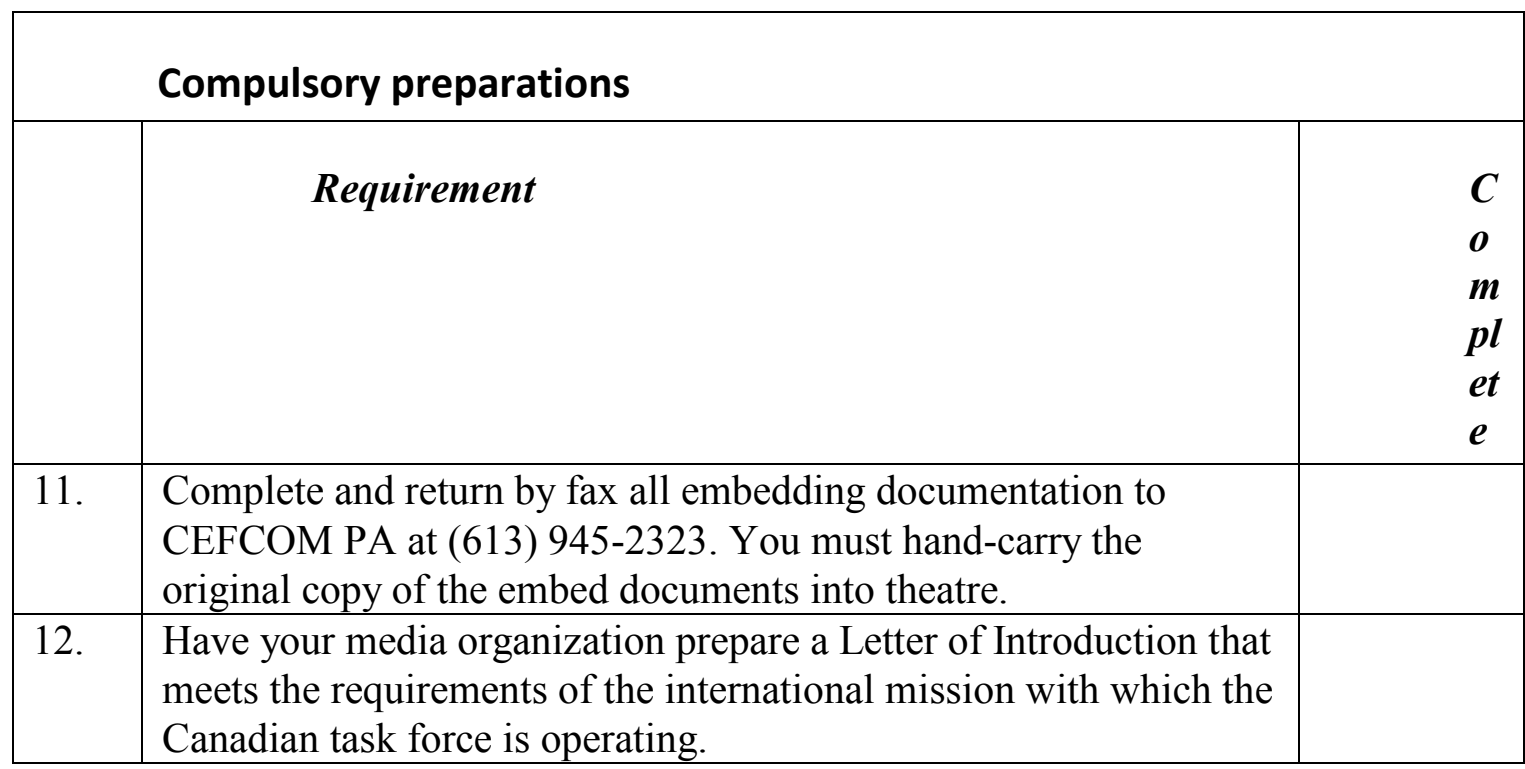

2. If you skip any of these preparations, you could be unable to travel. For example, you will not be allowed to embed if you arrive in a theatre of operations without vaccination certificates, proper credentials, or personal protective equipment. Information on the characteristics of protective equipment and where it can be purchased is available in the Journalist Safety Guide published by the Committee to Protect Journalists (see http://www.cpj.org/Briefings/2003/safety/journo_safe_guide.pdf).

3. Journalists must bring the following items to a theatre of operations.

\begin{tabular}{|c|c|c|}
\hline \multicolumn{3}{|c|}{ Don't leave home without ... } \\
\hline & Description & $\boldsymbol{P}$ \\
\hline 1. & $\begin{array}{l}\text { Body armour vest (see "Travel Arrangements" at paragraph } 4 \text { for } \\
\text { information about couriers) }\end{array}$ & \\
\hline 2. & $\begin{array}{l}\text { Helmet (see "Travel Arrangements" at paragraph } 4 \text { for information } \\
\text { about couriers) }\end{array}$ & \\
\hline 3. & Ballistic eyewear (or safety glasses with shatterproof lenses) & \\
\hline 4. & $\begin{array}{l}\text { Fire-retardant gloves (leather or Nomex; a thin leather work glove } \\
\text { will suffice) }\end{array}$ & \\
\hline 5. & $\begin{array}{l}\text { Long-sleeved shirt made of natural fibre that does not burn at low } \\
\text { temperature (cotton, linen, silk or wool; no nylon or polyester) for } \\
\text { wear while travelling in CF vehicles }\end{array}$ & \\
\hline 6. & Personal clothing & \\
\hline
\end{tabular}




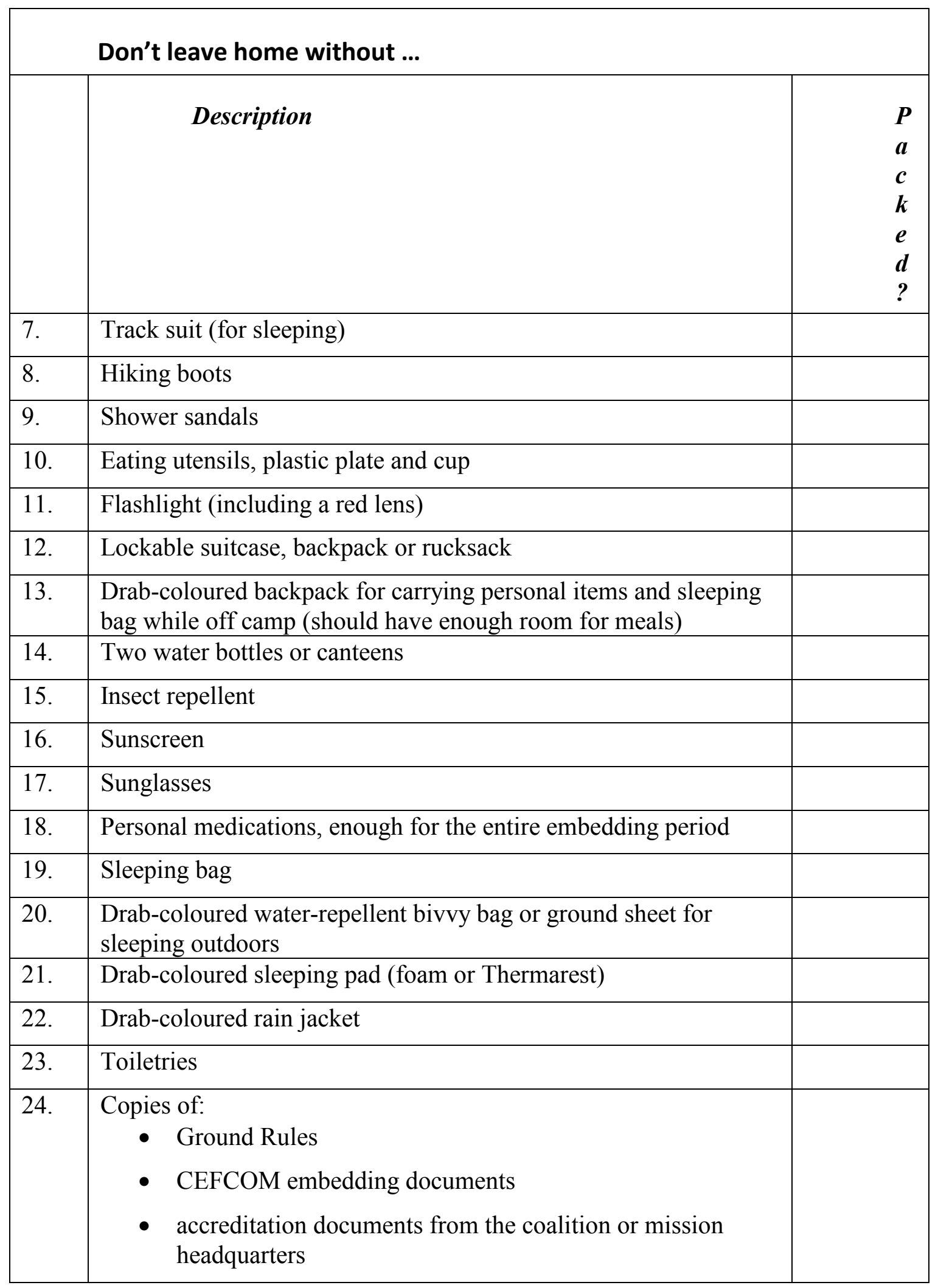


- Travel to theatre of operations and civilian accommodation

4. Journalists may choose to courier their personal protective equipment and technical equipment in advance of their embed to ease movement in and out of the airport, avoid airline charges for excess baggage weight, and prevent delays at customs or security screening. Although the CF does not endorse any particular courier company, several media organizations with embedding experience have reported good results with FedEx and DFL services.

5. Journalists are responsible for their own travel to and from any theatre of operations.

6. The CF reserves the right to deny, postpone or cancel any embedding request.

Such actions will be taken only when absolutely necessary; however, media organizations and journalists will not be reimbursed for expenses incurred in preparing to embed. Media organizations and journalists are encouraged to arrange refundable airline tickets and make any other arrangements pertinent to minimizing expenses in case the CF cancels or postpones the planned embedding period. Journalists required to extend their stay in civilian accommodations while waiting to embed will do so at their own expense.

- $\quad \underline{\text { Internet resources }}$

\section{On Afghanistan}

- Operation ATTENTION mission page: http://www.cefcomcomfec.forces.gc.ca/pa-ap/ops/attention/index-eng.asp

- Canada's Engagement in Afghanistan: http://www.afghanistan.gc.ca/canada-afghanistan/index.aspx?lang=en

- CF Media Embedding Program: http://www.cefcom.forces.gc.ca/site/home_e.asp

- Canadian Forces Image Gallery: http://www.combatcamera.forces.gc.ca/common/combatcamera/default.asp

- Afghanistan Compact: http://www.unama-afg.org/news/ londonConf/ docs/06jan30AfghanistanCompact-Final.pdf

- NATO/ISAF website: http://www.nato.int/isaf/index.html

- The Canadian Embassy in Kabul: http://www.afghanistan.gc.ca/canada-afghanistan/embassyambassade/index.aspx?menu id $=3 \& m e n u=L$

- DFAIT fact sheet on Afghanistan: http://geo.international.gc.ca/cip-pic/geo/Afghanistan-fs-en.aspx

- Army units: http://www.army.forces.gc.ca/lf/English/7_0.asp

- Army vehicles weapons and equipment: http://www.army.forces.gc.ca/lf/English/2_0.asp 


\section{On other Canadian Forces missions overseas}

- Backgrounders on current operations:

http://www.cefcom-comfec.forces.gc.ca/pa-ap/ops/index-eng.asp

\section{Media preparation}

- On Assignment: A Guide to Reporting in Dangerous Situations by the Committee to Protect Journalists: http://www.cpj.org/Briefings/2003/safety/journo_safe_guide.pdf

- Canadian Forces rank structure: http://www.forces.gc.ca/site/about/Insignia/index e.asp

- R. Nicholls Distributors, supplier of personal protective equipment: http://www.rnicholls.com/en/index.php

- DFS Middle East F.Z.E.: www.dfsmiddleeast.com

- Ariana Afghan Airlines: http://www.flyariana.com/

- United Nations Humanitarian Air Service: http://www.unama-afg.org/docs/_UN-Docs/_fact-sheets/August2006-FactSheetUNHAS.pdf

- Journalists' frequently asked questions

Q1. How much personal equipment should I bring?

A1. The checklist "Don't leave home without ..." (Part 3, paragraph 3 of this document) includes the items you must bring if you are to be comfortable and productive in Afghanistan. If you bring too much gear, you will only hinder yourself - remember: if you bring it, you must carry it. CEFCOM highly recommends consulting journalists who have been embedded with Canadian Forces previously; ask what worked for them.

Q2. What is Internet access like in a theatre of operations?

A2. Although you can get on the Internet at most camps, you should use it only for email, limiting yourself to comparatively small attachments (i.e., files that do not require much bandwidth to transmit). In the evenings, CF members use the Internet service to communicate with family and friends at home, which is one reason why the speed of connectivity is somewhere between high-speed and dialup. Connectivity at other camps is less reliable, and more like dial-up service. Small camps, such as team sites and forward operating bases, typically have only satellite communications equipment, so bring your own BGAN transmitter to ensure you can file stories when you accompany troops into the field.

Q3. Do you recommend renting local cell phones?

A3. Deployed PAOs find local rented cell phones quite reliable, and in some countries you can buy phones. In Afghanistan, however, you should have a satellite phone if you require reliable connectivity with Canada .

Q4. Can you recommend any suppliers of personal protective equipment?

A4. No, but the Committee for the Protection of Journalists does in Chapter 3 of $\mathrm{On}$ Assignment: A Guide to Reporting in Dangerous Situations. Download this 
publication at http://www.cpj.org/Briefings/2003/safety/journo_safe_guide.pdf. If you need more information, contact CEFCOM PA.

Q5. What kind of television programming is available to deployed task forces?

A5. Most deployed task forces can get the feed from the Canadian Forces Radio and Television Service (CFRTS), which broadcasts programming selected from all the networks in Canada.

Q6. What are the risks to journalists in a theatre of operations?

A6. The risk associated with reporting on the CF operations overseas depends on the location, the time of year, the level of military activity, and the amount of time the journalist wants to spend reporting from forward locations. Embedded journalists enjoy the protection offered by military equipment (especially armoured vehicles) and highly trained CF personnel, but their safety cannot be guaranteed as long as they are "outside the wire." Journalists and media organizations must be willing to accept this risk if they are to operate in any theatre of operations.

Q7. How much can journalists expect to interact directly with the troops?

A7. The amount of direct contact you have with troops will depend largely on whether you leave the main camp. There are opportunities to interview soldiers at main camps, but such contacts are normally arranged by the Task Force PAOs; at team sites and forward operating bases or on patrol, however, journalists live and work in close contact with the troops. Ideally, the CF prefers journalists to get maximum exposure to our men and women in uniform as they are the best sources of reliable information about what service overseas is really like. 
4. Part 4: Feedback Form

When you return from your embed period, please take a few moments to tell us about your experience. This information will help us develop the CFMEP to meet your requirements as well as those of the Canadian Forces.

\begin{tabular}{|l|l|}
\hline 1. & Was CEFCOM's pre-embedding preparation helpful? \\
\hline $2 . \quad$ Did you receive adequate support while you were embedded? \\
\hline 3. \\
\hline How do you suggest we improve the program? \\
\hline Please fax your completed form to 613-945-2323. \\
\hline Do you have any other comments? \\
\end{tabular}




\title{
APPENDIX K
}

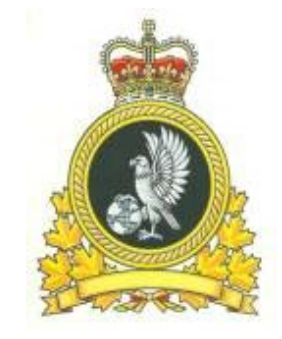

CANAdian EXPEDITIONARY FORCE COMMAND 101 Colonel By Drive Ottawa, Ontario K1A 0K2 COMMANDEMENT DE LA FORCE EXPÉDITIONNAIRE DU CANADA 101, promenade Colonel By Ottawa (Ontario) K1A 0K2

\section{Canadian Forces Media Embedding Program}

\section{Guidelines, Ground Rules and Documentation for Joint Task Force Afghanistan}

\author{
CANAdian Forces Media EMbedding Program Guidelines, Ground Rules AND \\ DOCUMENTATION FOR JTF-AFG
}




\section{Table of Contents}

PART 1: GENERAL INSTRUCTIONS....................................................................... 1

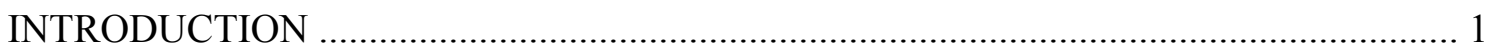

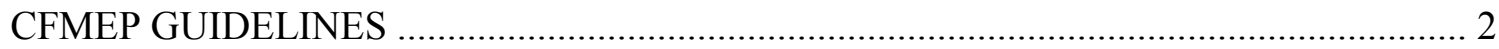

ABOUT THE CFMEP GROUND RULES................................................................ 4

JOURNALISTS' ACCESS TO OPERATIONS ……………………………………..... 5

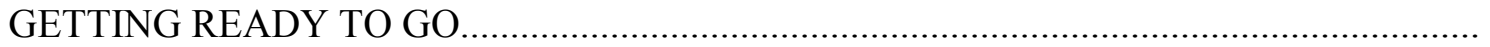

9

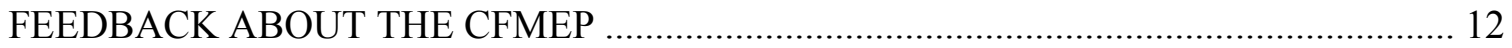

PART 2: GROUND RULES AND DOCUMENTATION................................................... 13

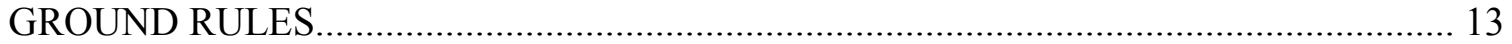

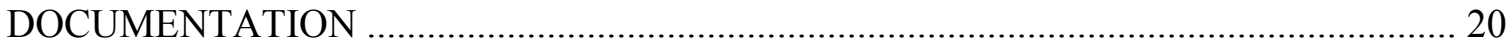

PART 3: PREPARATION ASSISTANCE AND FREQUENTLY ASKED QUESTIONS .30

CHECKLISTS FOR EMBEDDED JOURNALISTS............................................................. 30

TRAVEL TO KANDAHAR AND CIVILIAN ACCOMMODATION .................................. 32

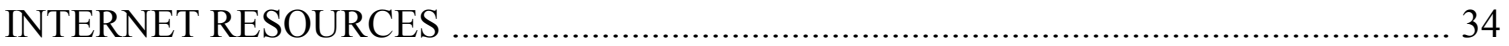

JOURNALISTS' FREQUENTLY ASKED QUESTIONS................................................. 35

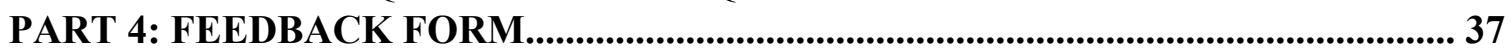

ii

CANADIAN EXPEDITIONARY FORCE COMMAND 101 Colonel By Drive Ottawa, Ontario K1A 0K2 COMMANDEMENT DE LA FORCE EXPÉDITIONNAIRE DU

CANADA 101, promenade Colonel By Ottawa (Ontario) K1A 0K2 Page 1 


\section{Part 1: General Instructions}

\section{I_n_t_r_o_d_u_c_t_i_o_n}

1. The objective of the Canadian Forces Media Embedding Program (CFMEP) is to inform Canadians about the role, mandate and activities of the Canadian Forces (CF) on deployed operations.

2. The aim of this document is to provide the necessary guidelines to journalists who intend to embed with Joint Task Force Afghanistan to cover Operation ACCIUS, Operation ARCHER and Operation ATHENA.

\section{Definitions}

3. The following definitions apply throughout this package of documents:

a. Accreditation: The formal acknowledgement by a media organization that it employs or has a contract with a journalist, intends to publish or broadcast the journalist's material, and assumes the responsibilities laid out in this document.

b. Embedding: The formal attachment of a journalist to the CF for an extended period.

c. Journalist: A person who is employed by or under contract to a media organization, and is seeking to embed with the CF to report on its activities. A journalist may be (but is not limited to) a reporter, a photographer, an equipment operator, a producer, or a technician.

d. Media organization: A business that employs journalists to produce news reports and features for broadcast and/or publication through media outlets (e.g., newspapers, radio stations, television stations, Internet sites).

e. CEFCOM: Canadian Forces Expeditionary Force Command (CEFCOM) is responsible for the planning and conduct of all $\mathrm{CF}$ operations outside North America except for those conducted by Canadian Special Operations Forces Command (CANSOFCOM).

f. Task Force Senior Public Affairs Officer: The senior member of the Public Affairs staff in Joint Task Force Afghanistan (JTF-Afg), usually a major.

g. Government of Canada institutions: This phrase refers to organizations such as the Department of Foreign Affairs and International Trade (DFAIT), Canadian International Development Agency (CIDA), the Royal Canadian Mounted Police (RCMP), and Correctional Services Canada (CSC).

h. Casualty: In the military context, a "casualty" is a person who has died, or who is injured, sick, or missing. 


\section{Acceptance and Priority}

4. To be accepted for the CFMEP, journalists must be accredited and in possession of documents identifying them as journalists.

5. Applications to the CFMEP are accepted in the following order:

Priority 1: Journalists representing national Canadian media organizations, at the rate of one radio or print journalist or one two-person television team from each major media organization.

Priority 2: Journalists representing regional Canadian media organizations.

Priority 3: Journalists representing international media organizations.

\section{Embedding Authority}

6. The Chief of the Defence Staff delegates the authority to embed journalists with deployed $\mathrm{CF}$ task forces to the Commander CEFCOM. The Public Affairs section at CEFCOM Headquarters (CEFCOM PA) manages and coordinates the CFMEP, handling the relationship between journalists and their media organizations and the Task Force Commander, who conducts the CFMEP in theatre.

\section{C_F_M_E_P__G_u_i_d_e_l_i_n_e_s}

7. Here are the general guidelines for the conduct of the CFMEP in Joint Task Force Afghanistan (JTF-Afg):

a. JTF-Afg can accommodate up to 16 journalists; however, operational conditions could require a reduction in the number of embedded journalists at any time.

b. Journalists are embedded for a fixed period of time agreed to in advance before entering JTF-Afg.

c. Participation in the CFMEP is based on the understanding that journalists will primarily cover $\mathrm{CF}$ and Government of Canada activities, and will deploy into the field when viable opportunities are made available.

d. As a general rule, JTF-Afg will support only one international embed request at a time.

e. Handovers that require out-going and in-coming journalists from the same media organization to be in theatre at the same time are granted on an exceptional basis only, and requests must be submitted to CEFCOM PA well in advance to determine feasibility.

f. Journalists who wish to extend their embedding must submit a request to CEFCOM PA at least 10 days before the scheduled departure date. This request may be submitted through either their media organization or the Senior Public Affairs Officer at JTF-Afg Headquarters. CEFCOM PA is the authority that grants or denies extensions. Journalists and media organizations must not consider 
themselves entitled to extensions.

g. Embedded television crews may operate in a media pool or independently. When operating independently, each television crew will comprise only two people: one reporter and one videographer. This limit is strictly enforced to permit all the major Canadian television networks to have teams in theatre at the same time.

\section{General conduct in theatre}

a. Journalists and their media organizations must respect the privacy of CF personnel, in particular their right to relax away from cameras and questions.

b. An embedded journalist is his or her media organization's primary news source and point of contact in JTF-Afg. A media organization with a journalist embedded in Kandahar should request interviews with JTF-Afg personnel through their embedded journalist, not the Media Liaison Office in Ottawa. Journalists should, therefore, deploy with reliable communications equipment, such as a satellite telephone, so they can maintain direct two-way communication with their employer at all times.

c. Media organizations should be mindful of the phenomenon of "journalists interviewing journalists". Although a journalist embedded with JTF-Afg will learn a great deal about Canada's mission in Afghanistan, a few weeks in theatre does not make anyone a subject matter expert. Embedded journalists should interview the Task Force Commander, designated spokespersons or appropriate $\mathrm{CF}$ subject matter experts to ensure that $\mathrm{CF}$ operations are reported accurately and without speculation.

d. Embedding with JTF-Afg does not give a journalist access to the forces of other nations operating in Afghanistan. Before interviewing foreign military personnel, even if they are based at Kandahar Airfield, an embedded journalist must ask the Task Force Senior PAO to obtain permission from the potential interviewee's chain of command.

\section{Embedding Agreement}

9. Before embedding, journalists and their sponsoring media organizations must complete and sign the documents found in Part 2: Ground Rules and Documentation. By submitting the embedding documents with their signature, journalists and media organizations certify that:

a. they have read all the rules and guidelines contained therein, and

b. they understand that failure to comply with the Ground Rules and the embedding guidelines could result in the termination of their embedding agreement and their immediate removal from JTF-Afg.

\section{Subject to Code of Service Discipline}


10. As long as they are embedded with a deployed CF task force, journalists are subject to the Code of Service Discipline (Part III of the National Defence Act). This arrangement is one of the terms set out in the document entitled "Engagement with the Minister of National Defence" (page 24), which journalists must sign indicating acceptance before embedding. Consequently, embedded journalists can be charged for violations of the Code of Service Discipline. 


\section{Release of Information}

11. Embedded journalists will be frequently reminded of the need for operations security (OPSEC) and technical accuracy. The Task Force Commander retains the right to review and require changes in media products containing potentially sensitive information, but only to the extent necessary to ensure that OPSEC is neither violated nor breached. A subject matter expert may revise technical information, but changes will be factual and not editorial. Content will not otherwise be restricted. Media products and equipment will not be confiscated or impounded.

12. The goal of OPSEC is to prevent the adversary from obtaining information that is essential to our mission. This objective allows for the safeguarding of some information that has an operational impact on our mission, while permitting Canadians to know as much as possible about their soldiers, sailors, air personnel, and the civilian members of the deployed "whole of government" team.

13. Journalists shall be aware that failure to obey directions regarding the release of information concerning force protection might result in the termination of their embedding and removal from the deployed task force.

14. Should personal information be disclosed inadvertently during a media briefing, and journalists are told that releasing that information would result in a violation of the Privacy Act, the Crown may choose to take legal action against a journalist who then includes the sensitive information in a media product, thus exposing the Crown to liability.

15. When a deployed PAO or a military spokesperson presents a formal briefing, conditions may be applied to the information provided. These conditions are stated in advance, using the following release caveats:

Attributable: Journalists are free to quote the spokesperson fully, using the information with direct attibution - identifying the source by name - or indirect attribution, in which the name of the source is not given and he/she is identified institutionally; e.g., as "a DND official" or "a CF spokesperson."

Not for attribution: The information may be used, but without attribution to a named source.

Background: The information is provided only to help journalists understand the situation; the briefer will state whether the information may be published. If published, the information may not be attributed in any way.

Not for use: The information may not be published and is provided only to help journalists understand the situation.

Note: CF members and Defence civilians do not speak "off the record."

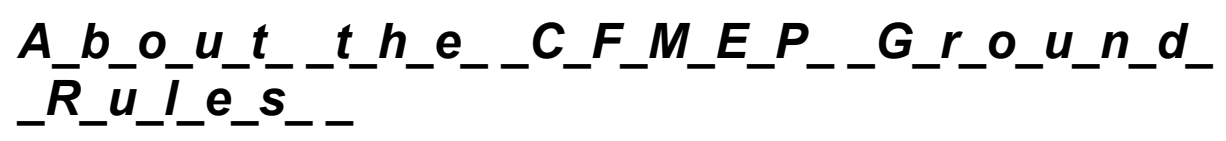


16. Commander CEFCOM developed the current CFMEP Ground Rules for embedded journalists in consultation with the Commander, Joint Task Force Afghanistan (JTF-Afg) in Kandahar and the Assistant Deputy Minister (Public Affairs) at National Defence Headquarters (NDHQ) in Ottawa. The aim of the CFMEP Ground Rules is to safeguard sensitive information (that is, both classified national security information and designated personal information) as required by Canadian legislation and Canadian Forces orders. The Ground Rules acknowledge the right of journalists to unclassified and undesignated information and are not intended to prevent the release of information that could be construed as derogatory, embarrassing, negative or uncomplimentary.

17. To be accepted for the CFMEP, journalists and their media organizations must formally agree to obey the Ground Rules; consequently, journalists should read them thoroughly and ensure that they understand them. The CFMEP Ground Rules are set out in Part 2: Ground Rules and Documentation. Journalists are encouraged to carry a copy of the Ground Rules with them at all times while they are embedded.

18. Clear violations of the CFMEP Ground Rules will result in termination of the journalist's embedding and his/her removal from JTF-Afg.

19. Release of information, imagery or video gathered while embedded with the CF must comply with the CFMEP Ground Rules at all times, both during embedding and after departure from the CFMEP.

\section{Resolving Disputes}

20. Disputes about the CFMEP Ground Rules or General Instructions and their application should be resolved at the lowest level as soon as possible. Disputes that cannot be resolved locally are forwarded through the chain of command to CEFCOM PA (representing Commander CEFCOM) for resolution in consultation with the affected media organization and, if necessary, the Assistant Deputy Minister (Public Affairs).

21. Sub-unit commanders (e.g., company and squadron commanders) may temporarily restrict a journalist's access to operations until a dispute is resolved; however, they must not assume that a dispute will lead to termination of the journalist's embedding.

\section{Terminating Embedding}

22. An embedding agreement can be terminated at any time by Commander CEFCOM, the embedded journalist, or the journalist's media organization. When Commander CEFCOM takes the initiative to terminate, the action will be based on a recommendation by the Task Force Commander. CEFCOM PA will make every effort to resolve the situation with an embedded journalist's media organization before terminating embedded status. If a journalist or media organization demonstrates a history of terminating embed status either voluntarily or involuntarily, CEFCOM PA may refuse further embedding requests from that journalist or media organization.

23. Commander CEFCOM reserves the right to deny, postpone or cancel any request to embed, and accepts no liability for expenses incurred by journalists or media organizations in preparation for an embedding that does not proceed on schedule, including (but not limited

to) the cost of airline tickets, immunization, and travel documentation such as passports and 
visas.

24. Clear violations of the CFMEP Ground Rules will result in termination of the journalist's embedding and his/her removal from Joint Task Force Afghanistan.

\section{J_o_u_r_n_a_l_i_s_t_s_o_A_c_c_e_s_s_- t_o_ _o_p_e_r_a_t_i_o_n_s_-}

25. Journalists will be given access to operational missions, including mission preparations and debriefings, whenever possible, as determined by the Task Force Commander.

26. Journalists' access to patients in CF medical facilities is governed by the instructions of attending physicians as well as all applicable regulations, standard operating procedures, and operations orders. If the Commanding Officer of the facility and Task Force Commander authorize embedded journalists to visit a medical facility, a Public Affairs Officer or medical personnel must escort the journalists at all times. Visits by journalists must not interfere with medical treatment.

\section{Reporting Non-CF Stories}

27. Journalists apply to the CFMEP on the understanding that they will primarily cover CF and Government of Canada activities.

28. Embedded journalists who decide to leave the task force to report a non-CF story must convey their intentions to both their media organization and the Senior PAO at JTF-Afg Headquarters, who then informs CEFCOM PA. This measure is required to ensure the CF has a general awareness of their whereabouts for security purposes.

29. Embedded journalists must comply with the CFMEP Ground Rules even when they have left the task force to report a non-CF story.

\section{Protection of Journalists and Media Equipment}

30. Embedded journalists are entitled to protection of their person and their equipment to the limit allowed by the Rules of Engagement governing JTF-Afg. Journalist must acknowledge and accept that JTF-Afg cannot guarantee their personal safety or the safety of media equipment in Afghanistan.

31. Journalists who leave the protection of JTF-Afg to meet "fixers" and report non-CF stories do so at their own risk. The $\mathrm{CF}$ is not responsible for rendering any assistance to journalists in these situations.

\section{Hazards to Embedded Journalists: Injury, Death and Kidnapping}

32. Embedded journalists and the media organizations they represent are each responsible for ensuring that they have adequate indemnity and insurance coverage. Any journalist who is 
injured while embedded with JTF-Afg will receive emergency medical care to the extent available to the task force and in accordance with $\mathrm{CF}$ regulations.

Note: A journalist who has been contaminated with a radiological, biological or chemical agent may not be repatriated until the situation is resolved.

33. The employing media organization is responsible for repatriating a journalist who is killed or injured while embedded, and for providing injured journalists with any medical care they require beyond that offered by JTF-Afg. (Media organizations with freelance journalists under contract must pay particular attention to these obligations.)

34. Here is the procedure the CF will follow should an embedded journalist be killed or injured:

a. The unit with which the journalist was embedded immediately reports the incident and the journalist's condition to the chain of command, which then informs CEFCOM PA.

b. CEFCOM PA contacts the affected media organization, which is responsible for notifying the journalist's next of kin.

c. When the journalist's next of kin have been notified, the media organization informs CEFCOM PA, which - if required - coordinates the release of information in accordance with the procedure for notifying the next of kin of military casualties.

Note: If the media organization decides to announce the injury or death of a journalist before DND formally releases information about the incident, the news report must not contain any information about the incident or CF members involved.

35. Although the media organization is primarily responsible for obtaining medical care and repatriating an injured journalist, military airlift may be made available to evacuate or repatriate journalists injured or killed while embedded with JTF-Afg. Decisions about use of military airlift are made on a case-by-case basis and the sole criterion is availability.

36. Embedded journalists greatly increase their risk of being kidnapped or taken hostage if they leave the task force. Journalists who choose to work in an operational area without a military escort must accept that they do so at their own risk, and that the CF is not responsible for their safety. Should a journalist be seized while under CF escort, the Head of Mission at the Embassy of Canada in Kabul would take the lead in co-operating with the Government of Afghanistan to obtain the journalist's safe release, and in all related communications and notifications.

\section{Reporting Casualties: Injuries, Deaths and Missing in Action}

37. Following an incident involving a CF death and/or critical or serious injury, media organizations represented by embedded journalists are placed under embargo to protect OPSEC and allow time for the CF to notify the casualties' next of kin. Such an embargo applies to any release of the subject information, including to Afghan journalists and local fixers.

Note: Embed status will be immediately terminated for any embedded journalist or media organization that releases information provided by the $\mathrm{CF}$ under embargo. 
The decision to lift an embargo will be made by Commander CEFCOM in consultation with the Task Force Commander. As much information as possible is made available as quickly as possible, within the constraints imposed by OPSEC and the requirement for time to notify next of kin.

38. While under embargo, media organizations are permitted to echo reports that are already in the public domain. These reports, however, will lack CF or Canadian confirmation of events and should clearly state that the embedded journalists under embargo did not generate the content of these reports.

39. When a member of JTF-Afg is killed, embedded journalists are invited to a media opportunity with the Task Force Commander. Shortly after this media opportunity, a news release is issued from NDHQ to Canadian national media.

40. When a critical incident involves mass casualties, the Task Force Commander may decide to identify the unit or group involved, and indicate the scale of the incident - for example, how many people have been killed and injured - before all the next of kin have been informed. This is done to counter enemy propaganda and to minimize the anxiety of families whose loved ones are not involved.

41. When a member of JTF-Afg is wounded in action and the injuries are deemed by the medical staff to be either critical or serious (following the scale set out in The Canadian Press Stylebook), embedded journalists receive the details of the incident as quickly as possible within the constraints of OPSEC and following notification of the next of kin.

42. When medical staff assess the condition of an injured CF member as fair or good, embedded journalists may not be briefed. The Task Force Commander's decision in such a case is influenced by the impact of operations, operations security, and the frequency of these occurrences.

43. Here is the medical condition assessment scale set out in The Canadian Press Stylebook and used in media briefings:

Critical: Death may be imminent. The pulse, breathing and other vital signs are abnormal and unstable and there are major complications.

Serious: The patient is acutely ill and the chance of recovery is uncertain. The pulse, breathing and other vital signs may be abnormal or unstable.

Fair: The pulse, breathing and other vital signs are near normal and the patient is conscious, but he or she is uncomfortable or may have minor complications. The outlook for recovery is favourable.

Good: The pulse, breathing and other vital signs are normal and stable. The patient is comfortable and conscious, and the outlook for recovery is good.

44. OPSEC, patient welfare, patient privacy, and family considerations are the concerns that govern coverage of sick and wounded CF members. Permission to interview or photograph patients, including those undergoing surgery, is granted under the following strict conditions:

a. with the informed consent of the patient, witnessed by the embedded journalist's escort; 
Note: "Informed consent" means the patient understands that the journalist is taking pictures and asking questions for news reports, and his/her image and quotes may appear in a wide variety of news media. The attending physician must confirm that the patient is medically capable of giving informed consent. In all such cases, disclosure of information will conform to paragraphs 3b, 7 and 8 of the Privacy Act.

b. with the consent of both the attending physician and Task Force Commander; and

c. as a general rule, injured CF members will not be interviewed until at least 24 hours after the relevant incident.

45. Media visits to medical facilities will be in accordance with applicable regulations, standard operating procedures, operations orders and instructions by attending physicians. If the Task Force Commander authorizes embedded journalists to visit a JTF-Afg medical facility, CF or medical personnel must escort the embedded journalists at all times. Visits must not interfere with medical treatment.

46. When a member of JTF-Afg — including Canadian civilians, embedded journalists and personnel from allied nations as well as CF members - is missing in action, information about the circumstances may be placed under embargo or otherwise withheld in anticipation of a rescue mission or to keep it from an adversary in the event the missing person is trying to evade capture. Media organizations may echo reports that have already been released, but they must not report on any aspect of CF or Government of Canada response to the incident, or any other action taken in relation to the incident.

Note: Journalists and their media organizations should be aware that an adversary can derive significant value from news reports about individuals who are missing. If the person has been taken prisoner, news reports about him/her could provide personal information that an interrogator would find useful.

\section{Reporting on Detainees}

47. Media access to detainees shall be authorized only by the Chief of the Defence Staff, and strictly on a case-by-case basis.

\section{Reporting on Special Forces Personnel}

48. Embedded journalists shall not report on or capture any kind of imagery of Canadian Special Operations Forces Command (CANSOFCOM) personnel or operations.

\section{G_e_t_t_i_n_g_- $R$ _e_a_d_y _-t_o__G_o_-}

\section{In-Theatre Training}

49. Upon arrival in Afghanistan, and before leaving Kandahar Airfield, journalists are required to attend security and safety briefings, which are provided as frequently as possible to incoming embeds. The content of these briefings is at the discretion of the Task Force 
Commander.

\section{Physical Fitness}

50. Journalists considering embedding should be physically fit and prepared to withstand the conditions of southern Afghanistan.

51. Before completing and submitting the embedding documents, journalists are required to consult a physician to ensure that they are fit to travel, able to withstand the Afghan climate, and strong enough to cope with the physical demands of living with and accompanying soldiers on operations. When they embed, journalists must bring their own medication, including allergy kits, and advise CEFCOM PA and the JTF-Afg Public Affairs staff of any special medical requirements.

52. Before embedding, journalists must ensure that they complete all appropriate immunization procedures, including malaria chemoprophylaxis if required, and obtain all vaccination certificates required by Health Canada for travellers returning from Afghanistan.

\section{Administrative Requirements}

\section{Personal travel documents: Passports, visas and insurance}

53. Journalists must obtain their own passports, visas, and any additional life, medical and air medevac insurance they or their media organization consider appropriate. Journalists (or their media organizations) are responsible for the cost of any medical care they obtain from civilian facilities. 


\section{ISAF media registration}

54. When they apply to the CFMEP, journalists must also apply for permission to embed to ISAF Joint Command Headquarters in Kabul and the Media Support Centre at ISAF Regional Command (South) Headquarters at Kandahar Airfield.

a. Go to the Media Visit Information page on the ISAF website at www.isaf.nato.int/en/media-accreditation.html.

b. Carry out the instructions for:

i. acquiring an ISAF Embed Request; and

ii. acquiring an ISAF Credential.

c. When the forms are completed and supporting documentation is assembled, submit them by e-mail to:

i. the IJC Media Embed Office in Kabul, at IJC.EMBEDS@afghan.swa.army.mil; and

ii. the Media Support Centre at ISAF Regional Command (South), at

KDHRKAFMSCFutureOps@afghan.swa.army.mil

55. When ISAF has accepted a journalist's application, the journalist receives an ISAF

Notice of Approval and Invitational Travel Order.

\section{CEFCOM embedding documents}

56. Before embedding, journalists must provide CEFCOM PA with the following documentation, completed according to the instructions, by fax to 613-943-5471.

a. The following documents, located at page 21 to 29 in Part 2: Ground Rules and Documentation (the journalist must bring the original signed copies of these documents to Kandahar Airfield):

i. Media Embedding and Ground Rules Agreement

ii. Indemnity Agreement and Liability Waiver

iii. Engagement with the Minister of National Defence

iv. Kandahar Airfield Policy Statement

v. Personal Information Sheet for Embedding Journalists

vi. Authority to Release Medical Information

b. a cover letter from the media organization supporting the embedding request;

c. materials for preparation of media identification before arrival in Kandahar:

i. a photocopy of a valid passport spread open at the signature page,

ii. a photocopy of a valid visa for Afghanistan, and

iii. a passport-style photo in digital format (200-300 Kb; send by e-mail);

d. a biography; and

e. story ideas to pursue while embedded. 
57. All journalists applying to the CFMEP receive acknowledgement of their documentation from CEFCOM PA, which also provides confirmation of acceptance and follow-up to ensure the safe arrival of each embedding journalist.

\section{Equipment, luggage and travel arrangements}

58. Media organizations are responsible for ensuring that their journalists arrive in Afghanistan with appropriate personal protection equipment, including:

a. For everyone:

i. Kevlar helmet, and

ii. Level-IV body armour with ceramic plates.

b. For all persons travelling in military transport outside Kandahar Airfield, the following equipment is also MANDATORY in addition to helmet and body armour:

i. ballistic eyewear,

ii. long-sleeved shirt of natural material (e.g., cotton, linen, wool), and

iii. fire-retardant gloves.

59. Journalists must pack their personal equipment, clothing, boots, sleeping bag and hygiene items in an appropriate bag or rucksack, remembering that they will have to carry all their own gear. They should also bring insect repellent, sunscreen, a water bottle, a flashlight, eating utensils, and a plastic plate and cup. All clothing and equipment must be subdued in colour and appearance.

60. Journalists must bring their own communications equipment to Afghanistan; a satellite cellular telephone with a good footprint, such as the Iridium and Thuraya systems, is recommended. If a journalist's equipment fails, the Task Force Commander may authorize the use of military communications equipment for filing or transmitting media products, depending on operational tempo and availability of CF equipment. No communications equipment used by journalists will be specifically prohibited, although the Task Force Commander may impose temporary restrictions for security or operational reasons. Unless specifically authorized by the Task Force Commander or a designated representative, journalists must ask permission to use electronic devices in operational environments.

61. Journalists must travel to and from Kandahar by commercial means and stay in hotels and other commercial accommodations at their own expense. Journalists embedded with JTF-Afg are not allowed to use their own vehicles.

62. JTF-Afg provides journalists with transport only while covering JTF-Afg operations, events and activities. Journalists who choose to leave the Joint Task Force are responsible for their own transportation both to the main gate of the camp and outside the camp.

\section{Services Offered by the CF}


63. Embedded journalists receive rations, workspace and basic accommodations from the $\mathrm{CF}$, and may use the sports facilities, messes, CANEX outlets and postal services at Kandahar Airfield. Once journalists are forward-deployed - i.e., with troops on operations "outside the wire" - they may find conditions more austere than those at Kandahar Airfield, Camp Nathan Smith, or even the Forward Operating Bases and Patrol Bases. The basic needs of forward-deployed journalists - security, food and water - are met to the greatest extent possible, but it should be understood that they will face limitations with respect to comfort, workspace and facilities for filing or transmitting stories.

\section{Final Operational Authority}

64. Commander CEFCOM is the final authority, through the chain of command, for support to embedded journalists, and may add instructions and/or rules to those set out in these documents.

\section{F_e_e_d_b_a_c_k__A_b_o_u_t_-t_h_e_-C_F_M_E_P - -}

65. Media organizations and journalists are encouraged to provide feedback on the embedding program to CEFCOM PA. A generic feedback form is included in Part 4 of these instructions, Feedback Form. Please complete it and return it by fax to 613-943-5471. 


\section{Part 2: Ground Rules and Documentation}

1. The Chief of the Defence Staff (CDS), through Commander CEFCOM, is the authority to embed journalists with CF formations, units and task forces. CEFCOM Public Affairs (PA) is responsible for managing and coordinating the embedding program with the journalist and his/her employing media organization. The Commander of Joint Task Force Afghanistan (JTF-Afg) is responsible for the conduct of the media embedding program in theatre.

2. The journalist and a supervisor from his/her media organization must complete and sign the following documents:
a. Media Embedding and Ground Rules Agreement;
b. Indemnification Agreement and Liability Waiver;
c. Engagement with the Minister of National Defence;
d. Kandahar Airfield Policy Statement;
e. Personal Information Sheet for Embedding Journalists; and
f. Authority to Release Medical Information.

3. The Authority to Release Medical Information form was developed in case an embedded journalist who has been injured cannot personally contact his/her next of kin. The journalist's signature on this form gives consent to the release of his/her medical information by a CF medical officer to the journalist's next of kin. Without this prior consent, the Privacy Act bars the disclosure of medical information even to the next of kin.

4. Before leaving for Kandahar, journalists must become familiar with the attached Ground Rules. It is also recommended that journalists carry a copy of these rules at all times while embedded with Canadian troops. Journalists wondering how the Ground Rules apply to any particular situation should consult deployed Public Affairs Officers (PAOs) or CEFCOM PA.

5. The media organization employing an embedded journalist is responsible for ensuring that the documentation in this section is accurately completed. Please consult "Administrative Requirements" at paragraph 50 in Part I: General Instructions to ensure that all requirements are met before the journalist travels to Kandahar.

\section{G_r_o_u_n_d__R_u_I_e_s_-}

6. The following Ground Rules are intended to encourage open reporting and transparency, while balancing the needs of operations security (OPSEC) and privacy of individual CF members. The intent is to restrict the release of certain categories of information that could provide mission details useful to the enemy, thus putting military and civilian lives at risk. 
7. Violation of any of the Ground Rules may result in termination of embedding status and removal of the journalist from the Canadian Forces Joint Task Force:

\section{Administrative Rules}

\section{a. Discipline and dress}

i. While they are embedded with Joint Task Force Afghanistan, journalists are subject to the Code of Service Discipline (National Defence Act) and all Joint Task Force Afghanistan orders and policies (e.g. alcohol, substance abuse, fraternization and de-embedding or "walking out").

ii. Embedded journalists must wear their media passes in a clearly visible location at all times to ensure that their status is made known to $\mathrm{CF}$ and ISAF personnel.

iii. Clothing and equipment used by embedded journalists must be subdued in colour and appearance, and obviously not military.

iv. Embedded journalists will not carry any weapons.

\section{b. Equipment}

i. Embedded journalists are responsible for procuring and using protective personal equipment. Such equipment must include a military-grade helmet and body armour.

ii. Embedded journalists must carry and support any personal and professional gear they take with them, including (but not limited to) protective cases for professional equipment, batteries, cables and converters.

iii. When operating with Canadian troops at night, embedded journalists will not use visible light sources or infra-red devices, including flash or television lights, unless the on-scene commander gives specific prior approval.

\section{c. Movement}

i. Embedded journalists will not enter restricted areas without an escort, including the Canadian headquarters building, or the Battle Group headquarters compound in Site 26, and similarly restricted buildings and areas at Camp Nathan Smith and Canadian forward operating locations.

ii. Embedded journalists will remain with military escorts at all times, when directed, and follow their instructions regarding activities and movement.

\section{d. Datelines, interviews, and information release caveats}

i. All stories will be datelined according to local Ground Rules provided to all journalists upon their arrival at Kandahar Airfield. When journalists are with a unit outside Kandahar Airfield, they will use a general geographical description (e.g. "northern area") as a dateline. No 
specific locations will be used when filing stories without prior approval from the on-scene Commander and approval from the JTFAfg Senior PAO.

ii. All interviews with members of the Task Force are on the record. Security of information is the responsibility of the CF member being interviewed; however, the journalist must inform the CF member when he/she is in an interview situation.

iii. Interviews with CF members are authorized upon completion of missions; however, release of information must conform to these Ground Rules.

iv. When a briefer applies a restrictive release caveat (i.e., "not for attribution", "background" or "not for use") to the information he/she is providing, journalists must observe that caveat.

Note: For detailed information on release caveats, see Part 1, paragraph 15.

\section{e. Embargoed information}

i. Information on future operations is under embargo until the operation is completed and release authority is received from both the commander in the field (the "battle-space" commander) and the Task Force Senior PAO.

ii. When a critical incident has occurred, embedded journalists are placed under embargo to protect operations security and/or CF members' privacy. Any violation of such an embargo, by either the embedded journalist or his/her media organization in Canada, constitutes grounds for termination of the embedding agreement.

iii. When a critical incident involves casualties, embedded journalists are placed under embargo to allow time for the CF to notify their primary and secondary next of kin. Journalists who receive any information about such a critical incident shall assume they are automatically under embargo, and will neither call their desks nor file a story until they have received formal permission to do so from a PAO.

iv. Journalists are placed under embargo when they are given information about impending visits by prominent individuals, both military and civilian. The embargo continues until the Task Force Commander authorizes release.

v. Information indicating or confirming the location of important military and civilian visitors at the time of a critical incident is subject to embargo until the Task Force Commander authorizes release.

vi. Any other type of information may be subject to embargo by the Task Force Commander for OPSEC reasons or to protect the privacy of individuals.

\section{f. Reporting casualties}

i. The names and images of fallen soldiers will not be released until the next 
of kin have given the CF explicit permission to do so.

ii. With respect to specific incidents, DND will not distribute information on, and journalists will not report on, non-fatal casualties (i.e., individuals who are injured, sick or missing).

iii. Journalists will not interview or photograph patients in health care facilities without the informed consent of the patient. This restriction applies to all patients, whatever their nationality. If applicable, the attending physician will confirm whether the patient is medically capable of giving informed consent.

iv. When reporting from "outside the wire," journalists will not reveal the identities (i.e., names, faces, nametags, labelled equipment, or any other thing that might serve to identify them) of sick or injured $\mathrm{CF}$ members without their prior written consent. If a CF member dies of wounds or illness, next-of-kin reporting rules apply.

Note: For a full explanation of the reasoning behind the rules on reporting casualties, see Part 1, paragraphs 37 to 46.

9. The following information is releasable:

a. People

i. Arrival of military units in theatre (after the official announcement), with special attention exercised when a unit is being relieved in place:

1) Mode of travel (sea or air),

2) dates of departure, and

3) home station.

ii. Approximate strength of friendly forces (rounded figures).

iii. Type of forces involved (e.g., air defence, infantry, armour), except for Canadian special operations forces and the forces of other nations.

\section{b. Operations}

i. Non-sensitive, unclassified information regarding air and ground operations, past and present.

ii. Size of friendly forces participating in an action or operation, in general terms such as "multi-unit." The specific name and description of forces or units may be released when authorized by the Task Force Commander or his designated representative.

iii. Generic origin information on air operations, such as "land-based."

iv. Date, time, location and results of completed operations.

v. Number of air combat or reconnaissance sorties or missions flown.

c. Equipment

i. Types of ordnance expended (general terms only). 
10. The following information shall not be visually recorded:

a. People

i. The identities (i.e., faces, name tags, labelled equipment, or any other thing that might serve to identify them) of:

1) casualties whose injuries can be visually identified (unless they have given prior written consent), and

2) detainees.

Note: All imagery of detainees will be reviewed by the Canadian Forces to ensure respect for detainees' rights, and to protect detainees from "public curiosity" in accordance with Article 13 of the Third Geneva Convention. No photograph or other graphic representation of a detained person's recognizable face, nametag or any other feature or item that may serve to identify a detainee may be created.

ii. Unless specifically authorized by the Task Force Commander, the identities (i.e., faces, name tags, labelled equipment, or any other thing that might serve to identify them) of:

1) military and civilian close-protection personnel,

2) snipers,

3) aircrew,

4) members of the intelligence community,

5) Special Forces personnel,

6) counter-IED operators,

7) language and cultural advisors (e.g., interpreters), and

8) dog-handlers while operating.

iii. Unless specifically permitted by the individual, the identities of Canadian civilian police officers.

\section{b. Equipment}

i. Damage sustained by CF or ISAF vehicles and/or air assets as a result of insurgent attacks, including (but not limited to) IEDs and suicide bombers, unless specifically authorized by the Task Force Commander.

ii. Interiors of Type A (front-line) vehicles, such as the RG-31, LAV III and the Coyote. Permission to capture imagery while inside any of these vehicles may be granted to journalists who allow a PAO to screen their imagery for operations security concerns before it is filed for publication.

iii. Classified systems and equipment, and demonstrations of their capabilities, unless specifically authorized by the Task Force Commander. 


\section{c. Infrastructure}

i. Restricted military areas, facilities and installations, such as the Tactical Operations Centre (TOC).

ii. The flight line at Kandahar Airfield and military aircraft operating on or near it, even during ramp ceremonies. Journalists are briefed on the applicable local Ground Rules before each ramp ceremony. Journalists may ask PAOs for special permission to film aircraft on the flight line during a ramp ceremony, but even if permission is granted they will be accompanied at all times by an authorized media escort.

\section{The following information shall not be released:}

a. People

i. Specific information on troop strength.

ii. Unless specifically authorized by the Task Force Commander, the identities of:

1) military and civilian close-protection personnel,

2) snipers,

3) aircrew,

4) members of the intelligence community,

5) Special Forces personnel,

6) counter-IED operators,

7) language and cultural advisors (e.g., interpreters), and

8) dog-handlers while operating.

iii. Unless specifically authorized by the individual concerned, the identities of Canadian civilian police officers.

iv. Information about JTF 2 or Canadian Special Operations Regiment personnel.

Note: Embedded journalists will not interview, photograph, film or report on JTF 2 or Canadian Special Operations Regiment (CSOR) personnel, or operations they conduct or participate in, without prior approval from a representative of Canadian Special Operations Forces Command (CANSOFCOM) and the Task Force Commander.

v. Information about friendly Special Operations Forces.

vi. Details of visits by prominent individuals, until the Task Force Commander authorizes release; also, confirmation of the location of important visitors at the time of a significant incident.

vii. Information about detainees.

viii. Information about CF personnel who kill or injure insurgents, including 
name and military occupation, unless authorized by the Task Force Commander.

\section{b. Operations}

i. Rules of Engagement.

ii. Details of current operations (unless otherwise indicated), future operations, postponed and cancelled operations.

iii. Extra precaution in reporting is required at the start of an operation to maximize surprise; therefore, broadcasts by embedded journalists are prohibited until authorized by the unit commander.

iv. During an operation, specific information on friendly force troop movements, tactical deployments, and dispositions that would jeopardize the security of the operation. Information on engagements will not be released until authorized by the on-scene commander.

v. Information about intelligence-collection activities including targets, methods of attack and results.

vi. Information about force-protection measures, including (but not limited to) those at military installations or encampments, except those that are visible or readily apparent.

vii. Information on effectiveness of enemy camouflage, deception, targeting, direct and indirect fire (e.g., rocket attacks, even within the perimeter of Kandahar Airfield), intelligence collection, security measures and electronic warfare measures.

\section{c. Equipment and aircraft}

i. The type of CF and ISAF vehicles and/or aircraft involved in insurgent attacks (including explosions of improvised explosive devices and attacks on aircraft), crashes, and incidents such as mine strikes, suicide attacks and explosions of improvised explosive devices.

ii. Specific information on availability of critical equipment and supplies (e.g., artillery, radars, trucks, water);

iii. Information on friendly forces' electronic warfare equipment and procedures.

iv. The number and type of aircraft flown by any unit smaller than a Wing, except in very general terms (e.g., "large flight," "small flight," "many," "few," "fighters," "fixed wing").

v. The point of origin of any operational flight, other than "land-based" or "carrier-based".

vi. Information on missing or downed aircraft, and JTF-Afg personnel who are missing or known to be captured, during planning and execution of search and rescue and recovery operations. "JTF-Afg personnel" include Canadian civilians, embedded journalists and personnel from allied nations as well as CF members. 


\section{d. Infrastructure and units}

i. Names of tactical infrastructure and specific geographic locations of military units in the area of operations, unless otherwise approved by the Task Force Commander.

ii. Information about security precautions at military installations or encampments, including imagery that shows security arrangements at military sites, especially aerial and satellite imagery that reveals the name and/or specific location of military units and/or installations.

e. Other

i. Any other information the Task Force Commander orders restricted for operational reasons.

\section{D_o_c_u_m_e_n_t_a_t_i_o_n_-}

12. The documents that follow must be completed as directed and submitted by fax or postal mail to CEFCOM PA. 


\section{Media Embedding and Ground Rules Agreement}

$\mathrm{I}$, following statements are true. (PRINT NAME), confirm that the

a. I am not aware of any physical or health conditions that would adversely affect my participation in strenuous activities. (Initial)

(Medical certificate is enclosed)

b. I have read the General Instructions and Ground Rules for Embedding Journalists and agree, with my signature, to abide by them. I understand that any violation of these Instructions and Ground Rules is cause for termination of my embedding with Joint Task Force Afghanistan. (Initial)

\begin{tabular}{|c|c|}
\hline Signature of Journalist & Date \\
\hline \multicolumn{2}{|c|}{ Printed name, media affiliation, address and telephone number of Journalist } \\
\hline $\begin{array}{l}\text { Signature of Journalist's Supervisor (Assignment Editor, News } \\
\text { Director) }\end{array}$ & Date \\
\hline \multicolumn{2}{|l|}{ Printed name of Journalist's Supervisor } \\
\hline Signature of Witness (CF Member) & Date \\
\hline
\end{tabular}

Printed name, rank and unit of Witness 


\section{APPENDIX L: Questionnaire, Military, Revised}

Revised Questionnaire for Military Personnel

Please answer each of the following questions with as much detail as possible. We can go through them in person, via telephone or Skype, or you can respond via email.

\section{General}

27. Name

28. Title/organization

29. Age

30. Gender

31. Education

32. How many years of experience have you had in working with the media (e.g. Public Affairs, Communications, Media Relations, personal interview(s), etc.)?

33. Have you had experience(s) working with domestic or foreign-news reporters?

34. Do you wish for this interview to be
a) on the record (you may be quoted and your name given),
b) on the record but no attribution (quoted but no name),
c) off the record (background only), or
d) some combination of the above (please specify)?

II. Canadian Forces (CF) Media Embedding Program (CFMEP)

5. Are you familiar with the Canadian Forces (CF) Media Embedding Program (CFMEP)?

e) If so, what do you believe was the intent of the CFMEP?

f) In your opinion, what are the advantages as well as disadvantages of the CFMEP for the CF?

g) In your opinion, what are the advantages as well as disadvantages of the CFMEP for the media?

h) To your knowledge, who decides which and how many reporters are embedded with whom and for how long?

6. Are you familiar with CFMEP operations?

f) Do you recall if/when embedded or dis-embedded reporters did not observe CFMEP policies?

g) In your opinion, were CFMEP policies fair to the media?

h) To your knowledge, have significant changes been made to the CFMEP since its initiation at the beginning of the Afghanistan mission?

i) Did you find that CFMEP policy rules matched practice "on the ground?"

j) Do you perceive the structure and flexibility of the CFMEP favourably in comparison to other countries' embed programs?

7. Do you think the CFMEP should be continued?

8. Do you think the CFMEP could be changed/improved? 

a) If so, how?

III. Media experience

11. Were your experiences with embedded or dis-embedded reporters what you had anticipated?

12. Did you have any experience(s) with unilateral reporters (e.g. unaffiliated with the military, neither embedded nor dis-embedded)?

13. Did you feel that embedded reporters effectively relayed stories?

14. Did you feel that dis-embedded and unilateral reporters effectively relayed a bigger picture of the war (e.g. Canadian reconstruction efforts, the war's effects)?

15. Did you witness disagreements/conflicts between Canadian authorities and embedded, dis-embedded, or unilateral reporters?

a) If so, what was the source of these disagreements?

16. Did you believe that censorship in the name of operations security (OPSEC) was/is warranted?

17. Would you have changed anything about the way that embedded, dis-embedded, or unilateral reporters were treated?

a) If so, what?

18. Could you easily speak on the record to reporters?

19. Did you think that PA personnel provided thorough information to reporters?

20. To your knowledge, how did the CF military treat embedded, dis-embedded, and unilateral reporters compared to how the US military treated reporters?

IV. Media coverage

18. Do you think Canadian coverage of the Afghanistan mission was top quality?

a) Why?

19. Did you notice a difference between print and television coverage?

20. Did you notice a difference between English and French coverage?

21. Did you notice a difference in coverage over the duration of the Afghan mission?

22. Do you think any reporter stood out as part of the Afghanistan mission?

d) If so, who and why?

V. Federal oversight

18. Any advice for future military/government personnel who may work with embedded, dis-embedded, or unilateral reporters? 


\section{APPENDIX M: Map of Afghanistan}

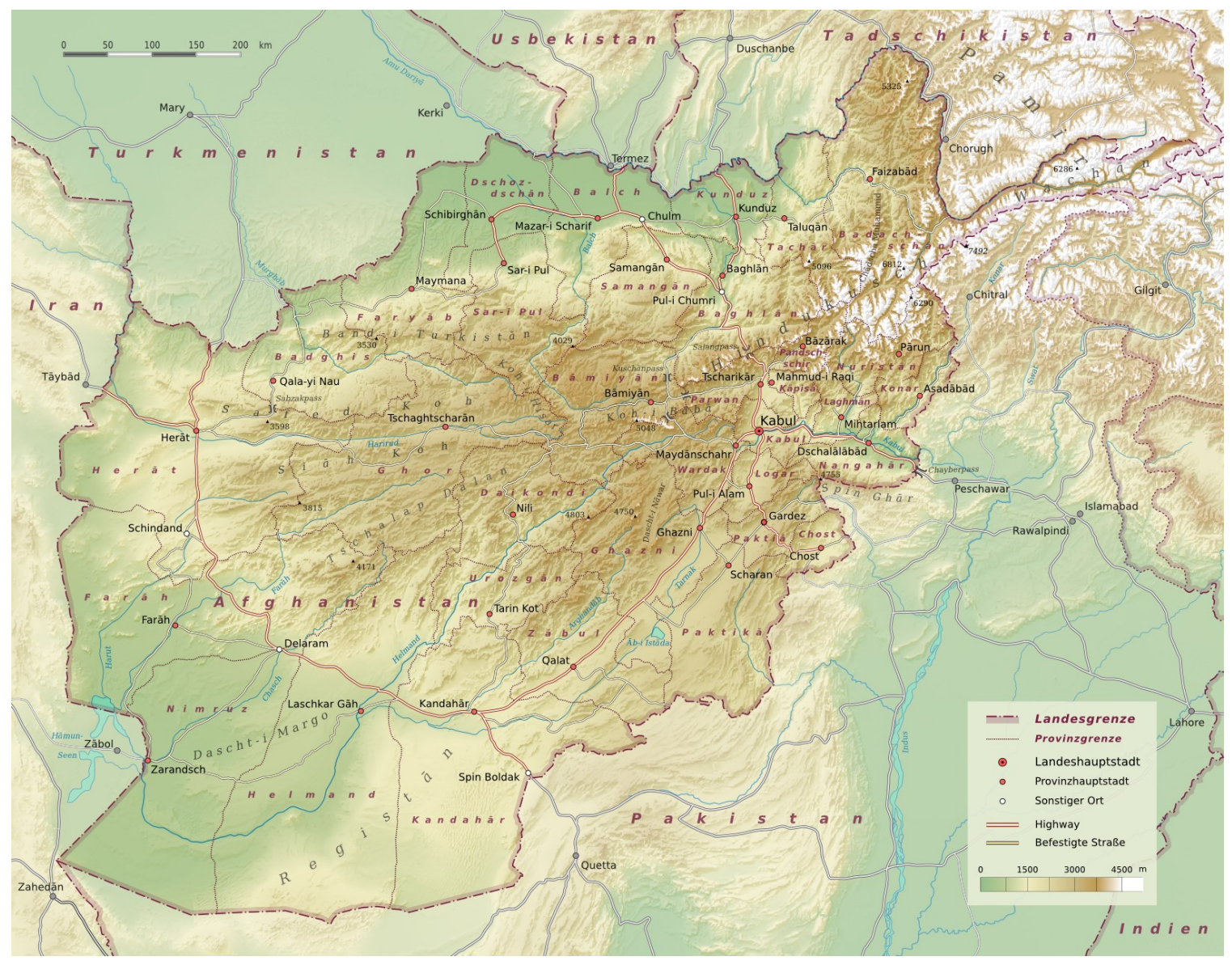

